\begin{abstract}
Title of Dissertation:

TRAFFIC FATALITIES AND

ECONOMIC GROWTH

Elizabeth Anne Kopits, Doctor of Philosophy, 2004

Dissertation directed by: Professor Maureen Cropper

Department of Economics
\end{abstract}

This dissertation adds to the current understanding of the socioeconomic determinants of traffic fatality rates by examining the variation in road deaths across countries and over time. Chapter two investigates the relationship between road safety and economic development within an Environmental Kuznets Curve framework. Reduced-form models of fatality risk as a function of per capita income are estimated using panel data for over 80 countries. The results confirm an inverted U-shaped relationship with income, with traffic fatality risk (fatalities per population) beginning to decline at incomes similar to those found for several environmental externalities. The turning point is driven by the rate of decline in fatalities per vehicle as income rises, since motorization rates (vehicles per population), while increasing with income at a decreasing rate, never decline with economic growth. This suggests that road safety improvements accompanying income growth depend on policies that reduce fatalities per vehicle rather than on reducing motorization. 
Projections suggest that the global road death toll will grow by $66 \%$ between 2000 and 2020 if historic trends continue. This number, however, reflects divergent rates of change in different parts of the world.

Chapter three focuses on factors underlying the decline in fatalities per distance traveled, i.e., the downward sloping part of the road safety Kuznets curve. Formal models of traffic fatalities are developed for vehicle occupants and pedestrians. Reduced-form approximations to these models are estimated using panel data for over 30 high-income countries over 1964-2002.

Estimates suggest that demographic changes and road building contributed to declines in both vehicle occupant and non-occupant fatality rates. In addition, increases in the size of the vehicle fleet, as predicted by theory, have increased occupant deaths while decreasing pedestrian deaths per distance driven. Improvements in medical care also played a role in reducing both fatality rates. The results do not offer evidence of a significant increase in demand for risky driving in response to newer, safer vehicles or seatbelt usage. The extent to which alcohol and increases in the elderly population have detrimental effects on fatality rates is found to be twice as large for pedestrians as for vehicle occupants. 


\title{
TRAFFIC FATALITIES AND ECONOMIC GROWTH
}

$$
\text { by }
$$

\author{
Elizabeth Anne Kopits
}
Dissertation submitted to the Faculty of the Graduate School of the University of Maryland, College Park in partial fulfillment of the requirements for the degree of
Doctor of Philosophy 2004

Advisory Committee:

Professor Maureen Cropper, Chair

Professor Kenneth Beck

Professor Roger Betancourt

Professor Jonah Gelbach

Professor Seth Sanders 
(C) Copyright by

\section{Elizabeth Anne Kopits}

2004 


\section{ACKNOWLEDGEMENTS}

I would like to thank Professor Maureen Cropper for her never-ending support and encouragement throughout the writing of this dissertation. I feel extremely fortunate to have been under her guidance during the past few years. I would also like to thank the participants of the University of Maryland graduate microeconomics seminar-especially Profs. Roger Betancourt, Jonah Gelbach, Seth Sanders, and Jeff Smith for their insightful comments and suggestions, and Jonah Gelbach for his persistent help with econometric issues.

I would like to thank the World Bank Research Board for funding and the Bank’s Road Safety Thematic Group for comments and support. Paulus Guitink and Hua Wang generously provided data. I would also like to thank the following people for their comments and suggestions: Amy Aeron-Thomas, Tony Bliss, Jagadish Guria, Goff Jacobs, Matthijs Koornstra, Richard Scurfield, Zmarak Shalizi, and V. Kerry Smith. I appreciate the comments of seminar participants at Resources for the Future, Camp Resources, and the International Conference on Vehicle Safety and Reliability in Keszthely, Hungary.

Finally, this work would not have been possible without the moral support of all my family and friends and friends at RFF. Thank you for believing in me and putting up with me for the past few years!

The findings, interpretation, and conclusions expressed in this dissertation do not necessarily represent the views of the World Bank, its Executive Directors, or the countries they represent. All responsibility for errors rests solely with me. 


\section{TABLE OF CONTENTS}

List of Tables vi

List of Figures viii

CHAPTER 1: INTRODUCTION 1

CHAPTER 2: IS THERE AN ENVIRONMENTAL KUZNETS CURVE FOR 7

ROAD SAFETY?

2.1 Introduction 7

2.2 The Environmental Kuznets Curve Hypothesis 10

2.3 Methodology and Data 12

2.3.1 Statistical models of fatalities and vehicle ownership 12

2.3.2 Data sources 16

$\begin{array}{ll}2.4 \text { Results } & 17\end{array}$

2.4.1 Plots of dependent variables versus income $\quad 17$

2.4.2 Estimates of fatalities per capita 19

2.4.3 Estimates of vehicles per capita 22

2.4.4 Estimates of fatalities per vehicle 24

2.5 Future Trends in Motorization and Road Safety 25

2.5.1 Methodology for projecting vehicle usage and traffic fatalities 25

2.5.2 Projections of the world vehicle fleet to $2020 \quad 27$

2.5.3 Projections of world traffic fatalities to $2020 \quad 29$

2.5.4 Implications of traffic fatality projections 31

2.6 Conclusion

\section{CHAPTER 3: WHY HAVE TRAFFIC FATALITIES DECLINED IN}

INDUSTRIALIZED COUNTRIES? $\quad 58$

3.1 Introduction $\quad 58$

3.2 Existing Literature on Road Safety 60

3.2.1 Micro-level studies of the causes of accidents or fatalities 61

3.2.2 Evaluation of specific road safety policies $\quad 62$

3.2.2.a. Speed and speed limits 63

3.2.2.b. Alcohol and alcohol control policies $\quad 65$

3.2.2.c. Seatbelt laws and seatbelt usage $\quad 67$

3.2.2.d. Vehicle safety features and vehicle inspections 69

3.2.2.e. Roads 70

3.2.2.f. Medical care $\quad 71$ 
3.2.3 Cross-country literature on road safety 72

3.3 Traffic Fatality Patterns in IRTAD Countries 74

3.4 Models of Pedestrian and Occupant Fatalities 75

3.4.1 Models of motor vehicle accidents $\quad 76$

3.4.2 Models of accident fatalities $\quad 79$

3.4.3 Implications of the models 79

3.5 Estimates of Fatalities per Distance Traveled 80

3.5.1 Estimates as a function of income and time only $\quad 80$

3.5.2 Reduced-form specification 83

3.5.2.a. Specification of occupant fatalities per VKT 83

3.5.2.b. Specification of pedestrian fatalities per VKT 87

3.5.3 Data sources $\quad 88$

3.5.4 Reduced-form estimates 90

3.5.4.a. Estimates of occupant fatality equations - no seatbelt usage 90

3.5.4.b. Estimates of occupant fatality equations - with seatbelt usage 99

3.5.4.c. Estimates of pedestrian fatality equations - no seatbelt usage 103

3.5.4.d. Estimates of non-occupant fatality equations - with seatbelt usage 109

3.6 Conclusions and Further Research

A.3 Complete Regression Results, Including Country Dummy Coefficients

A.4 Regression Results Using Same Observations Across All Equations

A.5 Fatalities/Population Estimates with Year Dummies Instead of Common Time Trend

A.6. Sensitivity Analysis of Turning Point in Fatalities/Population

Model to Subsets of Sample

A.7. Sensitivity Analysis of Turning Point in Fatalities/Population

Model to Spline Segmentation

A.8. Pooling of HD1 and HD2 Countries in Spline Specification of

Fatalities/Population Equation 
APPENDIX B. APPENDIX TO CHAPTER THREE 157

B.1 Data Sources 157

B.2 Extension of VKT Series Using Fuel Consumption Data 162

B.3 Income-Only Regression Results Using Base VKT Data 164

B.4 Extension of Per Capita Income Data (1996 International Dollars) to 2002

B.5 Income-Only Regression Results Using Per Capita Income in 1985 International Prices 165

B.6 Sensitivity Analysis of VEHGROWTH Variable in Estimates of Occupant Fatalities/VKT 165

$\begin{array}{lr}\text { REFERENCES } & 178\end{array}$ 


\section{LIST OF TABLES}

Chapter 2

Table 2.1: Change in Traffic Fatality Risk (Deaths/10,000 Persons), 1975-1998 48

Table 2.2: Regional Distribution of Countries Used in Model Estimation 49

Table 2.3: Descriptive Statistics $\quad 50$

Table 2.4: Motorization Rates, 1999, 60 Countries 51

Table 2.5: Regression Results from Fatalities/Population Models 52

Table 2.6: Regression Results from Vehicles/Population Models 54

Table 2.7: Regression Results from Fatalities/Vehicles Models 55

Table 2.8: Forecasts of Real Per Capita GDP Annual Growth Rates (\%), 2000-2020

Table 2.9: Predicted Road Traffic Fatalities by Region (000s), Adjusted for Under-

Reporting, 1990-2020

Chapter 3

Table 3.1: Traffic Fatality Trends in IRTAD Countries, 1970-99

Table 3.2: Pedestrian and Occupant Fatalities/VKT as a Function of Income Only 113

Table 3.3: Number of Observations Included in Chapter Three Samples, by Country

Table 3.4: List of Variables

Table 3.5: Descriptive Statistics

Table 3.6: Correlation Coefficients Among Independent Variables 117

Table 3.7: Results for Occupant Fatalities/VKT Models - No Seatbelt Usage 118

Table 3.8: Results for Occupant Fatalities/VKT Models - Seatbelt Usage 120

Table 3.9: Results for Pedestrian Fatalities/VKT Models - No Seatbelt Usage 122

Table 3.10: Results for Non-Occupant Fatalities/VKT Models - Seatbelt

Usage Table

Appendix A

Table A.1: Classification of Countries for Which Fatalities Are Projected

Table A.2: F/P, V/P, and F/V Regression Results Using Same Spline Segments Across All Equations

Table A.3: Country Dummy Coefficients from F/P Models (Table 2.5)

Table A.4: Country Dummy Coefficients from V/P Models (Table 2.6)

Table A.5: Country Dummy Coefficients from F/V Models (Table 2.7)

Table A.6: Regression Results from Fatalities/Population Models, Common time trend vs. year dummies

Table A.7: Sensitivity Analysis of Turning Point in Fatalities/Population Model to Subsets of Sample

Table A.8: Sensitivity Analysis of Turning Point in Fatalities/Population Model to Spline Segmentation 
Appendix B

Table B.1: Descriptive Statistics for Base and Extended VKT Data

Table B.2: Income-Only Regression Results Using Base and Extended VKT Data

Table B.3: Annual Growth Rates of Real per capita GDP in OECD countries, 2000-2002

Table B.4: Income-Only Regression Results Using Per Capita Income Series in 1985 and 1996 International Dollars

Table B.5: Sensitivity Analysis of Income and VEHGROWTH Variable Specification, Occupant Fatalities/VKT Equation

Table B.6: Number of Observations Included in Table 3.7 and Table 3.9 Samples, by Country

Table B.7: Number of Observations Included in Table 3.8 and Table 3.10 Samples, by Country

Table B.8: Country-Specific Time Trend Coefficients from Income-Only Pedestrian and Occupant Fatalities/VKT Models (Table 3.2) 


\section{LIST OF FIGURES}

Chapter 2

Figure 2.1: Motorization Rate vs. Income: All Countries and Years 36

Figure 2.2: Motorization Rates vs. Income: Selected Countries 37

Figure 2.3: Fatalities/Vehicle vs. Income: All Countries and Years 38

Figure 2.4: Fatalities/Vehicle v. Income: Selected Countries 39

Figure 2.5: Traffic Fatality Rate vs. Income: All Countries and Years 40

Figure 2.6: Fatalities/Population Results, Common Time Trend 41

Figure 2.7: Fatalities/Population Results, Region-specific Time Trends 42

Figure 2.8: Vehicles/Population Results, Spline Models 43

Figure 2.9: Fatalities/Vehicle Results, Spline Models 44

Figure 2.10: World Vehicle Fleet Projections Corresponding to Models in Table 545

Figure 2.11: Global Road Traffic Fatalities, Before Adjusting for Under-Reporting, 1990-2020 46

Figure 2.12: Global Traffic Fatalities, Adjusted for Under-Reporting, 1990-2020 47 


\section{CHAPTER ONE}

\section{INTRODUCTION}

Road traffic crashes claim the lives of hundreds of thousands of people each year and currently account for a quarter of all fatalities resulting from injury. The problem is especially acute in the developing world: Developing countries, which account for only $32 \%$ of the world's vehicle fleet, bear over $85 \%$ of the global road death toll. Recent trends suggest the situation is only worsening. In the past fifteen years, traffic fatalities have increased by almost $80 \%$ in Asia, and by $40 \%$ in Latin America and Africa. The opposite is true in industrialized countries, however, where road death rates have been declining for several decades.

These facts raise two key questions. First, is there an observable relationship between traffic fatalities and economic development and, if so, what is the magnitude of that relationship and what does it imply for the future course of fatalities in developing countries? Secondly, what can be done to improve road safety conditions, particularly in low-income regions? Offering policy guidance to developing countries must be based on a comprehensive understanding of which policies have proved to be the most influential in reducing fatality risk in industrialized countries. The goal of this dissertation is to add to the current understanding of the socioeconomic determinants of traffic fatality rates by examining the variation in road traffic fatalities across countries and over time.

Chapter two of the dissertation investigates the relationship between road safety and economic development within an Environmental Kuznets Curve (EKC) 
framework. According to the EKC hypothesis, environmental quality declines during early stages of economic development but improves in later stages. This is usually depicted as an inverted $U$ curve between pollutants and per capita income, similar to the relationship Simon Kuznets (1955) suggested to exist between income inequality and per capita income.

Reduced form models of fatality risk as a function of per capita income are estimated using panel data for over 80 countries to examine whether road traffic fatalities follow an observable pattern as countries develop. The results confirm that traffic fatalities do indeed follow an inverted U-shaped relationship with income, with traffic fatality risk (fatalities per population) beginning to decline at income levels similar to those found for several environmental externalities. The fatality riskincome relationship is disentangled by separating fatalities per population into two components - fatalities per vehicle and vehicles per population. The EKC turning point is found to be driven by the rate of decline in fatalities per vehicle as income rises, since motorization rates (vehicles per population), while increasing with income at a decreasing rate, never decline with economic growth. This suggests that improvements in road safety that accompany income growth will depend on policies that reduce fatalities per vehicle rather than on reducing motorization.

Projections of future traffic fatalities based on the results in chapter two suggest that the global road death toll will grow by approximately $66 \%$ over the next twenty years. This number, however, reflects divergent rates of change in different parts of the world. The road death rate is projected to rise to approximately 2 per 
10,000 persons in developing countries by 2020 , while it will fall to less than 1 per 10,000 in high-income countries.

Chapter three of the dissertation focuses on the factors underlying the decline in fatalities per distance traveled, i.e., the downward sloping part of the road safety Kuznets curve. It seeks to shed light on the extent to which policy intervention, rather than technological advances or trends in motorization, can explain the reductions in traffic fatalities experienced in industrialized countries since the early 1970s. Formal models of traffic fatalities are developed for vehicle occupants and for vulnerable road users (pedestrians and bicyclists). Reduced-form approximations to these models are then estimated using panel data for over 30 high-income countries for 1964 through 2002.

Estimates suggest that demographic changes and road building alone contributed to declines in both vehicle occupant and non-occupant fatalities per vehicle distance traveled. Motorization trends also matter. Increases in the size of the vehicle fleet, as predicted by theory, have increased occupant deaths while decreasing pedestrian deaths per distance driven. Improvements in medical care have also played a role in reducing both fatality rates. With regard to the effectiveness of behavioral policy interventions, the results in chapter three do not offer evidence of a significant increase in demand for risky driving in response to newer, safer vehicles or seatbelt usage. There is greater support, however, of offsetting behavior related to trends in road infrastructure conditions. Finally, the extent to which excessive alcohol consumption and increases in the elderly population have detrimental effects on fatality rates is found to be twice as large for pedestrians as for vehicle occupants. 
Determining whether this reflects an increased risk posed by the driving or walking behavior of these two populations is a topic for further study.

This dissertation contributes to the existing research on road safety in several ways. Chapter two presents the first application of the Environmental Kuznets Curve hypothesis to road safety. In part, the absence of this type of analysis in the road safety or EKC literature is due to a lack of data. One of the contributions of the chapter is the assembly of a panel dataset on traffic fatalities and vehicle fleets for over 80 countries covering 1963 to 1999 . This dataset is part of a larger effort on my part to digitize all data in the International Road Federation's World Road Statistics going back to 1963 . These data, which are now publicly available, may be used to answer a host of transport related questions using country-level panel data.

The forecasts of traffic fatalities have helped draw attention to the growing magnitude of the road death toll in developing regions of the world. As the second global prediction of this kind, they offer policymakers a baseline scenario for the next twenty years, thus raising awareness of what is likely to happen if additional measures are not enacted to reduce traffic accidents. They were used as input to the joint World Health Organization-World Bank World Report on Road Traffic Injury Prevention (Peden et al., 2004) and are continuing to be used by the World Bank to help low-income countries develop long-term targets for reducing road deaths.

The documentation of a Kuznets Curve for road safety in chapter two also provides an indication of the level of income at which traffic fatality risk historically has begun to decline. This finding should not be interpreted to mean that countries automatically grow out of their road safety problems as incomes increase. Instead, 
the central question for policy concerns the factors underlying the downward sloping part of the EKC. Chapter three attempts to further the understanding of these factors by examining the importance of various factors in reducing traffic fatality risk in industrialized countries.

The empirical approach taken in chapter three provides a broader understanding of the factors influencing traffic fatality rates than is offered by the existing literature. Much of the literature on road safety is devoted to evaluating the effectiveness of specific safety interventions such as speed limits or alcohol control policies on the basis of within-country data. Most U.S. studies using panel data are limited to state level analysis for several years. The analysis in chapter three is among the first attempts to use cross-country panel data to examine the role of various factors on both pedestrian and vehicle occupant fatality rates.

The dissertation is organized as follows. Chapter two begins by describing the Environmental Kuznets Curve hypothesis and its application to the death rate due to road traffic crashes (Section 2.2). After explaining the methodology and data (Section 2.3), data trends are presented to show how fatality risk (fatalities/population), motorization rates (vehicles/population) and fatalities per vehicle vary with income both within and across countries (Section 2.4). Finally, the estimation results are discussed (Section 2.5) and used to forecast vehicle growth and traffic fatalities by region from 2000 to 2020 (Section 2.6).

Chapter three begins with a summary of the existing empirical literature on road safety. This is followed by a discussion of patterns of traffic fatalities by road user group in a subset of high-income countries (Section 3.3). Then formal models 
are developed to explain the annual number of pedestrian and occupant fatalities occurring within a country (Section 3.4). Reduced-form specifications of the models are estimated using panel data for 1964-2002 from a subset of the high-income countries included in chapter two (Section 3.5). Chapter four concludes. 


\section{CHAPTER TWO}

\section{IS THERE AN ENVIRONMENTAL KUZNETS CURVE FOR ROAD SAFETY?}

\section{$2.1 \quad$ Introduction}

As countries develop death rates usually fall, especially for diseases that affect the young and result in substantial life-years lost. Deaths due to traffic accidents are a notable exception: the growth in motor vehicles that accompanies economic development usually brings an increase in road traffic accidents. Indeed, the World Health Organization has predicted that traffic fatalities will be the sixth leading cause of death worldwide and the second leading cause of disability-adjusted life-years lost in developing countries by the year 2020 (Murray and Lopez, 1996).

Table 2.1 highlights the increasing importance of the problem in selected developing countries. For example, between 1975 and 1998, road traffic deaths per capita increased by $44 \%$ in Malaysia and by over $200 \%$ in Colombia and Botswana. The situation in high-income countries is quite different. Over the same period, traffic fatalities per person decreased by $60 \%$ in Canada and Hong Kong, and by amounts ranging from $25 \%$ to $50 \%$ in most European countries. This reflects a downward trend in fatality risk (deaths/population) that began in most OECD countries in the early 1970's and has continued to the present.

These facts suggest two questions. The first deals with how traffic fatalities per person change as countries develop. Specifically, is there a recognizable pattern between growth in per capita income and traffic fatalities? In the literature on environmental externalities one finds that some pollutants (e.g., ambient particulate 
matter) at first increase with income, reach a peak, and then decline. If a similar pattern holds for the death rate due to traffic fatalities, what does it imply about the future course of fatalities in developing countries?

To answer these questions, this chapter examines how the fatality risk (fatalities/population) associated with traffic accidents changes as countries grow. Despite the extensive road safety literature that has developed in the U.S. and Europe, there has been surprisingly little empirical research explaining how traffic fatality rates change as a country develops. ${ }^{1}$ The topic is of interest for two reasons. Documenting the relationship between road safety and economic development and examining its implications for developing countries provides an important first step in dealing with what is a serious public health problem. For planning purposes it important to forecast the growth in traffic fatalities. Equations relating fatality risk to per capita income can be used to predict traffic fatalities by region. These forecasts should alert policymakers to what is likely to happen if measures are not enacted to reduce traffic accidents.

A second motive for the work comes from the literature on Environmental Kuznets Curves (Grossman and Krueger, 1995). This literature examines the relationship between environmental externalities, such as air and water pollution, and economic growth. A focus of this literature has been in identifying the income levels

\footnotetext{
${ }^{1}$ One exception is the literature on Smeed's "Law" which asserts that fatalities per vehicle are inversely related to vehicles per capita. Several studies (Smeed, 1949; Jacobs and Cutting, 1986) have found the elasticity of fatalities per vehicle with respect to vehicles per capita to be about -0.66 ; hence the relationship has been elevated to the status of a "law." A few cross-country studies focusing on the effect of income on traffic fatality rates have appeared in the epidemiology literature (Van Beeck et al., 2000) but most are based on a single cross section.
} 
at which externalities begin to decline. Road traffic fatalities are, indeed, an externality associated with motorization, even though a portion of road traffic accident costs are internalized by drivers (e.g., own injury risk to drivers). The external cost of traffic accidents is especially large in developing countries where pedestrians and bicyclists comprise a large share of casualties and motorists are often not insured. ${ }^{2}$ It is of interest to examine the income level at which the traffic fatality risk historically has begun to decline and to compare this with the pattern observed for other externalities.

I investigate these issues by estimating equations for the motor vehicle death rate (fatalities/population) and for its two components - the rate of motorization (vehicles/population) and fatalities per vehicle $(\mathrm{F} / \mathrm{V})^{3}$ - using panel data from 196399 for 88 countries. I estimate fixed effects models in which the natural logarithm of $\mathrm{F} / \mathrm{P}, \mathrm{V} / \mathrm{P}$ and $\mathrm{F} / \mathrm{V}$ are expressed as quadratic and spline functions of per capita income. Time trends during the period 1963-99 are modeled in several ways. The coefficient estimates from these models are then used to project traffic fatalities and the stock of motor vehicles to 2020 .

The chapter is organized at follows. Section 2.2 provides a brief discussion of the extension of the Environmental Kuznets Curve hypothesis to road safety. Section

\footnotetext{
${ }^{2}$ Studies that have focused on quantifying the magnitude of the accident externality per mile in the U.S. and several European countries include Delucchi et al. (1997), Jones-Lee (1990), Mayeres et al. (1996), Newbery (1988), and Persson and Odegaard (1995).

${ }^{3}$ Traffic fatality risk may also be expressed as the product of fatalities per distance traveled and distance traveled per person. Lack of reliable time-series data on distance traveled, especially for developing countries, prevents using this measure for the analysis.
} 
2.3 describes the econometric models and data used in the analysis. Section 2.4 presents trends in fatality risk $(\mathrm{F} / \mathrm{P})$, motorization rates $(\mathrm{V} / \mathrm{P})$, and fatalities per vehicle $(\mathrm{F} / \mathrm{V})$ for various countries and summarizes the estimation results. The road traffic fatality projections are developed in Section 2.5. Section 2.6 concludes.

\subsection{The Environmental Kuznets Curve Hypothesis}

A logical framework for investigating the questions posed above comes from the literature on Environmental Kuznets Curves (Grossman and Krueger, 1995; Shafik and Bandyopadhyay, 1992; Seldon and Song, 1994). This literature examines the relationship between environmental externalities, such as air and water pollution, and economic growth. According to the EKC hypothesis, environmental quality declines during early stage of economic development but improves in later stages. This is usually depicted as an inverted $\mathrm{U}$ curve between pollutants and per capita income, similar to the relationship Simon Kuznets (1955) suggested to exist between income inequality and per capita income. Although EKC results have been misinterpreted by some policy analysts to suggest that countries will naturally grow out of their environmental problems (Beckerman, 1992; Bartlett, 1994), there is no reason to believe that the process is an automatic one (Grossman and Krueger, 1995).

The EKC describes a statistical relationship but does not explain why the inverted U shape occurs. For this reason, the literature has often been criticized for offering limited insight into the mechanisms that explain the decline in pollutants after certain income levels, arguing that without an explicit consideration of the underlying determinants of environmental quality, there is little scope for policy 
intervention. Some studies have taken steps to provide a deeper analysis of the income-environment relationship by decomposing the income effect into its scale, composition, and abatement (or "technique") components.

In the case of a common air pollutant such as total suspended particulates (TSP), the traditional EKC "decomposition" is as follows. Total emissions per population is written as: TSP Emissions/Population $\equiv($ TSP Emissions/Manufacturing Output)*(Manufacturing Output/GDP)*(GDP/Population). The first term in the equation is the abatement effect, the second the composition effect and the third the scale effect. According to the "composition" effect, the EKC relationship occurs as a result of the changing composition of economic activity that accompanies development; economies shift from clean agrarian activities to more pollution intensive manufacturing activity to clean service industries (Arrow et al., 1995).

Hilton and Levinson (1998) simplify the "decomposition" to only a scale and abatement (also called "intensity") component. In the example above, this would reduce the emissions rate to: TSP Emissions/Population $\equiv(T S P$ Emissions/Output)*(Output/Population). The "scale" of pollution activity (Output/Population) increases with economic growth—wealthier countries (with more polluting activity) generate more pollution — but since environmental quality is a normal good, citizens will demand cleaner environments as incomes increase and, hence, regulations will be adopted to reduce the emissions per unit of output, the "intensity" of the polluting activity.

In examining the behavior of the death rate from traffic crashes, it is straightforward to break down the relationship between the traffic death rate and per 
capita income into a "scale" and "intensity" effect. The death rate,

Fatalities/Population, may be expressed as the product of vehicle distance traveled per capita and the number of deaths per distance traveled. Measuring distanced traveled by total vehicle kilometers (VKT), fatalities per capita may be written as:

$$
\text { (2.1) } \frac{\text { Fatalities }}{\text { Population }} \equiv \frac{\text { Fatalities }}{\text { VKT }} * \frac{\text { VKT }}{\text { Population }}
$$

The consumption (or "scale") of transportation services (as measured by VKT/population) increases with economic activity but if road safety, like environmental quality, is a normal good, demand for road safety will increase as incomes rise and, policies will be adopted to reduce Fatalities/VKT, the risk "intensity" associated with driving. Therefore, a Kuznets curve for the traffic death rate implies that at low levels of income the first effect dominates - the income elasticity of VKT/population will exceed that of Fatalities/VKT - causing Fatalities/Population to increase. At higher incomes, the reverse occurs; the income elasticity of Fatalities/VKT exceeds in absolute value the income elasticity of VKT per person, causing the road traffic death rate to fall. ${ }^{4}$

\subsection{Methodology and Data}

2.3.1 Statistical models of fatalities and vehicle ownership

\footnotetext{
${ }^{4}$ Hilton and Levinson (1998) recently examined a similar decomposition of the EKC for the case of automotive lead emissions. Also, since traffic deaths, like automotive emissions, are a result of a consumption activity (driving) the finding of an EKC for these externalities are not subject to the common criticism that the downward sloping portion of the Kuznets curve is a result of locational displacement, or pollution haven effects (Suri and Chapman, 1998).
} 
I examine the relationship between the road death rate and economic development and separate the scale and technique effects of growth by estimating the relationship between each of the terms in equation (2.1) and per capita income using panel data from 1963-99 for 88 countries. In order to include a broad range of countries, however, VKT must be replaced by the vehicle stock $(\mathrm{V})^{5}$ and all factors affecting fatality risk are proxied by the economic development of a country, as measured by per capita GDP. I estimate equations for Fatalities/Population (F/P), Vehicles/Population (V/P), and Fatalities/Vehicles (F/V), using reduced form statistical models of the general form:

$$
\text { (2.2) } \ln \left(\mathrm{Z}_{\mathrm{it}_{\mathrm{t}}}=\mathrm{a}_{\mathrm{i}}+G\left[\ln \left(\mathrm{Y}_{\mathrm{it}}\right)\right]+H(\mathrm{t})+\varepsilon_{\mathrm{it}}\right.
$$

where $Z_{\mathrm{it}}=\mathrm{F} / \mathrm{P}$ (fatalities/10,000 persons), $\mathrm{V} / \mathrm{P}$ (vehicles/10,000 persons), or $\mathrm{F} / \mathrm{V}$ (fatalities $/ 10,000$ vehicles) in country $i$ in year $t, \mathrm{Y}=$ Real Per Capita GDP (measured in 1985 international prices), $\mathrm{a}_{\mathrm{i}}$ is a country-specific intercept, and $G$ and $H$ are functions. Two specific forms of $G$ are used, a quadratic specification (equation (2.3)) and a spline (piecewise linear) specification (equation (2.4)):

$$
\begin{aligned}
& \text { (2.3) } \ln (\mathrm{Z})_{i t}=a_{i}+b \ln Y_{i t}+c\left(\ln Y_{i t}\right)^{2}+H(t)+\varepsilon_{i t} \\
& \text { (2.4) } \ln \left(Z_{i t}=a_{i}+b \ln Y_{i t}+\Sigma_{S}\left[c_{S} D_{S}\left(\ln Y_{i t}-\ln Y_{S}\right)\right]+H(t)+\varepsilon_{i t}\right.
\end{aligned}
$$

where $D_{s}$ is a dummy variable $=1$ if $Y_{\text {it }}$ is in income category $s+1$, and $Y_{s}$ is the cutoff income value between the $s$ and $s+1$ income group.

By allowing the slope of the fatality risk-income relationship to vary by income interval, the spline offers a great deal more flexibility than a quadratic

\footnotetext{
${ }^{5}$ The correlation between VKT and number of vehicles for countries with available data on both variables exceeds 0.975 .
} 
function. Following Schmalensee et al. (2000), in equation (2.4) the observations are divided into 10 income groups with an equal number of observations in each spline segment. The results are not qualitatively different if fewer or more income segments are specified. (Regression results using different segmentations are presented Section A.7 in Appendix A.) Another issue in model specification is whether or not the same functional form of income applies to different groups of countries (e.g., high-income versus low-income countries). Although it is difficult to test this statistically using the spline specification, this concern is addressed in Section A.8 in Appendix A.

The inclusion of a time trend, $H(\mathrm{t})$, eliminates any spurious correlation that may exist between per capita income and fatality risk over time. In addition, $H(\mathrm{t})$ captures the effect of any trends in technology and driver behavior that are unrelated to income. Four different forms of $H(\mathrm{t})$ are used: (1) a common linear time trend; (2) a common log-linear time trend $(\ln t) ;(3)$ regional, linear time trends; and (4) regional, log-linear $(\ln t)$ time trends. ${ }^{6,7}$

For purposes of defining time trends, the countries are divided into two groups: highly developed countries (HD1) - i.e., countries that have a Human Development Index in 1999 of 0.8 or greater-and all other countries (HD2). ${ }^{8}$ In

\footnotetext{
${ }^{6}$ Income coefficient estimates from models using time dummies are similar to those using a common time trend. Results using time dummies are displayed in Section A.5 of Appendix A.

${ }^{7}$ Although time trends are rarely assumed to be log-linear, this specification is appropriate if the effect of technological changes on fatality rates diminishes over time.

${ }^{8}$ The United Nations Human Development Index measures per capita income, life expectancy and educational achievement.
} 
practice, this division of countries (shown in detail in Table A.1 of Appendix A) corresponds closely to highly-motorized countries versus other countries. All HD1 countries are treated as a single region for the purposes of computing time trends. HD2 countries, in turn, are classified according to region. Table 2.2 shows the number of countries in each geographic region, for both HD1 and HD2 countries.

The inclusion of country-specific intercepts in equations (2.3) and (2.4) implies that the impact of income on the fatality rate will reflect within- rather than between-country variation in $\ln (\mathrm{F} / \mathrm{P})$ and $\ln (\mathrm{Y})$. This is desirable for two reasons. For the purposes of predicting future trends in $\mathrm{F} / \mathrm{P}$ it is more desirable to rely on within-country experience rather than on largely cross-sectional variation in income and fatality risk. Using only cross-country variation to predict the future pattern of traffic fatalities is equivalent to saying that once Indonesia reaches the income level of Greece, its road safety record will mirror that of Greece. The second reason is that countries differ in their definition of what constitutes a traffic death and in the percentage of deaths that are reported. (This topic is discussed more fully in Section 2.6.2.) To the extent that the degree of under-reporting remains constant over time but varies across countries it will not affect estimates of the impact of economic growth on fatality risk. ${ }^{9}$ Since Hausman specification tests suggest that the individual effects are correlated with the explanatory variables (see Tables 2.5-2.7), fixed effects rather than random effects estimation is performed in all cases.

\footnotetext{
${ }^{9}$ To illustrate, when equation (2.3) is estimated using country-specific intercepts, the coefficients $b$ and $c$ reflect within-country variation in fatalities and income. Multiplying country i's fatality rate by a constant to reflect under-reporting would not change the estimates of $b$ and $c$.
} 


\subsubsection{Data sources}

Equations (2.3) and (2.4) are estimated using panel data for 88 countries for the period 1963-99. To be included in the dataset a country must have at least 10 years of data on traffic fatalities. Table A.1 lists the countries used to estimate the models and the number of years of data that are available for each country. Population data come from the U.S. Census Bureau's International Data Base and income data are taken from the World Bank Global Development Network Growth Database Macro Time Series. To account for differences in purchasing power across countries and allow for comparisons over time, per capita income is measured by real per capita GDP, chain method (1985 international prices). ${ }^{10,11}$ The data on traffic fatalities and vehicles come primarily from the International Road Federation World Road Statistics annual yearbooks, which have been supplemented by and crosschecked against various other sources. The sources of fatality and vehicle data are described more fully in Section A.1 and A.2 of Appendix A. Table 2.3 contains descriptive statistics for all variables.

\footnotetext{
${ }^{10}$ This series was created from the Penn World Tables 5.6 RGDPCH variable for 1960-1992 and the 1992-1999 data were estimated using the 1985 GDP per capita and GDP per capita growth rates from the Global Development Finance and World Development Indicators.
}

${ }^{11}$ One issue with using PPP-adjusted income series in panel data analysis should be noted. Between 1963 and 1999, only the numeraire country will have 37 independent data points. For each of the other countries, there are only as many independent data points as there were PPP surveys for that particular country (approximately 6 to 10 for most countries in the present sample). The values for the remaining observations are computed through an interpolation procedure. 


\section{$2.4 \quad$ Results}

\subsubsection{Plots of dependent variables versus income}

Figures 2.1 through 2.5 plot each of the three dependent variables against per capita income for the countries in the dataset. The plots show how these quantities vary with income both within and across countries, foreshadowing the results in Tables 2.5 through 2.7 (discussed below).

It is widely recognized that the motorization rate rises with income (Ingram and Liu (1999), Dargay and Gately (1999), Button et al. (1993)), implying that one should find large differences in vehicles per capita across countries at different stages of development and within countries as per capita incomes grow. Table 2.4 presents data on motorization rates for various countries in 1999. Figure 2.1 plots the motorization rates for these countries against per capita income, pooling data from all countries and years, while Figure 2.2 shows how motorization rates have grown with income over time for a sample of countries.

The cross-sectional variation in motorization rates in Table 2.4 is striking. In 1999 vehicles per capita ranged from a high of 780 per 1,000 persons in the United States to fewer than 30 per 1,000 persons in countries such as Pakistan and Nigeria. High-income countries tend to have more vehicles per capita than lower income countries, but there are important exceptions. Low motorization rates in Hong Kong, Singapore, Chile, and Costa Rica are notable outliers. ${ }^{12}$ Figure 2.1, which plots data

\footnotetext{
12 The low motorization level in these countries could reflect physical limitations in the case of Hong Kong and Singapore and highly mountainous topography in the case of Chile and Costa Rica. These country characteristics will be accounted for in the fixed effects estimation.
} 
on $\mathrm{V} / \mathrm{P}$ for all countries and years in the dataset, suggests that, overall, motorization is strongly correlated with income. The within-group variation in motorization varies from country to country, however, as shown in Figure 2.2. Growth in vehicle ownership appears to have slowed down (but not declined) in many high-income countries such as Norway, Australia, Hong Kong, and the United States. In countries experiencing lower levels of per capita GDP such as Greece, Malaysia, and Thailand, however, vehicle fleets have continued to expand rapidly with income.

Fatalities per vehicle, by contrast, appear to decline steadily with income, at least after some low level of income, and then reach a floor. Both Figure 2.3, which plots the fatality rate $(\mathrm{F} / \mathrm{V})$ against income using data for all countries and years, and Figure 2.4, which shows how F/V has changed with income over time for a sample of countries, attest to this fact. ${ }^{13}$ In part, the sharp decline in $\mathrm{F} / \mathrm{V}$ with income reflects that, as income rises, a higher percentage of travelers are vehicle passengers rather than pedestrians, and thus, are less likely to die in the event of a crash. ${ }^{14}$ It also may reflect the move to safer vehicles (e.g., from two-wheelers to four-wheelers), safer roads, and changing attitudes toward risk as incomes grow.

The foregoing data suggest that one would expect to see motor vehicle fatality risk $(\mathrm{F} / \mathrm{P})$ first increase and then decrease with income. Figure 2.5, which plots F/P versus income for all years and countries in the dataset, supports this inverted U-

\footnotetext{
${ }^{13}$ The fatality figures used in Figures 2.3 - 2.5 have not been adjusted for underreporting of road deaths. Thus, $\mathrm{F} / \mathrm{V}$ and $\mathrm{F} / \mathrm{P}$ levels in developing countries may be underestimated.

${ }^{14}$ This point was first publicized by Smeed (1949), who demonstrated that F/V declines as $\mathrm{V} / \mathrm{P}$ increases.
} 
shaped pattern. As incomes grow and vehicle fleets increase during initial stages of development, traffic fatality risk tends to worsen. At higher income levels, however, as growth in motorization slows and governments and individuals invest more in road safety, the decline in $\mathrm{F} / \mathrm{V}$ drives the death rate $(\mathrm{F} / \mathrm{P})$ down.

\subsubsection{Estimates of fatalities per capita}

Table 2.5 summarizes the estimates of 8 specifications formed by combining the quadratic and spline functions with 4 methods of treating time trends. The table shows the income elasticities for each spline interval as well as the time trend coefficients for each model. The Durbin-Watson statistics indicate the need to correct for autocorrelation in all equations. ${ }^{15}$ The standard errors have been adjusted to account for serial correlation in disturbances within countries over time, as well as for heteroskedasticity. ${ }^{16}$ To give a more complete picture of the model results, Figures 2.6 and 2.7 plot F/P as a function of per capita income. ${ }^{17}$ Figure 2.6 shows the quadratic and spline models with a common time trend while Figure 2.7 plots the quadratic and spline models with region-specific time trends.

\footnotetext{
${ }^{15}$ The Durbin Watson statistic was calculated using a STATA program (xtdw) written for calculating DW statistics in fixed effects panel data models (Nunziata, 2002), following Baltagi (1995), page 94. The DW statistic is less than the lower bound critical value in all regressions, indicating the presence of positive within-panel serial correlation in the disturbances.

${ }^{16}$ This procedure is theoretically justified when the number of panels is large (Liang and Zeger, 1986). Recent studies of finite sample properties of robust variance matrix estimators find that this fully robust variance estimator works reasonably well in the context of fixed effects estimation and panel data even when the number of panels is not especially large relative to the length of each panel (Wooldridge, 2003).

${ }^{17}$ In both figures, F/P results are displayed using the country intercept for India with the time trend set equal to 1999 .
} 
Several results are worth emphasizing. It is clear from examining Figures 2.6 and 2.7 that the relationship between per capita income and the fatality rate is quite similar (holding the treatment of time constant) whether one uses the quadratic or spline function. When a common time trend is assumed $\mathrm{F} / \mathrm{P}$ begins to decline at an income of $\$ 4,800-\$ 5,400$ using the quadratic specification and at an income of $\$ 6,100$ with the spline model. When region-specific time trends are included $\mathrm{F} / \mathrm{P}$ begins to decline at an income of $\$ 5,700-\$ 10,800$ in the quadratic model and at an income of $\$ 8,600$ in the spline model. In both figures, the two models are almost identical at low levels of income; however, the fatality rate peaks at a higher level of income in the spline model (except in the spline specification with linear regional time trends) and falls faster than in the quadratic model after it peaks. Despite common practice in the Kuznets curve literature to estimate quadratic (or higher order polynomial) functions of income, since the spline is a more flexible functional form, I focus on the spline results in Table 2.5. ${ }^{18}$

In the spline specification, the income levels at which the death rate first declines are higher when region-specific time trends are included in the models rather than a common time trend. For example, F/P begins to decline at approximately $\$ 8600$ in the spline models with region-specific time trends but at approximately $\$ 6100$ in the spline models with a common time trend (although the income elasticity is not statistically significant for incomes in the $\$ 6,100-\$ 8,600$ range in the common

\footnotetext{
${ }^{18}$ Sensitivity of the turning point to various subsets of the sample is summarized in Section A.5 and Table A.5 of Appendix A. In the quadratic specification of income with logged, region-specific time trends, the turning point estimate is generally robust to variations in the sample. Using the spline specification of income, the turning point increases (to as high as $\$ 9,700$ ) for a few subsets of the sample.
} 
time trend case). ${ }^{19}$ This reflects the fact that, in many developing countries, fatality risk over the period 1963-99 grew faster than could be explained by income growth alone. Because the time trends are found to be significantly different across regions, more emphasis should be placed on these models than on models with a common time trend.

In the spline models with region-specific time trends, the income level at which traffic fatality risk ( $\mathrm{F} / \mathrm{P}$ ) first declines is $\$ 8,600$ (1985 international prices), regardless of how the regional time trends are specified. This is the approximate income level attained by countries such as Belgium, the United Kingdom, and Austria in the early 1970s, South Korea in 1994, and New Zealand in 1968. However, the income elasticity for per capita incomes up to $\$ 8,600$ is larger when the time trends enter in linear form. Thus, the maximum fatality risk is over $60 \%$ higher than the level reached if the time trends enter the model in log-linear form. ${ }^{20}$

Whether the time trends enter the models linearly or in log-linear form, the differences in trends across regions are generally similar. Over the estimation period

\footnotetext{
${ }^{19}$ As shown in Table A.6 of Appendix A, the income range of the estimated turning point is fairly robust to using a different number of spline segments. When using 8,9 , 11 , or 12 spline intervals, the income elasticity becomes negative for incomes greater than $\$ 6,800-7,700$, but generally is not statistically significant until income exceeds $\$ 9,200$. There is no real difference in the turning point between common linear trend and logged region-specific time trend cases; except in the case of 9 intervals, the elasticity is significant for incomes exceeding $\$ 7,700$ with the common time trend but is only statistically significant for incomes over $\$ 10,400$ with the logged regionspecific trends.

${ }^{20}$ This difference is clearly seen in Figure 2.7. Including higher-order polynomials of the time trend $t$ may help to resolve the large discrepancy. The log-linear function constrains coefficients on higher-order terms to be equal, whereas the linear specification assumes coefficients on higher-order terms to be zero.
} 
(1963-99) fatality risk grew fastest in India and in Latin America (holding income constant), and almost as fast in Sub-Saharan Africa as in Latin America. Fatalities per capita also increased nearly as fast in the East Asia and Pacific region as in Latin America when log-linear time trends are specified. By contrast, (holding income constant) F/P declined in high-income countries. Results for other regions are statistically insignificant in at least some specifications.

In the Kuznets Curve literature it is standard practice to focus on the income level at which the externality in question begins to decline. The usual interpretation is that, if a country follows historical trends, the problem in question will eventually lessen once per capita income reaches this turning point. Because the spline is a more flexible functional form, I focus on the spline results in Table 2.5. The income levels at which fatalities per person peak in the spline models, $\$ 6100$ and $\$ 8600$ (1985 international dollars) are within the range of incomes at which Kuznets curves for common air and water pollutants peak (Grossman and Krueger, 1995). To better understand why this occurs, and to help distinguish between the two specifications of the time trend, the next sections examine the corresponding models for the two components of the death rate - vehicles per capita (V/P) and fatalities per vehicle $(\mathrm{F} / \mathrm{V})$.

\subsubsection{Estimates of vehicles per capita}

Models for vehicles per capita (V/P) are summarized in Table 2.6 and Figure 2.8. Table 2.6 shows how motorization $(\mathrm{V} / \mathrm{P})$ varies with income in the both the quadratic and spline models. The discussion, however, focuses on the spline models. 
Figure 2.8 plots the four spline models using the country intercept for India, with the time trend set equal to 1999 .

The spline model with log-linear region specific time trends is the preferred specification for the following reasons. Of the four spline models in Table 2.6, only two (Models 6 and 8) show vehicles per capita increasing with per capita income at a decreasing rate for all relevant values of per capita income. This result occurs when time is entered in a log-linear fashion; when it enters the motorization equation linearly, V/P peaks at a value of income observed in the data, and begins to decline with income for per capita GDP exceeding $\$ 8,600$. The time trend associated with vehicle ownership is large and positive. The log-linear time trend thus seems to yield more reasonable results than the linear. Of the two models with log-linear time trends, only the model with regional log-linear time trends yields non-negative income elasticities for all levels of income and the equality of time trends across regions is statistically rejected; hence I focus on this model.

The preferred model of vehicle ownership (Model 8), which together with models of fatalities per vehicle provides a check on the validity of the fatality results, accords with results in the literature. Elasticities based on the model with log-linear time trends are consistent with previous studies of motorization, which find that the income elasticity of demand for motor vehicles declines with income (Ingram and Liu, 1998; Dargay and Gately, 1999; Button et al., 1993). In Model 8, the income elasticity of vehicle ownership attains a maximum value of 1.67 in the second spline segment (\$946 - \$1,535 (1985 international dollars)) and decreases to a low of 0.18 in the highest income category. Above the lowest income category, income elasticities 
in income categories 2 through 5 are significantly higher than income elasticities in income categories 7 to $10 .^{21}$ Figure 2.8 suggests that the rate of increase in motorization slows down considerably after reaching a per capita income of $\$ 9,400$ (1985 international dollars), the level of income attained by Norway and the United Kingdom in 1974.

\subsubsection{Estimates of fatalities per vehicle}

Table 2.7 and Figure 2.9 confirm that fatalities per vehicle decline sharply with income. Focusing once again on the spline models with log-linear time trends (Models 6 and 8), F/V declines with income for per capita GDP in excess of $\$ 1,180$ (1985 international dollars), the per capita income of Mozambique, Ghana, and Cameroon in 1999 and India in the mid-1980s. Figure 2.9, which plots the four spline models for India (year $=1999)$ indicates exactly how fast F/V declines as income grows. Fatalities per vehicle fall by a factor of 3 (e.g., from 360 to 120 per 100,000 vehicles for India) as per capita income grows from $\$ 1200$ to $\$ 4400$. After reaching a per capita income of $\$ 15,200$ (1985 international dollars), the approximate income of the United States in the early 1980s and Switzerland in 1986, F/V declines very slowly in absolute terms: from 25 per 100,000 vehicles at an income of $\$ 20,000$ to 15 per 100,000 vehicles at an income of $\$ 30,000$. By contrast, with linear time trends, the estimated income elasticity of fatalities per vehicle is smaller in magnitude and statistically insignificant in most spline segments.

${ }^{21}$ Income elasticity estimates generated from a two-segment spline model are statistically different from each other, decreasing from $1.32(0.240)$ to $0.719(0.219)$ once per capita income exceeds $\$ 4,682$ (1985 international dollars). 
Combining the results of the models for $\mathrm{F} / \mathrm{V}$ and for $\mathrm{V} / \mathrm{P}$ explains the results for deaths per capita observed in Figure 2.7. The elasticity of V/P with respect to income exceeds in absolute value the elasticity of $\mathrm{F} / \mathrm{V}$ with respect to income for incomes up to $\$ 7,000-\$ 9,000$, where the two elasticities are approximately equal- the condition for $(\mathrm{F} / \mathrm{V}) *(\mathrm{~V} / \mathrm{P})$ to peak. ${ }^{22}$ This is the income range reached by countries such as Austria, Finland, Norway, and the United Kingdom in the early 1970s and Malaysia and Greece in the late 1990s. At higher incomes, the elasticity of fatalities per vehicle with respect to income exceeds the elasticity of motorization with respect to income. This is consistent with the coefficients reported in Model 8 of Table 2.5, which show the income elasticity of the death rate decreasing from 1.253 at the lowest levels of income to -0.996 once per capita income exceeds $\$ 13,500$.

\subsection{Future Trends in Motorization and Road Safety}

2.5.1 Methodology for projecting vehicle usage and traffic fatalities

One reason for estimating the preceding models is to predict what will happen to traffic fatalities if historic trends continue. Results from Kuznets curve studies have rarely been used for forecasting purposes, which raises the question of their usefulness in policy discussions. Although an EKC relationship is not to be viewed as an inevitable consequence of income growth, the estimated income elasticities can be used to suggest what trends can be expected in the future, assuming that, as developing economies continue to grow, they will adopt road safety policies at the

${ }^{22}$ This comparison is approximate since the width of the income intervals differs in Tables 2.6 and 2.7 . 
same rate as high-income countries did. These forecasts provide policymakers with a baseline scenario of what is likely to happen if historic trends continue.

Perhaps one reason that most EKC studies avoid making predictions is because they are predominantly based on polynomial specifications of income, which are notoriously unreliable in out-of-sample predictions. ${ }^{23}$ The use of a flexible, spline specification of income, however, alleviates this problem to some degree, and prevents a third order polynomial term, for example, from significantly distorting the out-of-sample predictions for high-income countries. ${ }^{24}$ Schmalensee et al. (2000) base their projections of $\mathrm{CO}_{2}$ emissions on a spline specification for this reason as well.

Future traffic fatalities can be predicted directly from equation (2.2), i.e., by predicting future fatality rates $(\mathrm{F} / \mathrm{P})$ and multiplying by estimates of future population, or by predicting vehicle ownership, $\mathrm{V}$, from the $\mathrm{V} / \mathrm{P}$ equation and multiplying the vehicle stock by fatalities per vehicle. The second method serves as a check on the first since more is known about vehicle ownership. In particular, one

${ }^{23}$ Another reason pertains to the nature of the externality in question. According to the pollution haven theory, the downward sloping part of some EKCs is due to pollution intensive industries being exported to low-income countries. If there are no lower-income countries to which these activities may be passed on then it will be impossible to expect the poorest countries to experience improvements in environmental quality at the same rate as high-income countries did. This argument does not pertain to externalities resulting from a consumption activity such as driving, and is, thus, irrelevant to the present analysis.

${ }^{24}$ Grossman and Krueger (1995) find that the EKC turns back up again at high incomes, but note that it is probably due to in-sample curvature and the third-order polynomial term. 
can reject models that yield unbelievably high rates of vehicle ownership; e.g., ownership significantly in excess of one vehicle per person in the year 2020.

To project future vehicle ownership and traffic fatalities assumptions must be made about income and population growth. The real per capita GDP series is projected to 2020 using the World Bank's forecasts of regional growth rates (20002010) (Global Economic Prospects, 2002) with the assumption that the average annual 2001-2010 growth rates continue through 2020. A list of the growth rates is provided in Table 2.8. Population projections are taken from the U.S. Census International Data Base. In total, the explanatory variables are available for 156 countries (representing $92 \%$ of total world population in 2000), including 45 highly developed countries (HD1) and 111 developing countries (HD2). Table 2.2 shows the number of countries in each geographic region for which predictions are made.

To calculate the point estimates for the out-of-sample countries, assumptions must be made regarding the country-specific intercept. The coefficient on the country dummy variable for Chile is used to compute the predicted values for the 10 out-ofsample HD1 countries. ${ }^{25}$ For the HD2 countries, the intercept is set equal to the mean of the country intercepts for the corresponding region.

\subsubsection{Projections of the world vehicle fleet to 2020}

I begin by examining the implications of the models in Table 2.6 for future growth in vehicle ownership. Figure 2.10 displays projections of the vehicle fleet corresponding to all 8 models in Table 2.6. Not surprisingly, it is the form of the time

\footnotetext{
${ }^{25}$ The choice of Chile is motivated by the fact that the most populous out-of-sample HD1 countries for which predictions must be made are Argentina and Uruguay.
} 
trend, rather than the choice between the spline and quadratic specifications, that makes the greatest difference in the projections. Both the spline and quadratic models with linear regional time trends yield unbelievably large estimates of the world motor vehicle stock in 2020, as well as estimates of vehicle ownership per capita for certain groups of countries that are well over 1. For this reason I focus on the spline models with log-linear time trends. The model with region-specific log-linear time trends (Model 8) generates forecasts of 1.47 billion vehicles in 2020, whereas the vehicle stock is predicted to be over 1.37 billion vehicles when a common log-linear time trend is used (Model 6). ${ }^{26}$

Vehicle projections based on these models agree fairly well with other estimates of vehicle growth in the literature. Dargay and Gately (1999) project that the total vehicle fleet in OECD countries will reach 705 million by 2015 (a 62\% increase from 1992 values). The spline model (with the common time trend or the log-linear regional time trends) yields a 2015 estimate of 687 million vehicles for the same group of countries.

Other studies have made projections of vehicle growth for the automobile fleet only or for passenger cars and commercial vehicles. Since the motor vehicle counts here include all buses and two-wheelers, direct comparisons with these studies is difficult. However, vehicle fleet estimates based on the V/P results do exceed their automobile forecasts under all specifications. Under Schafer's (1998) results, the global automobile fleet would more than double from 470 million in 1990 (this

\footnotetext{
${ }^{26}$ The corresponding quadratic models give almost identical vehicle projections but I continue to focus on the more flexible spline specifications.
} 
includes light trucks for personal travel in the U.S.) to 1.0-1.2 billion automobiles in 2020. This amounts to a $113 \%-155 \%$ increase in total automobiles. The spline model with log-linear regional time trends generates a $140 \%$ increase in the total vehicle fleet during the same period (from 609 million to 1.47 billion total vehicles). Because it yields reasonable predictions of the vehicle fleet, as well as reasonable income elasticity estimates, the focus remains on the spline model with regional, loglinear time trends.

\subsubsection{Projections of world traffic fatalities to 2020}

Figure 2.11 shows predictions of road traffic fatalities for all countries to the year 2020, based on the spline model for F/P with log-linear regional time trends. Ninety-five percent confidence levels for the predictions also appear on the graph. ${ }^{27}$ The estimates indicate that total road traffic fatalities will increase from 539,000 ( $95 \%$ C.I.: $459,000,640,000)$ in 2000 to over 864,000 (95\% C.I.: 706,000, 1,070,000) by $2020 .{ }^{28}$ Note these projections assume that the income elasticity estimated for the observations in the highest spline interval also apply at higher income levels.

It must be emphasized that these predictions represent traffic fatalities unadjusted for under-reporting. To compare these figures with fatality risks from

\footnotetext{
${ }^{27}$ The model generates point estimates of the log of the fatality risk $(\ln$ (Fatalities/10,000 People)). The confidence intervals for the predicted values of $\ln$ (Fatalities/10,000 People) are symmetric, but the forecast intervals for the total number of fatalities are not. These intervals are computed as the predicted value $+/-$ 1.96 times the estimated standard error.

${ }^{28}$ Projections based on the $\ln (\mathrm{F} / \mathrm{V})$ and $\ln (\mathrm{V} / \mathrm{P})$ equations yield similar estimates. That is, if future fatalities are calculated by first predicting the vehicle stock, $\mathrm{V}$, from the $\ln (\mathrm{V} / \mathrm{P})$ equation and then multiplying $\mathrm{V}$ by fatalities per vehicle (predicted from the $\ln (\mathrm{F} / \mathrm{V})$ equation), the global road death toll is expected to increase from over 510,000 in 2000 to 790,000 by 2020 .
} 
other causes of death, it is necessary to adjust for the fact that (a) the definition of what constitutes a traffic fatality differs across countries and (b) the percentage of traffic fatalities reported by the police also varies across countries.

The under-reporting adjustments follow the conservative factors used by Jacobs, Aeron-Thomas and Astrop (2000). ${ }^{29}$ To update all point estimates to the 30day traffic fatality definition, ${ }^{30}$ a correction factor of 1.15 is applied in the developing countries and the standard ECMT correction factors are used for the high-income countries. ${ }^{31}$ The estimates are then adjusted to account for general under-reporting of traffic fatalities, by $25 \%$ in developing countries and by $2 \%$ in highly developed countries. ${ }^{32}$ With these adjustments, global road deaths are projected to climb to over 1.2 million by 2020 (a $40 \%$ increase over the base estimate of 864,000 ).

Although this represents a $66 \%$ increase from the 2000 world estimate, the trend varies considerably across different regions of the world. Table 2.9 and Figure 2.12 indicate that, between 2000 and 2020, fatalities are projected to increase by over $80 \%$ in developing countries, but decrease by nearly $30 \%$ in high-income countries.

\footnotetext{
${ }^{29}$ Jacobs et al. (2000) reviewed numerous underreporting studies and found evidence of underreporting rates ranging from $0-26 \%$ in highly motorized countries and as high as $351 \%$ in less motorized countries. Fatalities in China, for example, were $42 \%$ higher in 1994 than reported in official statistics (Liren, 1996).

${ }^{30}$ The standard international definition of a traffic fatality is a death that occurs within 30 days as a result of a traffic accident. Correction factors are applied to death statistics to account for countries using different reporting procedures.

${ }^{31}$ High-Income countries with ECMT correction factors greater than 1 include: France: 1.057, Italy: 1.07, Portugal: 1.3, Japan: 1.3 (ECMT, 1998, 2000, 2001).

${ }^{32}$ The $25 \%$ under-reporting adjustment is applied to $111 \mathrm{HD} 2$ countries and the $2 \%$ adjustment is used for $45 \mathrm{HD} 1$ countries. See Table 2.2 for a regional breakdown of countries.
} 
Within the developing world, the greatest percentage increases in traffic deaths between 2000 and 2020 will occur in South Asia (144\% increase), followed by East Asia and Sub-Saharan Africa (both showing an $80 \%$ increase). It is also interesting to note that the number of traffic fatalities per 100,000 persons is predicted to diverge considerably by 2020 . By 2020 the fatality risk is predicted to be less than 8 in 100,000 in high-income countries but nearly 20 in 100,000 in low-income countries.

\subsubsection{Implications of traffic fatality projections}

The forecasts presented here are significantly lower than the World Health Organization's (WHO) 1990-2020 estimates of road traffic fatalities presented in The Global Burden of Disease (GBD) (Murray and Lopez, 1996). WHO estimates that 1.39 million people would die in road traffic accidents in 2000 and that 2.34 million would die in 2020. The reason for the higher figures is that WHO started from a higher base (999,000 deaths in 1990). In part, the high GBD base estimate for 1990 may be due to severe data limitations in developing regions. For example, 1990 estimates for the entire Sub-Saharan Africa (SSA) region were based only on data from South Africa (Cooper et al., 1997; Jacobs et al., 2000). South Africa has by far the highest reported fatality risk $(\mathrm{F} / \mathrm{P})$ of nearly 20 SSA countries for which I have 1990 data. Even after adjusting predicted values for non-reporting and underreporting of fatalities, the SSA estimate in Table 2.9 is 59,150 deaths for 1990 whereas the GBD baseline is 155,000 for the same year. Despite such large differences between these 1990 estimates and theirs, Murray and Lopez predict that global traffic fatalities will grow at approximately the same rate as the present 
projections. (Fatalities grow by $62 \%$ between 2000 and 2020 according to WHO and by $66 \%$ according to the estimates in Table 2.9.)

I believe that Murray and Lopez (1996) have over-estimated road traffic fatalities and stand behind the estimates presented here. One reason for this is that the estimate of fatalities in $2000(723,439)$ agrees with the U.K. Transportation Research Laboratory's (TRL) estimate of global road deaths for 1999 (Jacobs et al., 2000), i.e., 745,769 fatalities worldwide (low under-reporting adjustment case). The TRL 1999 estimate is based on published 1996 data from 142 countries updated to 1999 levels and adjusted for non-reporting and under-reporting of fatalities. Since this seems to be the most comprehensive, bottom-up approach to estimating the global road death toll to date, I feel that it is the most appropriate estimate against which to compare the present projections. The prediction of traffic fatalities in 2020 (1.2 million deaths worldwide) also lies within the range suggested by TRL for 2020 (1 to 1.3 million deaths), although the latter is not based on a statistical model.

\subsection{Conclusion}

Despite the extensive road safety literature that has developed in the U.S. and several European countries, there has been no comprehensive study of the variation in traffic fatalities across countries at different stages of economic development. This chapter begins to fill this void by documenting the road safety-income relationship using an Environmental Kuznets curve framework. The results suggest that traffic fatalities do indeed follow an inverted U-shaped relationship with income, with traffic 
fatality risk beginning to decline at income levels similar to those found for several environmental externalities.

The nature of the externality in question allows one to conduct a more detailed examination than most EKC studies. By estimating reduced form models of fatalities/population and its two components - vehicles/population and fatalities/vehicle -the traffic fatality-income relationship is decomposed into a "scale" and "intensity" effect. The scale of transportation activity (as measured by the motorization rate) is found to increase at a decreasing rate with income, but never declines. Since the risk "intensity" associated with driving falls steadily with increases in per capita income, however, the traffic fatality risk-income relationship becomes negative once the income elasticity of Fatalities/Vehicle exceeds in absolute value the income elasticity of Vehicles/Population. This occurs at a per capita income of approximately $\$ 8,600$ (1985 international dollars). The relatively large number of countries and long panels included in the dataset helps make this result less fragile to the functional form of income and specification of the time trend than in most EKC studies, even after controlling for country fixed effects, heteroskedasticity, and within panel serial correlation, econometric issues often ignored in most EKC analyses.

Forecasts of traffic fatalities based on the results presented above suggest that, if developing countries follow historic trends, it will take many years for them to achieve the motor vehicle fatality risks of high-income countries. Provided that historic policies continue into the future, the road death rate in India, for example, 
will not begin to decline until 2042. ${ }^{33}$ (The projected peak corresponds to approximately 24 fatalities per 100,000 persons prior to any adjustment for underreporting but becomes 34 fatalities per 100,000 persons if one maintains the underreporting adjustment factors chosen above.) This is primarily due to the fact that India's per capita income (in 1985 international dollars) was only $\$ 2,900$ in 2000, whereas F/P peaks at a per capita income of approximately $\$ 8,600$. Similarly, in Brazil F/P will not peak until 2032, and the model projects over 26 deaths per 100,000 persons as far out as 2050 .

In other developing countries, the traffic fatality risk will begin to decline before 2020 but F/P risks will still exceed the levels experienced in high-income countries today (which average about 11 fatalities per 100,000 persons). Malaysia, for example, is estimated to have over 20 fatalities per 100,000 persons (after adjusting for under-reporting) in 2020. If 5.1\% growth continues beyond 2020, F/P will reach 11.1 by 2033 (using the same under-reporting adjustment as above); however, if the growth rate decreases to $2.5 \%$ after $2020, \mathrm{~F} / \mathrm{P}$ will reach 11.0 only in 2049.

The predictions in Section 2.5, and the estimates of the income level at which traffic fatality risk begins to decline, assume the policies that were in place from 1963 through 1999 will continue in the future and that, as they continue to grow, developing economies will adopt road safety policies at the same rate as high-income countries did. Clearly, this may not be the case. In many developing countries

\footnotetext{
${ }^{33}$ This assumes the annual real per capita GDP growth rate of $3.87 \%$ and India's loglinear time trend (from the last column in Table 2.5) will continue into the future.
} 
fatalities per vehicle could be reduced significantly through interventions that are not explicitly reflected in the data. For example, drivers of two-wheelers could be required to wear white helmets, traffic calming measures could be instituted in towns, and measures could be taken to separate pedestrian traffic from vehicular traffic. The central question for policy in low-income countries is to identify the factors that underlie the decline in fatalities per vehicle (or per VKT) and to implement policies that are cost-effective. 
Figure 2.1. Motorization Rate vs. Income: All Countries and Years

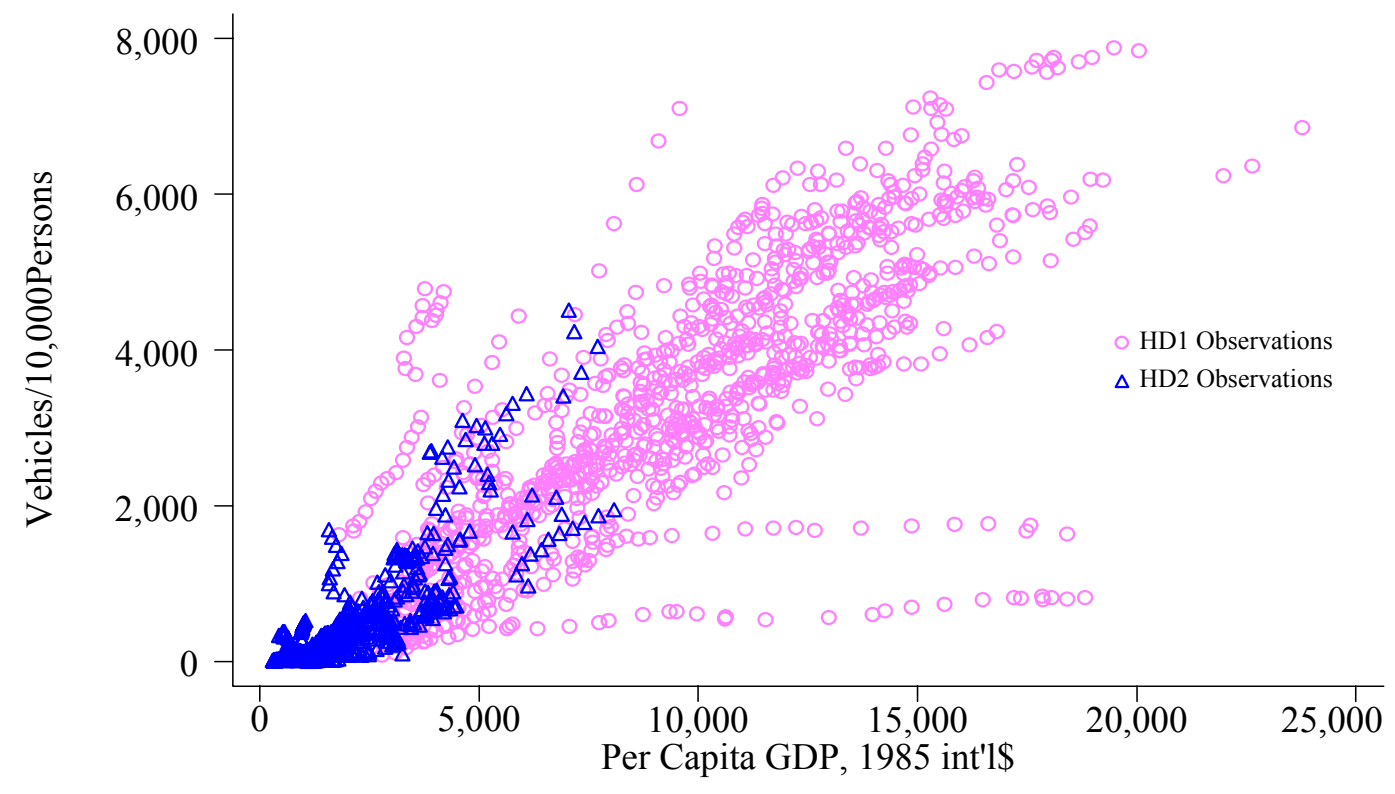


Figure 2.2. Motorization Rates vs. Income: Selected Countries
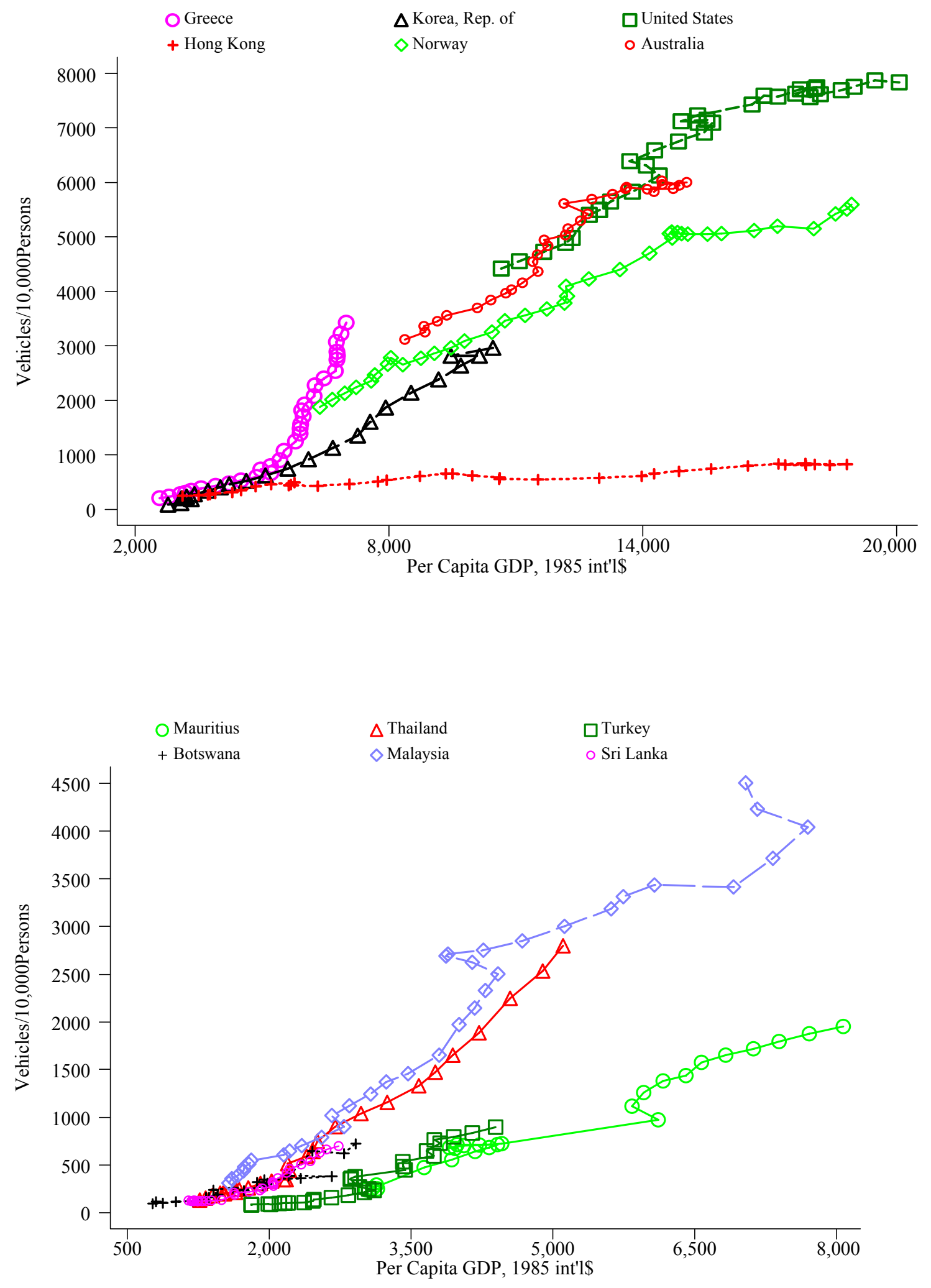
Figure 2.3. Fatalities/Vehicle vs. Income: All Countries and Years

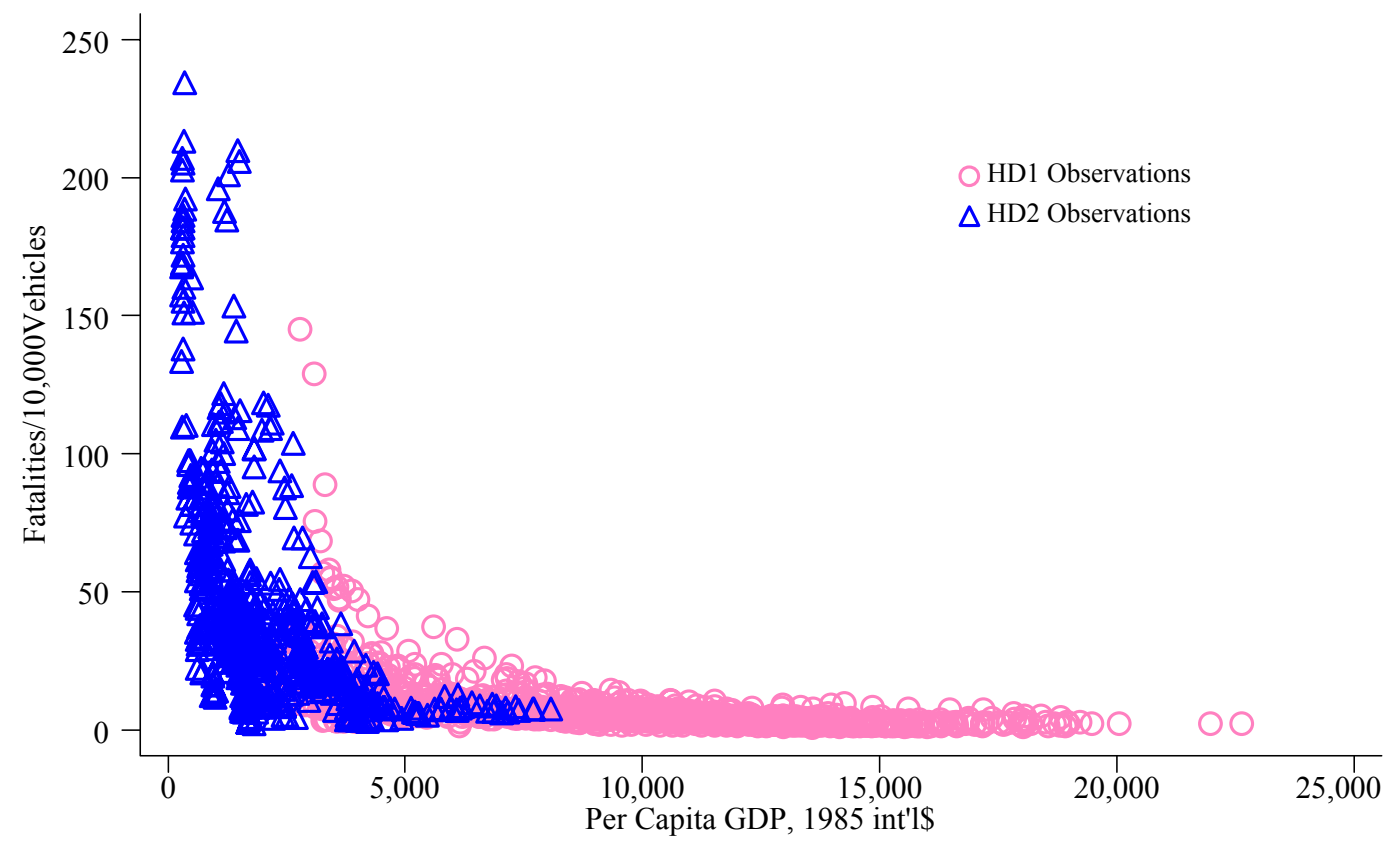


Figure 2.4. Fatalities/Vehicle v. Income: Selected Countries
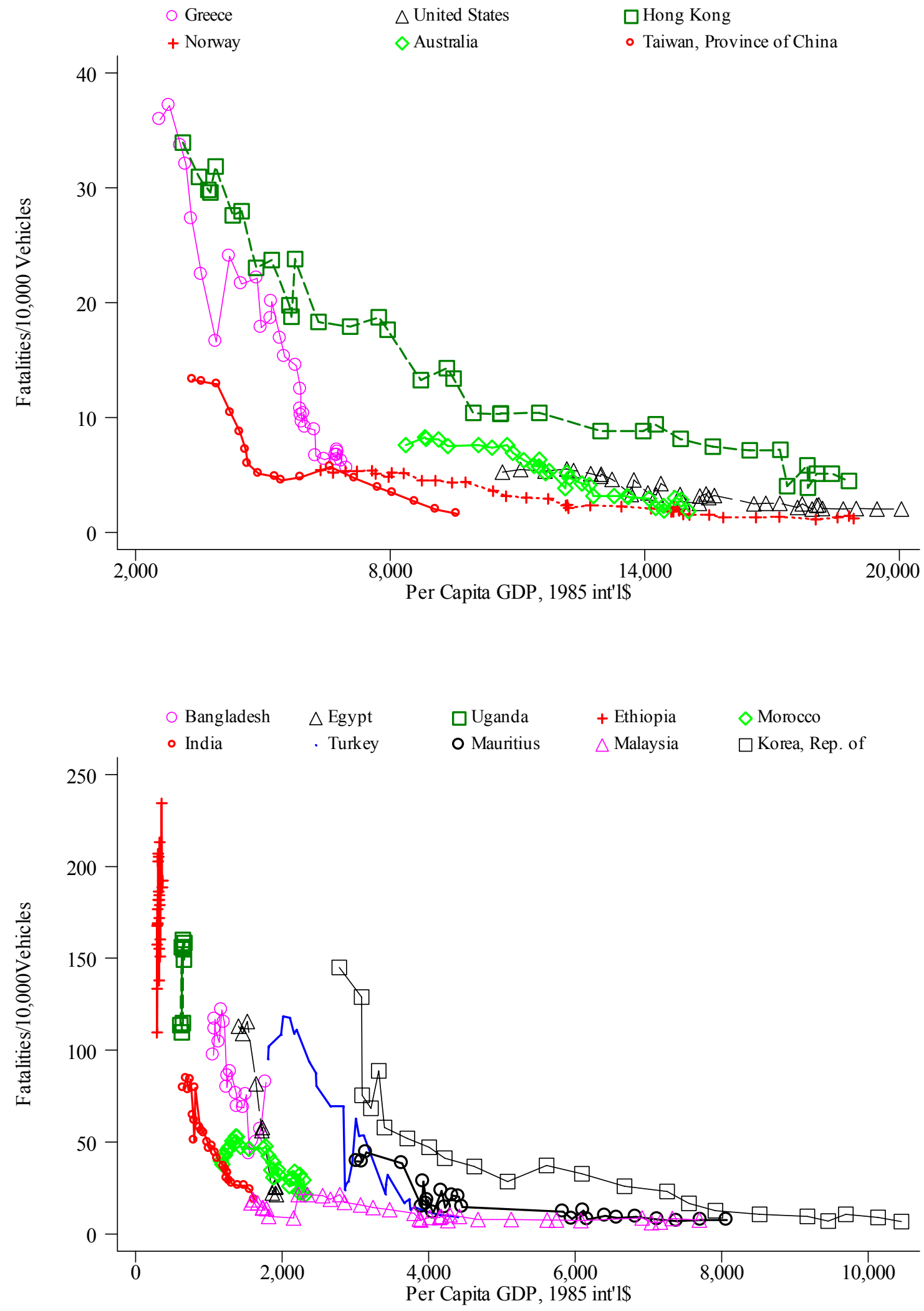
Figure 2.5. Traffic Fatality Risk vs. Income: All Countries and Years

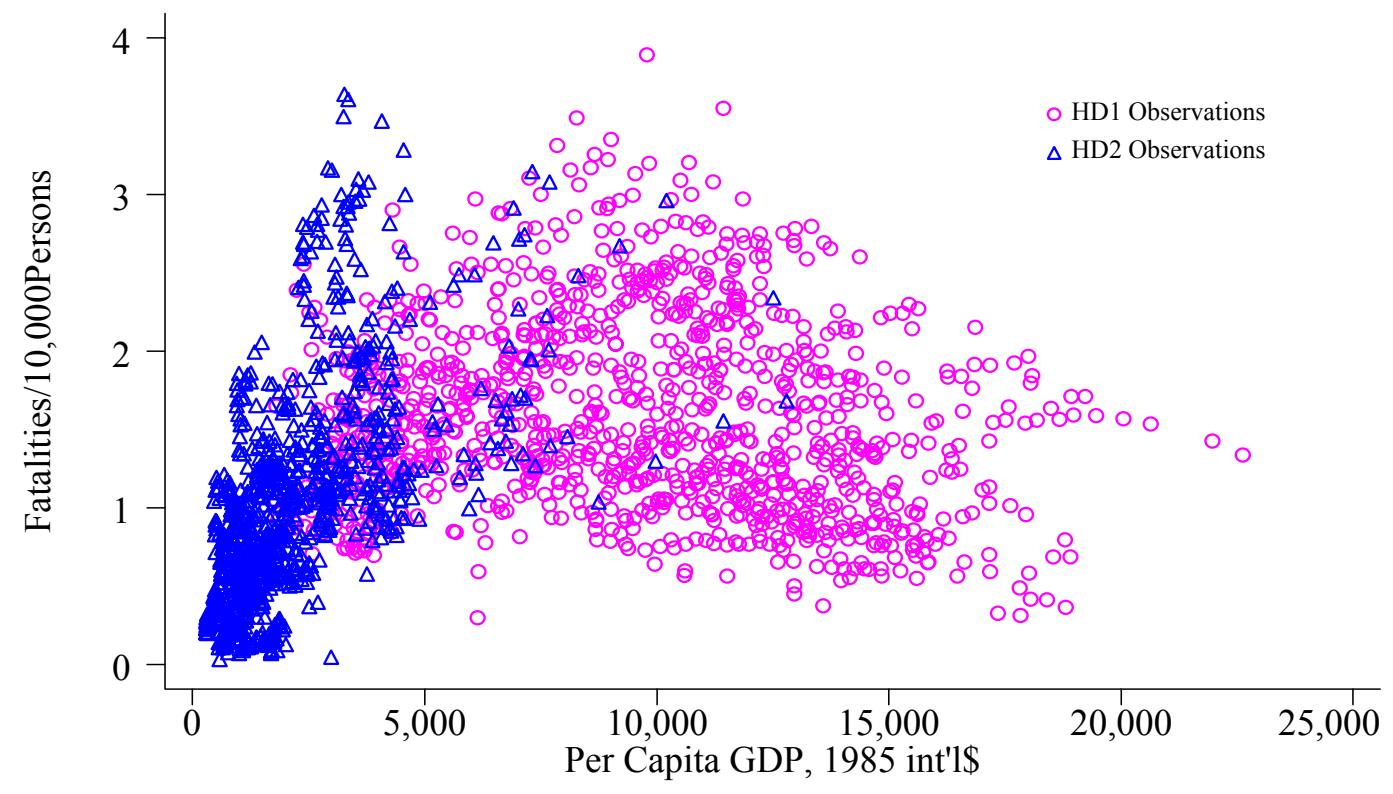


Figure 2.6. Fatalities/Population Results, Common Time Trend Models

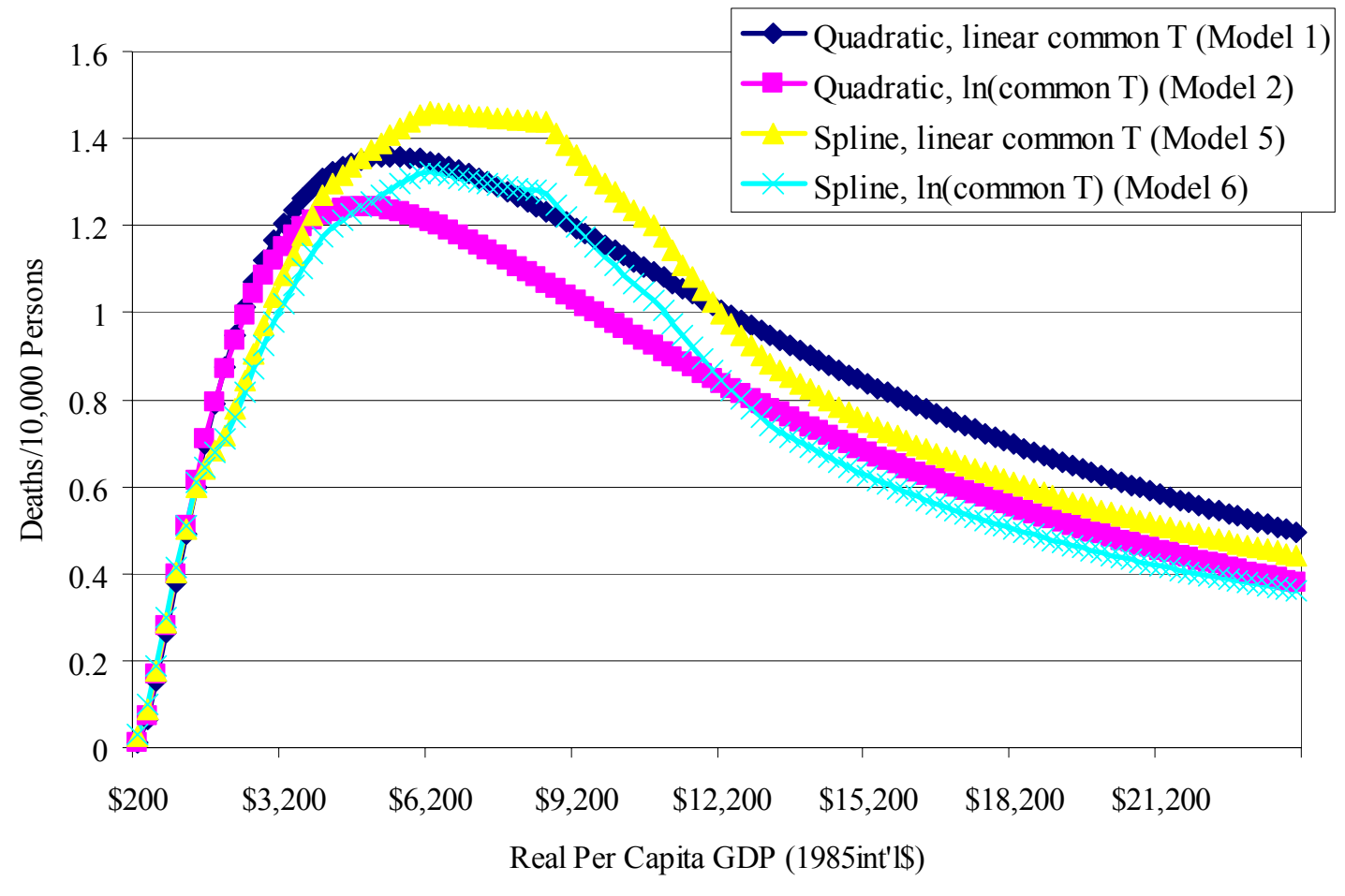


Figure 2.7. Fatalities/Population Results, Region-Specific Time Trend Models

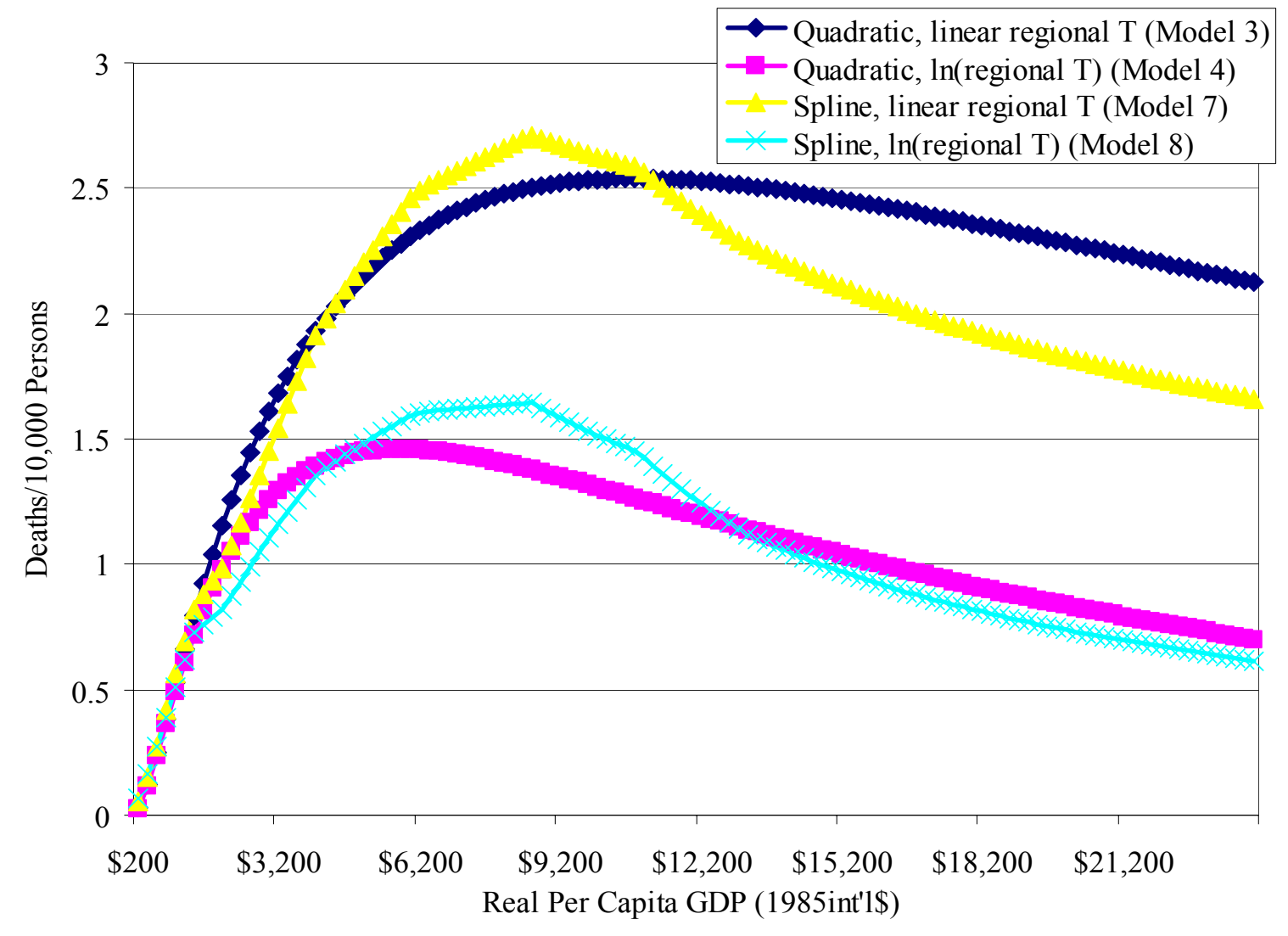


Figure 2.8. Vehicles/Population Results, Spline Models

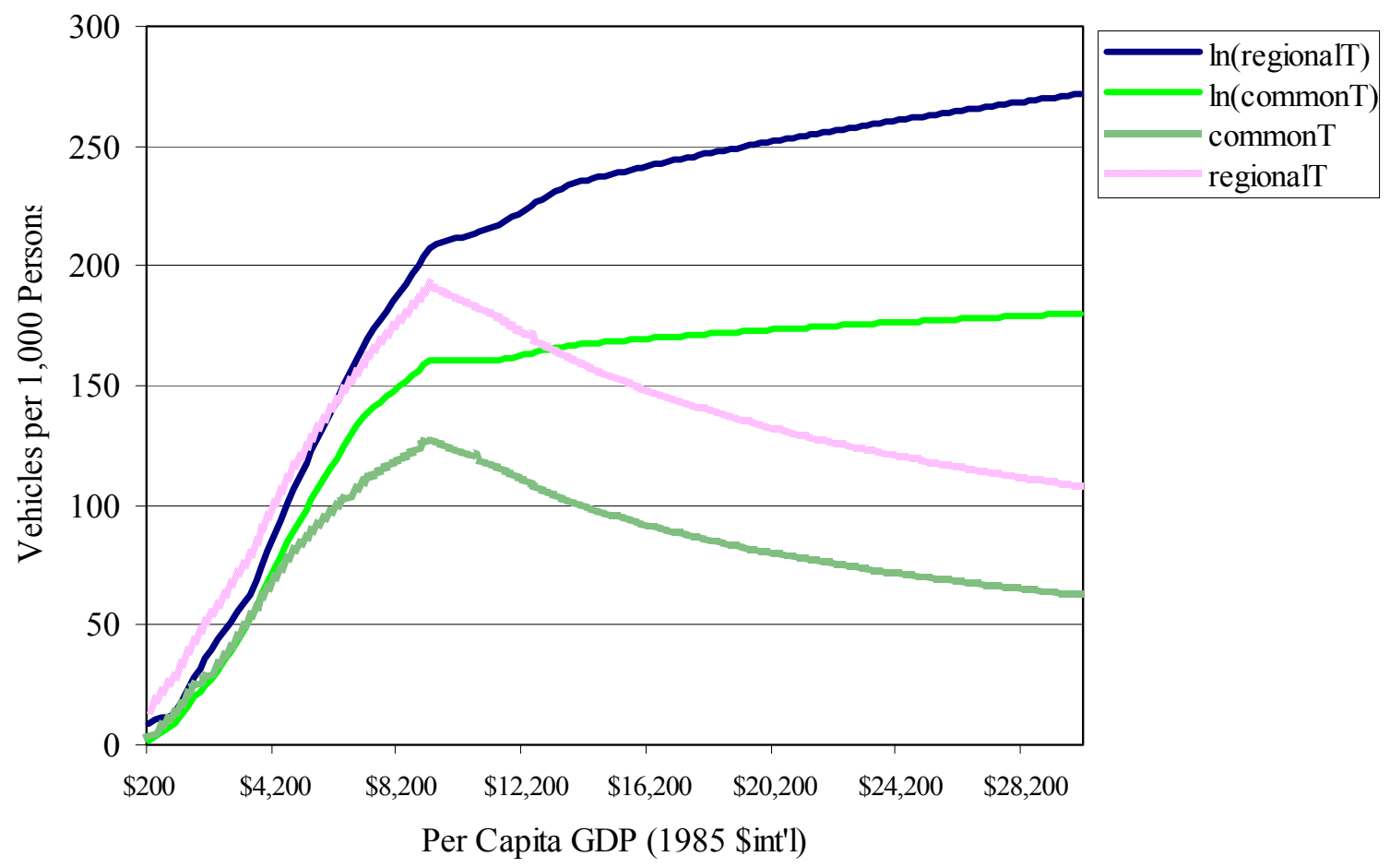


Figure 2.9. Fatalities/Vehicle Results, Spline Models

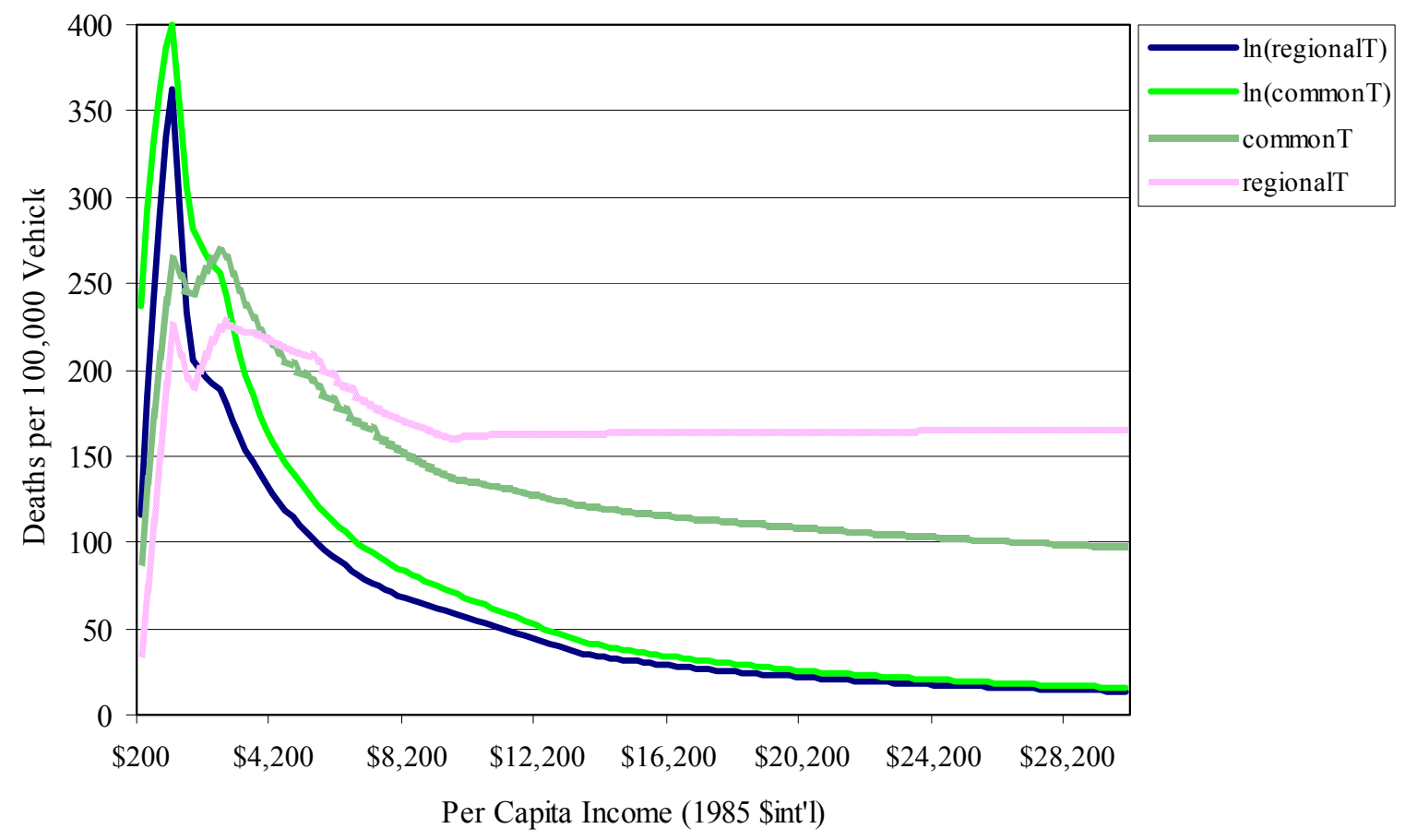


Figure 2.10. World Vehicle Fleet Projections Corresponding to Models in Table 5

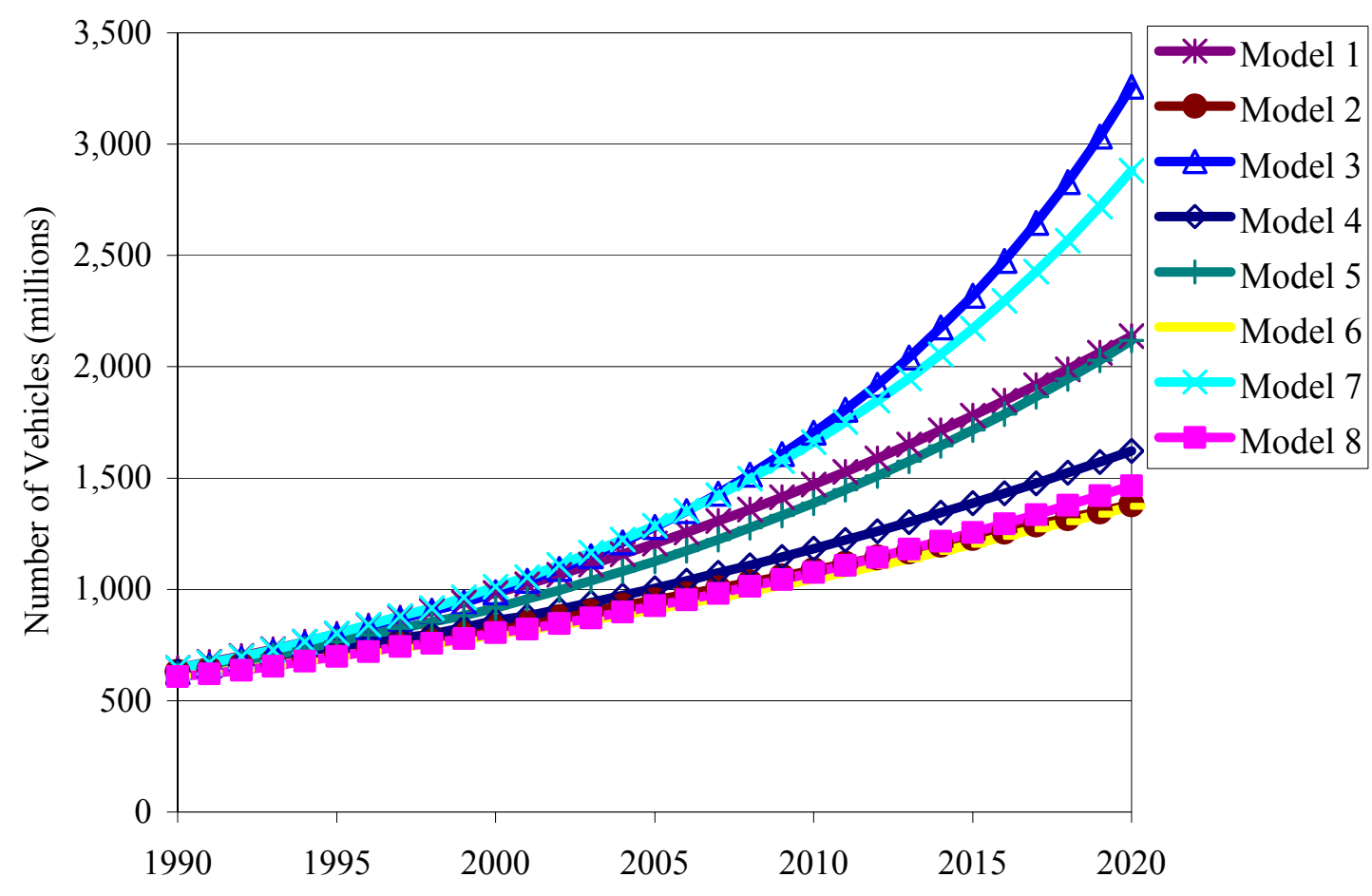


Figure 2.11. Global Road Traffic Fatalities, Before Adjusting for Under-Reporting, 1990-2020

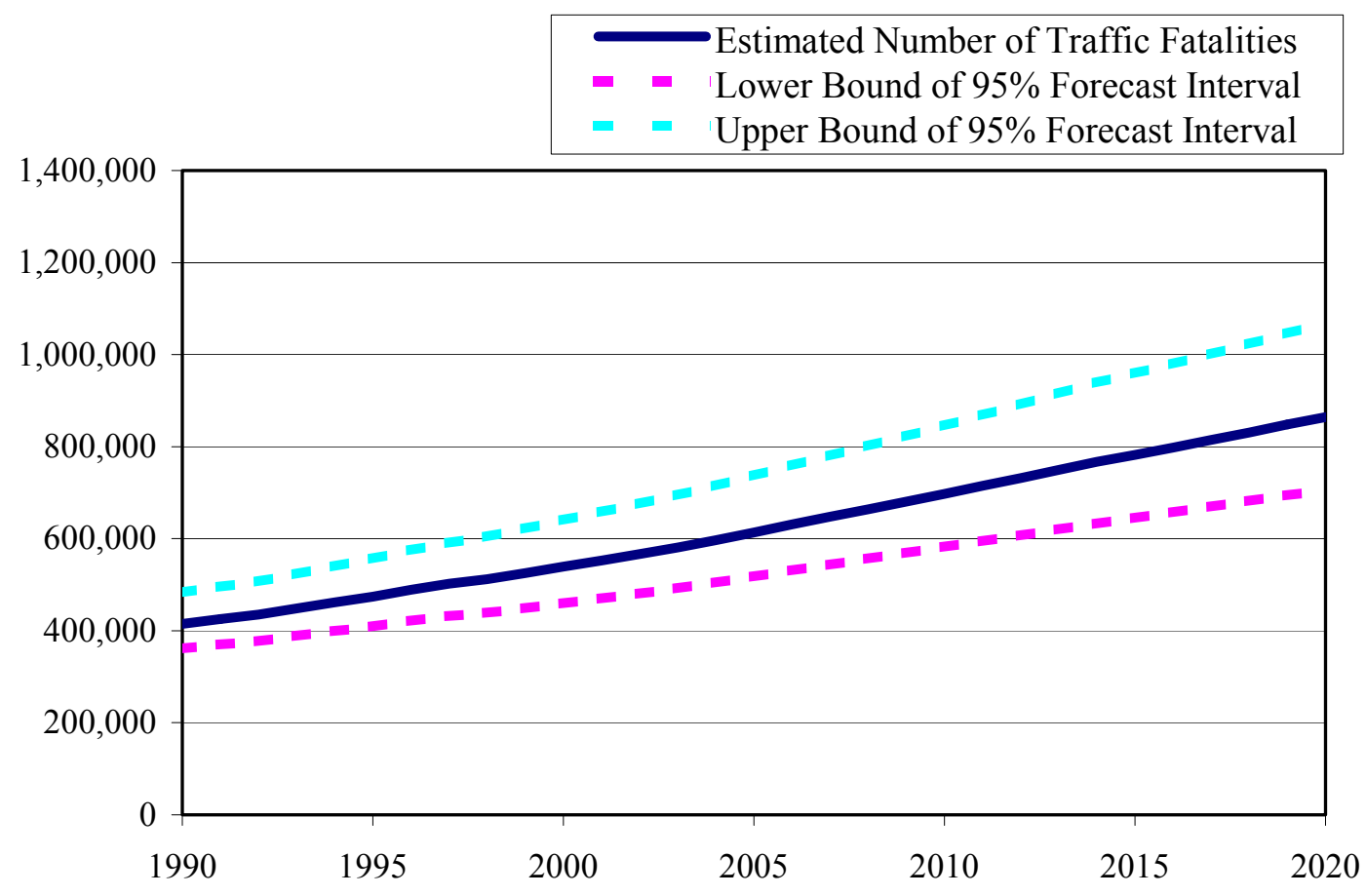


Figure 2.12. Global Traffic Fatalities, Adjusted for Under-Reporting, 1990-2020

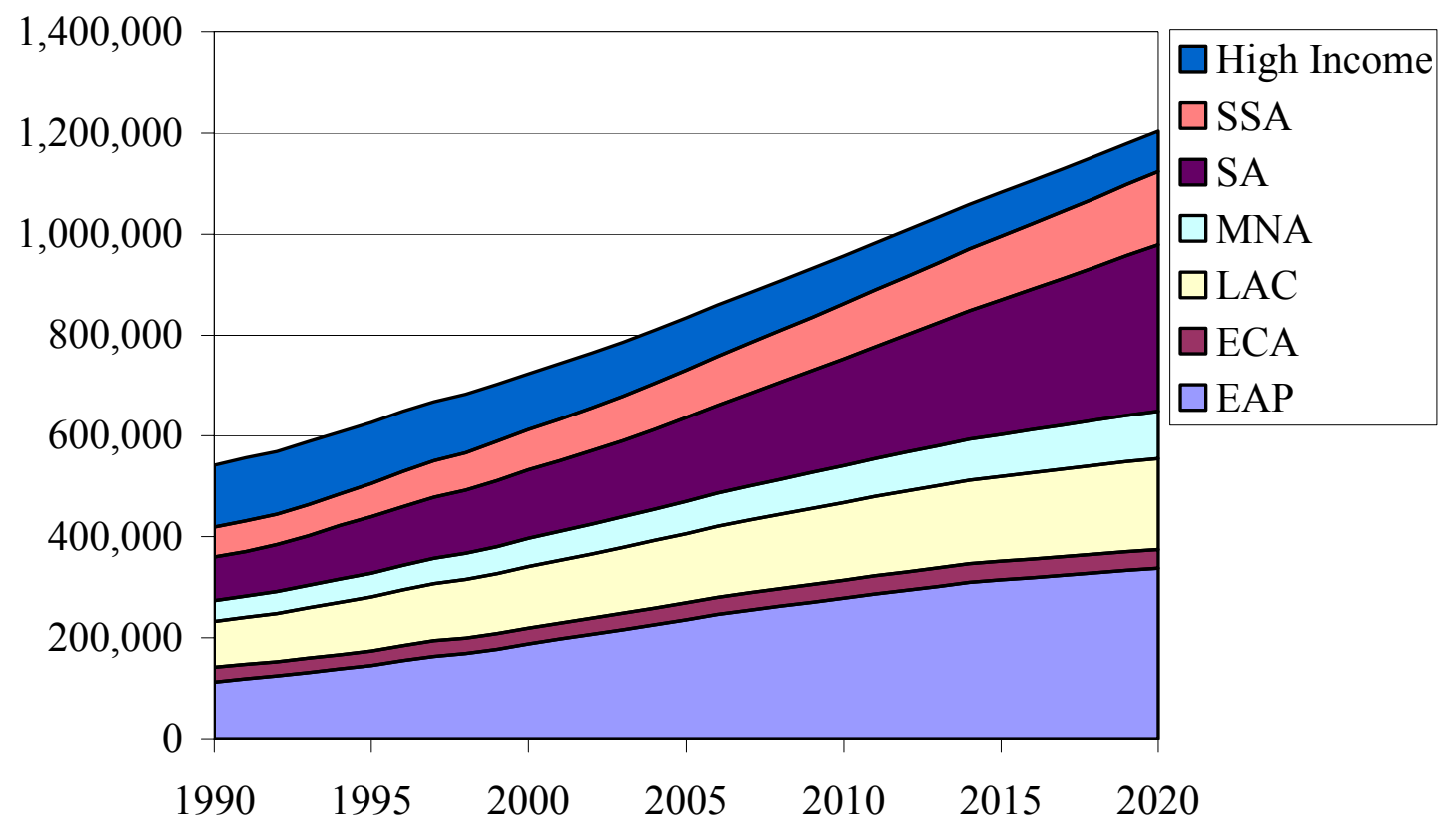


Table 2.1. Change in Traffic Fatality Rate (Deaths/10,000 Persons), 1975-1998

\begin{tabular}{|c|c|c|c|}
\hline Country & $\begin{array}{c}\% \text { Change } \\
(675-98) \\
\end{array}$ & Country & $\begin{array}{c}\text { \% Change } \\
\text { ('75-'98) } \\
\end{array}$ \\
\hline Canada & $-63.4 \%$ & Malaysia & $44.3 \%$ \\
\hline Hong Kong & -61.7 & India $^{b}$ & 79.3 \\
\hline Finland & -59.8 & Sri Lanka & 84.5 \\
\hline Austria & -59.1 & Lesotho & 192.8 \\
\hline Sweden & -58.3 & Colombia & 237.1 \\
\hline Israel & -49.7 & China & 243.0 \\
\hline Belgium & -43.8 & Botswana $^{c}$ & 383.8 \\
\hline France & -42.6 & & \\
\hline Italy $^{\mathrm{a}}$ & -36.7 & & \\
\hline New Zealand & -33.2 & & \\
\hline Taiwan & -32.0 & & \\
\hline United States & -27.2 & & \\
\hline Japan & -24.5 & & \\
\hline
\end{tabular}


Table 2.2. Regional Distribution of Countries Used in Model Estimation ${ }^{\text {a }}$

\begin{tabular}{|c|c|c|c|c|}
\hline World Bank Region & \multicolumn{2}{|c|}{ HD2 } & \multicolumn{2}{|c|}{ HD1 } \\
\hline East Asia \& Pacific & 10 & $(14)$ & 1 & (1) \\
\hline Eastern Europe \& Central Asia & 5 & (5) & 3 & (4) \\
\hline Latin America \& Caribbean & 5 & (27) & 2 & (4) \\
\hline Middle East \& North Africa & 8 & (12) & 1 & (1) \\
\hline South Asia & 5 & (7) & - & \\
\hline Sub-Saharan Africa & 20 & (46) & - & \\
\hline High-Income Countries & - & & 28 & (35) \\
\hline Total: & 53 & $(111)$ & 35 & (45) \\
\hline
\end{tabular}

${ }^{\mathrm{a}}$ For each region, the number of countries for which predictions are made is given in parentheses. 
Table 2.3. Descriptive Statistics ${ }^{\mathrm{a}}$

\begin{tabular}{lllll}
\hline Variable & N & Mean & Std. Dev. & Minimum \\
\hline
\end{tabular}

F/P Sample:

\begin{tabular}{|c|c|c|c|c|c|}
\hline Deaths per 10,000 persons & 2200 & 1.333 & 0.768 & 0.033 & 6.190 \\
\hline $\begin{array}{l}\text { Real per capita GDP } \\
(1985 \text { int'1\$) }\end{array}$ & 2200 & $\$ 5,891$ & $\$ 4,826$ & $\$ 290$ & $\$ 22,626$ \\
\hline Year & 2200 & 1981.901 & 10.149 & 1963 & 1999 \\
\hline Number of countries: & 88 & & & & \\
\hline \multicolumn{6}{|l|}{ V/P Sample: } \\
\hline $\begin{array}{l}\text { Vehicles per } 10,000 \\
\text { persons }\end{array}$ & 1876 & 2096.06 & 1974.38 & 4.100 & 7873.68 \\
\hline $\begin{array}{l}\text { Real per capita GDP } \\
\text { (1985int'1\$) }\end{array}$ & 1876 & $\$ 6,284$ & $\$ 4,938$ & $\$ 274$ & $\$ 23,763$ \\
\hline Year & 1876 & 1981.238 & 10.221 & 1963 & 1999 \\
\hline
\end{tabular}

F/V Sample:

\begin{tabular}{lrrrrr}
\hline $\begin{array}{l}\text { Deaths per 10,000 } \\
\text { Vehicles }\end{array}$ & 1695 & 22.366 & 32.993 & 0.697 & 234.290 \\
\hline $\begin{array}{l}\text { Real per capita GDP } \\
(1985 \text { int'1\$) }\end{array}$ & 1695 & $\$ 6,601$ & $\$ 4,879$ & $\$ 290$ & $\$ 22,626$ \\
\hline Year & 1695 & 1981.303 & 10.095 & 1963 & 1999 \\
\hline Number of countries: & 70 & & & & \\
\hline
\end{tabular}

${ }^{\mathrm{a}}$ Vehicles include cars, buses, trucks, and two-wheelers. Note that none of the data has been adjusted for under-reporting. Deaths and some vehicle fleet estimates shown here may be underestimated. 
Table 2.4. Motorization Rates, 1999, 60 Countries

\begin{tabular}{|c|c|c|c|}
\hline Country & $\begin{array}{c}\text { Vehicles* } \\
/ 1,000 \text { Persons }\end{array}$ & Country & $\begin{array}{c}\text { Vehicles* } \\
\text { /1,000 Persons } \\
\end{array}$ \\
\hline HD1 Countries: & \multicolumn{3}{|c|}{ HD2 Countries: } \\
\hline United States & 779 & Malaysia & 451 \\
\hline Luxembourg & 685 & Bulgaria & 342 \\
\hline $\operatorname{Japan}^{\mathrm{a}}$ & 677 & Thailand $^{\mathrm{c}}$ & 280 \\
\hline Italy $^{\mathrm{b}}$ & 658 & Latvia & 267 \\
\hline Iceland & 629 & Mauritius & 195 \\
\hline Switzerland & 622 & Romania & 169 \\
\hline Australia $^{c}$ & 616 & South Africa & 144 \\
\hline Austria & 612 & Panama $^{\mathrm{b}}$ & 112 \\
\hline Canada $^{\mathrm{a}}$ & 585 & Turkey & 100 \\
\hline Germany $^{\mathrm{a}}$ & 572 & Indonesia $^{\mathrm{a}}$ & 81 \\
\hline New Zealand ${ }^{\mathrm{b}}$ & 565 & Sri Lanka $^{a}$ & 74 \\
\hline Norway & 559 & Botswana & 72 \\
\hline Cyprus & 551 & Swaziland $^{\mathrm{a}}$ & 69 \\
\hline Belgium & 522 & Colombia & 67 \\
\hline Spain $^{b}$ & 499 & Benin $^{c}$ & 52 \\
\hline Finland & 498 & Morocco & 51 \\
\hline Sweden $^{a}$ & 496 & Ecuador $^{\mathrm{a}}$ & 47 \\
\hline Czechoslovakia & 440 & Philippines $^{\mathrm{a}}$ & 42 \\
\hline United Kingdom $^{\mathrm{a}}$ & 434 & $\operatorname{Togo}^{c}$ & 39 \\
\hline Netherlands & 427 & Mongolia & 38 \\
\hline Denmark & 424 & Egypt $^{\mathrm{c}}$ & 35 \\
\hline Portugal $^{\mathrm{b}}$ & 423 & India ${ }^{\mathrm{b}}$ & 34 \\
\hline Bahrain & 339 & Nigeria $^{c}$ & 29 \\
\hline Poland & 323 & Pakistan & 23 \\
\hline Ireland $^{\mathrm{c}}$ & 312 & Kenya $^{c}$ & 14 \\
\hline Israel & 301 & Senegal $^{\mathrm{c}}$ & 14 \\
\hline Korea, Rep. & 296 & Bangladesh $^{\mathrm{b}}$ & 3.1 \\
\hline Hungary & 283 & Ethiopia $^{\mathrm{a}}$ & 1.5 \\
\hline Singapore & 164 & & \\
\hline Costa Rica & 162 & & \\
\hline Chile & 138 & & \\
\hline Hong Kong & 80 & & \\
\hline
\end{tabular}

*Including passenger cars, buses, trucks, and motorized two-wheelers.

a- 1998 data, b- 1997 data, c- 1996 data. 


\section{Notes for Table 2.5 - 2.7:}

Heteroskedasticity-corrected standard errors, clustered on country to allow for within panel autocorrelation, are given in parentheses.

The constant term reflects the intercept term for India. Country fixed effects were included in all regressions but are not displayed here.

$* * *$ indicates $1 \%$ level of significance $* *$ indicates $5 \%$ level of significance.

$* 10 \%$ level of significance.

\section{Model Specifications:}

1. Quadratic, common linear time trend

2. Quadratic, common log-linear time trend

3. Quadratic, regional linear time trends

4. Quadratic, regional, log-linear time trends

5. Spline, common linear time trend

6. Spline, common log-linear time trend

7. Spline, regional linear time trends

8. Spline, regional, log-linear time trends 
Table 2.5. Regression Results from Fatalities/Population Models

\begin{tabular}{|c|c|c|c|c|c|c|c|c|}
\hline \multirow{2}{*}{$\begin{array}{l}\text { Independent } \\
\text { Variables }\end{array}$} & \multicolumn{4}{|c|}{ Quadratic } & \multicolumn{4}{|c|}{ Spline } \\
\hline & 1 & 2 & 3 & 4 & 5 & 6 & 7 & 8 \\
\hline $\ln Y$ & $\begin{array}{c}7.750 * * * \\
(0.624)\end{array}$ & $\begin{array}{c}7.815^{* * *} * \\
(0.625)\end{array}$ & $\begin{array}{c}5.171 * * * \\
(0.944)\end{array}$ & $\begin{array}{c}6.193 * * * \\
(0.819)\end{array}$ & & & & \\
\hline$\left(\ln Y_{i t}\right)^{2}$ & $\begin{array}{c}-0.451^{* * *} \\
(0.036)\end{array}$ & $\begin{array}{c}-0.461^{* * *} \\
(0.035)\end{array}$ & $\begin{array}{c}-0.278^{* * * *} \\
(0.058)\end{array}$ & $\begin{array}{c}-0.358^{* * * *} \\
(0.049)\end{array}$ & & & & \\
\hline$\frac{\ln Y \text { for: }}{\$ 1-\$ 938}$ & & & & & $\begin{array}{c}1.684 * * * \\
(0.393)\end{array}$ & $\begin{array}{c}1.607 * * * \\
(0.371)\end{array}$ & $\begin{array}{c}1.444 * * * \\
(0.346)\end{array}$ & $\begin{array}{c}1.253 * * * \\
(0.328)\end{array}$ \\
\hline$\$ 938-\$ 1,395$ & & & & & $\begin{array}{c}1.180 * * * \\
(0.325)\end{array}$ & $\begin{array}{c}1.144 * * * \\
(0.306)\end{array}$ & $\begin{array}{c}1.119 * * * \\
(0.307)\end{array}$ & $\begin{array}{c}1.060^{* * *} \\
(0.282)\end{array}$ \\
\hline$\$ 1,395-\$ 2,043$ & & & & & $\begin{array}{c}0.506 * * \\
(0.242)\end{array}$ & $\begin{array}{l}0.428^{*} \\
(0.236) \\
\end{array}$ & $\begin{array}{l}0.512 * \\
(0.268) \\
\end{array}$ & $\begin{array}{c}0.326 \\
(0.283) \\
\end{array}$ \\
\hline$\$ 2,043-\$ 3,045$ & & & & & $\begin{array}{l}0.920^{*} \\
(0.481) \\
\end{array}$ & $\begin{array}{l}0.818^{*} \\
(0.485) \\
\end{array}$ & $\begin{array}{c}0.976^{* *} \\
(0.386) \\
\end{array}$ & $\begin{array}{l}0.765^{*} \\
(0.413) \\
\end{array}$ \\
\hline$\$ 3,045-\$ 4,065$ & & & & & $\begin{array}{l}0.699 * \\
(0.392) \\
\end{array}$ & $\begin{array}{c}0.622 \\
(0.395) \\
\end{array}$ & $\begin{array}{c}0.960 * * * \\
(0.327) \\
\end{array}$ & $\begin{array}{c}0.701 * * \\
(0.347) \\
\end{array}$ \\
\hline$\$ 4,065-\$ 6,095$ & & & & & $\begin{array}{c}0.323 \\
(0.258) \\
\end{array}$ & $\begin{array}{c}0.276 \\
(0.241) \\
\end{array}$ & $\begin{array}{c}0.602 * * \\
(0.277) \\
\end{array}$ & $\begin{array}{c}0.390 \\
(0.248) \\
\end{array}$ \\
\hline$\$ 6,095-\$ 8,592$ & & & & & $\begin{array}{l}-0.048 \\
(0.251) \\
\end{array}$ & $\begin{array}{l}-0.112 \\
(0.247) \\
\end{array}$ & $\begin{array}{c}0.258 \\
(0.284) \\
\end{array}$ & $\begin{array}{c}0.075 \\
(0.274) \\
\end{array}$ \\
\hline$\$ 8,592-\$ 10,894$ & & & & & $\begin{array}{c}-0.791 * * * \\
(0.247)\end{array}$ & $\begin{array}{c}-0.938^{* * *} \\
(0.244)\end{array}$ & $\begin{array}{l}-0.207 \\
(0.265) \\
\end{array}$ & $\begin{array}{c}-0.542 * * \\
(0.267)\end{array}$ \\
\hline$\$ 10,894-13,234$ & & & & & $\begin{array}{c}-1.572 * * * \\
(0.363)\end{array}$ & $\begin{array}{c}-1.673 * * * \\
(0.326) \\
\end{array}$ & $\begin{array}{l}-0.668 * \\
(0.384) \\
\end{array}$ & $\begin{array}{c}-1.338 * * * \\
(0.332)\end{array}$ \\
\hline$>\$ 13,234$ & & & & & $\begin{array}{c}-1.151 * * * \\
(0.277) \\
\end{array}$ & $\begin{array}{c}-1.206^{* * *} \\
(0.283) \\
\end{array}$ & $\begin{array}{c}-0.522 * \\
(0.274) \\
\end{array}$ & $\begin{array}{c}-0.996 * * * \\
(0.242) \\
\end{array}$ \\
\hline $\begin{array}{l}\text { Turning Point } \\
\text { (1985\$int'1) } \\
95 \% \text { C.I.: }\end{array}$ & $\begin{array}{c}\$ 5,385 \\
{[\$ 4,116,} \\
\$ 7,046] \\
\end{array}$ & $\begin{array}{c}\$ 4,825 \\
{[\$ 3,800,} \\
\$ 6,127] \\
\end{array}$ & $\begin{array}{l}\$ 10,784 \\
{[\$ 5,584,} \\
\$ 10,784] \\
\end{array}$ & $\begin{array}{c}\$ 5,738 \\
{[\$ 4,360,} \\
\$ 7,551] \\
\end{array}$ & $\$ 6,095$ & $\$ 6,095$ & $\$ 8,592$ & $\$ 8,592$ \\
\hline $\begin{array}{l}\text { Common time } \\
\text { trend: } \mathrm{t}\end{array}$ & $\begin{array}{l}-0.001 \\
(0.004) \\
\end{array}$ & $\begin{array}{r}0.035 \\
(0.040) \\
\end{array}$ & & & $\begin{array}{c}0.001 \\
(0.003) \\
\end{array}$ & $\begin{array}{c}0.056 \\
(0.037) \\
\end{array}$ & & \\
\hline $\begin{array}{l}\text { Regional t: } \\
\text { EAP }\end{array}$ & & & $\begin{array}{c}0.005 \\
(0.008) \\
\end{array}$ & $\begin{array}{c}0.238^{* *} \\
(0.118) \\
\end{array}$ & & & $\begin{array}{c}0.006 \\
(0.007) \\
\end{array}$ & $\begin{array}{c}0.257 * * * \\
(0.096)\end{array}$ \\
\hline ECA & & & $\begin{array}{c}-0.010^{*} \\
(0.006)\end{array}$ & $\begin{array}{c}0.016 \\
(0.099)\end{array}$ & & & $\begin{array}{c}-0.013 * * \\
(0.006)\end{array}$ & $\begin{array}{l}-0.031 \\
(0.087)\end{array}$ \\
\hline India & & & $\begin{array}{c}0.019 * * * \\
(0.004)\end{array}$ & $\begin{array}{c}0.279 * * * \\
(0.042)\end{array}$ & & & $\begin{array}{c}0.022 * * * \\
(0.005)\end{array}$ & $\begin{array}{c}0.319 * * * \\
(0.046) \\
\end{array}$ \\
\hline LAC & & & $\begin{array}{l}0.014^{*} \\
(0.008) \\
\end{array}$ & $\begin{array}{c}0.310 \\
(0.190) \\
\end{array}$ & & & $\begin{array}{c}0.012 \\
(0.007) \\
\end{array}$ & $\begin{array}{c}0.264 \\
(0.168) \\
\end{array}$ \\
\hline MNA & & & $\begin{array}{l}-0.009 \\
(0.011) \\
\end{array}$ & $\begin{array}{l}-0.030 \\
(0.132) \\
\end{array}$ & & & $\begin{array}{l}-0.007 \\
(0.010) \\
\end{array}$ & $\begin{array}{c}0.011 \\
(0.127) \\
\end{array}$ \\
\hline SA & & & $\begin{array}{l}-0.001 \\
(0.004) \\
\end{array}$ & $\begin{array}{c}0.036 \\
(0.038) \\
\end{array}$ & & & $\begin{array}{c}0.004 \\
(0.004) \\
\end{array}$ & $\begin{array}{c}0.096 * * \\
(0.041) \\
\end{array}$ \\
\hline SSA & & & $\begin{array}{c}0.010^{* *} \\
(0.005)\end{array}$ & $\begin{array}{c}0.147 * * \\
(0.065)\end{array}$ & & & $\begin{array}{c}0.011^{* *} \\
(0.005)\end{array}$ & $\begin{array}{c}0.161^{* *} \\
(0.068)\end{array}$ \\
\hline High Income & & & $\begin{array}{c}-0.019^{* * *} \\
(0.005)\end{array}$ & $\begin{array}{c}-0.078 * \\
(0.046) \\
\end{array}$ & & & $\begin{array}{c}-0.015^{* * *} \\
(0.005) \\
\end{array}$ & $\begin{array}{c}-0.057 \\
(0.043) \\
\end{array}$ \\
\hline $\begin{array}{l}\text { F statistic on } \\
\text { regional ts: }\end{array}$ & & & $\begin{array}{l}\mathrm{F}(7,87)= \\
20.48 * * *\end{array}$ & $\begin{array}{l}\mathrm{F}(7,87)= \\
75.08 * * *\end{array}$ & & & $\begin{array}{c}\mathrm{F}(7,87)= \\
8.67 * * *\end{array}$ & $\begin{array}{c}\mathrm{F}(7,87) \\
=9.28 * * *\end{array}$ \\
\hline constant & $\begin{array}{c}-32.948 * * * \\
(2.659) \\
\end{array}$ & $\begin{array}{c}-33.046 * * * \\
(2.647) \\
\end{array}$ & $\begin{array}{c}-23.796 * * * \\
(3.702) \\
\end{array}$ & $\begin{array}{c}-27.427 * * * \\
(3.263) \\
\end{array}$ & $\begin{array}{c}-12.550^{* * *} \\
(2.650) \\
\end{array}$ & $\begin{array}{c}-12.149 * * * \\
(2.494) \\
\end{array}$ & $\begin{array}{c}-11.360 * * * \\
(2.290) \\
\end{array}$ & $\begin{array}{c}-10.463^{* * *} \\
(2.141) \\
\end{array}$ \\
\hline Adjusted R2: & 0.8455 & 0.8460 & 0.8634 & 0.8557 & 0.8554 & 0.8567 & 0.8695 & 0.8656 \\
\hline Hausman chi $^{2}$ & $36.20 * * *$ & $40.63 * * *$ & $80.90 * * *$ & $353.13 * * *$ & $40.75 * * *$ & $53.42 * * *$ & $90.27 * * *$ & $70.17 * * *$ \\
\hline DW statistic & 0.734 & 0.732 & 0.807 & 0.768 & 0.774 & 0.776 & 0.841 & 0.815 \\
\hline
\end{tabular}


Table 2.6. Regression Results from Vehicles/Population Models

\begin{tabular}{|c|c|c|c|c|c|c|c|c|}
\hline \multirow{2}{*}{$\begin{array}{l}\text { Independent } \\
\text { Variables }\end{array}$} & \multicolumn{4}{|c|}{ Quadratic } & \multicolumn{4}{|c|}{ Spline } \\
\hline & 1 & 2 & 3 & 4 & 5 & 6 & 7 & 8 \\
\hline $\ln Y$ & $\begin{array}{c}5.523 * * * \\
(0.917)\end{array}$ & $\begin{array}{c}5.046^{* * *} \\
(0.989)\end{array}$ & $\begin{array}{l}3.078^{* * *} \\
(1.269)\end{array}$ & $\begin{array}{c}3.083 * * \\
(1.397)\end{array}$ & & & & \\
\hline$(\ln Y)^{2}$ & $\begin{array}{c}-0.286 * * * \\
(0.055)\end{array}$ & $\begin{array}{c}-0.241 * * * \\
(0.056)\end{array}$ & $\begin{array}{l}-0.142 * \\
(0.076)\end{array}$ & $\begin{array}{l}-0.124 \\
(0.081)\end{array}$ & & & & \\
\hline$\frac{\ln Y \text { for: }}{\$ 1-\$ 946}$ & & & & & $\begin{array}{l}0.857^{*} \\
(0.485)\end{array}$ & $\begin{array}{l}0.955^{*} \\
(0.528)\end{array}$ & $\begin{array}{c}0.425 \\
(0.386)\end{array}$ & $\begin{array}{c}0.190 \\
(0.478)\end{array}$ \\
\hline$\$ 938-\$ 1,395$ & & & & & $\begin{array}{c}1.431^{* * * *} \\
(0.547)\end{array}$ & $\begin{array}{c}1.775^{* * * *} \\
(0.642)\end{array}$ & $\begin{array}{l}0.909^{*} \\
(0.494)\end{array}$ & $\begin{array}{c}1.675^{* * *} \\
(0.638)\end{array}$ \\
\hline$\$ 1,535-\$ 2,290$ & & & & & $\begin{array}{l}0.675^{*} \\
(0.349)\end{array}$ & $\begin{array}{c}1.043^{* * * *} \\
(0.387)\end{array}$ & $\begin{array}{c}0.708^{* * *} \\
(0.256)\end{array}$ & $\begin{array}{c}1.085^{* * *} \\
(0.320)\end{array}$ \\
\hline$\$ 2,290-\$ 3,441$ & & & & & $\begin{array}{c}1.379 * * * \\
(0.357)\end{array}$ & $\begin{array}{c}1.508^{* * *} \\
(0.410)\end{array}$ & $\begin{array}{c}0.882^{* * *} \\
(0.235)\end{array}$ & $\begin{array}{c}1.038^{* * *} \\
(0.341)\end{array}$ \\
\hline$\$ 3,441-\$ 4,682$ & & & & & $\begin{array}{c}1.218 * * * \\
(0.352)\end{array}$ & $\begin{array}{c}1.570 * * * \\
(0.336)\end{array}$ & $\begin{array}{c}1.136^{* * *} \\
(0.336)\end{array}$ & $\begin{array}{c}1.566^{* * * *} \\
(0.332)\end{array}$ \\
\hline$\$ 4,682-\$ 6,911$ & & & & & $\begin{array}{c}0.805 * * * \\
(0.284)\end{array}$ & $\begin{array}{c}1.144 * * * \\
(0.327)\end{array}$ & $\begin{array}{c}0.838 * * * \\
(0.294)\end{array}$ & $\begin{array}{c}1.187 * * * \\
(0.331)\end{array}$ \\
\hline$\$ 6,911-\$ 9,238$ & & & & & $\begin{array}{l}0.569 * \\
(0.299)\end{array}$ & $\begin{array}{c}0.595 \\
(0.405)\end{array}$ & $\begin{array}{c}0.688 * * \\
(0.324)\end{array}$ & $\begin{array}{l}0.822 * \\
(0.432)\end{array}$ \\
\hline$\$ 9,238-\$ 11,263$ & & & & & $\begin{array}{l}-0.436 \\
(0.312)\end{array}$ & $\begin{array}{l}-0.022 \\
(0.322)\end{array}$ & $\begin{array}{c}-0.337 \\
(0.1663)\end{array}$ & $\begin{array}{c}0.188 \\
(0.286)\end{array}$ \\
\hline$\$ 11,263-13,663$ & & & & & $\begin{array}{c}-0.714^{*} \\
(0.382)\end{array}$ & $\begin{array}{c}0.213 \\
(0.239)\end{array}$ & $\begin{array}{c}-0.550^{*} \\
(0.333)\end{array}$ & $\begin{array}{l}0.412 * \\
(0.223)\end{array}$ \\
\hline$>\$ 13,663$ & & & & & $\begin{array}{c}-0.612 * * \\
(0.301)\end{array}$ & $\begin{array}{c}0.098 \\
(0.178)\end{array}$ & $\begin{array}{c}-0.509^{* *} \\
(0.259)\end{array}$ & $\begin{array}{c}0.190 \\
(0.166)\end{array}$ \\
\hline $\begin{array}{l}\text { Turning Point } \\
\text { (1985\$int'l) }\end{array}$ & $\begin{array}{l}\$ 15,587 \\
{[\$ 6,160,} \\
\$ 39,438]\end{array}$ & $\begin{array}{c}\$ 35,723 \\
{[\$ 10684,} \\
119,447] \\
\end{array}$ & $\begin{array}{c}\$ 51,179 \\
{[\$ 2,437} \\
1,074,650] \\
\end{array}$ & $\begin{array}{c}\$ 244117 \\
{[\$ 1304,} \\
45704111]\end{array}$ & $\$ 9,238$ & - & $\$ 9,238$ & - \\
\hline $\begin{array}{l}\text { Common time } \\
\text { trend: } \mathrm{t}\end{array}$ & $\begin{array}{c}0.028 * * * \\
(0.006)\end{array}$ & $\begin{array}{c}0.236^{* * * *} \\
(0.069)\end{array}$ & & & $\begin{array}{c}0.032 * * * \\
(0.006)\end{array}$ & $\begin{array}{c}0.263 * * * \\
(0.066)\end{array}$ & & \\
\hline $\begin{array}{l}\text { Regional t: } \\
\text { EAP }\end{array}$ & & & $\begin{array}{c}0.054 * * * \\
(0.012)\end{array}$ & $\begin{array}{c}0.559 * * * \\
(0.193)\end{array}$ & & & $\begin{array}{c}0.058^{* * *} \\
(0.014)\end{array}$ & $\begin{array}{c}0.599 * * * \\
(0.219)\end{array}$ \\
\hline ECA & & & $\begin{array}{c}0.060 * * * \\
(0.005)\end{array}$ & $\begin{array}{c}0.540 * * * \\
(0.072)\end{array}$ & & & $\begin{array}{c}0.056^{* * *} \\
(0.005)\end{array}$ & $\begin{array}{c}0.505^{* * *} \\
(0.078)\end{array}$ \\
\hline India & & & $\begin{array}{c}0.066^{* * *} \\
(0.006)\end{array}$ & $\begin{array}{c}0.662 * * * \\
(0.071)\end{array}$ & & & $\begin{array}{c}0.075^{* * *} \\
(0.007)\end{array}$ & $\begin{array}{c}0.733 * * * \\
(0.085)\end{array}$ \\
\hline LAC & & & $\begin{array}{c}0.026^{* * * *} \\
(0.007)\end{array}$ & $\begin{array}{c}0.218^{* * * *} \\
(0.073)\end{array}$ & & & $\begin{array}{c}0.023 * * * \\
(0.006)\end{array}$ & $\begin{array}{c}0.202^{* * *} \\
(0.075)\end{array}$ \\
\hline MNA & & & $\begin{array}{c}0.016^{* *} \\
(0.007)\end{array}$ & $\begin{array}{c}0.045 \\
(0.086) \\
\end{array}$ & & & $\begin{array}{c}0.020 * * * \\
(0.007)\end{array}$ & $\begin{array}{c}0.036 \\
(0.078) \\
\end{array}$ \\
\hline SA & & & $\begin{array}{c}0.036^{* * *} \\
(0.007)\end{array}$ & $\begin{array}{c}0.255^{* * *} \\
(0.084)\end{array}$ & & & $\begin{array}{c}0.041^{* * *} \\
(0.008)\end{array}$ & $\begin{array}{c}0.247 * * \\
(0.101)\end{array}$ \\
\hline SSA & & & $\begin{array}{c}0.029 * * * \\
(0.011)\end{array}$ & $\begin{array}{c}0.312 * * \\
(0.129)\end{array}$ & & & $\begin{array}{c}0.030 * * * \\
(0.009)\end{array}$ & $\begin{array}{c}0.353 * * * \\
(0.120)\end{array}$ \\
\hline High Income & & & $\begin{array}{c}0.022^{* * *} \\
(0.006)\end{array}$ & $\begin{array}{c}0.160 * * \\
(0.064)\end{array}$ & & & $\begin{array}{c}0.029^{* * *} \\
(0.005)\end{array}$ & $\begin{array}{c}0.198 * * * \\
(0.059)\end{array}$ \\
\hline $\begin{array}{l}\text { F statistic on } \\
\text { regional ts: }\end{array}$ & & & $\begin{array}{l}\mathrm{F}(7,74)= \\
32.12 * * *\end{array}$ & $\begin{array}{c}\mathrm{F}(7,74)= \\
46.27 * * *\end{array}$ & & & $\begin{array}{c}\mathrm{F}(7,74)= \\
19.38 * * *\end{array}$ & $\begin{array}{l}\mathrm{F}(7,74)= \\
25.73 * * *\end{array}$ \\
\hline Constant & $\begin{array}{c}-20.688 * * * \\
(3.804)\end{array}$ & $\begin{array}{c}-19.675 * * * \\
(4.171)\end{array}$ & $\begin{array}{c}-11.378^{* *} \\
(5.083)\end{array}$ & $\begin{array}{c}-12.806^{* *} \\
(5.650)\end{array}$ & $\begin{array}{l}-2.287 \\
(3.291)\end{array}$ & $\begin{array}{l}-3.104 \\
(3.536)\end{array}$ & $\begin{array}{l}-0.069 \\
(2.553)\end{array}$ & $\begin{array}{c}0.842 \\
(3.134)\end{array}$ \\
\hline Adjusted R2: & 0.9783 & 0.9742 & 0.9818 & 0.9775 & 0.9820 & 0.9767 & 0.9849 & 0.9799 \\
\hline Hausman chi ${ }^{2}$ & $133.87 * * *$ & $21.96^{* * *}$ & $127.23 * * *$ & $164.60 * * *$ & $87.94 * * *$ & $21.47 * * *$ & $185.42 * * *$ & $118.67 * * *$ \\
\hline DW statistic & 0.181 & 0.188 & 0.175 & 0.187 & 0.188 & 0.190 & 0.190 & 0.196 \\
\hline
\end{tabular}


Table 2.7. Regression Results from Fatalities/Vehicles Models

\begin{tabular}{|c|c|c|c|c|c|c|c|c|}
\hline \multirow{2}{*}{$\begin{array}{l}\text { Independent } \\
\text { Variables }\end{array}$} & \multicolumn{4}{|c|}{ Quadratic } & \multicolumn{4}{|c|}{ Spline } \\
\hline & 1 & 2 & 3 & 4 & 5 & 6 & 7 & 8 \\
\hline $\ln Y$ & $\begin{array}{c}2.380 * * * \\
(0.836)\end{array}$ & $\begin{array}{c}3.004 * * * \\
(0.952)\end{array}$ & $\begin{array}{c}2.293 * * \\
(1.165)\end{array}$ & $\begin{array}{c}3.055^{* *} \\
(1.553)\end{array}$ & & & & \\
\hline$(\ln Y)^{2}$ & $\begin{array}{c}-0.161 * * * \\
(0.050)\end{array}$ & $\begin{array}{c}-0.231 * * * \\
(0.053)\end{array}$ & $\begin{array}{c}-0.146 * * \\
(0.070)\end{array}$ & $\begin{array}{c}-0.234^{* * * *} \\
(0.089)\end{array}$ & & & & \\
\hline $\begin{array}{l}\ln Y \text { for: } \\
\$ 1-\$ 1,179\end{array}$ & & & & & $\begin{array}{l}0.619^{*} \\
(0.357) \\
\end{array}$ & $\begin{array}{c}0.302 \\
(0.467) \\
\end{array}$ & $\begin{array}{c}1.052^{* * *} \\
(0.340)\end{array}$ & $\begin{array}{c}0.655 \\
(0.515) \\
\end{array}$ \\
\hline$\$ 1,179-\$ 1,730$ & & & & & $\begin{array}{l}-0.229 \\
(0.575)\end{array}$ & $\begin{array}{l}-0.926 \\
(0.614)\end{array}$ & $\begin{array}{l}-0.502 \\
(0.566)\end{array}$ & $\begin{array}{c}-1.523 * * * \\
(0.576)\end{array}$ \\
\hline$\$ 1,730-\$ 2,698$ & & & & & $\begin{array}{c}0.254 \\
(0.487)\end{array}$ & $\begin{array}{l}-0.261 \\
(0.567)\end{array}$ & $\begin{array}{c}0.446 \\
(0.365)\end{array}$ & $\begin{array}{c}-0.243 \\
(0.535)\end{array}$ \\
\hline$\$ 2,698-\$ 3,813$ & & & & & $\begin{array}{l}-0.581 \\
(0.402) \\
\end{array}$ & $\begin{array}{c}-1.095^{* * *} \\
(0.541) \\
\end{array}$ & $\begin{array}{l}-0.091 \\
(0.358) \\
\end{array}$ & $\begin{array}{l}-0.832 \\
(0.530) \\
\end{array}$ \\
\hline$\$ 3,813-\$ 5,391$ & & & & & $\begin{array}{l}-0.388 \\
(0.292) \\
\end{array}$ & $\begin{array}{c}-0.934 * * * \\
(0.318) \\
\end{array}$ & $\begin{array}{l}-0.175 \\
(0.293) \\
\end{array}$ & $\begin{array}{c}-0.873 * * * \\
(0.325) \\
\end{array}$ \\
\hline$\$ 5,391-\$ 7,532$ & & & & & $\begin{array}{c}-0.555^{* *} \\
(0.233) \\
\end{array}$ & $\begin{array}{c}-1.003 * * * \\
(0.288)\end{array}$ & $\begin{array}{r}-0.491^{*} \\
(0.255) \\
\end{array}$ & $\begin{array}{c}-1.036^{* * * *} \\
(0.300)\end{array}$ \\
\hline$\$ 7,532-\$ 9,614$ & & & & & $\begin{array}{l}-0.635 \\
(0.402) \\
\end{array}$ & $\begin{array}{c}-0.944^{*} \\
(0.502) \\
\end{array}$ & $\begin{array}{l}-0.368 \\
(0.409)\end{array}$ & $\begin{array}{c}-0.875^{*} \\
(0.522) \\
\end{array}$ \\
\hline$\$ 9,614-\$ 11,469$ & & & & & $\begin{array}{l}-0.283 \\
(0.464) \\
\end{array}$ & $\begin{array}{c}-1.198 * * * \\
(0.461) \\
\end{array}$ & $\begin{array}{c}0.086 \\
(0.448) \\
\end{array}$ & $\begin{array}{c}-1.141 * * \\
(0.475) \\
\end{array}$ \\
\hline$\$ 11,469-13,682$ & & & & & $\begin{array}{l}-0.444 \\
(0.417)\end{array}$ & $\begin{array}{c}-1.845^{* * * *} \\
(0.395)\end{array}$ & $\begin{array}{c}0.005 \\
(0.454)\end{array}$ & $\begin{array}{c}-1.798^{* * * *} \\
(0.411)\end{array}$ \\
\hline$>\$ 13,682$ & & & & & $\begin{array}{l}-0.278 \\
(0.298) \\
\end{array}$ & $\begin{array}{c}-1.249 * * * \\
(0.286) \\
\end{array}$ & $\begin{array}{c}0.014 \\
(0.346) \\
\end{array}$ & $\begin{array}{c}-1.223 * * * \\
(0.271) \\
\end{array}$ \\
\hline $\begin{array}{l}\text { Turning Point } \\
\text { (1985\$int'l) } \\
95 \% \text { C.I.: }\end{array}$ & $\begin{array}{l}\$ 1,603 \\
{[\$ 504,} \\
\$ 5,102] \\
\end{array}$ & $\begin{array}{c}\$ 661 \\
{[\$ 183,} \\
\$ 2,382] \\
\end{array}$ & $\begin{array}{l}\$ 2,593 \\
{[\$ 747,} \\
\$ 8,999] \\
\end{array}$ & $\begin{array}{c}\$ 683 \\
{[\$ 119,} \\
\$ 3,920] \\
\end{array}$ & $\$ 2,698$ & $\$ 1,179$ & $\$ 2,698$ & $\$ 1,179$ \\
\hline $\begin{array}{l}\text { Common time } \\
\text { trend: } \mathrm{t}\end{array}$ & $\begin{array}{c}-0.037 * * * \\
(0.005) \\
\end{array}$ & $\begin{array}{c}-0.233 * * * \\
(0.059) \\
\end{array}$ & & & $\begin{array}{c}-0.039^{* * *} \\
(0.005)\end{array}$ & $\begin{array}{c}-0.228 * * * \\
(0.059)\end{array}$ & & \\
\hline $\begin{array}{l}\text { Regional t: } \\
\text { EAP }\end{array}$ & & & $\begin{array}{c}-0.051^{* * *} \\
(0.015)\end{array}$ & $\begin{array}{l}-0.266 \\
(0.243) \\
\end{array}$ & & & $\begin{array}{c}-0.056^{* * * *} \\
(0.015)\end{array}$ & $\begin{array}{l}-0.283 \\
(0.238) \\
\end{array}$ \\
\hline ECA & & & $\begin{array}{c}-0.067 * * * \\
(0.009)\end{array}$ & $\begin{array}{c}-0.442 * * * \\
(0.153)\end{array}$ & & & $\begin{array}{c}-0.070 * * * \\
(0.010)\end{array}$ & $\begin{array}{c}-0.461 * * * \\
(0.158)\end{array}$ \\
\hline India & & & $\begin{array}{c}-0.045^{* * *} \\
(0.006)\end{array}$ & $\begin{array}{c}-0.355^{* * * *} \\
(0.085)\end{array}$ & & & $\begin{array}{c}-0.054 * * * \\
(0.007)\end{array}$ & $\begin{array}{c}-0.442 * * * \\
(0.110)\end{array}$ \\
\hline LAC & & & $\begin{array}{c}-0.012^{* * *} \\
(0.005)\end{array}$ & $\begin{array}{l}-0.022 \\
(0.073)\end{array}$ & & & $\begin{array}{c}-0.013 * * \\
(0.006)\end{array}$ & $\begin{array}{c}-0.014 \\
(0.114) \\
\end{array}$ \\
\hline MNA & & & $\begin{array}{c}-0.027 * * * \\
(0.009) \\
\end{array}$ & $\begin{array}{l}-0.050 \\
(0.120) \\
\end{array}$ & & & $\begin{array}{c}-0.023 * * * \\
(0.009) \\
\end{array}$ & $\begin{array}{c}0.092 \\
(0.119) \\
\end{array}$ \\
\hline SA & & & $\begin{array}{c}-0.039^{* * *} \\
(0.006)\end{array}$ & $\begin{array}{c}-0.192 * * \\
(0.083) \\
\end{array}$ & & & $\begin{array}{c}-0.038^{* * * *} \\
(0.008)\end{array}$ & $\begin{array}{l}-0.123 \\
(0.123) \\
\end{array}$ \\
\hline SSA & & & $\begin{array}{c}-0.029 * * * \\
(0.009)\end{array}$ & $\begin{array}{c}-0.253 * * \\
(0.112) \\
\end{array}$ & & & $\begin{array}{c}-0.028 * * * \\
(0.008)\end{array}$ & $\begin{array}{c}-0.236^{* *} \\
(0.099) \\
\end{array}$ \\
\hline High Income & & & $\begin{array}{c}-0.042 * * * \\
(0.006)\end{array}$ & $\begin{array}{c}-0.229 * * * \\
(0.065)\end{array}$ & & & $\begin{array}{c}-0.047 * * * \\
(0.005)\end{array}$ & $\begin{array}{c}-0.245 * * * \\
(0.068)\end{array}$ \\
\hline $\begin{array}{l}\text { F statistic on } \\
\text { regional ts: }\end{array}$ & & & $\begin{array}{c}\mathrm{F}(7,69)= \\
9.91 * * *\end{array}$ & $\begin{array}{c}\mathrm{F}(7,69)= \\
13.07 * * *\end{array}$ & & & $\begin{array}{c}\mathrm{F}(7,69)= \\
10.42 * * *\end{array}$ & $\begin{array}{c}\mathrm{F}(7,69)= \\
7.00 * * *\end{array}$ \\
\hline Constant & $\begin{array}{c}-11.105^{* * * *} \\
(3.477)\end{array}$ & $\begin{array}{c}-12.166^{* * *} \\
(4.067)\end{array}$ & $\begin{array}{c}-11.092 * * \\
(4.665)\end{array}$ & $\begin{array}{c}-12.055^{*} \\
(6.299)\end{array}$ & $\begin{array}{c}-6.583 * * * \\
(2.440)\end{array}$ & $\begin{array}{l}-4.518 \\
(3.121)\end{array}$ & $\begin{array}{c}-9.243 * * * \\
(2.214)\end{array}$ & $\begin{array}{l}-6.327^{*} \\
(3.266)\end{array}$ \\
\hline Adjusted $\mathrm{R}^{2}$ : & 0.9532 & 0.9363 & 0.9569 & 0.9377 & 0.9540 & 0.9368 & 0.9588 & 0.9394 \\
\hline Hausman $\mathrm{chi}^{2}$ & $257.15 * * *$ & $21.75 * * *$ & $175.57 * * *$ & $32.86 * * *$ & $167.26^{* * *}$ & $29.58 * * *$ & $190.31 * * *$ & $101.17 * * *$ \\
\hline DW statistic & 0.534 & 0.443 & 0.576 & 0.457 & 0.548 & 0.451 & 0.606 & 0.476 \\
\hline
\end{tabular}


Table 2.8. Forecasts of Real Per Capita GDP Annual Growth Rates (\%), 2000-2020

\begin{tabular}{|c|c|c|c|}
\hline Region/Country & 2000 & 2001 & $2002-2020$ \\
\hline South Asia & 3.0 & 2.8 & 3.8 \\
\hline India & 3.3 & 2.8 & \\
\hline East Asia and Pacific & 6.4 & 3.6 & 5.1 \\
\hline China & 7.0 & 6.4 & \\
\hline Korea, Rep. & 7.9 & 1.7 & \\
\hline Indonesia & 3.5 & 2.1 & \\
\hline Europe and Central Asia & 6.1 & 1.9 & 3.3 \\
\hline Russian Federation & 8.6 & 5.0 & \\
\hline Turkey & 5.5 & -8.7 & \\
\hline Poland & 4.1 & 1.4 & \\
\hline Latin America and the Caribbean & 2.2 & -0.7 & 2.1 \\
\hline Brazil & 3.0 & 0.2 & \\
\hline Mexico & 5.2 & -1.3 & \\
\hline Argentina & -1.7 & -3.2 & \\
\hline Middle East and North Africa & 1.9 & 1.5 & 1.4 \\
\hline Saudi Arabia & 0.7 & -1.5 & \\
\hline Iran & 3.5 & 2.5 & \\
\hline Egypt & 3.5 & 2.7 & \\
\hline Sub-Saharan Africa & 0.5 & 0.3 & 1.3 \\
\hline South Africa & 1.4 & 1.0 & \\
\hline Nigeria & 0.4 & 0.3 & \\
\hline \multicolumn{4}{|l|}{ High-income Economies } \\
\hline \multicolumn{4}{|l|}{ Industrial } \\
\hline G-7 & 2.7 & 0.3 & 2.1 \\
\hline US & 3.2 & 0.3 & 2.0 \\
\hline Japan & 1.5 & -0.9 & 2.0 \\
\hline G-4 Europe & 3 & 1.3 & 2.3 \\
\hline Germany & 3.1 & 0.7 & 2.1 \\
\hline Euro Area & 3.3 & 1.4 & 2.5 \\
\hline Non-G7 Industrial & 3.5 & 1.6 & 2.7 \\
\hline Other High-income & 4.7 & -0.7 & 2.8 \\
\hline Asian NIEs (KOR, HKG, SGP) & 6.4 & -0.7 & 3.4 \\
\hline
\end{tabular}

Source: World Bank Global Economic Prospects 2002. 
Table 2.9. Predicted Road Traffic Fatalities by Region (000s), Adjusted for UnderReporting, 1990-2020

\begin{tabular}{|c|c|c|c|c|c|c|c|c|}
\hline \multirow[b]{2}{*}{$\begin{array}{l}\text { World Bank } \\
\text { Region }\end{array}$} & \multirow[b]{2}{*}{$\begin{array}{c}\text { No. of } \\
\text { Countries }\end{array}$} & \multirow[b]{2}{*}{1990} & \multirow[b]{2}{*}{2000} & \multirow[b]{2}{*}{2010} & \multirow[b]{2}{*}{2020} & \multirow[b]{2}{*}{$\begin{array}{l}\text { \% change } \\
2000-20\end{array}$} & \multicolumn{2}{|c|}{$\begin{array}{c}\text { Fatality Risk } \\
\text { (Deaths/100,000 } \\
\text { Persons) }\end{array}$} \\
\hline & & & & & & & 2000 & 2020 \\
\hline $\begin{array}{l}\text { East Asia \& } \\
\text { Pacific }\end{array}$ & 15 & 112 & 188 & 278 & 337 & $79.8 \%$ & 10.9 & 16.8 \\
\hline $\begin{array}{l}\text { E. Europe \& } \\
\text { Central Asia }\end{array}$ & 9 & 30 & 32 & 36 & 38 & $18.2 \%$ & 19.0 & 21.2 \\
\hline $\begin{array}{l}\text { Latin America } \\
\text { \& Caribbean }\end{array}$ & 31 & 90 & 122 & 154 & 180 & $48.1 \%$ & 26.1 & 31.0 \\
\hline $\begin{array}{l}\text { Middle East \& } \\
\text { N. Africa }\end{array}$ & 13 & 41 & 56 & 73 & 94 & $67.5 \%$ & 19.2 & 22.3 \\
\hline South Asia & 7 & 87 & 135 & 212 & 330 & $143.9 \%$ & 10.2 & 18.9 \\
\hline $\begin{array}{l}\text { Sub-Saharan } \\
\text { Africa }\end{array}$ & 46 & 59 & 80 & 109 & 144 & $79.8 \%$ & 12.3 & 14.9 \\
\hline Subtotal: & 121 & 419 & 613 & 862 & 1,124 & $83.3 \%$ & 13.3 & 19.0 \\
\hline $\begin{array}{l}\text { High-Income } \\
\text { Countries: }\end{array}$ & 35 & 123 & 110 & 95 & 80 & $-27.8 \%$ & 11.8 & 7.8 \\
\hline World Total: & 156 & 542 & 723 & 957 & 1,204 & $66.4 \%$ & 13.0 & 17.4 \\
\hline
\end{tabular}




\section{CHAPTER 3}

\section{WHY HAVE TRAFFIC FATALITIES DECLINED IN INDUSTRIALIZED COUNTRIES?}

\subsection{Introduction}

If historic trends continue, the Kuznets curve findings of the previous chapter suggest fatality rates will continue to increase in the developing world for several decades. However, in many developing countries fatalities per vehicle could be reduced significantly through interventions that are not studied explicitly in chapter two. Examining which factors and interventions were most influential in reducing fatalities per vehicle in high-income countries, i.e., which factors explain the downward sloping portion of the income-fatality relationship, could help formulate policies in low-income countries that are just beginning to tackle the problem.

This chapter deals with the decline in traffic deaths per distance traveled observed in OECD countries since the early 1970s, the approximate period during which these countries have been on the downward sloping portion of the EKC. ${ }^{34}$ It seeks to answer a central question: Why has this decline in Fatalities/VKT occurred? To what extent have fatality rates declined because of changes in the vehicle mix (reductions in the proportion of two-wheelers and in the ratio of pedestrians to vehicles), because of safer roads, or because of safer vehicles? How important are improvements in the behavior of drivers due to changes in demographics,

\footnotetext{
${ }^{34}$ The mean road death rate of these countries has fallen by half since 1970 (from 24 deaths/100,000 persons in 1970 to approximately 12 deaths/100,000 persons in 2000).
} 
enforcement of alcohol controls, seatbelt laws, and speeding regulations? What role have improved medical services played in reducing fatalities?

A review of the existing literature addressing these questions is followed by an examination of the pattern of traffic fatalities by road user group for the 30 member countries of the OECD International Road Traffic Accident Database (IRTAD). Then formal models are developed for both pedestrian fatalities and occupant fatalities. Both reduced-form and structural versions of these models may be estimated. Here, reduced-form estimation is performed using panel data for the IRTAD countries for 1964 through 2002.

The use of cross-country panel data to study traffic fatalities is relatively rare in the road safety literature. Much of the literature is devoted to evaluating the effectiveness of specific safety interventions such as seat belt laws (Leonard Evans, 1986), speed limits (Lave, 1985), vehicle safety standards (Peltzman, 1975), or alcohol control policies (Dee, 1999; Asch and Levy, 1987), on the basis of withincountry data. It is, however, difficult for such studies to assess the relative contribution of different sets of factors to the historic decline in fatality risk. For example, part of the decline in pedestrian deaths in developed countries is due to pedestrians becoming vehicle occupants, and part of the decline in total fatalities reflects the movement from two- to four-wheeled vehicles. The effect of changes in the motorization rate (vehicles/population) and changes in the composition of the vehicle fleet are difficult to capture without country-level panel data. This is also true for demographic factors: in virtually every country in the world the death rate due to traffic crashes is higher for persons 15-24 than for any other age group. Whether this 
reflects inexperience or low risk aversion, it suggests that demographic changes are likely to affect the death rate due to traffic crashes, an effect that can be examined using country-level panel data.

Country-level panel data can also be used to examine the impact of alcohol abuse, medical services and seatbelt usage on road traffic deaths. The impact of seatbelt usage and alcohol control policies (e.g., alcohol taxes, minimum drinking age laws) have been examined extensively using panel data for states in the U.S., but not (to my knowledge) using cross-country panel data.

The chapter is organized as follows. Section 3.2 summarizes the existing literature on road safety. This is followed in section 3.3 by a description of the pattern of traffic fatalities by road user group in a subset of high-income (HD1) countries. Section 3.4 develops a theoretical model of traffic fatalities, with separate equations for pedestrian and occupant fatalities. Section 3.5 presents results from reduced-form specifications of the formal models for pedestrian and occupant fatalities and Section 3.6 concludes.

\subsection{Existing Literature on Road Safety}

The existing literature on road safety can be divided into three categories. The first body of research consists of very micro-level studies (studies based on data for a single road segment or set of segments) of the causes of an accident or a fatality. The second uses data of a more aggregate level (e.g., from U.S. states) to test the influence of specific policy interventions on traffic accident and fatality rates. Finally, there are 
also a few studies that have used cross-country panel data to examine the variation in traffic fatalities across countries.

\subsubsection{Micro-level studies of the causes of accidents or fatalities}

The micro-level studies generally use accident level data on a particular segment/area of the road network to study the causes of an accident or a fatality. Many of these have examined the role of speed or traffic flow on the probability of an accident or traffic fatality and are useful in calculating road user charges (Golob, Recker, and Alvarez, (in press); Dickerson, Peirson and Vickerman, 2000; Shefer and Rietveld, 1997; Vitaliano and Held, 1991). Other studies (mostly appearing in the transport engineering literature) examine the impact of road environment conditions (roadway design and weather) on accident rates and severity (Milton and Mannering, 1998). Lee and Mannering (2002) use detailed data from a 96.6-km section of highway in Washington State to focus on the impact of roadside features on the frequency and severity of run-off roadway accidents. Abdelwahab and Abdel-Aty (2001) look at determinants of driver injury severity in traffic accidents at signalized intersections in an area of Central Florida. Some focus solely on determinants of truck-involved crash rates (Golob and Regan, 2004; Charbotel et al., 2003; Chang and Mannering, 1999). Studies of the role of weather and lighting conditions include Edwards (1998) and Golob and Recker (2003).

Recently, Graham and Glaister (2003) began to investigate how the nature of the urban environment affects accident frequency. Using U.K. data from 1999 and 2000 (from the commonly known 'STATS 19' database), they estimate a model to 
explain the effect of urban density (population and employment density) on the frequency of pedestrian accidents. Finally, some have explored the behavior of road users along a particular road segment. For example, Das et al. (2002) look at pedestrian crossing decisions using videotape data from three intersections in New Delhi. Porter and England (2000) examine red light running behavior in urban settings.

Understanding road user behavior and the impact of road conditions and vehicle characteristics on accident frequency and severity are useful in designing vehicle safety features and developing particular traffic calming measures. These micro-level studies can also help inform local transport and land use planning policies.

\subsubsection{Evaluation of specific road safety policies}

The second branch of literature consists of studies that estimate the impact of specific measures aimed at reducing road traffic accidents and fatalities. This research has developed primarily in the U.S., Europe, New Zealand, Australia, and Japan, and is generally based on (a) accident data for a particular region, (b) monthly or annual within-country data (e.g, from U.S. counties, states, Canadian provinces), or (c) national time-series data from a single country.

There is a distinction between the efficacy and effectiveness of any road safety policy intervention. The impact of vehicle safety standards (air bags, anti-lock brakes) on fatality rates, for example, depends not only on their ability to reduce the number of fatalities per accident occurring at a given speed but also on the behavioral 
response of road users to the intervention (e.g., driving faster when vehicles are safer). Empirical evidence of this risk compensation hypothesis (formally set forth by Peltzman (1975)) is still somewhat inconclusive but the theory continues to be tested in regard to all types of road safety related policies. ${ }^{35}$ These include policies aimed at improving road user behavior (speed, driving under the influence of alcohol, seatbelt use, motorcycle helmet use) as well as studies of the role of medical care, improved vehicle safety (air bags, anti-lock brakes, inspections), and road infrastructure design in reducing traffic fatalities.

\subsection{2.a. Speed and speed limits}

Two factors often singled out to be leading causes of fatal vehicle crashes are speed and alcohol. The body of research evaluating the effect of speed (reviewed by McCarthy (2001)) can be divided into those studies that estimate the relationship between speed (and speed distribution) on road safety and work that evaluates the impact of posted speed limits on highway safety. Most studies that use data on vehicle speed center on the effects of mean speed versus speed variance. ${ }^{36}$ Lave

${ }^{35}$ Peltzman (1975) and Garbacz $(1990,1992)$ find that a reduction in vehicle occupant deaths due to improved vehicle safety standards is offset by increases in non-occupant deaths. However, Crandall and Graham (1984), Loeb and Gilad (1984), Garbacz (1985), and Loeb (1987) find little evidence of offsetting behavior and claim that safety regulations (mostly seatbelts, but also vehicle inspections, speed limits) have significantly reduced traffic fatalities. Keeler (1994) controls for more variables than other studies and finds some evidence that either offsetting behavior or the effect of the variance of speed itself (a topic first explored by Lave (1985)) caused speed limits to have little effect in reducing traffic fatalities, while educational attainment has a positive effect on road safety, even exceeding the returns to income.

${ }^{36}$ Zlatoper (1984), however, controls only for average speed on rural roads in his single time-series analysis of U.S. road safety over 1947-1980 and does not address the importance of speed variance. 
(1985) was the first to explore empirically the role of mean speed versus speed variance on fatalities per vehicle mile traveled. Using state level data for 1981 and 1982 he estimates separate cross sectional regressions for six road types and found mean speed to have no effect after controlling for speed variance. His results sparked a lengthy dialogue in the literature (Fowles and Loeb, 1989; Levy and Asch, 1989) which ultimately all provide evidence that speed variance is an important influence on fatality rates. ${ }^{37}$ Synder (1989) appears to be the first to control for state and year fixed effects (although in separate specifications) using data from 26 states for 197274. He finds higher mean speed and an increase in the speed of the faster vehicles ${ }^{38}$ to increase total fatalities per VKT (but no symmetric effect for slower slow speeds).

Much of the U.S. research that evaluates the impact of speed limits on road safety (including Garber and Graham (1989), Godwin (1992), McCarthy (1994a, 1994b)) focuses on the effects of increasing the speed limit from 55 to $65 \mathrm{mph}$ on rural interstate highways ${ }^{39}$ and generally finds that increases in posted speed limits reduce road safety on highways. A widely cited study by Garber and Graham (1989), for example, finds that the higher rural interstate speed limits led to a $15 \%$ increase in fatalities on rural interstate highways and a 5\% increase on non-rural interstate

\footnotetext{
${ }^{37}$ Most of these control for more variables than Lave but are still generally based on data for a single cross section of states. Fowles and Loeb (1989), for example, use state level data (aggregated for all road types) for 1979 only.

${ }^{38}$ Speed distribution is measured by the $85^{\text {th }}$ percentile speed minus the median speed on main rural roads.

${ }^{39}$ One exception is Keeler (1994) who, using county level data for 1970 and 1980 , finds greater evidence of urban speed limits reducing fatalities than rural limits did. He cites evasion and variance in driving speeds as possible explanations for this result.
} 
roads. ${ }^{40}$ The significant effect for non-rural interstate roads has raised discussions of the extent of spillover effects and of the merits of using aggregate data to account for such effects.

Most of the U.S. research on speed limits pertains to higher-speed interstate and non-interstate roads. McCarthy does cite some international studies that have focused on the effect of speed limits on lower speed roads, but notes that most, like many of the higher speed road studies, suffer from not accounting for traffic route diversion effects and other confounding factors.

\subsection{2.b. Alcohol and alcohol control policies}

Research that attempts to quantify the influence of drunk driving on traffic fatalities and the effectiveness of alcohol control policies has found mixed results. Among studies that control for the amount of drunk driving with proxies such as per capita alcohol consumption, Zlatoper (1984) finds per capita adult alcohol consumption had no statistically significant effect on either pedestrians or occupants deaths in the U.S. between 1947-1980. Similarly, Keeler (1994) finds a positive but statistically insignificant effect of alcohol consumption on total fatalities in U.S. counties over 1970-1980. The imprecision of these coefficients could be a result of measurement error since per capita alcohol consumption is such a crude measure of the amount of drunk driving. Despite this concern, Noland and Quddus (2002) and Loeb (1987) do find alcohol consumption to be related to increases in traffic fatalities (in Great Britain and the U.S., respectively). Noland (2003b, 2000) also finds per

\footnotetext{
${ }^{40}$ This is the median effect found from estimating separate regression models (using monthly data) for 40 states that raised rural interstate speed limits to $65 \mathrm{mph}$ in 1988.
} 
capita expenditure on alcohol to be statistically significant in increasing the total number of fatalities in Great Britain and in the U.S. McCornac (1993) attributes his insignificant coefficient on annual real expenditure on alcohol beverages per household in Japan (the coefficient is positive but insignificant for both non-occupant and occupant deaths) to the fact that alcohol plays a much smaller role in accidents in Japan than other countries such as the U.S. Similarly, Lindgren and Stuart (1980) find that adult per capita alcohol sales (liters of pure ethanol) had no effect on either the occupant or non-occupant fatality rate in Sweden over 1947-73.

Most studies evaluating specific alcohol control policies focus on their effects on drinking by young drivers. U.S. studies of minimum legal drinking ages (MLDA) generally find a strong negative relationship between legal drinking ages and vehicle fatalities (Asch and Levy, 1987; Dee, 1999; Dee and Evans, 2001). Keeler (1994) and Michener and Tighe (1992), however, find an unexpected insignificant, positive effect of beer drinking age on total fatalities and on total fatal accidents, respectively. Asch and Levy (1990) suggest that perhaps drinking experience, not drinking age matters.

Regarding the influence of beer taxes, there is less consensus. Using annual state level data for 1982-88 and controlling for year and state fixed effects, Ruhm (1996) finds higher beer taxes to be the only policy to have reduced total vehicle fatalities per capita. Also controlling for state-level heterogeneity with pooled crosssections of data from the 1977-92 Monitoring the Future (MTF) surveys of high school seniors, Dee (1999) finds that beer taxes have relatively small and statistically insignificant effects on teen drinking. Mann et al. (2001) review research evaluating 
the impact of introducing a legal BAC limit in five countries (United Kingdom, Canada, Japan, Netherlands, and the United States) and review the literature examining the effect of reducing the legal BAC limit in seven countries (Canada, Australia, United States, Sweden, France, Denmark, Austria). They find a large variation in the degree of sophistication in statistical modeling and results across studies. However, most studies do find a general deterrence effect of BAC legislation.

The research studying the effectiveness of alcohol enforcement policies find conflicting results. Kenkel (1993) and Sloan et al. (1994), for example, find mandatory jail sentences for DUI have a deterrent effect on drunk driving but Wilkinson (1987), Chaloupka et al. (1993), and Evans et al. (1991) do not find any significant effect.

\subsection{2.c. Seatbelt laws and seatbelt usage}

Most of the literature examining the impact of seatbelts exploits the crossstate and time-series variation in the adoption of seatbelt laws in the U.S. (or Canadian provinces) to estimate the reduced form effect of the regulation on traffic fatalities (including Evans and Graham (1991), Michener and Tighe (1992), Houston et al. (1995), and Sen (2001)). ${ }^{41}$ After controlling for state and year fixed effects, Michener and Tighe (1992) find the number of fatal accidents in 1989 would have been reduced by $1.9 \%$ with nationwide secondary seatbelt laws and by $9 \%$ with

${ }^{41}$ Others using time-series data from before and after a seatbelt law was passed include Bhattacharyya and Layton (1979), Harvey and Durbin (1986), and Wagenaar et al. (1988). 
primary seatbelt laws. ${ }^{42}$ Using panel data from 1975-1987 and also estimating a twoway fixed effects model, Evans and Graham (1991) find seatbelt laws led to an 8\% decline in vehicle occupant fatalities. Sen (2001), however, finds that the introduction of seatbelt legislation in Canadian provinces between 1975 and 1992 led to a $21 \%$ decline in driver fatalities and claims the effect is dampened by an increase in risky driving behavior. ${ }^{43}$

A few studies have looked at the direct effect of seatbelt wearing rates on traffic fatalities (Garbacz, 1990, 1991; McCornac, 1993; Risa, 1994; Noland, 2003b), but Cohen and Einav (2003) seem to be the first to account for the endogeneity of the seatbelt usage variable - i.e., people wearing seatbelts more often on roads known to be more dangerous. The failure to control for this endogeneity could be the reason that Garbacz $(1990,1991)$ and Risa (1994) find fatalities to increase with seatbelt usage. ${ }^{44}$ After instrumenting the seatbelt wearing rates with dummies for primary and secondary state enforcement laws, Cohen and Einav find the beneficial effect of

${ }^{42}$ Primary and secondary refer to the allowable enforcement of the seatbelt laws. In primary enforcement states, police can stop and fine violators even if they have not committed other offenses. In secondary enforcement states, police can fine violators only when they are stopped for some other traffic offense.

${ }^{43}$ Garbacz (1992) also claims that the beneficial effect of seatbelts has been offset by an increase in risky driving since his results show seatbelt laws have an insignificant effect on vehicle occupant fatalities and a significant, positive effect on non-occupant fatalities. However, his findings are based on cross-sectional data from a single year (1987), which will clearly bias his estimates if unobserved factors are correlated with the cross-state variation in the adoption of seatbelt laws.

${ }^{44}$ On the other hand, McCornac (1993) finds a significant effect of seatbelt use on both occupant and non-occupant fatalities in Japan over 1966-1985 and Noland (2003b) finds increased seatbelt use significantly reduces total deaths in the U.S. during 1990-97. 
seatbelt use doubles for vehicle occupants and has no effect on non-occupant fatalities.

Analogous to seatbelt use by vehicle occupants, the effect of helmet use by motorcyclists has also been studied. Sass and Zimmerman (2000), for example, use state-level panel data for 22 years to examine the impact of mandatory motorcycle helmet laws in the U.S. They find that the laws led to a $29-33 \%$ decline in motorcyclist fatality risk (as measured by per capita motorcyclist deaths). Branas and Knudson (2001) also find that motorcycle death rates are lower in states with full motorcycle helmet laws than in those without, but their study is based only on data from 1994 to 1996.

\subsection{2.d. Vehicle safety features and vehicle inspections}

The studies that look at the effectiveness of motor vehicle safety inspections are inconclusive. Loeb (1990) and Loeb and Gilad (1984) find inspections to have a significant impact on reducing various measures of fatalities, with their coefficient estimates appearing stable across specifications. Keeler (1994) finds inspections to be effective in 1970 but not 1980. More recently, Merrell, Poitras, and Sutter (1999) claim to be the first to control for state fixed effects (using panel data from 50 states over 1981-93) in examining the importance of vehicle inspections. They find no evidence that state automobile safety inspections significantly reduce fatality or injury rates.

In addition to the studies evaluating the effectiveness of safety inspections, several studies examine the role of particular vehicle characteristics on road safety rates. Studies of the effectiveness of vehicle safety features such as airbags and anti- 
lock brakes claim that improved standards have significantly reduced fatality rates (Farmer et al., 1997; Harless and Hoffer, 2003). Based on analysis of an insurance industry generated dataset, Peterson et al. (1995), however, contend that increases in injury claims following the initiation of an airbag system is a result of offsetting behavior rather than a sorting of auto buyers. Crandall and Graham (1989) study the effect of fuel economy standards on car size and argue that a decrease in car size led to a decline in road safety in the U.S. because the probability of a fatal accident occurring between two small cars is higher than between two larger vehicles. Recently, Gayer (2004) reexamined this question in the case of light trucks using microdata from the U.S. Fatal Analysis Reporting System (FARS). ${ }^{45}$

\subsection{2.e. Roads}

Relatively few studies have focused on the system wide effects that road infrastructure improvements have had on accident and fatality rates. The micro-level studies noted in the previous section may estimate the beneficial impact of roadway design on the probability of a crash or fatality but cannot capture the overall effect on accident and fatality rates. However, few studies using aggregate data even control for the size of the road network included in the sample. One recent exception is the work by Noland (2003b), which uses U.S. state level data for 1984 to 1997 to examine how road improvements such as lane widenings on arterial and collector

\footnotetext{
${ }^{45} \mathrm{He}$ also attempts to control for the selection bias issue with the FARS data. Because there is no reporting of non-fatal crashes, analysis using FARS data will bias the estimated safety impacts of vehicle features (a point raised by Levitt and Porter (2001) in their study of the effectiveness of airbags and seatbelts). Levitt and Porter eliminate the selection problem by limiting their sample to crashes in which someone in a different vehicle dies and find seat belts to be more effective and air bags to be less effective at preventing fatalities than previously found.
} 
roads have affected traffic deaths and injuries. He also controls for total lane miles and the fraction of lane miles in different road categories. His results refute the conventional engineering wisdom on the safety benefits of several infrastructure changes. In particular, he finds an increase in total lane miles, in the average number of lanes on collector roads, and in the percent of collectors with lanes 12 feet or wider increase total fatalities.

\subsection{2.f. Medical care}

Finally, few studies have explicitly focused on the role of improvements in medical technology in explaining road safety trends. The main exception is the research by Noland (2003a, 2003b) and Noland and Quddus (2002). ${ }^{46}$ Using various proxies for medical care (the number of licensed physicians per capita, the average length of inpatient hospital stay, indicators of the number of people waiting for hospital treatment, and the number of average acute care days in hospital), these studies suggest that improvements in medical services have significantly reduced traffic fatalities in the U.S., Great Britain, and other industrialized countries. However, they do not find the number of National Health Service staff (in the U.K.) per 1,000 persons (Noland and Quddus, 2002) or the number of hospitals per square mile (Noland (2003b)) to have any effect on the number of road deaths. In addition, Noland (2003a, 2003b) surprisingly finds increases in infant mortality rates (as a

${ }^{46}$ Others include Lave (1985) and Keeler (1994). In studying the importance of mean speed versus the variance of speed (based on state cross section data for 1981 and 1982), Lave (1985) finds that access to emergency medical care (as measured by the number of hospitals/square mile multiplied by the proportion of population living in non-metropolitan areas) significantly affects fatality rates on some road types. On the other hand, Keeler (1994) finds the presence of a nearby hospital to have no effect on fatality risk. 
proxy for medical technology improvements) to be associated with reductions in total traffic fatalities (but in Noland (2003a), only when the time trend is replaced by year dummies).

\subsubsection{Cross-country literature on road safety}

Although the road safety literature is most developed in the U.S. and some European countries (especially in Scandinavia (Elvik, Mysen, and Vaa, 1997)), ${ }^{47}$ there is, by contrast, little work explaining the variation in road traffic accidents and fatalities across countries. Two recent exceptions are studies by Page (2001) and Noland (2003a). Page (2001) uses data from IRTAD and other OECD sources to explain traffic fatalities across 21 OECD countries over 1980-1994. He finds total population, the level of motorization, the percentage of young persons in the population, per capita alcohol consumption, and employment rates to all have a positive effect on the total number of traffic fatalities while an increase in the percentage of buses and coaches in the vehicle fleet and the percentage of population living in urban areas are associated with reductions in the number of road deaths. No other variables (including per capita income, country or year effects) are controlled for in the model. Instead, he ranks the countries' road safety performance using an indicator based on the residuals of the regression.

Noland (2003a) uses a more sophisticated statistical model than Page (Hausman et al.'s (1984) fixed effects overdispersion model) to study road safety in a

${ }^{47}$ Peltzman's analysis has also been extended to a few countries in Asia, such as Taiwan (Garbacz 1989), New Zealand (Garbacz 1991, Scuffman and Langley, 2002; Scuffman, 2003), and Japan (McCornac 1993). 
similar set of countries over 1970-1996. He controls for all age cohorts, the motorization level, per capita income, and country and year effects, but focuses primarily on the role of medical services in reducing total road deaths. Using various proxies for advances in medical technology (discussed in greater detail in Section 3.5.4) he finds that improvements in medical care have played an important role in reducing traffic-related fatalities in industrialized countries over the past couple of decades. He does not examine the importance of other technological factors (improvements in road design and vehicle crash-worthiness) or policies aimed at changing road user behavior (speeding, driving under the influence of alcohol, seatbelt usage).

Although both of these studies use data for a similar set of OECD countries and years as I do, neither controls for as many variables (the most important of which is total risk exposure, as measured by vehicle-kilometers traveled) and neither investigates the importance of factors for different road user groups separately. In this chapter, I hope to provide a broader understanding of the importance different factors have played in improving road safety rates than can be gleaned from the current evaluation literature. I also hope to improve upon the existing cross-country studies of traffic fatality rates by controlling for more variables and examining how these factors influence vehicle occupants and pedestrian fatality rates differently. My sample uses data from more countries than any other study and covers the entire time period in which countries have experienced a decline in traffic fatality risk (deaths per population). Most of the existing evaluation studies focus on the short-term effects of specific policy interventions, because they do not have panel datasets that are 
sufficiently long. Longer observation periods may be able to shed more light on the importance of factors for the long run. My methodology and data are described more fully in Section 3.5.

\subsection{Traffic Fatality Patterns in Industrialized Countries}

This chapter focuses on a subset of the HD1 countries included in chapter two, countries that, from the early 1970's to the present have experienced a decline in traffic fatalities per VKT and were primarily on the downward-sloping portion of the relationship between per capita income and per capita fatalities. ${ }^{48}$ Before formulating and estimating models of pedestrian and occupant fatalities per VKT it is useful to examine the stylized facts regarding traffic fatalities in this set of countries over recent decades, as shown in Table 3.1. Between 1970 and 1999, total traffic fatalities have declined, on average, by nearly $35 \%$ in most OECD countries, while total vehicle kilometers driven increased by over $250 \%$ on average. ${ }^{49}$ Within each country, the decline was more dramatic for the most vulnerable road users: pedestrians and bicyclists. ${ }^{50}$ As shown in Table 3.1, on average, the number of pedestrian and bicyclist fatalities fell by over 60\% in high-income countries between 1970 and 1999 .

\footnotetext{
${ }^{48}$ The exceptions in the sample include: Czech Republic, Hungary, Poland, and Turkey. Per capita income was less than $\$ 6,100$ (1985 international dollars) in many years that these four countries (along with a few observations for Greece, Portugal, and South Korea) enter the sample. Sensitivity analysis of the empirical estimation with respect to these observations is addressed in Section 3.5.4.
}

${ }^{49}$ On average, the total number of vehicles increased by over $200 \%$ during this period.

${ }^{50}$ Hereafter, "pedestrian" deaths refers to both pedestrian and bicyclist fatalities resulting from a motor vehicle accident. 
Occupant fatalities, on the other hand, declined by $21 \%$ on average (and even increased in some countries) during this period. This corresponds to an average $86 \%$ decline in pedestrian fatalities per VKT and an average $76 \%$ decline in occupant fatalities per VKT.

It is likely that part of the decline in pedestrian deaths in developed countries is due to more pedestrians becoming vehicle occupants. In 1970, pedestrians and bicyclists comprised approximately $37 \%$ of the total road deaths but, by 1999 , the fraction of fatalities in these vulnerable road user categories had fallen to only $26 \%{ }^{51}$ Likewise, part of the decline in occupant fatalities may reflect the movement from two- to four-wheeled vehicles as well as overall technological improvements in vehicle crashworthiness. Policy-induced behavioral changes influence both the nonmotorized road users and vehicle occupants, but to different degrees.

To better understand how the death rate due to traffic accidents varies across road user groups, it is useful to develop a formal model of traffic fatalities, with separate equations for pedestrian and occupant fatalities.

\subsection{Models of Pedestrian and Occupant Fatalities}

The expected number of traffic deaths occurring in a country each year is the product of the expected number of accidents times the probability that an accident results in a fatality. In section 3.4.1, I develop separate equations for the expected

\footnotetext{
${ }^{51}$ On average, bicyclist deaths account for approximately $18 \%$ of the total "pedestrian" fatalities in many OECD countries over the sample period. The percentage is as high as $38 \%$ in Sweden, Finland, Denmark, and Belgium, however, and nearly $60 \%$ in the Netherlands.
} 
number of vehicle occupant accidents and pedestrian accidents occurring annually.

Section 3.4.2 models the likelihood that an accident results in a fatality. Implications of the models are summarized in Section 3.4.3.

\subsubsection{Models of motor vehicle accidents}

To model the number of motor vehicle accidents occurring annually in a country, I follow Edlin's (1999) derivation of the probability that vehicle i is involved an accident with another vehicle, $\mathrm{p}_{\mathrm{i}}$, and the probability that vehicle $\mathrm{i}$ is involved in a one-vehicle accident (for example, hitting a tree), $\mathrm{r}_{\mathrm{i}} \cdot{ }^{52}$ The expected number of occupant accidents occurring annually is the sum over all vehicles of $\mathrm{p}_{\mathrm{i}}+\mathrm{r}_{\mathrm{i}}$

Following Edlin, the probability that vehicle $i$ has an accident with vehicle $j$ is the probability that both vehicles are in the same location at the same time, and that neither driver avoids an accident. Formally,

(3.1) $\quad P(i$ has an accident with $\mathrm{j})=\mathrm{f}_{\mathrm{i}} \mathrm{f}_{\mathrm{j}} \mathrm{L}^{-1} \mathrm{q}_{\mathrm{i}} \mathrm{q}_{\mathrm{j}}$

where $f_{i}=$ probability that vehicle $i$ is on the road;

$\mathrm{L}=$ number of locations at which an accident may occur;

$\mathrm{q}_{\mathrm{i}}=$ probability that the driver of vehicle $\mathrm{i}$ does not avoid an accident.

${ }^{52}$ Single vehicle crashes account for a substantial portion of fatal crashes and cannot be ignored in the modeling. In the U.S., over $50 \%$ of fatal crashes result from single vehicle accidents (U.S. DOT, http://wwwfars.nhtsa.dot.gov/report.cfm?stateid $=0 \&$ year $=2000 \&$ title $=$ Trends). Of these, singlevehicle run-off-roadway accidents account for approximately one third of all U.S. highway fatalities (Lee and Mannering, 2002). 
$\mathrm{f}_{\mathrm{i}} \mathrm{f}_{\mathrm{j}} \mathrm{L}^{-1}$ is thus the probability that vehicle $\mathrm{j}$ is in the same location as vehicle $\mathrm{i},{ }^{53}$ and $\mathrm{q}_{\mathrm{i}} \mathrm{q}_{\mathrm{j}}$ the probability that neither driver avoids an accident. ${ }^{54}$ Following Edlin, I assume that $f_{i}$ is proportional to the number of kilometers that vehicle $i$ is driven annually, $m_{i}$, (i.e., $f_{i}=\rho m_{i}$ ) and that $L$ is proportional to the length of the road network, R.

The probability that vehicle $\mathrm{i}$ is involved in an accident with any other vehicle is

$$
\text { (3.2) } \quad p_{i}=\rho m_{i} q_{i} L^{-1}\left[\sum_{j \neq i} \rho m_{j} q_{j}\right] \text {. }
$$

Assuming for simplicity that all drivers are identical, i.e., $\mathrm{q}_{\mathrm{i}}=\mathrm{q}_{\mathrm{j}}=\mathrm{q}$, the probability that vehicle $\mathrm{i}$ is involved in a two-vehicle accident is given by

$$
\mathrm{p}_{\mathrm{i}} \approx \rho^{2} \mathrm{q}^{2} \mathrm{~m}_{\mathrm{i}} \mathrm{L}^{-1} \mathrm{M}
$$

where $\mathrm{M}=$ total kilometers traveled by all vehicles annually.

The probability that vehicle $\mathrm{i}$ is involved in a one-vehicle accident is the probability that vehicle $\mathrm{i}$ is in a given location $\left(\mathrm{f}_{\mathrm{i}} / \mathrm{L}\right)$, that an event occurs to precipitate an accident (e.g., an unforeseen bend in the road), and that the driver of vehicle $\mathrm{i}$ does not avoid the accident. Denote the probability of the event that precipitates the accident e. Then the probability that vehicle $\mathrm{i}$ is involved in a onevehicle accident is

\footnotetext{
${ }^{53} \mathrm{~L}$ is not squared in this expression since it does not matter where on the road the two vehicles meet. The probability that vehicle $\mathrm{i}$ is in any location on the road is $\mathrm{f}_{\mathrm{i}}$. The probability that vehicle $\mathrm{j}$ will then be in the same location as $\mathrm{i}$ is equal to the probability that vehicle $\mathrm{j}$ is on the road, $\mathrm{f}_{\mathrm{j}}$, times the probability that $\mathrm{j}$ is at the same location as vehicle $\mathrm{i}, 1 / \mathrm{L}$.

${ }^{54}$ This specification makes the simplifying assumption that accident rates and vehicle locations are both uniform.
} 


$$
\text { (3.4) } r_{i}=\rho q m_{i} L^{-1} e \text {. }
$$

The probability of a pedestrian accident may be derived analogously to the probability of a two-vehicle accident. ${ }^{55}$ It is the probability of pedestrian $\mathrm{j}$ and vehicle $\mathrm{i}$ being in the same place at the same time and neither avoiding the accident:

$$
\text { (3.5) } \begin{aligned}
\mathrm{P}(\text { Pedestrian } \mathrm{j} \text { in an Accident with Vehicle } \mathrm{i})=\mathrm{f}_{\mathrm{i}} \mathrm{f}_{\mathrm{j}} \mathrm{L}^{-1} \mathrm{q}_{\mathrm{i}} \mathrm{q}_{\mathrm{j}} \\
=\rho \mathrm{m}_{\mathrm{i}} \rho^{\prime} \mathrm{w}_{\mathrm{j}} \mathrm{L}^{-1} \mathrm{qe}^{\prime}
\end{aligned}
$$

where $f_{j}$ is assumed proportional to the number of kilometers pedestrian $j$ walks each year, $\mathrm{w}_{\mathrm{j}}$, and $\mathrm{e}^{\prime}$ is the probability that the pedestrian does not avoid the accident. The probability of vehicle $\mathrm{i}$ being involved in a pedestrian accident is the sum across all pedestrians of (3.5),

(3.6) $\mathrm{P}($ Vehicle $\mathrm{i}$ has an Accident with a Pedestrian $)=\rho \mathrm{m}_{\mathrm{i}} \rho^{\prime} \mathrm{WL}^{-1} \mathrm{qe}^{\prime}$ where $\mathrm{W}$ is the number of kilometers walked by all pedestrians in a year.

The number of pedestrian accidents occurring annually is the sum across all vehicles of (3.6). Assuming $\mathrm{m}_{\mathrm{i}}=\mathrm{m}$, the average number of kilometers driven per vehicle and noting that $\mathrm{M}=\mathrm{mV}$, where $\mathrm{V}$ is the number of vehicles in the country, (3.7) Pedestrian Accidents $=\rho \mathrm{M}^{\prime} \mathrm{WL}^{-1} \mathrm{qe}^{\prime}$ The number of accidents involving vehicle occupants is the sum across all vehicles of (3.3) and (3.4):

(3.8) Occupant Accidents $=\rho^{2} q^{2} M^{2} L^{-1}+\rho q M L^{-1} e$.

\footnotetext{
${ }^{55}$ For ease of notation, the probability that a driver is unable to avoid a one-vehicle accident or an accident with a pedestrian retains the same subscripting as the probability that the driver is unable to avoid a two-vehicle accident, $\mathrm{q}_{\mathrm{i}}$.
} 


\subsubsection{Models of accident fatalities}

The expected number of deaths that occur each year as a result of motor vehicle accidents equals the sum across all vehicles of the probability that an accident occurs times the probability of a fatality, given that an accident occurs. Letting $\gamma=$ $\mathrm{P}($ Pedestrian is killed $\mid$ Accident $)$ and $\lambda=\mathrm{P}($ Occupant is killed $\mid$ Accident $)$,

(3.9) Occupant Fatalities $=\left(\rho q M L^{-1} e+\rho^{2} q^{2} L^{-1}\right) \lambda$

(3.10) Pedestrian Fatalities $=\rho \mathrm{M} \rho^{\prime} \mathrm{WL}^{-1} \mathrm{qe}^{\prime} \gamma$.

Expressing (3.9) and (3.10) in terms of fatalities per distance traveled by all motor vehicles ( where distance traveled $=\mathrm{M}$ ),

(3.9') Occupant Fatalities/Distance Traveled $=\rho \mathrm{qL}^{-1} \mathrm{e} \lambda+\rho^{2} \mathrm{q}^{2} \mathrm{ML}^{-1} \lambda$

(3.10') Pedestrian Fatalities/Distance Traveled $=\rho \rho^{\prime} \mathrm{WL}^{-1} \mathrm{qe}^{\prime} \gamma$.

\subsubsection{Implications of the models}

Equation $\left(3.10^{\prime}\right)$ says that pedestrian fatalities per vehicle distance traveled should decline (other things equal), the more likely it is that a driver can avoid an accident (the smaller is q), the more extensive the road network (the larger is L), the less likely a pedestrian is to precipitate the accident (the smaller is $\mathrm{We}^{\prime}$ ), and the less likely the pedestrian is to die, given that he is struck by a vehicle (the smaller is $\gamma$ ). The number of occupant fatalities per distance traveled (equation $\left(3.9^{\prime}\right)$ ) should also decline with decreases in $\mathrm{q}$ and with increases in L. In addition, all else equal, the occupant fatality rate should decline the less likely an event occurs to precipitate a one-vehicle accident (the smaller is e) and the less likely an occupant dies given that an accident occurred (the smaller is $\lambda$ ). Finally, increases in the total distance 
traveled by all vehicles will increase the probability of any two vehicles meeting on the road and, hence, increase the occupant fatality rate.

\subsection{Estimates of Fatalities per Distance Traveled}

The models of pedestrian and occupant fatalities are estimated using a 2-step strategy. First, the relationship between fatalities per distance traveled and income is examined for pedestrians and occupants separately. Second, $\left(3.9^{\prime}\right)$ and $\left(3.10^{\prime}\right)$ are approximated with flexible, reduced-form functions of variables influencing q, e, L,

$\lambda, \gamma$. In all cases, the distance traveled by all vehicles is measured in vehiclekilometers and is denoted by VKT.

\subsubsection{Estimates as a function of income and time only}

Virtually all of the factors that should cause pedestrian fatalities per VKT (equation $\left(3.10^{\prime}\right)$ ) to fall should increase with income. Hence, pedestrian fatalities per VKT should decline with economic growth. The situation is somewhat different for occupant fatalities. Equation $\left(3.9^{\prime}\right)$ indicates that fatalities per VKT associated with two-vehicle crashes (the second term in $\left(3.9^{\prime}\right)$ ) should increase with total VKT. This suggests that occupant fatalities per VKT need not decline monotonically with economic growth, nor should they decline as rapidly with per capita income as pedestrian fatalities per VKT. Estimating a fixed-effects model for the fatalities per VKT simply as a function of per capita income and a linear time trend supports this claim. Using panel data from 32 HD1 countries over 1964-2002, Total Fatalities/VKT are found to be monotonically decreasing with income. However, the relationship varies for Pedestrian Fatalities/VKT and Occupant Fatalities/VKT. 
Setting the intercept equal to Austria's,

$$
\begin{aligned}
\ln (\text { Total Fatalities/VKT })_{\text {it }}= & 1.485-0.375 \ln \mathrm{Y}_{\mathrm{it}}-0.048 \mathrm{t} \\
& (1.655)(0.178)^{* *}(0.004)^{*}
\end{aligned}
$$

Adj. $R^{2}: 0.9591,32$ HD1 countries, 830 observations

$$
\begin{aligned}
\ln (\text { Occupant Fatalities/VKT })_{\text {it }}= & -0.267-0.237 \ln Y_{\text {it }}-0.044 \mathrm{t} \\
& (1.741)(0.188)
\end{aligned}
$$

Adj. $R^{2}: 0.9468,32$ HD1 countries, 830 observations.

(3.13) $\ln (\text { Pedestrian Fatalities/VKT })_{\text {it }}=3.056-0.643 \ln Y_{\text {it }}-0.060 \mathrm{t}$

$$
(1.360)^{* *}(0.146)^{*} \quad(0.004) *
$$

Adj. $R^{2}: 0.9543,32$ HDl countries, 830 observations

*Indicates $1 \%$ level of significance. **Indicates $5 \%$ level of significance.

The income elasticity of the pedestrian fatality rate is statistically significant and over twice as large in magnitude as that of the occupant fatality rate, confirming that pedestrian fatalities per VKT fall faster than occupant fatalities per VKT, as the models suggest. ${ }^{56,57}$

Estimation of (3.12) and (3.13) using more flexible functional forms of income show that the occupant fatality rate-income relationship is far from certain. As shown in Table 3.2, results from both a quadratic specification and a four segment spline function of income suggest the income elasticity of the occupant fatality rate

\footnotetext{
${ }^{56}$ Standard errors shown in parentheses under each coefficient are heteroskedasticitycorrected and clustered on country to allow for within panel autocorrelation.

${ }^{57}$ The regressions in equations (3.11) - (3.13) and those in Table 3.2 were performed using an extended VKT data series and per capita income measured in 1996 international dollars (extended from 2000-2002 using per capita GDP growth rates). The sources of data and methods used to extend these series are described in detail in Appendix B. Section B.3 and B.5 in the Appendix also display the regression results from using the unextended VKT data and the income series from chapter two (measured in 1985 international dollars).
} 
becomes positive at higher levels of income. ${ }^{58}$ When the time trend is held constant across countries, Occupant Fatalites/VKT begin to increase with income once income exceeds $\$ 25,384$ (1996 international dollars) in the quadratic specification (Model 4) and when income exceeds $\$ 20,700$ in the spline specification (Model 2), although the effect is not statistically significant. ${ }^{59}$ Results are similar if the time trend is allowed to vary across countries. In the log-linear case with country specific time trends (Model 1 in Table 3.2), the income elasticity of the occupant fatality rate remains negative and statistically insignificant. In the quadratic and spline specifications (Models 3 and 5), the income elasticity of Occupant Fatalities/VKT becomes positive once income reaches $\$ 14,572$ and $\$ 20,700$, respectively, but in this case the effect has greater statistical significance with the spline function.

In the case of pedestrians, the income elasticity falls in magnitude to -0.376 (0.187) when country specific time trends are assumed (Model 1). Four segment spline functions of income suggest that the income elasticity falls in magnitude in higher income ranges and is not significantly different than zero for per capita income exceeding \$20,700 (1996 international dollars).

\footnotetext{
${ }^{58}$ Country dummies and country specific time trend coefficients from equations (3.11)-(3.13) and all models in Table 3.2 are displayed in Appendix B.

${ }^{59} \$ 25,384$ (1996 international dollars) is the approximate per capita income of Australia and Denmark in the late 1990s and the level of income attained by the United States and Switzerland around 1990. \$20,700 (1996 international dollars) is the approximate per capita income of Austria, Netherlands, and Sweden in the early to mid- 1990s, and the level of income attained by the United States in 1982 and Canada in 1985.
} 


\subsubsection{Reduced-form specification}

I next go on to approximate the models developed in Section 3.4 with flexible, reduced-form functions of vehicle occupant and pedestrian fatalities per VKT. Given the multiplicative nature of equations $\left(3.9^{\prime}\right)$ and $\left(3.10^{\prime}\right)$, models of Occupant Fatalities/VKT (OccF/VKT) and Pedestrian Fatalities/VKT (PedF/VKT) are estimated in log-log form:

$$
\begin{array}{ll}
\text { (3.14) } & \ln (\mathrm{OccF} / \mathrm{VKT})_{\mathrm{it}}=\mathrm{a}_{\mathrm{i}}+\mathrm{b}_{1} \ln (\mathrm{q})_{\mathrm{it}}+\mathrm{b}_{2} \ln (\mathrm{e})_{\mathrm{it}}+\mathrm{b}_{3} \ln (\lambda)_{\mathrm{it}}+\mathrm{b}_{4} \ln \left(\mathrm{RD}_{\mathrm{it}}\right)+ \\
& \mathrm{b}_{5} \ln \left(\mathrm{VEH}_{\mathrm{it}}\right)+\mathrm{ct}+\varepsilon_{\mathrm{it}} \\
\text { (3.15) } & \ln (\mathrm{PedF} / \mathrm{VKT})_{\mathrm{it}}=\mathrm{a}_{\mathrm{i}}+\mathrm{b}_{1} \ln (\mathrm{q})_{\mathrm{it}}+\mathrm{b}_{2} \ln \left(\mathrm{e}^{\prime}\right)_{\mathrm{it}}+\mathrm{b}_{3} \ln (\gamma)_{\mathrm{it}}+\mathrm{b}_{4} \ln \left(\mathrm{RD}_{\mathrm{it}}\right)+ \\
& \mathrm{b}_{5} \ln \left(\mathrm{W}_{\mathrm{it}}\right)+\mathrm{ct}+\varepsilon_{\mathrm{it}}
\end{array}
$$

where $\mathrm{q}, \mathrm{e}, \mathrm{e}^{\prime}, \mathrm{W}, \gamma$, and $\lambda$ are proxied by the variables described below. ${ }^{60}$ (A complete list of variables is provided in Table 3.4). The dependent variables, $\ln (\mathrm{OccF} / \mathrm{VKT})$ and $\ln (\mathrm{PedF} / \mathrm{VKT})$, are measured as the natural logarithms of pedestrian fatalities per million vehicle kilometers driven and occupant fatalities per million vehicle kilometers driven, respectively. Country fixed effects once again control for permanent differences in fatality rates and traffic fatality definitions across countries. A common linear time trend is included in both equations.

\subsection{2.a. Specification of occupant fatalities per VKT}

In practice, $\mathrm{q}$, the probability that a driver avoids an accident, will reflect driver skill, the condition of the vehicle driven, the variance in speed of surrounding

\footnotetext{
${ }^{60}$ Although not serving as a proxy for the factors discussed above, VEH enters equation (3.14) directly from the formal model of Occupant Fatalities/VKT (equation $\left.\left(3.10^{\prime}\right)\right)$.
} 
traffic and other road conditions. Driver skill will be influenced by the driver's speed, attitudes towards risk/safety, education, driving experience, and alcohol consumption. Proxies for q include: the percentage of driving age population that is 15-24 years of age (YOUTH), the percentage of driving age population over age 64 (ELDERLY) ${ }^{61}$ and per capita income (Y). Per capita income (Y) and the percentage of young driving age population (YOUTH) enter the equation both separately and interactively. Since young drivers' education and attitudes toward risk could vary with per capita income, the interaction allows the impact of YOUTH on fatalities per VKT to change as countries become wealthier. The effect of older drivers on fatality rates has not often been examined in road safety studies. ${ }^{62}$ A priori, their effect on fatality rates is unclear: although older drivers may have more experience and drive at slower speeds, they may a have a slower reaction time to an imminent collision (thus, increasing q). I include the percentage of driving age population over 64 (ELDERLY) as an explanatory variable to control for this effect.

One crude proxy for the amount of drunk driving is the adult (18 years old and over) per capita alcohol consumption in the country (ALCOHOL). Another measure that might give a better indication of the amount of abusive drinking in the country is the death rate (deaths per population) due to cirrhosis of the liver (LIVER).

Additional proxies for $\mathrm{q}$ include the growth rate of the vehicle fleet (VEHGROWTH), the percentage of two-wheelers in the vehicle fleet

\footnotetext{
${ }^{61}$ I define "driving age population" to be persons ages 15 and higher. Therefore, YOUTH $=$ population ages $15-24$ / population ages 15 and up. Similarly, ELDERLY $=$ population ages 65 and up/population ages 15 and up.

${ }^{62}$ Exceptions include Noland (2003a) and Keeler (1994).
} 
(2WHEELERS), and interaction terms of the road length and total vehicle stock with a linear time trend (RDt and VEHt, respectively). In part, the rate of motorization (VEHGROWTH - measured as the growth rate of the vehicle fleet from the previous year) could reflect a country's level of driving experience or societal norms regarding road safety. The faster the fleet grows the less time drivers have to adjust to changes in the road environment (having to share roadways with more, less-experienced drivers). Therefore, a driver's inability to avoid collisions (q) should increase with VEHGROWTH.

2WHEELERS provides some measure of the heterogeneity of the vehicle mix and/or variance of speed on the road. Assuming the vehicle mix is tilted toward more recent model years, which have better safety features (such as anti-lock brakes), the vehicle-time trend interaction (VEHt) could serve as a proxy for safer vehicles over time. Similarly, if improvements in road design are allowing drivers more reaction time then the road length-time trend interaction $(\mathrm{RDt})$ may capture the extent to which trends in road conditions have affected a driver's ability to avoid an imminent accident. Of course, any beneficial effect of improved road and vehicle conditions could be offset by increased speeds or other risky driving behavior, a point to which I return below.

The probability of an event occurring to precipitate a one-vehicle accident, e, is difficult to measure. However, it will depend on the number of pedestrians in the area (proxied by the total population (POP) or the percentage of population living in urban areas (URBANPOP)), road conditions (guardrails, barriers separating roads from sidewalks, shoulder width, etc.) (proxied by RDt), and several country or region 
specific characteristics (topography, climate, animal habitats). Any of these characteristics that are constant over time will be captured by the country fixed effects. L is proportional to the size of the road network and is proxied by the total number of route-kilometers in the road network (RD). ${ }^{63}$

The probability of a vehicle occupant dying given that an accident occurs, $\lambda$, clearly depends on the quality of emergency medical services, but also on the health of the accident victim. Since indicators of emergency medical services are limited, I proxy medical quality by the number of licensed physicians per person (PHYSICIANS) as well as heart attack survival rates (HEART). ${ }^{64}$ HEART is perhaps a less crude indicator of the quality of emergency medical care since heart attack survival, like accident survival, depends on ambulance response time and trauma care available in hospitals. $\lambda$ should also be inversely related to vehicle crashworthiness. Again, assuming the vehicle mix is tilted toward more recent model years, which have better safety features (such as air bags), the vehicle-time trend interaction (VEHt) could serve as a proxy for safer vehicles over time ${ }^{65}$ Similarly, changes in road conditions could be captured by RDt.

${ }^{63}$ Although the number of lane-miles would be a better indicator of the size of the road infrastructure, limited data availability prevented me from using this measure in the analysis.

${ }^{64}$ The heart attack survival rate is measured as the number of hospital discharges after admission for acute myocardial infarction divided by the total heart attacks (= number of hospital discharges + deaths due to myocardial infarction).

${ }^{65}$ A confounding factor is that vehicle size, which has been found to have a significant, negative effect on occupant (but not pedestrian) fatalities (Zlatoper, 1984; Crandall and Graham, 1989), decreased in many countries over part of the sample period. Data limitations prevent me from controlling for average vehicle size directly. 
Finally, $\lambda$ should decrease with increased seatbelt usage. ${ }^{66}$ I proxy for the national seatbelt usage by the percentage of car drivers wearing seatbelts on three road types: urban roads, rural roads, and motorways. ${ }^{67}$ Increased seatbelt usage is expected to decrease the occupant fatality rate. However, if, as hypothesized by Peltzman (1975), the increased driver protection produces more careless driving, the safety benefits to belted drivers could be offset by increased risk to other vehicle occupants, perhaps even causing the overall fatality rate to rise. The potential endogeneity of this variable is discussed below.

\subsection{2.b. Specification of pedestrian fatalities per VKT}

Several of the factors that influence pedestrian fatalities per VKT are the same as those entering equation (3.14). A pedestrian's inability to avoid colliding with a vehicle ( $\left(\mathrm{e}^{\prime}\right)$, for example, depends on the pedestrian's attitudes towards safety, and also on road conditions - i.e., the extent to which pedestrians are separated from vehicular traffic. Hence, e' can be proxied by several of the same variables measuring $\mathrm{q}$, as discussed above.

W, the total kilometers walked by all pedestrians, should vary directly with population and inversely with the motorization rate. Therefore, proxies for $\mathrm{W}$ include: the total population (POP), as well as the percentage of population living in urban areas (URBANPOP), and the size of the vehicle fleet (VEH). As in the

However, the percentage of two-wheelers in the vehicle fleet (2WHEELERS) should at least capture the extent of part of the heterogeneity in the vehicle mix.

${ }^{66}$ Seatbelt usage has been estimated to increase the probability of crash survival by 50-60 percent (Evans, 1986).

${ }^{67}$ Rural roads include motorways. 
occupant equation, L is proxied by the total number of route-kilometers in the road network (RD).

The probability of a pedestrian dying given that an accident occurs, $\gamma$, is proxied by the same indicators of medical quality as described above: the number of licensed physicians per person (PHYSICIANS) and heart attack survival rates (HEART). Finally, seatbelt usage and certain vehicle characteristics (air bags, collapsible steering wheels) should have no beneficial effect on pedestrian safety. Pedestrian fatalities per VKT can only be affected by the presence of these vehicle safety devices if they indeed induce an increased demand for risky driving. Including the seatbelt usage variables and a proxy for safer vehicles (VEHt) in the pedestrian equation allows me to directly test for the presence of such compensating behavior on the part of drivers.

\subsubsection{Data sources}

Data for this analysis were compiled for 32 high-income (or HD1) countries covering 1964-2002. A complete list of countries included in the estimation of (3.14) and (3.15) is given in Table 3.3. Table 3.5 provides descriptive statistics for the variables in the sample.

The primary sources of transport and road safety related variables are the OECD International Road Traffic Accident Database (IRTAD) and the IRF World Road Statistics yearbooks. However, these series were checked against and supplemented by data from numerous national statistical agencies and other sources. Health related data come primarily from OECD Health Data 2003, the World Health 
Organization (WHO), and World Drink Trends 2000. Total population and population cohorts are taken from the U.S. Census International Database, IRTAD, and national statistical agencies. A detailed description of all data sources for each variable and country is given in Section B.1 of Appendix B.

Long time-series of total vehicle-kilometers traveled (VKT) are difficult to obtain, even for several high-income countries. In an effort to increase the sample size, the official VKT statistics were extended using predicted values from regressions of VKT on total motor vehicle fuel consumption (petrol and diesel). The sources of fuel data and methods used to estimate VKT are discussed in detail in Section B.2 of Appendix B. ${ }^{68}$ In addition, estimation results for equations (3.11) (3.13) using the base VKT data are displayed in Section B.3.

For all the analysis in this chapter, real per capita GDP is measured in 1996 international dollars. This series comes from the Penn World Tables 6.1 (Heston et al., 2002) for 1963-2000 and was extended to 2002 using per capita GDP growth rates. I discuss this extension and display the growth rates used in Section B.4 of Appendix B. To provide some comparison with the income coefficients from chapter two, Section B.5 also displays the regression results from equations (3.11) - (3.13) using the income series from chapter two (measured in 1985 international dollars).

\footnotetext{
${ }^{68}$ As noted in Section B.2, extrapolating the VKT series adds additional measurement error to the dependant variable. However, since all computed standard errors are already heteroskedasticity-corrected, no additional variance correction is necessary to account for the predicted data.
} 


\subsubsection{Reduced-form estimates}

Tables $3.7-3.10$ summarize the results from estimating various specifications of equations (3.14) and (3.15) for both occupant and pedestrian fatalities. I display the regression results in two groups. Tables 3.7 and 3.9 present specifications excluding the seatbelt variables, and Tables 3.8 and 3.10 show the models that include seatbelt usage. Due to missing values for some variables, the number of observations varies across specifications. (The number of observations used to estimate each specification in Tables $3.7-3.10$ are listed by country in Table B.6 and B.7 in Appendix B.) Again, in all tables, standard errors presented in parentheses are heteroskedasticity-corrected, clustered on country to allow for within panel autocorrelation.

Since drivers of two-wheelers do not wear seatbelts, seatbelt usage can only indirectly affect the number of two-wheeler fatalities through changes in behavior of belted drivers in other vehicles. Therefore, it is appropriate to move two-wheeler fatalities to the non-occupant death rate once the seatbelt variables are added to the model. The dependent variables in Tables 3.8 and 3.10 thus become Occupant Fatalities/VKT and Non-occupant Fatalities/VKT, respectively, where two-wheeler deaths are included in the latter. I discuss the results from the occupant fatality models (equation 3.14) before turning to examine the estimates of pedestrian fatalities per VKT (equation 3.15).

3.5.4.a. Estimates of occupant fatality equations - no seatbelt usage

In Table 3.7, which presents the occupant fatality models, several results stand out. Once other factors are included, per capita income and the time trend cease to be 
significant in explaining the decline in occupant fatalities/VKT. What is significant in explaining the decline in occupant fatalities are demographic trends, reductions in alcohol abuse, growth in the road network and improvements in motor vehicles and the availability of medical services. These results are discussed in detail below.

Income and the time trend. Adding more variables, as suggested by the formal models, reduces the importance of income in all specifications of occupant fatalities per VKT displayed in Table 3.7. The income elasticity of the occupant fatality rate decreases in magnitude (to -0.008 (0.129) in Model 1 (when evaluated at sample mean of YOUTH $=.1928)$ ) and remains statistically insignificant across virtually all specifications. Adding an income squared term to the base model (not shown in Table 3.7) suggests that, holding all else equal, occupant fatalities/VKT begin to increase again with income after per capita GDP exceeds $\$ 18,790$, although the coefficient on the quadratic term is insignificant. ${ }^{69}$ At the sample mean of YOUTH $=0.1928$, the income elasticity of the fatality rate remains small and insignificant (-0.065 (0.108)), however, and there is no change in magnitude or significance of the other coefficient estimates. (See Table B.5 in Appendix B for these results). Similarly, the time trend is still negative but has also decreased in magnitude and significance in all specifications of occupant fatalities/VKT.

Age. A striking result of the models is the importance of demographic trends. An increase in the percentage of driving age population between 15-24 (YOUTH) is found to have a positive effect on the occupant fatality rate. Evaluated at the Model 1

${ }^{69}$ McCornac (1993) finds income had a significant and positive effect on the total number of traffic deaths in Japan over 1966-85. However, he does not include a time trend in his model. 
(referred to as the Base Model) sample mean of Y, \$16,630 (1996 \$int'l), the elasticity with respect to YOUTH is statistically significant across all specifications in Table 3.7, ranging in magnitude from 0.610 (0.257) (Model 1) to 0.979 (0.322) (Model 11). ${ }^{70}$

These results imply that a $1 \%$ decrease in the percentage of driving population aged 15-24 leads to nearly a $1 \%$ decrease in fatalities per VKT. Considering that YOUTH decreased by over $20 \%$ in many OECD countries from 1964-2002, this suggests that this demographic trend alone could account for as much as $30 \%$ of the decline in occupant fatalities per VKT during this time. This finding agrees with results in the literature, although few country-level studies have examined the role of this age cohort on different road user groups separately. One exception is Peltzman (1975) who found YOUTH had a large, positive effect on the vehicle occupant death rate (with an elasticity of $0.594(t-s t a t=7.002)$ ) in the U.S. over 1947-65, although he included motorcyclist deaths with non-occupants. ${ }^{71}$ The result also agrees with Noland (2003a) and Page (2001) who find similar values for the elasticity of total traffic fatalities with respect to the percent of the population between 15-24 for a subset of OECD countries over 1970-96 and 1980-1994, respectively (although both

\footnotetext{
${ }^{70}$ The elasticity is larger when LIVER also enters the model (Models 5, 9, 10, 11). When HEART is included (Model 7), the elasticity rises to 1.397 (0.710) but the sample size is so small (181 observations) that I focus less on the results from this specification.

${ }^{71}$ Another is a study by Lindgren and Stuart (1980) who find no effect of YOUTH on the vehicle occupant fatality rate in Sweden between 1947 and 1973 (when they include motorcycle deaths in occupant fatalities as I have done). However, due to lack of VKT data, they compute the death rate as deaths/weighted vehicle sum where the number of vehicles is weighted by vehicle type.
} 
fail to control for several important variables, including VKT and RD). ${ }^{72}$ The importance of demographics is more pronounced here than in most within-country studies that are limited to shorter periods of analysis. Using county-level data for 1970 and 1980, Keeler (1994), for example, finds increases in the young population to increase traffic fatalities but the difference is not significant.

One of Keeler's more interesting results is that educational attainment has a positive effect on road safety that exceeds the returns to income. This is not inconsistent with the results presented here. The coefficient on the YOUTH-income interaction term is negative in all specifications in Table 3.7, indicating that the importance of young drivers diminishes as incomes increase. This result could reflect changes in young people's attitudes toward risk or an increase in education of young drivers with increases in economic prosperity.

The percentage of driving age population aged 65 and over (ELDERLY) is generally found to have a small positive but insignificant effect on occupant fatalities per VKT. Few other studies have examined the effect of this age cohort on occupant and pedestrian fatalities separately. Noland (2003a) did find an increase in the percentage of population aged 65 and over to be associated with an increase in total traffic deaths but the result loses significance as he adds other variables (medical treatment proxies) to the model. ${ }^{73}$

\footnotetext{
72 Page (2001) estimates the elasticity to be 0.83 (0.11) for OECD countries over 1980-94. Noland (2003a) finds the elasticity ranges from $0.49(\mathrm{t}-\mathrm{stat}=2.17)$ to 1.11 $(\mathrm{t}$-stat $=6.58)$, depending on what other controls are included in the model (along with year dummy variables).

${ }^{73}$ Using U.S. county level data for 1970 and 1980, Keeler (1994) also found a positive but insignificant effect of elderly on the total traffic deaths per capita.
} 
Motorization. The vehicle occupant fatality rate is found to increase with the size of the motor vehicle fleet (VEH). To the extent that increases in VEH reflect a shift of pedestrian road users into vehicles, this should increase vehicle occupant fatalities while reducing pedestrian fatalities. The coefficient is statistically significant for virtually all models in Table 3.7 , ranging in value from $0.360(0.140)$ (when POP is included (Model 2)) to 0.473 (0.160) (when both LIVER and PHYSICIANS are included (Model 10)). ${ }^{74}$ The coefficient drops to less than 0.28 and becomes insignificant in those specifications where a drunk driving proxy is included without controlling for medical care (Models 4, 5, 9).

The percentage of motorized two-wheelers in the vehicle stock (2WHEELERS) is found to have no effect on the occupant fatality rate (Model 8). This is somewhat surprising given the increased vulnerability of motorcycle accident victims to bodily injury.

The results in Table 3.7 suggest that the fatality rate of vehicle occupants increases with a country's rate of motorization. In Model 1, the elasticity of deaths per VKT with respect to the annual growth rate of the motor vehicle fleet (VEHGROWTH) is found to be $0.61(0.30){ }^{75}$ Since VEHGROWTH enters the model in linear form, the magnitude of this effect is not large. Considering that

\footnotetext{
${ }^{74}$ The coefficient on $\ln (\mathrm{VEH})$ increases in magnitude to $0.543(0.200)$ when medical care is proxied by heart attack survival rates (HEART) (Model 7), although the sample size decreases drastically.

75 The coefficient rises to approximately 1 when the liver cirrhosis death rate (LIVER) proxies for the amount of drunk driving (Models 5 and 9) but tends to decrease in magnitude and significance with the addition of medical control variables in Models 6 and 10.
} 
VEHGROWTH fell from approximately 0.06 to 0.02 in several countries over the sample period, ${ }^{76}$ the results imply that little more 0.03 percent of the decline in fatality rates can be attributed to decreases in the rate of motorization. ${ }^{77}$

Population. Neither total population (POP) nor the percentage of population living in urban areas (URBAN) is found to have a significant effect on the occupant fatality rate. This result differs somewhat from Noland's (2003a) finding that increasing population reduces total fatalities (when time dummies are used in place of a time trend). ${ }^{78}$ Noland attributes negative coefficient on total population to increasing congestion.

Road Infrastructure. Road building is found to increase road safety, as suggested by the formal models. The coefficient on $\ln (\mathrm{RD})$ is consistently negative and significant across the models in Table 3.7, with the magnitude increasing when LIVER is also included (Models 5, 9, 10,11). It is interesting to note, however, that trends in road conditions seem to counter the beneficial effect of road building to some degree. Since total route length presumably does not decrease over time,

\footnotetext{
${ }^{76}$ For example, the annual growth rate of the vehicle fleet fell from $5.9 \%$ in 1965 to $1.9 \%$ in 2002 in Austria, from $6.0 \%$ to $1.1 \%$ in Denmark, and from $5.0 \%$ to $2.0 \%$ in the United States.

${ }^{77}$ Sensitivity analysis of the Model 1 results with respect to the specification of this variable and the countries included in the sample is presented in Section B.6 of Appendix B. In general, the coefficient increases in magnitude as more years are included in the average growth rate and if South Korea is dropped from the sample. All other coefficient estimates remain stable across specifications. In the interest of maintaining the largest sample size possible, I continue to use VEHGROWTH in all other model specifications.

${ }^{78}$ Replacing the time trend with year dummies in Model 2 has no effect on the significance of $\ln (\mathrm{POP})$ for either road user group. The coefficient becomes 0.294 $(0.325)$ in the case of vehicle occupants.
} 
increases in the road-time interaction $(\operatorname{lnRD} * t)$ could reflect an aging or deterioration of the existing road network, if repairs are not kept up. Alternatively, if the building of new roads is positively correlated with road maintenance and improvements (lane widening, etc.) on existing routes, then the positive coefficient on the road lengthtime trend interaction may suggest that trends in road improvements have led to an increase in risk taking behavior on the part of drivers. In part, this could reflect the Peltzman (1975) hypothesis, which argues that the effectiveness of safety policies depends on the behavioral response of individuals to increased regulation. Applying the theory to roads, the positive coefficient on the road length-time interaction $(\operatorname{lnRD} * t)$ could reflect offsetting behavior of drivers in response to presumably safer roads conditions — driving faster on straighter, wider roads (or highways). ${ }^{79}$ This result is not inconsistent with Noland's (2003b) finding that road infrastructure improvements - additional lane-miles, lane widening and changes in geometric design - may even lead to increases in traffic fatalities. ${ }^{80}$ Since the interpretation of the route length-time trend interaction is not clear, measuring the net effect of trends in road conditions on traffic deaths per VKT clearly requires more detailed data on road maintenance.

Safer Vehicles. Safer vehicles (as proxied by interacting the number of vehicles with a linear time trend $(\operatorname{lnVEH} * t))$ are found to decrease the occupant

\footnotetext{
${ }^{79}$ Mahalel and Szternfeld (1986) hypothesize that drivers may also feel safer on wider roads and reduce cautionary behavior.

${ }^{80}$ Similarly, using monthly data for 18 counties in Norway, Fridstrom and Ingebrigsten (1991) also found improvements to the national road network had no beneficial effect on safety rates.
} 
fatalities per VKT. ${ }^{81}$ This result is consistent with the idea that safer vehicles provide additional protection to vehicle occupants, although the small magnitude of the effect on occupant fatalities could suggest some partial offsetting behavior on the part of drivers. In general, the empirical literature examining the offset hypothesis related to vehicle safety devices has been somewhat inconclusive. Peltzman (1975) and Garbacz $(1990,1992)$ find that a reduction in vehicle occupant deaths due to improved vehicle safety standards is offset by increases in non-occupant deaths. Merrell et al.'s (1999) finding that vehicle safety inspections do not reduce fatality or injury rates is not inconsistent with compensating behavior theory. Other studies of the effectiveness of inspections and vehicle safety features such as airbags and antilock brakes have found little evidence of offsetting behavior and claim that improved standards have significantly reduced fatality rates (Loeb, 1990; Loeb and Gilad, 1984; Farmer et al., 1997; Harless and Hoffer, 2003).

Alcohol. Alcohol consumption (ALCOHOL) has the expected positive sign (increasing fatalities per VKT) but it is small in magnitude and statistically insignificant (Model 4 in Table 3.7). Other studies using similar proxies for drunk driving have found mixed results. Zlatoper (1984) found per capita adult alcohol consumption had no statistically significant effect on either pedestrians or occupants deaths in the U.S. between 1947 and 1980. Similarly, Keeler (1994) found a positive

${ }^{81}$ Interacting the vehicle stock with a linear time trend does not pose the same problems of interpretation as the road-time interaction. As older vehicles go out of service, the vehicle mix is tilted toward more recent model year vehicles, which are equipped with better safety features. Hence, holding the size of the vehicle fleet constant, increases in the vehicle-time interaction reflect an increase in the average safety level of the vehicle stock. 
but statistically insignificant effect of alcohol consumption on fatalities in the U.S.

over 1970-1980. Noland and Quddus (2002) and Loeb (1987), however, suggest alcohol consumption to be related to increases in fatalities (in Great Britain and the U.S., respectively). ${ }^{82}$

As mentioned earlier, the imprecision of the ALCOHOL coefficient could reflect the classic errors in variables problem since it is a crude proxy for drunk driving. Replacing ALCOHOL with data on alcohol-attributable death rates, such as the number of deaths due to cirrhosis of the liver (LIVER), may provide a better measure of excessive alcohol consumption. The elasticity of traffic fatalities per VKT with respect to LIVER is found to be consistently positive and significant in across all specifications in Table 3.7 (Models 5, 9, 10, 11). This reflects an increase in the probability of a drunk driver being unable to avoid an imminent accident ( $\mathrm{q}$ in equation (3.14)).

Medical Treatment Indicators. The elasticity of the fatality rate with respect to the number of physicians per capita (PHYSICIANS) has the expected sign in all models, but the effect is only statistically significant in the occupant equation when

${ }^{82}$ Expenditure measures of alcohol consumption have also produced conflicting results. Noland $(2003 b, 2000)$ finds per capita expenditure on alcohol to be statistically significant at increasing the total number of fatalities in Great Britain and in the U.S. Whetten-Goldstein et al. (2000) found no significant effect of a price index of alcohol consumption on fatality rates in the U.S. over 1984-1995. McCornac (1993) attributes his insignificant coefficient on annual real expenditure on alcohol beverages per household in Japan (coefficient is positive but insignificant for both non-occupant and occupant deaths) to the fact that alcohol plays a much smaller role in accidents in Japan than other countries such as U.S. He notes that on average only $7 \%$ of traffic fatalities in Japan are attributed to drunk driving over his sample period (1966-85). Similarly, Lindgren and Stuart (1980) found that adult per capita alcohol sales (liters of pure ethanol) had no effect on either the occupant or non-occupant fatality rate in Sweden (over 1947-73) either. 
LIVER does not enter the model (Model 6). In part, the insignificance of the PHYSICIANS coefficient in Model 10 and 11 of Table 3.7 could be due to multicollinearity between PHYSICIANS and RD and VEH. (As shown in Table 3.6, the correlation coefficient of $\ln (\mathrm{PHYSICIANS})$ with $\ln (\mathrm{RD})$ and $\ln (\mathrm{VEH})$ is 0.9063 and 0.9558 , respectively.) Overall, my results are not inconsistent with Noland's (2003a) finding that more physicians per capita led to reductions in total fatalities in a similar set of countries during 1970-1996, although he did not control for the length of the road network.

Although better measures of the quality of emergency medical care are limited, I also explored the effects of an alternate measure, the heart attack survival rate (HEART). Since the correlation coefficient of $\ln ($ HEART) with the other explanatory variables is less than 0.57 , the precision of coefficient estimates should be less affected by multicollinearity issues than with PHYSICIANS. The elasticity of occupant fatalities per VKT with respect to HEART is found to be quite large but statistically insignificant (-1.016 (0.633) in Model 7). Since panel lengths and overall sample size shrink so dramatically with the inclusion of this variable, however, I hesitate to focus on the results from this specification.

3.5.4.b. Estimates of occupant fatality equations - with seatbelt usage Lack of data on seatbelt usage rates results in the models in Table 3.8 being estimated with fewer countries and fewer years of data per country than the models in Table 3.7. ${ }^{83}$ One should, therefore, not expect results as robust as those in Table 3.7.

${ }^{83}$ The number of countries with data on seatbelt wearing rates on urban roads, rural roads, and motorways (as well as data for all other variables in the base model (Model $1)$ ) is 20,16 , and 15 , respectively. Consequently, the number of observations falls 
In addition, the dependent variable no longer includes two-wheeler deaths. In general, the signs of the non-seatbelt variables in Table 3.8 agree with those in Table 3.7, although far fewer variables are statistically significant.

The elasticity of occupant deaths/VKT with respect to the urban seatbelt wearing rate is found to be -0.05 (Models $13-15$ ), but is only statistically significant (at the 10\% level) if one controls for the percentage of population living in urban areas (URBAN) ${ }^{84}$ The beneficial impact of seatbelts is twice as large on rural roads, however. The coefficient on rural seatbelt wearing rate ranges from $-0.10(0.02)$ to 0.14 (0.03) (Models 16-19) and the magnitude and significance (at the 1\% level) of this coefficient remains stable when other controls are added to the model. (If Model 13 is re-estimated using only those countries for which the rural wearing rates are available, the elasticity of Occupant Fatalities/VKT increases in magnitude to -0.068 (0.029) and becomes statistically significant at the $5 \%$ level. ${ }^{85}$ ) When wearing rates on motorways only enters the model, the elasticity falls slightly in magnitude to -0.09 (0.04) (Model 21). It is not surprising that the effect is similar to rural roads since motorways are a subset of rural roads.

There may, of course, be some partial offsetting behavior affecting the safety benefits to vehicle occupants that cannot be measured with the results here.

(from 680 in the Base Model) to 261, 198, and 191, respectively. Table 3.3 provides a list of the countries included in each subset.

${ }^{84}$ The elasticity estimates from Model 14 do not change if total population (POP) is included instead of URBAN but the seatbelt coefficient become insignificant ( $t$ stat falls to 1.57$)$.

${ }^{85}$ This drops Canada, Japan, South Korea, and the United States from the sample. 
Examining the extent to which offsetting behavior is influencing the effect of seatbelt use on the occupant fatality rate requires more detailed data. The negative coefficient on seatbelt usage can only reassure us that the beneficial effects of seatbelt use to vehicle occupants were not completely offset by changes in driver behavior.

The results in Table 3.9 agree with Cohen and Einav's (2003) recent estimates of the effect of seatbelt usage in the U.S. during 1983-1997. In fact, when controlling for state fixed effects, their estimate of the elasticity of occupant deaths per vehicle mile traveled with respect to seatbelt usage is -0.053 (0.022), identical to that found in Model 14 in Table 3.9. (Since the NHTSA observational survey data used by Cohen and Einav is collected at intersections, I feel their results are most comparable to the Models including the urban seatbelt usage rate.)

Unlike most other studies that control for seatbelt wearing rates (Noland, 2003b; McCornac, 1993; Garbacz, 1990, 1991; Risa, 1994), Cohen and Einav (2003) also attempt to account for the potential endogeneity of the seatbelt usage variable. ${ }^{86}$ Since the decision to wear a seatbelt is a choice variable, drivers (and passengers) may be more likely to wear a seatbelt when the probability of death is higher. This would create a positive correlation between the usage rate and the error term in equation (3.14), thus causing an upward bias in the seatbelt coefficient estimate. To correct for this, Cohen and Einav instrument seatbelt usage with dummy variables

\footnotetext{
${ }^{86}$ The failure to control for this endogeneity could be the reason that Garbacz (1990, 1991) and Risa (1994) find positive coefficients on usage. On the other hand, McCornac (1993) finds a significant effect of seatbelt use on both occupant and nonoccupant fatalities in Japan over 1966-1985 and Noland (2003b) finds increased seatbelt use significantly reduces total deaths in U.S. during 1990-97. It is not clear in either study if the seatbelt usage data measures an average national wearing rate or pertains to a particular road/occupant type.
} 
indicating the presence of a mandatory seatbelt law and type of enforcement. ${ }^{87}$ They find that the magnitude of the seatbelt effect doubles for occupant fatalities (to -0.133 (0.047)).

Unfortunately, since mandatory seatbelt laws did not change over the time period of some of the panels included in my sample (and data on the type of enforcement is not available for all countries), replicating Cohen and Einav's instrumental variables estimation strategy is not possible here. However, I did attempt to instrument seatbelt usage with a variable equal to the number of years since the first mandatory seatbelt law (for front passengers) was passed. Using this instrument (for Models 13, 16, and 20), the magnitude of the elasticity of the occupant fatality rate did increase for both urban roads and motorways to -0.229 (0.178) and -0.114 (0.136), respectively, but the effect is statistically insignificant for all three road types. ${ }^{88}$ Some researchers (including Cohen and Einav who mention also finding an insignificant result with a similar instrument) suggest that this result supports the hypothesis that the effects of seatbelt laws are immediate and permanent.

Finally, the estimated elasticities of occupant fatalities/VKT with respect to several other control variables become insignificant in the Table 3.8 models. The change in magnitude and significance of some of these elasticities in this smaller sample may be due to multicollinearity issues. For example, the insignificance of

${ }^{87}$ The authors argue that the timing of the adoption of mandatory seat belt laws is not likely to be endogenous itself due to several other political factors involved in the lengthy legislation process.

${ }^{88}$ The elasticity of the occupant fatality rate with respect to the rural seatbelt wearing rate becomes $0.069(0.085)$. 
road length and size of the vehicle fleet is probably due to the high correlation between these two regressors. The sample correlation coefficients of $\ln (\mathrm{RD})$ with $\ln (\mathrm{VEH})$ is 0.9191 . (Table 3.6 displays the correlation among all independent variables.)

3.5.4.c. Estimates of pedestrian fatality equations - no seatbelt usage The regression results from models of pedestrian fatalities/VKT (analogous to those for occupant fatalities in Table 3.7) are displayed in Table 3.9. As in the vehicle occupant equation, once other factors are included, per capita income ceases to be significant in explaining the decline in the pedestrian fatality rate. Demographic trends, reductions in alcohol abuse, growth in the road network and improvements in motor vehicles are found to be significant in explaining improvements in pedestrian safety, although to different degrees than in the case of vehicle occupants. Population aging trends, for example, are significantly associated with an increase in pedestrian deaths/VKT. These results along with all other specifications of Table 3.9 are discussed in detail below.

Income and the time trend. The income elasticity of the pedestrian fatality rate falls in magnitude from $-0.643(0.146)$ in equation (3.12) to $-0.211(0.233)$ (evaluated at base model sample mean of YOUTH $=.1928$ ). The opposite is true, however, of the importance of the linear time trend, $t$. The coefficient on $t$ increases slightly in magnitude from $-0.060(0.004)$ in equation $(3.13)$ to $-0.071(0.027)$ in the Base Model in Table 3.9, suggesting that the pedestrian death rate is falling over time even after including additional controls. 
Age. An increase in the percentage of driving age population between 15-24 (YOUTH) is found to have a positive effect on the pedestrian fatality rate. The elasticity is statistically significant across all specifications in Tables 3.9 , but the magnitude of the effect is generally smaller than in the case of occupant fatalities. Evaluated at the sample mean of Model 1 (referred to as the Base Model) of Y, $\$ 16,630$ (1996 \$int'l), the elasticity of pedestrian deaths/VKT with respect to YOUTH ranges from 0.528 (0.296) (Model 2) to 1.114 (0.284) (Model 11). ${ }^{89}$

These results imply that, as in the case of vehicle occupants, this demographic trend alone could account for as high as $30 \%$ of the decline in occupant fatalities per VKT over the sample period. (Likewise, the coefficient on the YOUTH-income interaction term is negative in all specifications in Table 3.9 although it is generally only significant in the pedestrian equation when LIVER is included in the model.) Peltzman (1975) also found YOUTH to have a large, positive effect on the nonoccupant death rate (elasticity of $1.274(\mathrm{t}$-stat $=11.234))$ in the U.S. over 1947-65, although he included motorcyclists deaths with non-occupants. Lindgren and Stuart (1980), however, find no effect of YOUTH on the non-occupant fatality rate in Sweden between 1947-73 (when they include motorcycle deaths in occupant fatalities).

Interestingly, the percentage of driving age population aged 65 and over (ELDERLY) is found to have a much larger positive effect on pedestrian fatalities per

\footnotetext{
${ }^{89}$ As in the case of occupant fatalities, the elasticity is larger when LIVER also enters the model (Models 5, 9, 10,11). When HEART is included (Model 7), the elasticity rises to $1.168(0.593)$ for pedestrians but the sample size is so small (181 observations) that I focus less on the results from this specification.
} 
VKT than on the occupant fatality rate. The cause of the differential effect of ELDERLY across the two equations is unclear. If elderly people are more likely to walk than to be drivers then the significant effect in the pedestrian equation could simply be a result of an increase in the total number of pedestrians. ${ }^{90}$ On the other hand, it could reflect an increase in accidents caused by elderly drivers ${ }^{91}$ or lower pedestrian crash survival rates of elderly accident victims (in which case the occupant fatalities/VKT remain unchanged because of the protection offered by vehicle safety devices such as seatbelt and airbags). Teasing out the causes of the ELDERLY coefficient remains a topic for future research.

Motorization. Increases in the size of the motor vehicle fleet (VEH) are found to have opposite effects in the two equations, reflecting the differential effect of removing the most vulnerable road users from the road environment (shifting pedestrians and bicyclists into vehicles) on the two types of accidents. To the extent that increases in VEH reflect a shift of pedestrian road users into vehicles, this should reduce pedestrian fatalities but increase vehicle occupant fatalities. The coefficient

\footnotetext{
${ }^{90}$ Alternatively, pedestrian-motor vehicle accident risk could be higher for older pedestrians. A recent case controlled study of the collision risk involving older pedestrians found crosswalk markings to be associated with increased risk of collision to older pedestrians at sites without signals or stop signs to stop traffic (Koepsell et al., 2002).

${ }^{91}$ If the accidents are occurring at lower speeds then vehicle occupant fatalities per accident may not increase but pedestrian deaths per accident will. One reason to think that an increase in elderly drivers might increase overall fatality rates could be that slower speeds by elderly drivers could increase the variance in driving speed on the roadway, which has been hypothesized by Lave (1985) and others to increase total deaths/VKT. The results here do not seem to be a result of this speed variance hypothesis, however, since that should have caused occupant deaths per VKT to increase as well.
} 
on $\ln (\mathrm{VEH})$ has the expected negative sign for pedestrians across all specifications in Table 3.9 but the result is only statistically significant (at the $10 \%$ level) when the percentage of population in urban areas (URBAN) is also included in the model (Model 3).

The percentage of motorized two-wheelers in the vehicle stock (2WHEELERS) is found to have no effect on the pedestrian fatality rate (Model 8.) The insignificance of this variable is perhaps less surprising than in the case of vehicle occupants if, in fact, a pedestrian's probability of dying given that he/she is struck does not depend heavily on the type of vehicle involved in the accident.

The results in Table 3.9 suggest that the pedestrian fatality rate increases with a country's rate of motorization. In Model 1, the elasticity of deaths per VKT with respect to the annual growth rate of the motor vehicle fleet (VEHGROWTH) is found to be $0.75(0.39),{ }^{92}$ although as discussed in the previous section, the magnitude of this effect is not large given that VEHGROWTH enters the model in linear form.

Population. Pedestrian Fatalities/VKT are not found to increase with total population (POP) itself, as the formal model suggests. However, the elasticity of the percentage of population living in urban areas (URBAN) with respect to the pedestrian fatality rate is found to be near one (Model 3, 9,11), presumably reflecting an increase in total pedestrian activity, although effect is only statistically significant (at the 10\% level) when LIVER does not enter the equation (Model 3). This result

\footnotetext{
${ }^{92}$ As in the occupant equation, the coefficient rises to approximately 1 when the liver cirrhosis death rate (LIVER) proxies for the amount of drunk driving (Models 5 and 9) but tends to decrease in magnitude and significance with the addition of medical control variables in Models 6 and 10.
} 
differs somewhat from Noland's (2003a) finding that increasing population reduces total fatalities (when time dummies are used in place of a time trend). ${ }^{93}$

Road Infrastructure. The beneficial effect of road building is generally larger in the pedestrian equation than in the occupant equation, perhaps because larger road networks include more motorways that are separated from foot traffic. The $\ln (\mathrm{RD})$ coefficient is consistently negative and significant across all specifications in Table 3.9, with the magnitude approximately doubling when LIVER is also included (Models 5, 9, 10, 11). However, the coefficient on the route length-time trend interaction $\left(\operatorname{lnRD} \mathrm{D}^{*}\right)$ is positive and of nearly the same magnitude as in the occupant fatality equation. As before, whether this reflects an increase in faster or careless driving on straighter, wider roads or the effect of decreased maintenance on existing networks is a topic requiring more detailed analysis.

Safer Vehicles. Safer vehicles (as proxied by $\left(\operatorname{lnVEH}^{*} \mathrm{t}\right)$ ) decrease the fatality rate of pedestrians. The magnitude of the effect is smaller than in the occupant equation, which is consistent with the idea that a pedestrian's chances of dying once being struck will not depend as much on the safety features of the vehicle involved. The negative coefficient on VEHt also suggests that there is little to no offsetting behavior on the part of drivers in response to improvements in vehicle safety devices. This finding conflicts with Peltzman (1975) and Garbacz $(1990,1992)$ who claim that a reduction in vehicle occupant deaths due to improved vehicle safety standards is offset by increases in non-occupant deaths.

\footnotetext{
${ }^{93}$ Replacing the time trend with year dummies in Model 2 has no effect on the significance of $\ln (\mathrm{POP})$ for either road user group. The coefficient becomes 0.294 $(0.325)$ in the case of occupants and $-0.051(0.789)$ in the pedestrian equation.
} 
Alcohol. The importance of drunk driving in explaining pedestrian deaths/VKT is similar to what was found in the occupant fatality model. Per adult alcohol consumption (ALCOHOL) has the expected positive, but insignificant effect of increasing fatalities per VKT (Model 4 in Table 3.9). The elasticity of fatalities per VKT with respect to the liver cirrhosis death rate (LIVER), however, is consistently positive and statistically significant across all specifications of the pedestrian equation (Models 5, 9, 10,11). The magnitude of the effect is nearly twice as large as it was for occupants. This reflects perhaps not only an increase in the probability of a drunk driver being unable to avoid an imminent accident (q), but also risky behavior by pedestrians under the influence of alcohol (thereby increasing $\mathrm{e}^{\prime}$ in equation $\left.\left(3.9^{\prime}\right)\right)$.

Medical Treatment Indicators. The elasticity of the fatality rate with respect to the number of physicians per capita (PHYSICIANS) has the expected sign but remains statistically insignificant in all specifications in Table 3.9. It is not surprising that an increase in medical services had a larger impact on the occupant fatality rate than on pedestrian fatalities. One could assume that the likelihood of death is higher for unprotected road users such as pedestrians and bicyclists than vehicle occupants, regardless of how quickly accident victims are rushed to the hospital or the quality of available medical care. The precision of the PHYSICIAN coefficient estimate is presumably influenced by multicollinearity issues as discussed in the previous section. The elasticity of pedestrian deaths/VKT with respect to the heart attack survival rate (HEART) is found to be nearly as large as for vehicle occupants (-0.887 (0.590) in Model 7) but also remains statistically insignificant. 
3.5.4.d. Estimates of non-occupant fatality equations - with seatbelt usage

Table 3.10 summarizes the estimates of the non-occupant fatality rate with the inclusion of the seatbelt variables. As mentioned earlier, the dependent variable includes all two-wheeler fatalities. The coefficient on seatbelt usage is consistently small and insignificant across all specifications of the non-occupant fatality rate, regardless of which of the three seatbelt wearing rates is used. ${ }^{94}$ Since seatbelt usage can only affect the non-occupant deaths indirectly as a result of increased risk taking by belted drivers, the insignificance of this variable suggests there is no evidence of such compensating behavior. ${ }^{95}$ This result is inconsistent with Cohen and Einav's (2003) fixed effects estimates that show a significant, negative effect of seatbelt usage on non-occupant fatality rates. The authors claim the beneficial effect is a result of increased safety consciousness of belted drivers, although once they instrument for seatbelt usage, their coefficient becomes small and insignificant $(-0.042(0.121))$ as well.

Finally, the estimated elasticities of the non-occupant fatality rate with respect to several other control variables become insignificant in the Table 3.10 specifications. As in the case of vehicle occupants, the change in magnitude and

\footnotetext{
${ }^{94}$ This result is robust to the inclusion of other controls variables: POP instead of URBAN, PHYSICIANS, etc.

${ }^{95}$ This result differs from Garbacz (1992) and Risa (1994) who find a positive and statistically significant effect of usage on nonoccupant fatalities, arguing for the presence of compensating behavior. However, Cohen and Einav (2003) show that the positive relationship disappears after controlling for state fixed effects. Sen (2001) also offers modest evidence of offsetting driver behavior resulting from seat belt laws in Canada.
} 
insignificance some of these elasticities in this smaller sample may be due to multicollinearity issues.

\subsection{Conclusions and Further Research}

The findings of this chapter shed light on the importance of underlying factors that have helped reduce fatality rates in industrialized countries, countries that have been on the downward sloping part of a so-called road safety Kuznets curve over the past few decades. Results from reduced-form models of pedestrian and occupant fatalities suggest that demographic changes and road building alone contributed to declines in both occupant and non-occupant fatalities per vehicle kilometers driven. Motorization trends also matter. Increases in the size of the vehicle fleet have the mechanical effect of increasing occupant deaths and decreasing pedestrian deaths per VKT but the significance of the effect on pedestrians is sensitive to model specification. Technological developments, such as the advances in the quality of medical services, have also played a role in reducing fatality rates, although multicollinearity issues with the available proxies prevent one from detecting the magnitude of the effect with precision.

Direct and indirect effects of policy interventions on the behavior of drivers are also found to play a role in improving road safety. Estimating separate equations for vehicle occupants and non-occupants enabled me to test Peltzman's risk compensation hypothesis, albeit with crude proxies measuring improvements in vehicle safety standards and road conditions. Contrary to Peltzman (1975) and Garbacz's $(1990,1992)$ findings, the results here do not offer strong evidence of an 
increased demand for risky driving in response to newer, safer vehicles or seatbelt usage. Examining whether offsetting behavior is related to trends in road infrastructure conditions requires more detailed data on road improvements and maintenance. The results also provide some evidence of the extent to which excessive alcohol consumption has influenced road fatality rates. The effect is found to be nearly twice as large on pedestrian deaths per VKT, suggesting a larger risk to pedestrians from drunk drivers and/or an increase in risk taking by pedestrians under the influence of alcohol.

The results presented here are limited in what they can say about the influence of factors on the occupant fatality rates of particular vehicle types. For example, the insignificant effect of the percentage of two-wheelers in the vehicle fleet is perplexing. More detailed analysis (using data on the vehicle-kilometers traveled by motorized two-wheelers and motorcycle helmet use) would shed more light on the factors underlying improvements in the overall occupant fatality rate. A better understanding of the determinants of two-wheeler deaths per VKT would be especially instructive in rapidly growing countries (e.g., India and Taiwan) where two-wheelers make up over $70 \%$ of the motorized vehicle fleet.

Finally, the finding that the pedestrian fatality rate increases with the percentage of driving population over the age of 64 is a result that requires further attention. 
Table 3.1. Traffic Fatality Trends in IRTAD Countries, 1970-99

(\% Change, unless otherwise indicated)

\begin{tabular}{|c|c|c|c|c|c|c|c|}
\hline Country & $\begin{array}{c}\text { Pedestrian } \\
\text { Deaths }\end{array}$ & $\begin{array}{l}\text { Occupant } \\
\text { Deaths }\end{array}$ & $\begin{array}{c}\text { Pedestrian } \\
\text { Deaths, } \\
1999 \\
\text { (\% of total) }\end{array}$ & $\begin{array}{l}\text { Total } \\
\text { VKT }\end{array}$ & $\begin{array}{c}\text { Pedestrian } \\
\text { Deaths/ } \\
\text { VKT }\end{array}$ & $\begin{array}{l}\text { Occupant } \\
\text { Deaths/ } \\
\text { VKT }\end{array}$ & $\begin{array}{c}\text { Total } \\
\text { Deaths/ } \\
\text { VKT }\end{array}$ \\
\hline Australia & $-54^{\mathrm{b}}$ & $-44^{\mathrm{b}}$ & 19 & +125 & $-65^{b}$ & $-57^{b}$ & -79 \\
\hline Austria & -76 & -47 & 23 & +207 & -92 & -83 & -86 \\
\hline Belgium & $-74^{\mathrm{a}}$ & $-40^{\mathrm{a}}$ & 20 & +204 & $-90^{a}$ & $-76^{a}$ & -85 \\
\hline Canada & -63 & -34 & 16 & $+127^{\mathrm{d}}$ & $-58^{n}$ & $-29^{n}$ & $-37^{n}$ \\
\hline Czech Republic & $-26^{b}$ & $+60^{b}$ & 33 & $+80^{\mathrm{b}}$ & $-59^{b}$ & $-12^{b}$ & $-36^{b}$ \\
\hline Denmark & -71 & -49 & 27 & +94 & -85 & -74 & -78 \\
\hline Finland & -73 & -48 & 30 & +177 & -90 & -81 & -85 \\
\hline France & -71 & -40 & 15 & +187 & -90 & -79 & -82 \\
\hline Germany & -82 & -52 & 21 & +168 & -93 & -82 & -87 \\
\hline Greece & 0 & +150 & 20 & $+585^{\mathrm{e}}$ & $-83^{\mathrm{e}}$ & $-65^{\mathrm{e}}$ & $-71^{\mathrm{e}}$ \\
\hline Hungary & -20 & -19 & 46 & $+238^{f}$ & $-75^{f}$ & $-74^{f}$ & $-75^{f}$ \\
\hline Iceland & $-44^{\mathrm{b}}$ & $0^{\mathrm{b}}$ & 24 & $+159^{g}$ & $-68^{b}$ & $-42^{b}$ & $-51^{b}$ \\
\hline Ireland & -62 & +16 & 26 & $+141^{\mathrm{h}}$ & $-74^{\mathrm{h}}$ & $-57^{\mathrm{h}}$ & $-64^{h}$ \\
\hline Italy & -70 & -22 & 19 & $+132^{i}$ & $-82^{i}$ & $-60^{i}$ & $-68^{i}$ \\
\hline Japan & -58 & -48 & 42 & +238 & -87 & -85 & -86 \\
\hline Luxembourg & -95 & -37 & 3 & $+116^{j}$ & $-85^{j}$ & $-66^{j}$ & $-69^{j}$ \\
\hline Netherlands & -73 & -62 & 28 & +127 & -88 & -83 & -85 \\
\hline New Zealand & -43 & -17 & 14 & +199 & -81 & -72 & -74 \\
\hline Norway & -79 & -24 & 16 & +178 & -92 & -73 & -80 \\
\hline Poland & $-2^{b}$ & $+28^{b}$ & 47 & +1317 & $-73^{b}$ & $-64^{b}$ & -86 \\
\hline Portugal & -42 & +79 & 22 & $+175^{\mathrm{k}}$ & $-95^{\mathrm{k}}$ & $-80^{k}$ & $-89^{k}$ \\
\hline South Korea & $-40^{c}$ & $+7^{\mathrm{c}}$ & 41 & $+594^{1}$ & -73 & $-48^{\circ}$ & $-62^{\circ}$ \\
\hline Spain & -43 & +29 & 18 & +448 & -90 & -77 & -81 \\
\hline Sweden & -71 & -48 & 23 & +88 & -85 & -72 & -76 \\
\hline Switzerland & -75 & -59 & 27 & +88 & -87 & -78 & -81 \\
\hline Turkey & $-59^{c}$ & $-18^{\mathrm{c}}$ & 22 & +716 & $-82^{c}$ & $-63^{c}$ & $-70^{c}$ \\
\hline \multicolumn{8}{|l|}{ United } \\
\hline Kingdom & -69 & -43 & 30 & $+130^{\mathrm{m}}$ & $-86^{\mathrm{m}}$ & $-75^{\mathrm{m}}$ & $-80^{\mathrm{m}}$ \\
\hline United States & -41 & -16 & 14 & +144 & -76 & -66 & -68 \\
\hline
\end{tabular}


Table 3.2. Pedestrian and Occupant Fatalities/VKT as a Function of Income and Time Trends ${ }^{\mathrm{a}}$

\begin{tabular}{|c|c|c|c|c|c|c|c|c|c|c|}
\hline & \multicolumn{5}{|c|}{ Ln(Pedestrian Fatalities/VKT) } & \multicolumn{5}{|c|}{ Ln(Occupant Fatalities/VKT) } \\
\hline & 1 & 2 & 3 & 4 & 5 & 1 & 2 & 3 & 4 & 5 \\
\hline $\ln Y$ & $\begin{array}{c}-0.376 * * \\
(0.187)\end{array}$ & & & $\begin{array}{c}-3.494 \\
(3.633) \\
\end{array}$ & $\begin{array}{l}-4.613 \\
(4.121) \\
\end{array}$ & $\begin{array}{c}-0.077 \\
(0.268) \\
\end{array}$ & & & $\begin{array}{c}-4.503 * * \\
(1.952) \\
\end{array}$ & $\begin{array}{l}-7.727 * \\
(4.676)\end{array}$ \\
\hline$(\ln Y)^{2}$ & & & & $\begin{array}{c}0.148 \\
(0.189) \\
\end{array}$ & $\begin{array}{c}0.223 \\
(0.212)\end{array}$ & & & & $\begin{array}{l}0.222 * * \\
(0.100)\end{array}$ & $\begin{array}{l}0.403 * \\
(0.242)\end{array}$ \\
\hline $\begin{array}{l}\text { lnY for: } \\
\$ 4,552-13,165\end{array}$ & & $\begin{array}{c}-0.706^{* * *} \\
(0.270) \\
\end{array}$ & $\begin{array}{c}-0.475^{*} \\
(0.286) \\
\end{array}$ & & & & $\begin{array}{c}-0.328 \\
(0.233) \\
\end{array}$ & $\begin{array}{c}-0.349 \\
(0.350)\end{array}$ & & \\
\hline$\$ 13,165-16,565$ & & $\begin{array}{c}-1.073 * * * \\
(0.339)\end{array}$ & $\begin{array}{c}-0.751 * * \\
(0.302)\end{array}$ & & & & $\begin{array}{c}-0.675^{* *} \\
(0.293)\end{array}$ & $\begin{array}{l}-0.284 \\
(0.406) \\
\end{array}$ & & \\
\hline$\$ 16,565-20,700$ & & $\begin{array}{c}-0.776^{* *} \\
(0.390) \\
\end{array}$ & $\begin{array}{l}-0.347 \\
(0.362) \\
\end{array}$ & & & & $\begin{array}{l}-0.210 \\
(0.364) \\
\end{array}$ & $\begin{array}{c}0.503 \\
(0.353) \\
\end{array}$ & & \\
\hline$\$ 20,700-44,227$ & & $\begin{array}{l}-0.180 \\
(0.339) \\
\end{array}$ & $\begin{array}{c}0.201 \\
(0.177) \\
\end{array}$ & & & & $\begin{array}{c}0.198 \\
(0.195) \\
\end{array}$ & $\begin{array}{c}0.570 * * \\
(0.266) \\
\end{array}$ & & \\
\hline Common $\mathrm{T}$ & & $\begin{array}{c}-0.059^{* * *} * \\
(0.005)\end{array}$ & & $\begin{array}{c}-0.060 * * * \\
(0.004)\end{array}$ & & & $\begin{array}{c}-0.043 * * * \\
(0.005)\end{array}$ & & $\begin{array}{c}-0.044 * * * \\
(0.004)\end{array}$ & \\
\hline $\begin{array}{l}\text { Constant } \\
\text { (Austria) }\end{array}$ & $\begin{array}{c}0.907 \\
(1.712) \\
\end{array}$ & $\begin{array}{c}3.692 \\
(2.533) \\
\end{array}$ & $\begin{array}{c}1.861 \\
(2.698) \\
\end{array}$ & $\begin{array}{c}16.748 \\
(17.451) \\
\end{array}$ & $\begin{array}{c}21.040 \\
(19.991) \\
\end{array}$ & $\begin{array}{l}-1.421 \\
(2.463) \\
\end{array}$ & $\begin{array}{c}0.642 \\
(2.158) \\
\end{array}$ & $\begin{array}{c}1.220 \\
(3.290) \\
\end{array}$ & $\begin{array}{c}20.222 * * \\
(9.591) \\
\end{array}$ & $\begin{array}{c}34.927 \\
(22.632) \\
\end{array}$ \\
\hline $\begin{array}{l}\text { Turning Point } \\
\text { (1996 Int'1\$): }\end{array}$ & & & & $\$ 129,500$ & $\$ 30,800$ & & & & $\$ 25,384$ & $\$ 14,572$ \\
\hline Adjusted $\mathrm{R}^{2}$ : & 0.9677 & 0.9560 & 0.9686 & 0.9547 & 0.9679 & 0.9587 & 0.9502 & 0.9617 & 0.9485 & 0.9604 \\
\hline Countries & 32 & 32 & 32 & 32 & 32 & 32 & 32 & 32 & 32 & 32 \\
\hline Observations & 830 & 830 & 830 & 830 & 830 & 830 & 830 & 830 & 830 & 830 \\
\hline
\end{tabular}

*** Indicates $1 \%$ level of significance ** Indicates $5 \%$ level of significance

* Indicates $10 \%$ level of significance

a Heteroskedasticity-corrected standard errors, clustered on country to allow for within panel autocorrelation, are given in parentheses.

Country fixed effects were included in all regressions but are not displayed here. Models 1, 3, and 5 for both Occupant Fatalities/VKT and Pedestrian Fatalities/VKT include country specific time trends. The time trend coefficients from these models are displayed in Table B.8 in Appendix B. 
Table 3.3. Number of Observations Included in Chapter Three Samples, by Country

\begin{tabular}{|c|c|c|c|c|c|}
\hline Country & $\begin{array}{c}\text { Income-Only } \\
\text { Regressions } \\
\text { (Equations } \\
3.11-3.13 \text { ) } \\
\end{array}$ & Base Sample & $\begin{array}{c}\text { Sample with } \\
\text { Urban } \\
\text { Seatbelt } \\
\text { Usage } \\
\end{array}$ & $\begin{array}{c}\text { Sample with } \\
\text { Rural } \\
\text { Seatbelt } \\
\text { Usage } \\
\end{array}$ & $\begin{array}{c}\text { Sample with } \\
\text { Motorway } \\
\text { Seatbelt } \\
\text { Usage } \\
\end{array}$ \\
\hline Australia & 21 & 12 & & & \\
\hline Austria & 34 & 23 & 22 & 22 & 22 \\
\hline Belgium & 29 & 29 & 5 & 5 & 5 \\
\hline Canada & 40 & 25 & 13 & & \\
\hline Chile & 4 & 4 & & & \\
\hline Czech Republic & 13 & 6 & & & \\
\hline Denmark & 33 & 32 & 2 & 2 & 21 \\
\hline Finland & 34 & 31 & 14 & 10 & 1 \\
\hline France & 34 & 33 & 23 & 31 & 31 \\
\hline Germany* & 33 & 26 & 9 & 17 & 9 \\
\hline Greece & 31 & 16 & & & 1 \\
\hline Hungary & 32 & 25 & 5 & 5 & 4 \\
\hline Iceland & 22 & 21 & & & \\
\hline Ireland & 27 & 19 & 1 & 1 & \\
\hline Israel & 13 & 13 & & & \\
\hline Italy & 30 & 27 & & & \\
\hline Japan & 33 & 33 & 26 & & 26 \\
\hline Korea, Republic & 13 & 13 & 3 & & \\
\hline Luxembourg & 30 & 27 & & & \\
\hline Netherlands & 33 & 31 & 17 & 17 & 17 \\
\hline New Zealand & 33 & 25 & 7 & 7 & \\
\hline Norway & 32 & 32 & 24 & 24 & 5 \\
\hline Poland & 18 & 14 & & & \\
\hline Portugal & 22 & 9 & & & \\
\hline Slovak Republic & 4 & 4 & & & \\
\hline Slovenia & 6 & 6 & 6 & 6 & 6 \\
\hline Spain & 32 & 20 & 4 & 3 & 1 \\
\hline Sweden & 34 & 26 & 9 & 9 & 9 \\
\hline Switzerland & 34 & 34 & 33 & 34 & 33 \\
\hline Turkey & 10 & 8 & & & \\
\hline United Kingdom & 33 & 27 & 20 & 5 & \\
\hline United States & 33 & 29 & 18 & & \\
\hline Countries: & 32 & 32 & 20 & 16 & 15 \\
\hline $\begin{array}{l}\text { Total } \\
\text { Observations: }\end{array}$ & 830 & 680 & 261 & 198 & 191 \\
\hline
\end{tabular}

*East and West Germany were treated as a single country for years prior to unification. 


\section{Table 3.4. List of Variables}

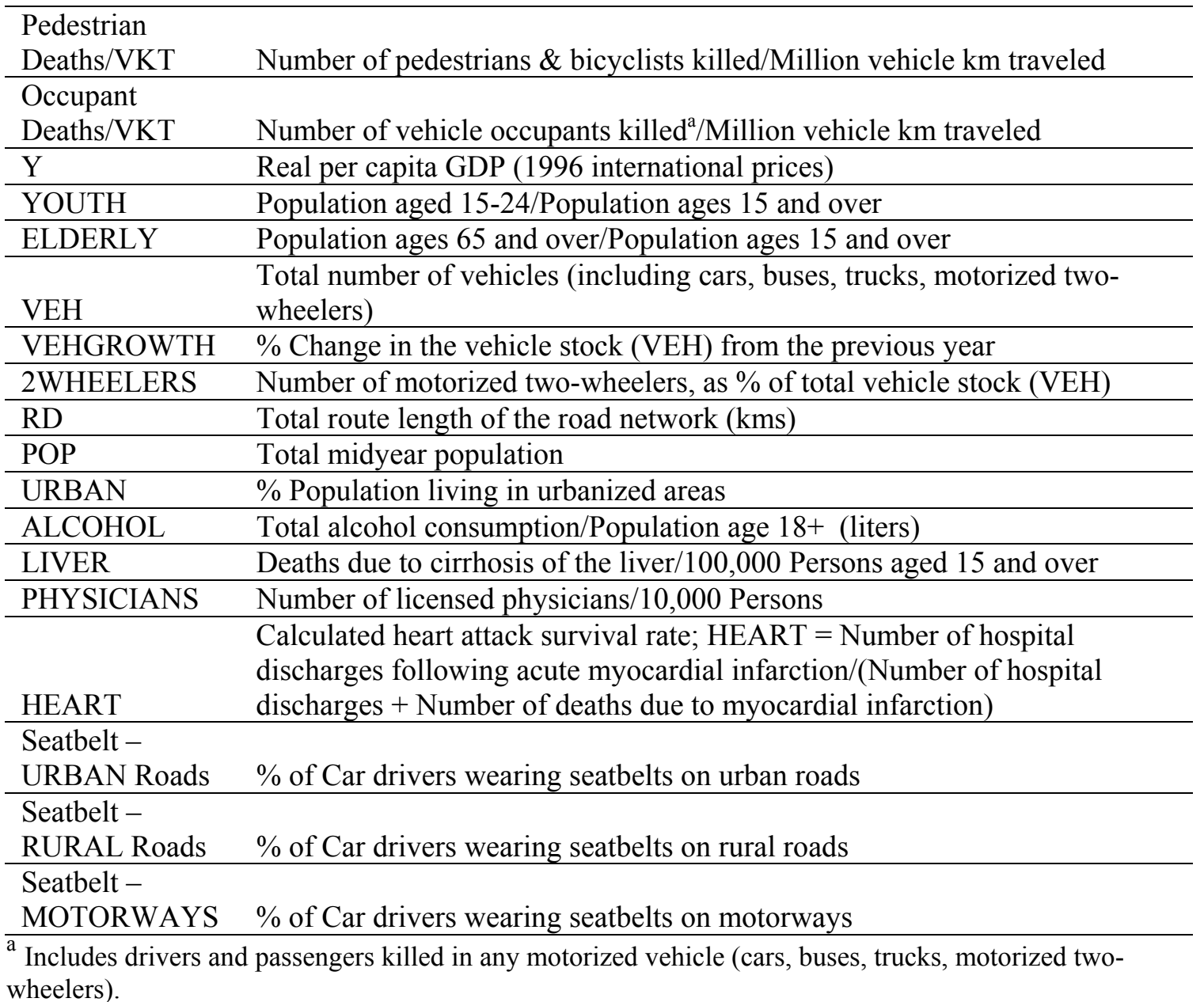


Table 3.5. Descriptive Statistics

\begin{tabular}{|c|c|c|c|c|c|}
\hline Variable & $\mathrm{N}$ & Mean & Std. Dev. & Minimum & Maximum \\
\hline \multicolumn{6}{|l|}{ Income-Only Sample: } \\
\hline Total Road Deaths & 830 & 5453.396 & 9309.744 & 10 & 54589 \\
\hline Pedestrian Deaths & 830 & 1474.543 & 2095.169 & 1 & 10243 \\
\hline Vehicle Occupant Deaths & 830 & 3978.849 & 7515.317 & 7 & 44399 \\
\hline \multicolumn{6}{|l|}{ Vehicle-Kilometers Traveled } \\
\hline Pedestrian Deaths/VKT & 830 & 0.0150 & 0.0254 & 0.0005 & 0.2867 \\
\hline Occupant Deaths/VKT & 830 & 0.0277 & 0.0289 & 0.0036 & 0.2561 \\
\hline \multicolumn{6}{|l|}{ Real per capita GDP } \\
\hline Year & 830 & 1986.434 & 9.799 & 1963 & 2002 \\
\hline \multicolumn{6}{|l|}{ Number of countries: } \\
\hline \multicolumn{6}{|c|}{ Base Sample (Models 1-3 in Tables 3.X-3.X): } \\
\hline Pedestrian Deaths & 680 & 1534.712 & 2172.096 & 1 & 10243 \\
\hline Vehicle Occupant Deaths & 680 & 4132.106 & 7739.631 & 7 & 44399 \\
\hline VKT (millions) & 680 & 254771.4 & 637936.8 & 1185 & 4478154 \\
\hline Pedestrian Deaths/VKT & 680 & 0.0143 & 0.0270 & 0.0005 & 0.2867 \\
\hline Occupant Deaths/VKT & 680 & 0.0260 & 0.0297 & 0.0036 & 0.2561 \\
\hline $\begin{array}{l}\text { Real per capita GDP } \\
(1996 \text { int'1\$) }\end{array}$ & 680 & 17559.22 & 5522.279 & 4552.19 & 43989.44 \\
\hline YOUTH & 680 & 0.1954 & 0.0326 & 0.1309 & 0.3226 \\
\hline ELDERLY & 680 & 0.1633 & 0.0281 & 0.0642 & 0.2169 \\
\hline VEH & 680 & $1.82 \mathrm{E}+07$ & $3.70 \mathrm{E}+07$ & 88000 & $2.21 \mathrm{E}+08$ \\
\hline $\mathrm{RD}(\mathrm{kms})$ & 680 & 522180 & 1242434 & 4447 & 6354229 \\
\hline VEHGROWTH & 680 & 0.0354 & 0.0359 & -0.1211 & 0.3069 \\
\hline POP & 680 & $3.50 \mathrm{e}+07$ & $5.34 \mathrm{e}+07$ & 227000 & $2.85 \mathrm{e}+08$ \\
\hline URBAN (\%) & 680 & 75.0110 & 12.2654 & 23.9000 & 97.3937 \\
\hline Year & 680 & 1987.246 & 9.150 & 1964 & 2002 \\
\hline Number of countries: & 32 & & & & \\
\hline \multicolumn{6}{|l|}{ Other Variables: } \\
\hline ALCOHOL & 581 & 10.67833 & 3.707288 & .6305346 & 21.66784 \\
\hline Countries (Model 4): & 30 & & & & \\
\hline LIVER & 515 & 19.13813 & 14.78251 & .5025126 & 102.9524 \\
\hline Countries (Model 5): & 30 & & & & \\
\hline PHYSICIANS & 536 & 68.02888 & 122.5449 & .397 & 763.519 \\
\hline Countries (Model 6): & 29 & & & & \\
\hline HEART & 181 & 0.6370562 & 0.0661428 & 0.486651 & 0.8059888 \\
\hline Countries (Model 7): & 23 & & & & \\
\hline 2WHEELERS (\%) & 613 & 12.84394 & 11.20714 & 0.6600004 & 60.61508 \\
\hline Countries (Model 8): & 31 & & & & \\
\hline Seatbelt-URBAN Roads (\%) & 261 & 63.82623 & 23.2948 & 3 & 97 \\
\hline Countries (Model 12): & 20 & & & & \\
\hline Seatbelt- RURAL Roads (\%) & 198 & 74.23889 & 19.41811 & 6 & 97 \\
\hline Countries (Model 13): & 16 & & & & \\
\hline Seatbelt-MOTORWAYS(\%) & 191 & 77.2644 & 21.26288 & 12 & 99 \\
\hline Countries (Model 14): & 15 & & & & \\
\hline
\end{tabular}


Table 3.6. Correlation Coefficients Among Independent Variables

Base Sample (Models 1-3; 680 observations):

\begin{tabular}{|c|c|c|c|c|c|c|c|c|c|c|c|c|}
\hline & $\operatorname{Ln}(Y)$ & Ln(YOUTH) & $\begin{array}{l}\mathrm{Ln}(\mathrm{YOUT} \\
\mathrm{H}) * \operatorname{Ln}(\mathrm{Y})\end{array}$ & $\begin{array}{r}\operatorname{Ln}(\mathrm{ELDE} \\
\mathrm{RLY}) \\
\end{array}$ & $\begin{array}{r}\text { VEHGRO } \\
\text { WTH } \\
\end{array}$ & $\mathrm{Ln}(\mathrm{VEH})$ & $\mathrm{Ln}(\mathrm{RD})$ & $\mathrm{Ln}(\mathrm{VEH}) * \mathrm{t}$ & $\operatorname{Ln}(\mathrm{RD}) * \mathrm{t}$ & $\mathrm{t}$ & $\mathrm{Ln}(\mathrm{POP})$ & $\begin{array}{r}\operatorname{Ln}(\mathrm{URB} \\
\mathrm{AN}) \\
\end{array}$ \\
\hline $\operatorname{Ln}(\mathrm{Y})$ & 1 & & & & & & & & & & & \\
\hline Ln(YOUTH) & -0.5508 & 1 & & & & & & & & & & \\
\hline Ln(YOUTH)* & & & & & & & & & & & & \\
\hline $\operatorname{Ln}(Y)$ & -0.7328 & 0.9708 & 1 & & & & & & & & & \\
\hline Ln(ELDERLY) & 0.4066 & -0.7042 & -0.6785 & 1 & & & & & & & & \\
\hline VEHGROWTH & -0.4156 & 0.3561 & 0.3998 & -0.5166 & 1 & & & & & & & \\
\hline $\operatorname{Ln}(\mathrm{VEH})$ & 0.1094 & -0.1013 & -0.1112 & 0.0403 & -0.1142 & 1 & & & & & & \\
\hline $\operatorname{Ln}(\mathrm{RD})$ & 0.0142 & 0.0225 & 0.0165 & -0.0226 & -0.1243 & 0.9191 & 1 & & & & & \\
\hline $\mathrm{Ln}(\mathrm{VEH}) * \mathrm{t}$ & 0.3915 & -0.4944 & -0.5219 & 0.2173 & -0.1742 & 0.2977 & 0.1611 & 1 & & & & \\
\hline $\mathrm{Ln}(\mathrm{RD}) * \mathrm{t}$ & 0.3756 & -0.4717 & -0.4987 & 0.2102 & -0.1927 & 0.326 & 0.2386 & 0.9897 & 1 & & & \\
\hline $\mathrm{T}$ & 0.383 & -0.4775 & -0.5067 & 0.2012 & -0.1506 & 0.0256 & -0.0942 & 0.957 & 0.9367 & 1 & & \\
\hline $\operatorname{Ln}(\mathrm{POP})$ & -0.1371 & 0.0385 & 0.0703 & -0.1106 & 0.0441 & 0.9588 & 0.8973 & 0.2086 & 0.2393 & -0.0583 & 1 & \\
\hline Ln(URBAN) & 0.4493 & -0.1193 & -0.2241 & 0.0914 & -0.2874 & 0.0974 & 0.035 & 0.1622 & 0.1517 & 0.1553 & -0.0082 & 1 \\
\hline
\end{tabular}

Other Variables (Number of observations vary according to model):

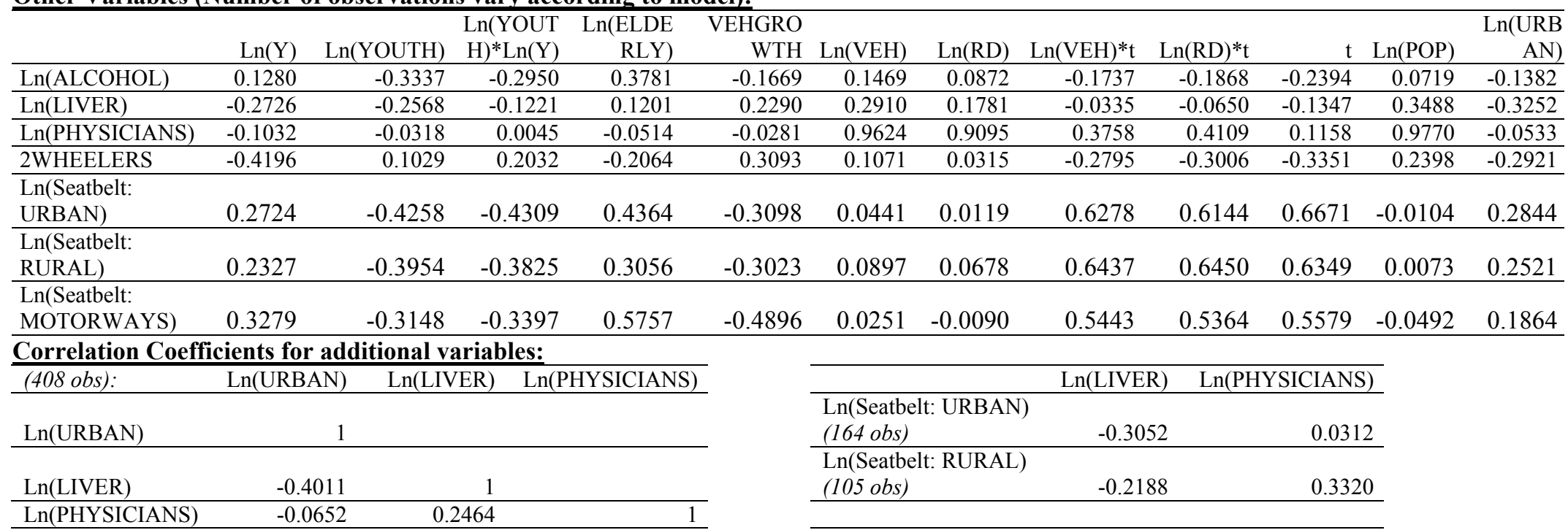


Table 3.7. Results for Occupant Fatalities/VKT Models - No Seatbelt Usage

\begin{tabular}{|c|c|c|c|c|c|c|c|}
\hline & 1 (Base & & & & & & \\
\hline & Model) & 2 & 3 & 4 & 5 & 6 & 7 \\
\hline $\operatorname{Ln}(Y)$ & $-2.144 * * *$ & $-2.136^{* * *}$ & $-2.158 * * *$ & $-2.299 * * *$ & $-2.718 * * *$ & $-2.506 * * *$ & -1.776 \\
\hline $\operatorname{Ln}(1)$ & $(0.635)$ & $(0.639)$ & $(0.642)$ & $(0.604)$ & $(0.727)$ & $(0.731)$ & $(2.181)$ \\
\hline & $13.220 * * *$ & $13.181 * * *$ & $13.279 * * *$ & $13.891 * * *$ & $15.850 * * *$ & $15.186^{* * *}$ & 14.652 \\
\hline Ln(YOUTH) & $(3.526)$ & $(3.543)$ & $(3.558)$ & $(3.481)$ & $(3.991)$ & $(4.022)$ & $(12.565)$ \\
\hline Ln(YOUTH) & $-1.297 * * *$ & $-1.293 * * *$ & $-1.304 * * *$ & $-1.364 * * *$ & $-1.542 * * *$ & $-1.489 * * *$ & -1.364 \\
\hline$* \ln (\mathrm{Y})$ & $(0.355)$ & $(0.357)$ & $(0.359)$ & $(0.353)$ & $(0.403)$ & $(0.405)$ & $(1.272)$ \\
\hline Jn(VFH) & $0.365 * * *$ & $0.360 * * *$ & $0.382 * *$ & 0.272 & 0.250 & $0.461 * * *$ & $0.543 * * *$ \\
\hline Ln(VEH) & $(0.129)$ & $(0.140)$ & $(0.167)$ & $(0.182)$ & $(0.194)$ & $(0.140)$ & $(0.200)$ \\
\hline & $-0.391 * *$ & $-0.390 * *$ & $-0.388 * *$ & $-0.372 *$ & $-0.728 * *$ & -0.260 & -1.211 \\
\hline $\operatorname{Ln}(\mathrm{RD})$ & $(0.155)$ & $(0.156)$ & $(0.156)$ & $(0.225)$ & $(0.285)$ & $(0.168)$ & $(0.944)$ \\
\hline & $-0.012 * * *$ & $-0.012 * * *$ & $-0.012 * * *$ & $-0.009 * * *$ & $-0.010 * * *$ & $-0.012 * * *$ & $-0.011^{*}$ \\
\hline $\operatorname{Ln}(V E H)^{*} t$ & $(0.002)$ & $(0.002)$ & $(0.002)$ & $(0.003)$ & $(0.003)$ & $(0.003)$ & $(0.006)$ \\
\hline $\mathrm{Ln}(\mathrm{RD}) * \mathrm{t}$ & $0.013 * * *$ & $0.012 * * *$ & $0.013 * * *$ & $0.010 * * *$ & $0.011 * * *$ & $0.013 * * *$ & $0.014 * *$ \\
\hline $\operatorname{Ln}(\mathrm{R} D) \cdots$ & $(0.002)$ & $(0.002)$ & $(0.002)$ & $(0.004)$ & $(0.004)$ & $(0.002)$ & $(0.005)$ \\
\hline & -0.015 & -0.015 & -0.014 & -0.028 & -0.015 & -0.010 & -0.032 \\
\hline $\mathrm{T}$ & $(0.014)$ & $(0.014)$ & $(0.015)$ & $(0.018)$ & $(0.021)$ & $(0.020)$ & $(0.046)$ \\
\hline VEHGROWTH & $0.609 * *$ & $0.610 * *$ & $0.587 * *$ & 0.644 & $1.039 * *$ & 0.250 & $1.271 * * *$ \\
\hline VEFUKUW & $(0.301)$ & $(0.305)$ & $(0.278)$ & $(0.420)$ & $(0.452)$ & $(0.304)$ & $(0.451)$ \\
\hline & 0.065 & 0.063 & 0.061 & 0.137 & 0.286 & -0.088 & -0.738 \\
\hline Ln(ELDERLY) & $(0.215)$ & $(0.208)$ & $(0.220)$ & $(0.244)$ & $(0.383)$ & $(0.239)$ & $(0.651)$ \\
\hline Ln(POP) & & 0.049 & & & & & \\
\hline Ln(PUP) & & $(0.331)$ & & & & & \\
\hline Ln(URBAN) & & & -0.091 & & & & \\
\hline Ln(UKBAN) & & & $(0.346)$ & & & & \\
\hline Ln(ALCOHOL) & & & & 0.008 & & & \\
\hline & & & & $(0.095)$ & & & \\
\hline Ln(LIVER) & & & & & $0.101 *$ & & \\
\hline & & & & & $(0.053)$ & $-0303 *$ & \\
\hline Ln(PHYSICIANS) & & & & & & $(0.167)$ & \\
\hline In(HEART) & & & & & & & -1.016 \\
\hline & & & & & & & $(0.633)$ \\
\hline & $18.134 * * *$ & $17.327 * *$ & $18.345 * * *$ & $20.991 * * *$ & $29.848 * * *$ & $19.262 * * *$ & 20.797 \\
\hline Constant & $(5.933)$ & $(7.829)$ & $(5.913)$ & $(7.540)$ & $(9.667)$ & $(6.849)$ & $(19.554)$ \\
\hline Adj. R-squared & 0.9602 & 0.9601 & 0.9601 & 0.9609 & 0.9543 & 0.9630 & 0.9733 \\
\hline Observations & 680 & 680 & 680 & 581 & 515 & 537 & 181 \\
\hline Countries & 32 & 32 & 32 & 30 & 30 & 29 & 23 \\
\hline Elasticity with & -0.008 & -0.009 & -0.011 & -0.054 & -0.180 & -0.056 & 0.469 \\
\hline respect to $\mathrm{Y}^{\mathrm{a}}$ : & $(0.129)$ & $(0.129)$ & $(0.130)$ & $(0.135)$ & $(0.133)$ & $(0.112)$ & $(0.396)$ \\
\hline Elasticity with & & & & & & & \\
\hline respect to YOUTH & $0.610 * *$ & $0.619 * *$ & $0.608 * *$ & $0.635 * *$ & $0.864 * * *$ & $0.717 * * *$ & $1.397 * *$ \\
\hline & $(0.257)$ & $(0.259)$ & $(0.258)$ & $(0.289)$ & $(0.291)$ & $(0.256)$ & $(0.710)$ \\
\hline
\end{tabular}

*** Indicates $1 \%$ level of significance ** Indicates $5 \%$ level of significance

* Indicates $10 \%$ level of significance

${ }^{a}$ Elasticities are evaluated at mean $\ln (\mathrm{Y})$ and $\ln (\mathrm{YOUTH})$ of base model sample: $\mathrm{Y}=\$ 16,630$ (1996 Int'l dollars), YOUTH $=0.1928$. For example, in Model 1, the income elasticity of the occupant fatality rate $=$ $\partial \ln ($ Occupant fatalities $/ \mathrm{VKT}) / \partial \ln (\mathrm{Y})=-2.144-1.297 *(\ln (0.192781))=-0.008$. 
(Table 3.7. continued)

\begin{tabular}{|c|c|c|c|c|c|}
\hline & $\begin{array}{l}1 \text { (Base } \\
\text { Model) }\end{array}$ & 8 & 9 & 10 & 11 \\
\hline $\operatorname{Ln}(\mathrm{Y})$ & $\begin{array}{c}-2.144 * * * \\
(0.635)\end{array}$ & $\begin{array}{c}-2.055^{* * *} \\
(0.670)\end{array}$ & $\begin{array}{c}-2.713 * * * \\
(0.734) \\
\end{array}$ & $\begin{array}{c}-3.587 * * * \\
(0.713) \\
\end{array}$ & $\begin{array}{c}-3.579 * * * \\
(0.719) \\
\end{array}$ \\
\hline Ln(YOUTH) & $\begin{array}{c}13.220^{* * *} \\
(3.526)\end{array}$ & $\begin{array}{c}12.746^{* * *} \\
(3.717)\end{array}$ & $\begin{array}{c}15.833 * * * \\
(4.019)\end{array}$ & $\begin{array}{c}20.531 * * * \\
(3.948)\end{array}$ & $\begin{array}{c}20.500 * * * \\
(4.003)\end{array}$ \\
\hline $\begin{array}{l}\text { Ln(YOUTH) } \\
* \ln (Y)\end{array}$ & $\begin{array}{c}-1.297 * * * \\
(0.355)\end{array}$ & $\begin{array}{c}-1.234 * * * \\
(0.378)\end{array}$ & $\begin{array}{c}-1.540 * * * \\
(0.406)\end{array}$ & $\begin{array}{c}-2.014 * * * \\
(0.391)\end{array}$ & $\begin{array}{c}-2.009 * * * \\
(0.397)\end{array}$ \\
\hline $\operatorname{Ln}(\mathrm{VEH})$ & $\begin{array}{c}0.365^{* * *} \\
(0.129)\end{array}$ & $\begin{array}{c}0.370^{* *} \\
(0.161) \\
\end{array}$ & $\begin{array}{c}0.232 \\
(0.229) \\
\end{array}$ & $\begin{array}{c}0.473 * * * \\
(0.160)\end{array}$ & $\begin{array}{c}0.425^{* *} \\
(0.205) \\
\end{array}$ \\
\hline $\operatorname{Ln}(\mathrm{RD})$ & $\begin{array}{c}-0.391 * * \\
(0.155) \\
\end{array}$ & $\begin{array}{c}-0.416^{* *} \\
(0.174) \\
\end{array}$ & $\begin{array}{c}-0.719 * * \\
(0.308) \\
\end{array}$ & $\begin{array}{c}-0.711^{* *} \\
(0.336) \\
\end{array}$ & $\begin{array}{c}-0.697 * * \\
(0.345) \\
\end{array}$ \\
\hline $\operatorname{Ln}(\mathrm{VEH}) * \mathrm{t}$ & $\begin{array}{c}-0.012 * * * \\
(0.002)\end{array}$ & $\begin{array}{c}-0.011 * * * \\
(0.002)\end{array}$ & $\begin{array}{c}-0.010^{* * * *} \\
(0.003)\end{array}$ & $\begin{array}{c}-0.013^{* * *} \\
(0.004)\end{array}$ & $\begin{array}{c}-0.013 * * * \\
(0.004)\end{array}$ \\
\hline $\operatorname{Ln}(\mathrm{RD}) * \mathrm{t}$ & $\begin{array}{c}0.013 * * * \\
(0.002)\end{array}$ & $\begin{array}{c}0.012 * * * \\
(0.002)\end{array}$ & $\begin{array}{c}0.011^{* * *} \\
(0.004)\end{array}$ & $\begin{array}{c}0.015^{* * *} \\
(0.004)\end{array}$ & $\begin{array}{c}0.015^{* * * *} \\
(0.004)\end{array}$ \\
\hline $\mathrm{T}$ & $\begin{array}{l}-0.015 \\
(0.014) \\
\end{array}$ & $\begin{array}{l}-0.020 \\
(0.015) \\
\end{array}$ & $\begin{array}{l}-0.017 \\
(0.023) \\
\end{array}$ & $\begin{array}{l}-0.011 \\
(0.017) \\
\end{array}$ & $\begin{array}{l}-0.018 \\
(0.019) \\
\end{array}$ \\
\hline VEHGROWTH & $\begin{array}{c}0.609 * * \\
(0.301)\end{array}$ & $\begin{array}{l}0.491^{*} \\
(0.288) \\
\end{array}$ & $\begin{array}{c}1.059 * * * \\
(0.388)\end{array}$ & $\begin{array}{c}0.525 \\
(0.454) \\
\end{array}$ & $\begin{array}{c}0.593 \\
(0.398) \\
\end{array}$ \\
\hline Ln(ELDERLY) & $\begin{array}{c}0.065 \\
(0.215)\end{array}$ & $\begin{array}{l}-0.108 \\
(0.214)\end{array}$ & $\begin{array}{c}0.290 \\
(0.385)\end{array}$ & $\begin{array}{l}-0.036 \\
(0.305)\end{array}$ & $\begin{array}{l}-0.040 \\
(0.285)\end{array}$ \\
\hline Ln(URBAN) & & & $\begin{array}{c}0.137 \\
(0.783)\end{array}$ & & $\begin{array}{c}0.394 \\
(0.712)\end{array}$ \\
\hline Ln(LIVER) & & & $\begin{array}{c}0.099 * * \\
(0.050)\end{array}$ & $\begin{array}{c}0.113 * * \\
(0.047)\end{array}$ & $\begin{array}{l}0.109^{* *} \\
(0.048)\end{array}$ \\
\hline Ln(PHYSICIANS) & & & & $\begin{array}{l}-0.267 \\
(0.168) \\
\end{array}$ & $\begin{array}{l}-0.238 \\
(0.162) \\
\end{array}$ \\
\hline 2WHEELERS & & $\begin{array}{c}0.001 \\
(0.004) \\
\end{array}$ & & & \\
\hline Constant & $\begin{array}{c}18.134 * * * \\
(5.933)\end{array}$ & $\begin{array}{c}17.271 * * * \\
(6.048)\end{array}$ & $\begin{array}{c}29.392 * * * \\
(10.489)\end{array}$ & $\begin{array}{c}34.847 * * * \\
(10.712)\end{array}$ & $\begin{array}{c}33.623 * * * \\
(11.092)\end{array}$ \\
\hline Adj. R-squared & 0.9602 & 0.9624 & 0.9542 & 0.9606 & 0.9606 \\
\hline Observations & 680 & 613 & 515 & 408 & 408 \\
\hline Countries & 32 & 31 & 30 & 26 & 26 \\
\hline $\begin{array}{l}\text { Elasticity with } \\
\text { respect to } \mathrm{Y}^{\mathrm{a}} \text { : }\end{array}$ & $\begin{array}{l}-0.008 \\
(0.129)\end{array}$ & $\begin{array}{l}-0.024 \\
(0.126)\end{array}$ & $\begin{array}{l}-0.179 \\
(0.136)\end{array}$ & $\begin{array}{c}-0.272 * * \\
(0.112)\end{array}$ & $\begin{array}{c}-0.273 * * \\
(0.113)\end{array}$ \\
\hline $\begin{array}{l}\text { Elasticity with } \\
\text { respect to } \\
\text { YOUTH }^{\text {a }} \text { : }\end{array}$ & $\begin{array}{c}0.610^{* * *} \\
(0.257)\end{array}$ & $\begin{array}{c}0.751 * * * \\
(0.226)\end{array}$ & $\begin{array}{c}0.870 * * * \\
(0.299)\end{array}$ & $\begin{array}{c}0.959 * * * \\
(0.315)\end{array}$ & $\begin{array}{c}0.979 * * * \\
(0.322)\end{array}$ \\
\hline
\end{tabular}

*** Indicates $1 \%$ level of significance ** Indicates $5 \%$ level of significance

* Indicates $10 \%$ level of significance.

${ }^{a}$ Elasticities are evaluated at mean $\ln (\mathrm{Y})$ and $\ln (\mathrm{YOUTH})$ of base model sample: $\mathrm{Y}=\$ 16,630$ (1996 Int'l dollars), YOUTH $=0.1928$. 
Table 3.8. Results for Occupant Fatalities/VKT Models - Seatbelt Usage

\begin{tabular}{|c|c|c|c|c|c|c|c|}
\hline & $\begin{array}{l}1 \text { (Base } \\
\text { Model) }\end{array}$ & $\begin{array}{l}12 \text { (Base, } \\
\text { excl. } \\
\text { 2wheeler } \\
\text { deaths) }\end{array}$ & 13 & 14 & 15 & 16 & 17 \\
\hline $\operatorname{Ln}(Y)$ & $\begin{array}{c}-2.144 * * * \\
(0.635)\end{array}$ & $\begin{array}{c}-1.903 * * * \\
(0.624)\end{array}$ & $\begin{array}{l}-1.966^{*} \\
(1.022) \\
\end{array}$ & $\begin{array}{l}-1.157 \\
(1.039) \\
\end{array}$ & $\begin{array}{c}0.282 \\
(1.600) \\
\end{array}$ & $\begin{array}{l}-1.719 \\
(1.510) \\
\end{array}$ & $\begin{array}{l}-1.142 \\
(1.656) \\
\end{array}$ \\
\hline Ln(YOUTH) & $\begin{array}{c}13.220^{* * * *} \\
(3.526)\end{array}$ & $\begin{array}{c}11.943^{* * *} \\
(3.981)\end{array}$ & $\begin{array}{c}14.396^{* * *} \\
(6.718)\end{array}$ & $\begin{array}{l}10.94^{*} \\
(6.152)\end{array}$ & $\begin{array}{c}2.299 \\
(9.825)\end{array}$ & $\begin{array}{l}11.038 \\
(9.224) \\
\end{array}$ & $\begin{array}{c}9.221 \\
(9.604)\end{array}$ \\
\hline $\begin{array}{l}\operatorname{Ln}(\text { YOUTH }) \\
* \ln (Y)\end{array}$ & $\begin{array}{c}-1.297 * * * \\
(0.355) \\
\end{array}$ & $\begin{array}{c}-1.156^{* * *} \\
(0.400)\end{array}$ & $\begin{array}{c}-1.380^{* * *} \\
(0.677) \\
\end{array}$ & $\begin{array}{l}-1.035^{*} \\
(0.630) \\
\end{array}$ & $\begin{array}{l}-0.165 \\
(0.970) \\
\end{array}$ & $\begin{array}{l}-1.103 \\
(0.922) \\
\end{array}$ & $\begin{array}{l}-0.916 \\
(0.972) \\
\end{array}$ \\
\hline $\operatorname{Ln}(\mathrm{VEH})$ & $\begin{array}{c}0.365 * * * \\
(0.129)\end{array}$ & $\begin{array}{c}0.215 \\
(0.146)\end{array}$ & $\begin{array}{c}0.241 \\
(0.316)\end{array}$ & $\begin{array}{c}0.222 \\
(0.302)\end{array}$ & $\begin{array}{c}0.252 \\
(0.400)\end{array}$ & $\begin{array}{c}0.274 \\
(0.261)\end{array}$ & $\begin{array}{c}0.214 \\
(0.331)\end{array}$ \\
\hline $\mathrm{Ln}(\mathrm{RD})$ & $\begin{array}{c}-0.391 * * \\
(0.155) \\
\end{array}$ & $\begin{array}{c}-0.377 * * \\
(0.153) \\
\end{array}$ & $\begin{array}{l}-0.788^{*} \\
(0.409) \\
\end{array}$ & $\begin{array}{c}-0.837 * * \\
(0.404) \\
\end{array}$ & $\begin{array}{l}-0.177 \\
(0.437) \\
\end{array}$ & $\begin{array}{l}-0.817^{*} \\
(0.480) \\
\end{array}$ & $\begin{array}{l}-0.845^{*} \\
(0.465) \\
\end{array}$ \\
\hline $\operatorname{Ln}(\mathrm{VEH}) * \mathrm{t}$ & $\begin{array}{c}-0.012 * * * \\
(0.002)\end{array}$ & $\begin{array}{c}-0.011 * * * \\
(0.002)\end{array}$ & $\begin{array}{c}-0.010 * * \\
(0.004)\end{array}$ & $\begin{array}{c}-0.010 * * \\
(0.004)\end{array}$ & $\begin{array}{l}-0.006 \\
(0.005)\end{array}$ & $\begin{array}{c}-0.015 * * \\
(0.006)\end{array}$ & $\begin{array}{c}-0.014 * * \\
(0.007)\end{array}$ \\
\hline $\operatorname{Ln}(\mathrm{RD}) * \mathrm{t}$ & $\begin{array}{c}0.013 * * * \\
(0.002)\end{array}$ & $\begin{array}{c}0.010 * * * \\
(0.002)\end{array}$ & $\begin{array}{l}0.010^{* *} \\
(0.004)\end{array}$ & $\begin{array}{c}0.011^{* *} \\
(0.004)\end{array}$ & $\begin{array}{c}0.010 \\
(0.006)\end{array}$ & $\begin{array}{c}0.014^{* *} \\
(0.006)\end{array}$ & $\begin{array}{c}0.014 * * \\
(0.007)\end{array}$ \\
\hline $\mathrm{T}$ & $\begin{array}{l}-0.015 \\
(0.014) \\
\end{array}$ & $\begin{array}{c}0.008 \\
(0.014) \\
\end{array}$ & $\begin{array}{l}-0.012 \\
(0.022)\end{array}$ & $\begin{array}{l}-0.027 \\
(0.024) \\
\end{array}$ & $\begin{array}{l}-0.084 * \\
(0.051) \\
\end{array}$ & $\begin{array}{c}0.021 \\
(0.025) \\
\end{array}$ & $\begin{array}{c}0.002 \\
(0.038) \\
\end{array}$ \\
\hline VEHGROWTH & $\begin{array}{l}0.609^{* *} \\
(0.301) \\
\end{array}$ & $\begin{array}{l}0.697 * * \\
(0.316) \\
\end{array}$ & $\begin{array}{l}0.778^{*} \\
(0.430) \\
\end{array}$ & $\begin{array}{l}0.936^{*} \\
(0.535) \\
\end{array}$ & $\begin{array}{c}0.882 \\
(0.738) \\
\end{array}$ & $\begin{array}{l}-0.145 \\
(0.489) \\
\end{array}$ & $\begin{array}{l}-0.015 \\
(0.414) \\
\end{array}$ \\
\hline Ln(ELDERLY) & $\begin{array}{c}0.065 \\
(0.215) \\
\end{array}$ & $\begin{array}{c}0.143 \\
(0.193) \\
\end{array}$ & $\begin{array}{c}0.349 \\
(0.267) \\
\end{array}$ & $\begin{array}{c}0.376 \\
(0.247) \\
\end{array}$ & $\begin{array}{c}0.426 \\
(0.361) \\
\end{array}$ & $\begin{array}{c}0.868 \\
(0.544) \\
\end{array}$ & $\begin{array}{c}0.958 \\
(0.608) \\
\end{array}$ \\
\hline Ln(LIVER) & & & & & $\begin{array}{c}0.079 \\
(0.077) \\
\end{array}$ & & \\
\hline $\operatorname{Ln}(\mathrm{URBAN})$ & & & & $\begin{array}{c}1.158 \\
(0.839)\end{array}$ & $\begin{array}{c}3.024 * * * \\
(1.137)\end{array}$ & & $\begin{array}{c}0.877 \\
(1.249)\end{array}$ \\
\hline \multicolumn{8}{|c|}{ Ln(Seatbelt wearing rates): } \\
\hline Urban roads & & & $\begin{array}{l}-0.045 \\
(0.028) \\
\end{array}$ & $\begin{array}{c}-0.053^{*} \\
(0.028) \\
\end{array}$ & $\begin{array}{l}-0.057^{*} \\
(0.033) \\
\end{array}$ & & \\
\hline Rural roads & & & & & & $\begin{array}{c}-0.113^{* * * *} \\
(0.021)\end{array}$ & $\begin{array}{c}-0.111^{* * * *} \\
(0.021)\end{array}$ \\
\hline \multicolumn{8}{|l|}{ Motorways } \\
\hline Constant & $\begin{array}{c}18.134 * * * \\
(5.933)\end{array}$ & $\begin{array}{c}17.785^{* * *} \\
(6.272)\end{array}$ & $\begin{array}{l}23.978^{* *} \\
(10.957)\end{array}$ & $\begin{array}{c}12.125 \\
(11.463)\end{array}$ & $\begin{array}{l}-18.730 \\
(25.101)\end{array}$ & $\begin{array}{c}21.475 \\
(14.659) \\
\end{array}$ & $\begin{array}{c}13.679 \\
(16.575)\end{array}$ \\
\hline Adj. R-squared & 0.9602 & 0.9480 & 0.9700 & 0.9712 & 0.9692 & 0.9661 & 0.9666 \\
\hline Observations & 680 & 636 & 261 & 261 & 180 & 198 & 198 \\
\hline Countries & 32 & 30 & 20 & 20 & 16 & 16 & 16 \\
\hline $\begin{array}{l}\text { Elasticity with } \\
\text { respect to } \mathrm{Y}^{\mathrm{a}} \text { : }\end{array}$ & $\begin{array}{l}-0.008 \\
(0.129) \\
\end{array}$ & $\begin{array}{c}0.000 \\
(0.155) \\
\end{array}$ & $\begin{array}{c}0.306 \\
(0.235) \\
\end{array}$ & $\begin{array}{c}0.547 * * \\
(0.237) \\
\end{array}$ & $\begin{array}{c}0.553 * * \\
(0.282) \\
\end{array}$ & $\begin{array}{c}0.097 \\
(0.193) \\
\end{array}$ & $\begin{array}{c}0.366 \\
(0.394) \\
\end{array}$ \\
\hline $\begin{array}{l}\text { Elasticity with } \\
\text { respect to YOUTH } \\
\text { a: }\end{array}$ & $\begin{array}{l}0.610^{* *} \\
(0.257)\end{array}$ & $\begin{array}{c}0.707 * * \\
(0.311)\end{array}$ & $\begin{array}{c}0.983 * * \\
(0.385)\end{array}$ & $\begin{array}{c}0.882 * * * \\
(0.296)\end{array}$ & $\begin{array}{c}0.695 \\
(0.460)\end{array}$ & $\begin{array}{c}0.321 \\
(0.724)\end{array}$ & $\begin{array}{c}0.320 \\
(0.693)\end{array}$ \\
\hline $\begin{array}{l}\text { Elasticity with } \\
\text { respect to } \mathrm{Y}^{\mathrm{b}} \text { : }\end{array}$ & $\begin{array}{c}0.101 \\
(0.124) \\
\end{array}$ & $\begin{array}{c}0.097 \\
(0.169) \\
\end{array}$ & $\begin{array}{c}0.422 \\
(0.267) \\
\end{array}$ & $\begin{array}{c}0.634 * * \\
(0.248) \\
\end{array}$ & $\begin{array}{l}0.567^{*} \\
(0.299) \\
\end{array}$ & $\begin{array}{c}0.119 \\
(0.687) \\
\end{array}$ & $\begin{array}{c}0.443 \\
(0.401) \\
\end{array}$ \\
\hline $\begin{array}{l}\text { Elasticity with } \\
\text { respect to YOUTH } \\
\text { b: }\end{array}$ & $\begin{array}{c}0.372 \\
(0.248) \\
\end{array}$ & $\begin{array}{l}0.494^{*} \\
(0.299)\end{array}$ & $\begin{array}{l}0.730 * * \\
(0.365)\end{array}$ & $\begin{array}{c}0.692 * * \\
(0.308)\end{array}$ & $\begin{array}{l}0.665^{* *} \\
(0.319)\end{array}$ & $\begin{array}{c}0.189 \\
(0.215)\end{array}$ & $\begin{array}{c}0.152 \\
(0.682)\end{array}$ \\
\hline \multicolumn{8}{|c|}{$\begin{array}{l}* * \text { Indicates } 1 \% \text { level of significance ** Indicates } 5 \% \text { level of significance } \\
\text { Indicates } 10 \% \text { level of significance } \\
\text { Elasticities are evaluated at mean } \ln (\mathrm{Y}) \text { and } \ln (\mathrm{YOUTH}) \text { of base model sample: } \mathrm{Y}=\$ 16,630 \text { (1996 Int'l dollars), } \\
\text { YOUTH }=0.1928 . \\
\text { Elasticities are evaluated at mean } \ln (\mathrm{Y}) \text { and } \ln (\mathrm{YOUTH}) \text { of model } \# 9 \text { sample: } \mathrm{Y}=\$ 19,980 \text { (1996 Int'l dollars), } \\
\text { YOUTH }=0.1777 .\end{array}$} \\
\hline
\end{tabular}


(Table 3.8. Continued)

\begin{tabular}{|c|c|c|c|c|c|c|}
\hline & $\begin{array}{l}1 \text { (Base } \\
\text { Model) }\end{array}$ & $\begin{array}{l}12 \text { (Base, } \\
\text { excl. } \\
\text { 2wheeler } \\
\text { deaths) }\end{array}$ & 18 & 19 & 20 & 21 \\
\hline $\operatorname{Ln}(Y)$ & $\begin{array}{c}-2.144 * * * \\
(0.635)\end{array}$ & $\begin{array}{c}-1.903^{* * *} \\
(0.624) \\
\end{array}$ & $\begin{array}{c}5.111^{* * *} \\
(1.892)\end{array}$ & $\begin{array}{l}-1.839 \\
(2.372) \\
\end{array}$ & $\begin{array}{c}-1.805^{* *} \\
(0.919) \\
\end{array}$ & $\begin{array}{l}-1.129 \\
(1.027) \\
\end{array}$ \\
\hline Ln(YOUTH) & $\begin{array}{c}13.220^{* * * *} \\
(3.526)\end{array}$ & $\begin{array}{c}11.943 * * * \\
(3.981)\end{array}$ & $\begin{array}{c}-29.149 * * \\
(12.995) \\
\end{array}$ & $\begin{array}{c}12.900 \\
(13.303)\end{array}$ & $\begin{array}{c}14.872 * * * \\
(5.499)\end{array}$ & $\begin{array}{l}12.545^{*} \\
(6.495) \\
\end{array}$ \\
\hline $\begin{array}{l}\mathrm{Ln}(\mathrm{YOUTH}) \\
* \ln (\mathrm{Y})\end{array}$ & $\begin{array}{c}-1.297 * * * \\
(0.355) \\
\end{array}$ & $\begin{array}{c}-1.156^{* * *} \\
(0.400)\end{array}$ & $\begin{array}{c}2.949 * * \\
(1.294) \\
\end{array}$ & $\begin{array}{c}-1.251 \\
(1.360) \\
\end{array}$ & $\begin{array}{c}-1.370 * * \\
(0.535) \\
\end{array}$ & $\begin{array}{l}-1.142 * \\
(0.635) \\
\end{array}$ \\
\hline $\operatorname{Ln}(\mathrm{VEH})$ & $\begin{array}{c}0.365^{* * *} \\
(0.129)\end{array}$ & $\begin{array}{c}0.215 \\
(0.146)\end{array}$ & $\begin{array}{c}0.243 \\
(0.274)\end{array}$ & $\begin{array}{l}0.582 * * \\
(0.234)\end{array}$ & $\begin{array}{l}-0.424 \\
(0.339)\end{array}$ & $\begin{array}{l}-0.357 \\
(0.390)\end{array}$ \\
\hline $\operatorname{Ln}(\mathrm{RD})$ & $\begin{array}{c}-0.391 * * \\
(0.155) \\
\end{array}$ & $\begin{array}{c}-0.377 * * \\
(0.153) \\
\end{array}$ & $\begin{array}{c}0.058 \\
(0.495) \\
\end{array}$ & $\begin{array}{l}-0.100 \\
(0.657) \\
\end{array}$ & $\begin{array}{l}-0.238 \\
(0.465) \\
\end{array}$ & $\begin{array}{l}-0.381 \\
(0.509) \\
\end{array}$ \\
\hline $\operatorname{Ln}(\mathrm{VEH}) * \mathrm{t}$ & $\begin{array}{c}-0.012 * * * \\
(0.002)\end{array}$ & $\begin{array}{c}-0.011 * * * \\
(0.002)\end{array}$ & $\begin{array}{c}-0.022 * * \\
(0.009) \\
\end{array}$ & $\begin{array}{l}-0.008 \\
(0.006) \\
\end{array}$ & $\begin{array}{c}0.000 \\
(0.007) \\
\end{array}$ & $\begin{array}{l}-0.003 \\
(0.009) \\
\end{array}$ \\
\hline $\operatorname{Ln}(\mathrm{RD}) * \mathrm{t}$ & $\begin{array}{c}0.013 * * * \\
(0.002)\end{array}$ & $\begin{array}{c}0.010 * * * \\
(0.002)\end{array}$ & $\begin{array}{c}0.017 * * \\
(0.007)\end{array}$ & $\begin{array}{c}0.003 \\
(0.007)\end{array}$ & $\begin{array}{l}-0.002 \\
(0.007)\end{array}$ & $\begin{array}{c}0.002 \\
(0.009)\end{array}$ \\
\hline $\mathrm{T}$ & $\begin{array}{l}-0.015 \\
(0.014) \\
\end{array}$ & $\begin{array}{c}0.008 \\
(0.014) \\
\end{array}$ & $\begin{array}{c}0.081 \\
(0.068) \\
\end{array}$ & $\begin{array}{c}0.037 \\
(0.044) \\
\end{array}$ & $\begin{array}{l}-0.014 \\
(0.030) \\
\end{array}$ & $\begin{array}{l}-0.013 \\
(0.034) \\
\end{array}$ \\
\hline VEHGROWTH & $\begin{array}{l}0.609^{* *} \\
(0.301) \\
\end{array}$ & $\begin{array}{c}0.697 * * \\
(0.316) \\
\end{array}$ & $\begin{array}{c}0.387 \\
(0.743) \\
\end{array}$ & $\begin{array}{c}0.337 \\
(0.483) \\
\end{array}$ & $\begin{array}{c}0.148 \\
(0.379) \\
\end{array}$ & $\begin{array}{c}0.261 \\
(0.368) \\
\end{array}$ \\
\hline Ln(ELDERLY) & $\begin{array}{c}0.065 \\
(0.215) \\
\end{array}$ & $\begin{array}{c}0.143 \\
(0.193) \\
\end{array}$ & $\begin{array}{c}0.701 \\
(0.457) \\
\end{array}$ & $\begin{array}{c}0.464 \\
(0.540) \\
\end{array}$ & $\begin{array}{l}0.498^{* *} \\
(0.237) \\
\end{array}$ & $\begin{array}{l}0.548^{* *} \\
(0.237) \\
\end{array}$ \\
\hline Ln(LIVER) & & & $\begin{array}{c}-0.128 \\
(0.110) \\
\end{array}$ & & & \\
\hline $\operatorname{Ln}(\mathrm{URBAN})$ & & & $\begin{array}{c}2.672 * * * \\
(0.735)\end{array}$ & $\begin{array}{c}0.422 \\
(0.525) \\
\end{array}$ & & $\begin{array}{l}1.122 * * \\
(0.540)\end{array}$ \\
\hline Ln(PHYSICIANS) & & & & $\begin{array}{c}-0.572 * * \\
(0.293)\end{array}$ & & \\
\hline \multicolumn{7}{|c|}{ Ln(Seatbelt wearing rates): } \\
\hline Rural roads & & & $\begin{array}{c}-0.142 * * * \\
(0.033)\end{array}$ & $\begin{array}{c}-0.104 * * * \\
(0.023)\end{array}$ & & \\
\hline Motorways & & & & & $\begin{array}{c}-0.082 * * \\
(0.035)\end{array}$ & $\begin{array}{c}-0.092^{* *} \\
(0.038)\end{array}$ \\
\hline Constant & $\begin{array}{c}18.134 * * * \\
(5.933)\end{array}$ & $\begin{array}{c}17.785^{* * * *} \\
(6.272)\end{array}$ & $\begin{array}{c}-67.054 * * * \\
(20.807)\end{array}$ & $\begin{array}{c}9.200 \\
(20.179) \\
\end{array}$ & $\begin{array}{c}27.383^{* * * *} \\
(9.882)\end{array}$ & $\begin{array}{c}16.786 \\
(10.563) \\
\end{array}$ \\
\hline Adj. R-squared & 0.9602 & 0.9480 & 0.9744 & 0.9724 & 0.9734 & 0.9744 \\
\hline Observations & 680 & 636 & 138 & 148 & 191 & 191 \\
\hline Countries & 32 & 30 & 14 & 15 & 15 & 15 \\
\hline $\begin{array}{l}\text { Elasticity with } \\
\text { respect to } \mathrm{Y}^{\mathrm{a}} \text { : }\end{array}$ & $\begin{array}{l}-0.008 \\
(0.129) \\
\end{array}$ & $\begin{array}{c}0.000 \\
(0.155)\end{array}$ & $\begin{array}{r}0.256 \\
(0.256) \\
\end{array}$ & $\begin{array}{c}0.220 \\
(0.189)\end{array}$ & $\begin{array}{c}0.450 \\
(0.310)\end{array}$ & $\begin{array}{l}0.751 * * \\
(0.315)\end{array}$ \\
\hline $\begin{array}{l}\text { Elasticity with } \\
\text { respect to } \\
\text { YOUTH }^{\text {a }} \text { : }\end{array}$ & $\begin{array}{c}0.610^{* *} \\
(0.257)\end{array}$ & $\begin{array}{c}0.707 * * \\
(0.311)\end{array}$ & $\begin{array}{l}-0.485 \\
(0.515)\end{array}$ & $\begin{array}{c}0.744 * * * \\
(0.243)\end{array}$ & $\begin{array}{c}1.560 * * * \\
(0.392)\end{array}$ & $\begin{array}{c}1.448 * * * \\
(0.370)\end{array}$ \\
\hline $\begin{array}{l}\text { Elasticity with } \\
\text { respect to } \mathrm{Y}^{\mathrm{b}} \text { : }\end{array}$ & $\begin{array}{c}0.101 \\
(0.124) \\
\end{array}$ & $\begin{array}{c}0.097 \\
(0.169) \\
\end{array}$ & $\begin{array}{r}0.008 \\
(0.360) \\
\end{array}$ & $\begin{array}{c}0.325^{* *} \\
(0.139) \\
\end{array}$ & $\begin{array}{l}0.565^{*} \\
(0.316) \\
\end{array}$ & $\begin{array}{c}0.847 * * \\
(0.330)\end{array}$ \\
\hline $\begin{array}{l}\text { Elasticity with } \\
\text { respect to } \\
\text { YOUTH }^{\text {b }} \text { : }\end{array}$ & $\begin{array}{c}0.372 \\
(0.248)\end{array}$ & $\begin{array}{l}0.494^{*} \\
(0.299)\end{array}$ & $\begin{array}{c}0.056 \\
(0.352)\end{array}$ & $\begin{array}{c}0.515 * * \\
(0.279)\end{array}$ & $\begin{array}{c}1.309 * * * \\
(0.323)\end{array}$ & $\begin{array}{c}1.239 * * * \\
(0.273)\end{array}$ \\
\hline
\end{tabular}

*** Indicates $1 \%$ level of significance ** Indicates $5 \%$ level of significance

* Indicates $10 \%$ level of significance

${ }^{a}$ Elasticities are evaluated at mean $\ln (\mathrm{Y})$ and $\ln (\mathrm{YOUTH})$ of base model sample: $\mathrm{Y}=\$ 16,630$ (1996 Int'l dollars), YOUTH $=0.1928$.

${ }^{\mathrm{b}}$ Elasticities are evaluated at mean $\ln (\mathrm{Y})$ and $\ln (\mathrm{YOUTH})$ of model \#9 sample: $\mathrm{Y}=\$ 19,980$ (1996 Int'l dollars), YOUTH $=0.1777$ 
Table 3.9. Results for Pedestrian Fatalities/VKT Models - No Seatbelt Usage

\begin{tabular}{|c|c|c|c|c|c|c|c|}
\hline & $\begin{array}{l}1 \text { (Base } \\
\text { Model) }\end{array}$ & 2 & 3 & 4 & 5 & 6 & 7 \\
\hline $\operatorname{Ln}(Y)$ & $\begin{array}{c}-0.951 \\
(0.761) \\
\end{array}$ & $\begin{array}{l}-0.962 \\
(0.718) \\
\end{array}$ & $\begin{array}{l}-0.805 \\
(0.741) \\
\end{array}$ & $\begin{array}{l}-1.027 \\
(0.808) \\
\end{array}$ & $\begin{array}{c}-1.844 * * \\
(0.916) \\
\end{array}$ & $\begin{array}{c}-0.807 \\
(1.011) \\
\end{array}$ & $\begin{array}{l}-1.738 \\
(1.421) \\
\end{array}$ \\
\hline Ln(YOUTH) & $\begin{array}{c}4.444 \\
(4.618) \\
\end{array}$ & $\begin{array}{c}4.504 \\
(4.394) \\
\end{array}$ & $\begin{array}{c}3.814 \\
(4.431) \\
\end{array}$ & $\begin{array}{c}4.230 \\
(4.989) \\
\end{array}$ & $\begin{array}{l}10.524^{*} \\
(5.662)\end{array}$ & $\begin{array}{c}4.023 \\
(5.763) \\
\end{array}$ & $\begin{array}{l}14.011 \\
(9.137) \\
\end{array}$ \\
\hline $\begin{array}{l}\mathrm{Ln}(\mathrm{YOUTH}) \\
* \ln (\mathrm{Y})\end{array}$ & $\begin{array}{l}-0.402 \\
(0.467)\end{array}$ & $\begin{array}{l}-0.409 \\
(0.439)\end{array}$ & $\begin{array}{l}-0.335 \\
(0.446)\end{array}$ & $\begin{array}{l}-0.378 \\
(0.505)\end{array}$ & $\begin{array}{l}-1.015^{*} \\
(0.575)\end{array}$ & $\begin{array}{l}-0.333 \\
(0.591)\end{array}$ & $\begin{array}{l}-1.321 \\
(0.914)\end{array}$ \\
\hline $\mathrm{Ln}(\mathrm{VEH})$ & $\begin{array}{l}-0.184 \\
(0.178) \\
\end{array}$ & $\begin{array}{l}-0.176 \\
(0.194) \\
\end{array}$ & $\begin{array}{l}-0.373^{*} \\
(0.215) \\
\end{array}$ & $\begin{array}{l}-0.305 \\
(0.214) \\
\end{array}$ & $\begin{array}{l}-0.194 \\
(0.223) \\
\end{array}$ & $\begin{array}{l}-0.201 \\
(0.178) \\
\end{array}$ & $\begin{array}{c}0.274 \\
(0.182) \\
\end{array}$ \\
\hline $\operatorname{Ln}(\mathrm{RD})$ & $\begin{array}{l}-0.464^{*} \\
(0.274) \\
\end{array}$ & $\begin{array}{l}-0.465^{*} \\
(0.281) \\
\end{array}$ & $\begin{array}{l}-0.493^{*} \\
(0.270) \\
\end{array}$ & $\begin{array}{l}-0.623^{*} \\
(0.350) \\
\end{array}$ & $\begin{array}{c}-1.039^{* * *} \\
(0.304)\end{array}$ & $\begin{array}{l}-0.546^{*} \\
(0.306) \\
\end{array}$ & $\begin{array}{l}-0.835 \\
(0.822) \\
\end{array}$ \\
\hline $\operatorname{Ln}(\mathrm{VEH}) * \mathrm{t}$ & $\begin{array}{c}-0.007 * * \\
(0.003) \\
\end{array}$ & $\begin{array}{l}-0.007^{*} \\
(0.004) \\
\end{array}$ & $\begin{array}{c}-0.006^{* *} \\
(0.003)\end{array}$ & $\begin{array}{c}-0.008^{* *} \\
(0.004) \\
\end{array}$ & $\begin{array}{l}-0.007^{*} \\
(0.004)\end{array}$ & $\begin{array}{l}-0.002 \\
(0.004) \\
\end{array}$ & $\begin{array}{l}-0.006 \\
(0.007) \\
\end{array}$ \\
\hline $\operatorname{Ln}(\mathrm{RD}) * \mathrm{t}$ & $\begin{array}{c}0.010 * * * \\
(0.003)\end{array}$ & $\begin{array}{l}0.010^{* *} \\
(0.005)\end{array}$ & $\begin{array}{c}0.010 * * * \\
(0.003)\end{array}$ & $\begin{array}{l}0.011 * * \\
(0.004)\end{array}$ & $\begin{array}{c}0.011 * * * \\
(0.004)\end{array}$ & $\begin{array}{c}0.007 * * \\
(0.003)\end{array}$ & $\begin{array}{c}0.010 \\
(0.007)\end{array}$ \\
\hline $\mathrm{T}$ & $\begin{array}{c}-0.071^{* * *} \\
(0.027)\end{array}$ & $\begin{array}{c}-0.070 * * \\
(0.028)\end{array}$ & $\begin{array}{c}-0.082 * * * \\
(0.024)\end{array}$ & $\begin{array}{c}-0.063 * * \\
(0.029)\end{array}$ & $\begin{array}{c}-0.076^{* *} \\
(0.031)\end{array}$ & $\begin{array}{c}-0.091 * * * \\
(0.034)\end{array}$ & $\begin{array}{c}-0.089 * * \\
(0.036)\end{array}$ \\
\hline VEHGROWTH & $\begin{array}{l}0.747^{*} \\
(0.391)\end{array}$ & $\begin{array}{l}0.744^{*} \\
(0.399) \\
\end{array}$ & $\begin{array}{c}0.974 * * \\
(0.396) \\
\end{array}$ & $\begin{array}{c}0.984 \\
(0.611) \\
\end{array}$ & $\begin{array}{l}0.906^{* *} \\
(0.417) \\
\end{array}$ & $\begin{array}{c}0.490 \\
(0.488) \\
\end{array}$ & $\begin{array}{c}0.328 \\
(0.539) \\
\end{array}$ \\
\hline Ln(ELDERLY) & $\begin{array}{l}0.669^{* *} \\
(0.274)\end{array}$ & $\begin{array}{c}0.673^{* *} \\
(0.271)\end{array}$ & $\begin{array}{c}0.714 * * * \\
(0.267)\end{array}$ & $\begin{array}{l}0.766^{* *} \\
(0.300)\end{array}$ & $\begin{array}{c}0.594 \\
(0.377)\end{array}$ & $\begin{array}{c}0.339 \\
(0.248)\end{array}$ & $\begin{array}{l}-0.905 \\
(1.019)\end{array}$ \\
\hline $\operatorname{Ln}(\mathrm{POP})$ & & $\begin{array}{l}-0.076 \\
(0.752) \\
\end{array}$ & & & & & \\
\hline $\operatorname{Ln}(\mathrm{URBAN})$ & & & $\begin{array}{l}0.974^{*} \\
(0.499)\end{array}$ & & & & \\
\hline Ln(ALCOHOL) & & & & $\begin{array}{c}0.189 \\
(0.152) \\
\end{array}$ & & & \\
\hline Ln(LIVER) & & & & & $\begin{array}{c}0.209^{* * * *} \\
(0.075)\end{array}$ & & \\
\hline Ln(PHYSICIANS) & & & & & & $\begin{array}{l}-0.295 \\
(0.321)\end{array}$ & \\
\hline Ln(HEART) & & & & & & & $\begin{array}{l}-0.887 \\
(0.590)\end{array}$ \\
\hline Constant & $\begin{array}{c}16.208 * * \\
(6.979)\end{array}$ & $\begin{array}{c}17.448 \\
(11.916)\end{array}$ & $\begin{array}{c}13.965^{* *} \\
(7.098)\end{array}$ & $\begin{array}{l}20.369^{* *} \\
(9.073)\end{array}$ & $\begin{array}{c}31.362 * * * \\
(10.965)\end{array}$ & $\begin{array}{c}16.375^{* *} \\
(7.529)\end{array}$ & $\begin{array}{c}18.964 \\
(13.711)\end{array}$ \\
\hline Adj. R-squared & 0.9606 & 0.9605 & 0.9613 & 0.9600 & 0.9604 & 0.9616 & 0.9677 \\
\hline Observations & 680 & 680 & 680 & 581 & 515 & 537 & 181 \\
\hline Countries & 32 & 32 & 32 & 30 & 30 & 29 & 23 \\
\hline $\begin{array}{l}\text { Elasticity with } \\
\text { respect to } \mathrm{Y}^{\mathrm{a}} \text { : }\end{array}$ & $\begin{array}{l}-0.290^{*} \\
(0.148)\end{array}$ & $\begin{array}{l}-0.289^{*} \\
(0.149)\end{array}$ & $\begin{array}{l}-0.254^{*} \\
(0.145)\end{array}$ & $\begin{array}{l}-0.405 * * \\
(0.195)\end{array}$ & $\begin{array}{l}-0.172 \\
(0.195)\end{array}$ & $\begin{array}{l}-0.259 \\
(0.158)\end{array}$ & $\begin{array}{c}0.438 \\
(0.310)\end{array}$ \\
\hline $\begin{array}{l}\text { Elasticity with } \\
\text { respect to YOUTH }{ }^{\mathrm{a}} \text { : }\end{array}$ & $\begin{array}{l}0.541 * * \\
(0.273) \\
\end{array}$ & $\begin{array}{l}0.528^{*} \\
(0.296) \\
\end{array}$ & $\begin{array}{l}0.561^{* *} \\
(0.268) \\
\end{array}$ & $\begin{array}{l}0.556^{*} \\
(0.291) \\
\end{array}$ & $\begin{array}{l}0.656^{* *} \\
(0.323) \\
\end{array}$ & $\begin{array}{c}0.785 * * * \\
(0.256)\end{array}$ & $\begin{array}{l}1.168^{* *} \\
(0.593) \\
\end{array}$ \\
\hline
\end{tabular}

$* * *$ Indicates $1 \%$ level of significance $* *$ Indicates $5 \%$ level of significance

* Indicates $10 \%$ level of significance

${ }^{a}$ Elasticities are evaluated at mean $\ln (\mathrm{Y})$ and $\ln (\mathrm{YOUTH})$ of base model sample: $\mathrm{Y}=\$ 16,630$ (1996 Int'l dollars), YOUTH $=0.1928$ 
(Table 3.9. continued)

\begin{tabular}{|c|c|c|c|c|c|}
\hline & $\begin{array}{l}1 \text { (Base } \\
\text { Model) }\end{array}$ & 8 & 9 & 10 & 11 \\
\hline $\operatorname{Ln}(Y)$ & $\begin{array}{l}-0.951 \\
(0.761)\end{array}$ & $\begin{array}{c}-1.906 * * * \\
(0.653)\end{array}$ & $\begin{array}{c}-1.806^{* *} \\
(0.904)\end{array}$ & $\begin{array}{l}-2.101^{*} \\
(1.210)\end{array}$ & $\begin{array}{l}-2.070^{*} \\
(1.201)\end{array}$ \\
\hline Ln(YOUTH) & $\begin{array}{c}4.444 \\
(4.618) \\
\end{array}$ & $\begin{array}{c}10.317 * * * \\
(3.775)\end{array}$ & $\begin{array}{l}10.397^{*} \\
(5.462)\end{array}$ & $\begin{array}{l}12.276^{*} \\
(7.082)\end{array}$ & $\begin{array}{l}12.160^{*} \\
(6.955)\end{array}$ \\
\hline $\begin{array}{l}\mathrm{Ln}(\mathrm{YOUTH}) \\
* \ln (\mathrm{Y})\end{array}$ & $\begin{array}{l}-0.402 \\
(0.467) \\
\end{array}$ & $\begin{array}{c}-1.007 * * * \\
(0.381)\end{array}$ & $\begin{array}{l}-0.997^{*} \\
(0.554) \\
\end{array}$ & $\begin{array}{l}-1.156 \\
(0.729) \\
\end{array}$ & $\begin{array}{l}-1.136 \\
(0.718) \\
\end{array}$ \\
\hline $\mathrm{Ln}(\mathrm{VEH})$ & $\begin{array}{l}-0.184 \\
(0.178)\end{array}$ & $\begin{array}{l}-0.043 \\
(0.190)\end{array}$ & $\begin{array}{l}-0.322 \\
(0.277)\end{array}$ & $\begin{array}{l}-0.146 \\
(0.192)\end{array}$ & $\begin{array}{l}-0.329 \\
(0.251)\end{array}$ \\
\hline $\mathrm{Ln}(\mathrm{RD})$ & $\begin{array}{l}-0.464^{*} \\
(0.274)\end{array}$ & $\begin{array}{l}-0.530^{*} \\
(0.288)\end{array}$ & $\begin{array}{c}-0.971 * * * \\
(0.298)\end{array}$ & $\begin{array}{c}-1.334 * * * \\
(0.276)\end{array}$ & $\begin{array}{c}-1.285^{* * *} \\
(0.269)\end{array}$ \\
\hline $\operatorname{Ln}(\mathrm{VEH}) * \mathrm{t}$ & $\begin{array}{c}-0.007 * * \\
(0.003)\end{array}$ & $\begin{array}{c}-0.007 * * \\
(0.003)\end{array}$ & $\begin{array}{l}-0.006 \\
(0.004)\end{array}$ & $\begin{array}{l}-0.004 \\
(0.007)\end{array}$ & $\begin{array}{l}-0.003 \\
(0.006)\end{array}$ \\
\hline $\operatorname{Ln}(\mathrm{RD}) * \mathrm{t}$ & $\begin{array}{c}0.010^{* * * *} \\
(0.003)\end{array}$ & $\begin{array}{c}0.012 * * * \\
(0.003)\end{array}$ & $\begin{array}{c}0.011^{* * *} \\
(0.004)\end{array}$ & $\begin{array}{c}0.010 \\
(0.006)\end{array}$ & $\begin{array}{l}0.010^{*} \\
(0.005)\end{array}$ \\
\hline $\mathrm{T}$ & $\begin{array}{c}-0.071 * * * \\
(0.027)\end{array}$ & $\begin{array}{c}-0.091 * * * \\
(0.022)\end{array}$ & $\begin{array}{c}-0.091 * * * \\
(0.033)\end{array}$ & $\begin{array}{c}-0.094 * * \\
(0.041)\end{array}$ & $\begin{array}{c}-0.119 * * * \\
(0.040)\end{array}$ \\
\hline VEHGROWTH & $\begin{array}{l}0.747^{*} \\
(0.391)\end{array}$ & $\begin{array}{c}0.787 * * \\
(0.344)\end{array}$ & $\begin{array}{c}1.053 * * * \\
(0.326)\end{array}$ & $\begin{array}{c}0.475 \\
(0.451)\end{array}$ & $\begin{array}{c}0.731 * * \\
(0.356)\end{array}$ \\
\hline Ln(ELDERLY) & $\begin{array}{l}0.669^{* * *} \\
(0.274)\end{array}$ & $\begin{array}{l}0.465^{*} \\
(0.260)\end{array}$ & $\begin{array}{l}0.628^{*} \\
(0.370)\end{array}$ & $\begin{array}{c}0.352 \\
(0.457)\end{array}$ & $\begin{array}{c}0.337 \\
(0.439)\end{array}$ \\
\hline Ln(URBAN) & & & $\begin{array}{c}1.024 \\
(0.928) \\
\end{array}$ & & $\begin{array}{c}1.494 \\
(0.950) \\
\end{array}$ \\
\hline Ln(LIVER) & & & $\begin{array}{c}0.194 * * * \\
(0.064))\end{array}$ & $\begin{array}{c}0.195 * * * \\
(0.067)\end{array}$ & $\begin{array}{c}0.178 * * * \\
(0.066)\end{array}$ \\
\hline Ln(PHYSICIANS) & & & & $\begin{array}{l}-0.137 \\
(0.226)\end{array}$ & $\begin{array}{l}-0.027 \\
(0.212)\end{array}$ \\
\hline 2WHEELERS & & $\begin{array}{l}-0.007 \\
(0.005)\end{array}$ & & & \\
\hline Constant & $\begin{array}{c}16.208^{* *} \\
(6.979)\end{array}$ & $\begin{array}{c}23.967 * * * \\
(6.793)\end{array}$ & $\begin{array}{c}27.960 * * \\
(12.075)\end{array}$ & $\begin{array}{c}36.974 * * * \\
(12.313)\end{array}$ & $\begin{array}{c}32.327 * * \\
(13.751)\end{array}$ \\
\hline Adj. R-squared & 0.9606 & 0.9633 & 0.9607 & 0.9622 & 0.9629 \\
\hline Observations & 680 & 613 & 515 & 408 & 408 \\
\hline Countries & 32 & 31 & 30 & 26 & 26 \\
\hline $\begin{array}{l}\text { Elasticity with } \\
\text { respect to } \mathrm{Y}^{\mathrm{a}} \text { : }\end{array}$ & $\begin{array}{l}-0.290^{*} \\
(0.148)\end{array}$ & $\begin{array}{l}-0.249 \\
(0.164)\end{array}$ & $\begin{array}{l}-0.164 \\
(0.201)\end{array}$ & $\begin{array}{l}-0.197 \\
(0.186)\end{array}$ & $\begin{array}{l}-0.199 \\
(0.190)\end{array}$ \\
\hline $\begin{array}{l}\text { Elasticity with } \\
\text { respect to YOUTH } \\
\text { a: }\end{array}$ & $\begin{array}{c}0.541 * * \\
(0.273)\end{array}$ & $\begin{array}{l}0.534^{*} \\
(0.304)\end{array}$ & $\begin{array}{l}0.704 * * \\
(0.327)\end{array}$ & $\begin{array}{c}1.036^{* * *} \\
(0.268)\end{array}$ & $\begin{array}{c}1.114 * * * \\
(0.284)\end{array}$ \\
\hline
\end{tabular}

*** Indicates $1 \%$ level of significance ** Indicates $5 \%$ level of significance

* Indicates $10 \%$ level of significance

${ }^{a}$ Elasticities are evaluated at mean $\ln (\mathrm{Y})$ and $\ln (\mathrm{YOUTH})$ of base model sample: $\mathrm{Y}=\$ 16,630$ (1996 Int'l dollars), YOUTH $=0.1928$ 
Table 3.10. Results for Non-Occupant Fatalities/VKT Models - Seatbelt Usage

\begin{tabular}{|c|c|c|c|c|c|c|c|}
\hline & $\begin{array}{l}1 \text { (Base } \\
\text { Model) }\end{array}$ & $\begin{array}{l}12 \text { (Base, } \\
\text { incl. } \\
\text { 2wheeler } \\
\text { deaths) }\end{array}$ & 13 & 14 & 15 & 16 & 17 \\
\hline $\operatorname{Ln}(Y)$ & $\begin{array}{l}-0.951 \\
(0.761)\end{array}$ & $\begin{array}{c}-2.636^{* * * *} \\
(0.763)\end{array}$ & $\begin{array}{c}-4.717 * * * \\
(1.511)\end{array}$ & $\begin{array}{c}-4.197 * * * \\
(1.617)\end{array}$ & $\begin{array}{c}-3.775 * * * \\
(1.140)\end{array}$ & $\begin{array}{c}-4.579 * * \\
(1.796)\end{array}$ & $\begin{array}{c}-4.684 * * * \\
(1.798)\end{array}$ \\
\hline Ln(YOUTH) & $\begin{array}{c}4.444 \\
(4.618) \\
\end{array}$ & $\begin{array}{c}16.195^{* * *} \\
(4.204)\end{array}$ & $\begin{array}{c}29.748^{* * *} \\
(9.302)\end{array}$ & $\begin{array}{c}27.529 * * * \\
(9.520)\end{array}$ & $\begin{array}{c}25.282 * * * \\
(7.445)\end{array}$ & $\begin{array}{l}26.416^{* * *} \\
(10.281)\end{array}$ & $\begin{array}{c}26.744 * * * \\
(10.178) \\
\end{array}$ \\
\hline $\begin{array}{l}\mathrm{Ln}(\mathrm{YOUTH}) \\
* \ln (\mathrm{Y})\end{array}$ & $\begin{array}{l}-0.402 \\
(0.467) \\
\end{array}$ & $\begin{array}{c}-1.583 * * * \\
(0.426)\end{array}$ & $\begin{array}{c}-2.942 * * * \\
(0.934)\end{array}$ & $\begin{array}{c}-2.720 * * * \\
(0.959) \\
\end{array}$ & $\begin{array}{c}-2.463 * * * \\
(0.737)\end{array}$ & $\begin{array}{c}-2.654^{* *} \\
(1.032) \\
\end{array}$ & $\begin{array}{c}-2.688^{* * * *} \\
(1.024) \\
\end{array}$ \\
\hline $\operatorname{Ln}(\mathrm{VEH})$ & $\begin{array}{l}-0.184 \\
(0.178)\end{array}$ & $\begin{array}{c}0.069 \\
(0.178)\end{array}$ & $\begin{array}{l}-0.006 \\
(0.239)\end{array}$ & $\begin{array}{l}-0.019 \\
(0.229)\end{array}$ & $\begin{array}{l}-0.111 \\
(0.279)\end{array}$ & $\begin{array}{l}-0.258 \\
(0.314)\end{array}$ & $\begin{array}{l}-0.248 \\
(0.325)\end{array}$ \\
\hline $\mathrm{Ln}(\mathrm{RD})$ & $\begin{array}{l}-0.464^{*} \\
(0.274)\end{array}$ & $\begin{array}{l}-0.193 \\
(0.282)\end{array}$ & $\begin{array}{c}0.412 \\
(0.312)\end{array}$ & $\begin{array}{c}0.381 \\
(0.328)\end{array}$ & $\begin{array}{c}0.604 \\
(0.435)\end{array}$ & $\begin{array}{c}0.397 \\
(0.387)\end{array}$ & $\begin{array}{c}0.402 \\
(0.385)\end{array}$ \\
\hline $\operatorname{Ln}(\mathrm{VEH}) * \mathrm{t}$ & $\begin{array}{c}-0.007 * * \\
(0.003) \\
\end{array}$ & $\begin{array}{l}-0.007^{*} \\
(0.004) \\
\end{array}$ & $\begin{array}{c}0.004 \\
(0.004) \\
\end{array}$ & $\begin{array}{c}0.003 \\
(0.004) \\
\end{array}$ & $\begin{array}{c}0.004 \\
(0.006) \\
\end{array}$ & $\begin{array}{l}-0.006 \\
(0.007) \\
\end{array}$ & $\begin{array}{l}-0.006 \\
(0.007) \\
\end{array}$ \\
\hline $\operatorname{Ln}(\mathrm{RD}) * \mathrm{t}$ & $\begin{array}{c}0.010^{* * *} \\
(0.003)\end{array}$ & $\begin{array}{c}0.009 * * \\
(0.003)\end{array}$ & $\begin{array}{l}-0.001 \\
(0.004)\end{array}$ & $\begin{array}{c}0.000 \\
(0.005)\end{array}$ & $\begin{array}{l}-0.003 \\
(0.006) \\
\end{array}$ & $\begin{array}{c}0.005 \\
(0.006)\end{array}$ & $\begin{array}{c}0.005 \\
(0.007)\end{array}$ \\
\hline $\mathrm{T}$ & $\begin{array}{c}-0.071 * * * \\
(0.027)\end{array}$ & $\begin{array}{c}-0.067 * * \\
(0.029) \\
\end{array}$ & $\begin{array}{c}-0.121 * * * \\
(0.019)\end{array}$ & $\begin{array}{c}-0.131 * * * \\
(0.017)\end{array}$ & $\begin{array}{c}-0.090 * * \\
(0.044) \\
\end{array}$ & $\begin{array}{l}-0.029 \\
(0.047) \\
\end{array}$ & $\begin{array}{l}-0.026 \\
(0.055) \\
\end{array}$ \\
\hline VEHGROWTH & $\begin{array}{l}0.747^{*} \\
(0.391) \\
\end{array}$ & $\begin{array}{l}0.693^{*} \\
(0.356) \\
\end{array}$ & $\begin{array}{l}0.721^{*} \\
(0.375) \\
\end{array}$ & $\begin{array}{c}0.822 * * \\
(0.331) \\
\end{array}$ & $\begin{array}{l}0.998^{*} \\
(0.531) \\
\end{array}$ & $\begin{array}{c}0.881 \\
(0.600) \\
\end{array}$ & $\begin{array}{c}0.858 \\
(0.555) \\
\end{array}$ \\
\hline Ln(ELDERLY) & $\begin{array}{l}0.669^{* *} \\
(0.274) \\
\end{array}$ & $\begin{array}{l}0.644^{* *} \\
(0.280) \\
\end{array}$ & $\begin{array}{c}0.463 * * * \\
(0.158)\end{array}$ & $\begin{array}{c}0.481 * * * \\
(0.145)\end{array}$ & $\begin{array}{c}0.966 * * * \\
(0.231)\end{array}$ & $\begin{array}{c}0.745 \\
(0.505) \\
\end{array}$ & $\begin{array}{c}0.729 \\
(0.512) \\
\end{array}$ \\
\hline $\operatorname{Ln}(\mathrm{URBAN})$ & & & & $\begin{array}{c}0.744 \\
(0.526) \\
\end{array}$ & & & $\begin{array}{l}-0.158 \\
(0.751) \\
\end{array}$ \\
\hline Ln(LIVER) & & & & & $\begin{array}{c}0.003 \\
(0.090) \\
\end{array}$ & & \\
\hline \multicolumn{8}{|c|}{ Ln(Seatbelt wearing rates): } \\
\hline Urban roads & & & $\begin{array}{c}0.010 \\
(0.023) \\
\end{array}$ & $\begin{array}{c}0.005 \\
(0.023) \\
\end{array}$ & $\begin{array}{c}0.009 \\
(0.023) \\
\end{array}$ & & \\
\hline Rural roads & & & & & & $\begin{array}{l}-0.015 \\
(0.018) \\
\end{array}$ & $\begin{array}{l}-0.016 \\
(0.020)\end{array}$ \\
\hline \multicolumn{8}{|l|}{ Motorways } \\
\hline Constant & $\begin{array}{c}16.208^{* *} \\
(6.979)\end{array}$ & $\begin{array}{c}26.398^{* * * *} \\
(6.694)\end{array}$ & $\begin{array}{l}40.603 * * \\
(16.309)\end{array}$ & $\begin{array}{l}32.984^{*} \\
(18.035)\end{array}$ & $\begin{array}{l}31.845^{* *} \\
(15.503)\end{array}$ & $\begin{array}{l}43.150 * * \\
(17.514)\end{array}$ & $\begin{array}{l}44.559 * * \\
(17.718)\end{array}$ \\
\hline Adj. R-squared & 0.9606 & 0.9609 & 0.9845 & 0.9847 & 0.9870 & 0.9812 & 0.9811 \\
\hline Observations & 680 & 636 & 261 & 261 & 180 & 198 & 198 \\
\hline Countries & 32 & 30 & 20 & 20 & 16 & 16 & 16 \\
\hline $\begin{array}{l}\text { Elasticity with } \\
\text { respect to } \mathrm{Y}^{\mathrm{a}} \text { : }\end{array}$ & $\begin{array}{l}-0.290^{*} \\
(0.148) \\
\end{array}$ & $\begin{array}{l}-0.030 \\
(0.219) \\
\end{array}$ & $\begin{array}{c}0.126 \\
(0.175) \\
\end{array}$ & $\begin{array}{c}0.281 * * * \\
(0.107)\end{array}$ & $\begin{array}{c}0.280 \\
(0.205) \\
\end{array}$ & $\begin{array}{l}-0.210 \\
(0.221) \\
\end{array}$ & $\begin{array}{l}-0.259 \\
(0.307) \\
\end{array}$ \\
\hline $\begin{array}{l}\text { Elasticity with } \\
\text { respect to YOUTH }\end{array}$ & $\begin{array}{l}0.541 * * \\
(0.273)\end{array}$ & $\begin{array}{c}0.806^{* * *} \\
(0.269)\end{array}$ & $\begin{array}{c}1.157 * * * \\
(0.345)\end{array}$ & $\begin{array}{c}1.092 * * * \\
(0.309)\end{array}$ & $\begin{array}{c}1.340 * * * \\
(0.341)\end{array}$ & $\begin{array}{c}0.620 \\
(0.415)\end{array}$ & $\begin{array}{c}0.620 \\
(0.427)\end{array}$ \\
\hline $\begin{array}{l}\text { Elasticity with } \\
\text { respect to } \mathrm{Y}^{\mathrm{b}} \text { : }\end{array}$ & $\begin{array}{l}-0.256^{*} \\
(0.159) \\
\end{array}$ & $\begin{array}{c}0.103 \\
(0.216) \\
\end{array}$ & $\begin{array}{l}0.373^{*} \\
(0.206) \\
\end{array}$ & $\begin{array}{c}0.509 * * * \\
(0.111)\end{array}$ & $\begin{array}{l}0.487^{* *} \\
(0.238) \\
\end{array}$ & $\begin{array}{c}0.013 \\
(0.203) \\
\end{array}$ & $\begin{array}{l}-0.033 \\
(0.294) \\
\end{array}$ \\
\hline $\begin{array}{l}\text { Elasticity with } \\
\text { respect to YOUTH }\end{array}$ & $\begin{array}{l}0.467^{*} \\
(0.262)\end{array}$ & $\begin{array}{l}0.516^{* *} \\
(0.263)\end{array}$ & $\begin{array}{l}0.617 * * \\
(0.268)\end{array}$ & $\begin{array}{l}0.593 * * \\
(0.238)\end{array}$ & $\begin{array}{c}0.888 * * * \\
(0.245)\end{array}$ & $\begin{array}{c}0.133 \\
(0.339)\end{array}$ & $\begin{array}{c}0.127 \\
(0.368)\end{array}$ \\
\hline
\end{tabular}

*** Indicates $1 \%$ level of significance $* *$ Indicates $5 \%$ level of significance

* Indicates $10 \%$ level of significance

${ }^{a}$ Elasticities are evaluated at mean $\ln (\mathrm{Y})$ and $\ln (\mathrm{YOUTH})$ of base model sample: $\mathrm{Y}=\$ 16,630$ (1996 Int'l dollars), YOUTH $=0.1928$.

${ }^{\mathrm{b}}$ Elasticities are evaluated at mean $\ln (\mathrm{Y})$ and $\ln (\mathrm{YOUTH})$ of model \#9 sample: $\mathrm{Y}=\$ 19,980$ (1996 Int'l dollars), YOUTH $=0.1777$. 
(Table 3.10. continued)

\begin{tabular}{|c|c|c|c|}
\hline & $\begin{array}{l}1 \text { (Base } \\
\text { Model) }\end{array}$ & $\begin{array}{l}12 \text { (Base, } \\
\text { incl. } \\
\text { 2wheeler } \\
\text { deaths) }\end{array}$ & 18 \\
\hline $\operatorname{Ln}(Y)$ & $\begin{array}{l}-0.951 \\
(0.761) \\
\end{array}$ & $\begin{array}{c}-2.636^{* * *} \\
(0.763) \\
\end{array}$ & $\begin{array}{c}-5.173 * * * \\
(1.334) \\
\end{array}$ \\
\hline Ln(YOUTH) & $\begin{array}{c}4.444 \\
(4.618) \\
\end{array}$ & $\begin{array}{c}16.195^{* * *} \\
(4.204)\end{array}$ & $\begin{array}{c}35.358^{* * * *} \\
(7.718)\end{array}$ \\
\hline $\begin{array}{l}\mathrm{Ln}(\mathrm{YOUTH}) \\
* \ln (\mathrm{Y})\end{array}$ & $\begin{array}{l}-0.402 \\
(0.467) \\
\end{array}$ & $\begin{array}{c}-1.583 * * * \\
(0.426)\end{array}$ & $\begin{array}{c}-3.466^{* * * *} \\
(0.760)\end{array}$ \\
\hline Ln(VEH) & $\begin{array}{l}-0.184 \\
(0.178)\end{array}$ & $\begin{array}{c}0.069 \\
(0.178)\end{array}$ & $\begin{array}{l}-0.548 \\
(0.345)\end{array}$ \\
\hline $\mathrm{Ln}(\mathrm{RD})$ & $\begin{array}{l}-0.464^{*} \\
(0.274)\end{array}$ & $\begin{array}{l}-0.193 \\
(0.282)\end{array}$ & $\begin{array}{l}0.751^{*} \\
(0.445)\end{array}$ \\
\hline $\operatorname{Ln}(\mathrm{VEH}) *_{\mathrm{t}}$ & $\begin{array}{c}-0.007 * * \\
(0.003) \\
\end{array}$ & $\begin{array}{l}-0.007^{*} \\
(0.004) \\
\end{array}$ & $\begin{array}{c}0.010 \\
(0.007) \\
\end{array}$ \\
\hline $\operatorname{Ln}(\mathrm{RD}) * \mathrm{t}$ & $\begin{array}{c}0.010^{* * *} \\
(0.003)\end{array}$ & $\begin{array}{l}0.009 * * \\
(0.003)\end{array}$ & $\begin{array}{l}-0.009 \\
(0.007)\end{array}$ \\
\hline $\mathrm{T}$ & $\begin{array}{c}-0.071 * * * \\
(0.027)\end{array}$ & $\begin{array}{c}-0.067 * * \\
(0.029) \\
\end{array}$ & $\begin{array}{c}-0.118 * * * \\
(0.027)\end{array}$ \\
\hline VEHGROWTH & $\begin{array}{l}0.747^{*} \\
(0.391) \\
\end{array}$ & $\begin{array}{l}0.693^{*} \\
(0.356) \\
\end{array}$ & $\begin{array}{l}0.598^{*} \\
(0.331) \\
\end{array}$ \\
\hline Ln(ELDERLY) & $\begin{array}{l}0.669^{* *} \\
(0.274) \\
\end{array}$ & $\begin{array}{l}0.644^{* *} \\
(0.280) \\
\end{array}$ & $\begin{array}{c}0.327 * * * \\
(0.099)\end{array}$ \\
\hline $\begin{array}{l}\text { Ln(URBAN) } \\
\operatorname{Ln}(\text { LIVER })\end{array}$ & & & \\
\hline$\frac{\text { Ln(Seatbelt wearing } \mathrm{r}}{\text { Urban roads }}$ & tes): & & \\
\hline Rural roads & & & \\
\hline Motorways & & & $\begin{array}{c}0.030 \\
(0.022) \\
\end{array}$ \\
\hline Constant & $\begin{array}{c}16.208^{* *} \\
(6.979)\end{array}$ & $\begin{array}{c}26.398 * * * \\
(6.694)\end{array}$ & $\begin{array}{l}50.116^{* * * *} \\
(13.554)\end{array}$ \\
\hline Adj. R-squared & 0.9606 & 0.9609 & 0.9858 \\
\hline Observations & 680 & 636 & 191 \\
\hline Countries & 32 & 30 & 15 \\
\hline $\begin{array}{l}\text { Elasticity with } \\
\text { respect to } \mathrm{Y}^{\mathrm{a}} \text { : }\end{array}$ & $\begin{array}{l}-0.290^{*} \\
(0.148)\end{array}$ & $\begin{array}{l}-0.030 \\
(0.219)\end{array}$ & $\begin{array}{c}0.532 * * * \\
(0.186)\end{array}$ \\
\hline $\begin{array}{l}\text { Elasticity with } \\
\text { respect to YOUTH }\end{array}$ & $\begin{array}{l}0.541 * * \\
(0.273) \\
\end{array}$ & $\begin{array}{c}0.806^{* * *} \\
(0.269)\end{array}$ & $\begin{array}{c}1.672 * * * \\
(0.368)\end{array}$ \\
\hline $\begin{array}{l}\text { Elasticity with } \\
\text { respect to } \mathrm{Y}^{\mathrm{b}} \text { : }\end{array}$ & $\begin{array}{l}-0.256^{*} \\
(0.159) \\
\end{array}$ & $\begin{array}{c}0.103 \\
(0.216) \\
\end{array}$ & $\begin{array}{c}0.823 * * * \\
(0.171)\end{array}$ \\
\hline $\begin{array}{l}\text { Elasticity with } \\
\text { respect to YOUTH }\end{array}$ & $\begin{array}{l}0.467^{*} \\
(0.262) \\
\end{array}$ & $\begin{array}{l}0.516^{* *} \\
(0.263) \\
\end{array}$ & $\begin{array}{c}1.036^{* * *} \\
(0.247)\end{array}$ \\
\hline
\end{tabular}

*** Indicates $1 \%$ level of significance $* *$ Indicates $5 \%$ level of significance

* Indicates $10 \%$ level of significance

${ }^{a}$ Elasticities are evaluated at mean $\ln (\mathrm{Y})$ and $\ln (\mathrm{YOUTH})$ of base model sample: $\mathrm{Y}=\$ 16,630$ (1996 Int'l dollars), YOUTH $=0.1928$.

${ }^{\mathrm{b}}$ Elasticities are evaluated at mean $\ln (\mathrm{Y})$ and $\ln (\mathrm{YOUTH})$ of model $\# 9$ sample: $\mathrm{Y}=\$ 19,980$ (1996 Int'l

dollars), YOUTH $=0.1777$. 


\section{CHAPTER FOUR \\ SUMMARY AND CONCLUSION}

This dissertation makes a contribution to the understanding of the socioeconomic determinants of road traffic fatality rates worldwide. It provides the first comprehensive documentation of the variation in traffic fatalities across countries at different stages of economic development in recent decades. Using panel data from over 80 countries since the 1960 s, the basic relationship between road safety and income levels is investigated in an Environmental Kuznets Curve framework.

The results confirm that traffic fatalities do indeed follow an inverted Ushaped relationship with income, with traffic fatality risk beginning to decline at income levels (above $\$ 8,000$ in 1985 international prices) similar to those found for several environmental externalities. A decomposition of the fatality risk-income relationship also suggests that the improvement in road safety that accompanies income growth will depend on policies that reduce fatalities per vehicle rather than on those that reduce the level of motorization.

The significance of these findings is twofold. First, the results identify the income level at which road safety tends to improve rather than worsen. Second, projections of traffic fatalities based on the Kuznets curve estimates indicate that, if developing countries follow historic trends, it will take many years for them to achieve the motor vehicle fatality risks of high-income countries. This alerts policymakers to what is likely to happen if additional measures are not enacted to 
reduce traffic accidents. The forecasts also offer a baseline scenario for the next twenty years, against which to evaluate progress towards achieving national road safety goals.

Formulation of a policy framework in developing countries that are intent on reducing road death tolls should be based on an understanding of the interventions that have proved to be the most cost-effective in industrialized countries. Such a framework includes measures aimed at improving driving behavior and road conditions so as to reduce the number of accidents, on one hand, and measures focused on improving vehicle crashworthiness and medical care to reduce the fatality risk of accident victims, on the other.

The quantitative results highlight the factors that contributed to the historic decline in traffic fatality rates in industrialized countries since 1970. Against the background of a large empirical literature evaluating the effectiveness of particular road safety policies, the analysis presented here is an initial attempt to use crosscountry time-series data to examine the role of various factors on pedestrian and vehicle occupant fatality rates separately. Although in some respects analysis based on aggregate level inter-country panel data should provide more general and robust estimates of the systemwide effects of certain factors than studies using withincountry data, country level analysis is still subject to certain limitations. Sufficiently long time-series data on specific road safety policies (e.g., alcohol taxes and law enforcement measures) at the country level, for example, are limited. The availability of emergency transport services and medical technology is also difficult to measure. Most important, data limitations prevent the explicit control for vehicle speed. Even 
if enough speed data were available for panel analysis, however, an examination of the effect of average traffic speed on road safety would be more reliable if it was specific to road type.

The present analysis is unable to capture the effectiveness of policies across different road classes (urban vs. rural, high speed vs. low speed). As countries continue to develop, the types of road networks that will be built will depend, in part, on trends in urbanization. Therefore, it is important to understand the effects that various interventions have had on different types of roads. For example, the finding that seatbelt usage on rural roads has a greater impact on vehicle occupant deaths per distance traveled than increased urban seatbelt use could imply that seatbelts are more effective on rural roads (including higher speed roads) than on urban (presumably lower speed) roads. On the other hand, it could simply reflect a greater amount of vehicle travel outside of urban areas. Separate estimates for urban and rural vehicle occupant death rates could help shed light on the extent to which this is true.

Examination of death rates by road class could also help to quantify the extent to which an intervention on one road will influence safety rates on other road classes and/or the number of traffic deaths per distance traveled on all roads. Road design or legislative changes allowing for higher speeds on motorways, for example, could induce drivers to increase vehicle speeds on adjoining roads. Likewise, the overall fatality rate could increase due to route diversion effects resulting from certain policies. If non-motorway rural roads have more deaths per vehicle distance traveled than highways, increased enforcement of highway speeds could cause a diversion of 
traffic onto other (less safe) roads, thereby increasing the deaths per distance traveled on all road types.

Subject to the caveats mentioned above, the findings point to three areas of policy that may be influential in reducing fatality rates in developing countries. First, in countries where young persons (between 15 and 24 years of age) comprise an increasing share of the driving population, adopting policies aimed at improving young driver education and reducing speeds will be crucial. The importance of young drivers in road fatalities is found to have diminished in industrialized countries as incomes increased, reflecting either increased risk aversion or more widespread driver education with increases in economic prosperity. However, the increased risk to both vehicle occupants and pedestrians posed by young road users still more than offsets this beneficial effect of income growth, thereby suggesting that interventions aimed at young drivers continues to command considerable attention.

Second, mandating vehicle safety standards and enforcing seatbelt usage may be more effective in achieving road safety targets than increasing expenditures on roadway infrastructure improvements. Increasing the size of the road network, holding all else equal, may prove to be beneficial by reducing the probability of a traffic collision. However, evidence from the experience of industrialized countries suggests that the road safety problem may be exacerbated if existing road networks are not properly maintained and repaired, or if significant investments in new roadway design technologies are made without effective speed enforcement to prevent an increase in risk-taking behavior on the part of drivers. The safety benefits from newer vehicle fleets (equipped with safety innovations, such as airbags and anti- 
lock brakes) and seatbelt usage may also be partially offset by changes in driving behavior (the extent to which cannot be disentangled in the present analysis) but these factors are still found to have an overall beneficial impact on the safety of both vehicle occupants and non-occupants.

Third, the findings confirm that special attention must be paid to improving the safety of the most vulnerable road users. Although a mechanical decline can be expected in the number of pedestrian deaths per vehicle distance traveled as motorization rates increase, policies targeted toward pedestrian safety (with a special focus on urban areas and the role of alcohol consumption) remain critical.

Among the numerous topics for further research a few key paths stand out. As discussed above, developing separate models of traffic fatalities for different road categories could shed light on the importance of factors in improving road safety in rural versus urban road environments. Such an analysis may provide a richer understanding of the effect of seatbelt usage on different speed roads and the extent of offsetting driving behavior due to road improvements. This investigation would be especially useful in developing road safety interventions in rapidly urbanizing lowincome countries. A separate assessment of the determinants of motorcycle fatality rates would also be instructive in shaping policy in developing countries where motorized two-wheelers comprise the vast majority of the vehicle fleet. In addition, the finding that the pedestrian fatality rate increases with the proportion of elderly population (over 64 years of age) is a result that requires further attention. The policy significance of this result depends on whether the finding simply reflects an increase in pedestrian activity or if it is a result of elderly driving behavior. Disentangling 
these effects would be even more informative for industrialized countries that are aging much faster than most developing countries.

Finally, in this analysis, by its very nature, all countries regardless of size are treated as observationally equivalent, for estimation purposes. Hence, as more reliable data becomes available, it could be usefully complemented with a somewhat analogous within-country panel analysis applied to large countries (such as Brazil, China, India, Nigeria) that display significant internal variations, including in levels of development, urbanization, driver behavior, transport modes, and overall public administration. Such variations across subnational regions may in fact yield considerable differences in parameter estimates, which in turn could lead to more specific policy implications, particularly in these large economies facing daunting challenges in this area of public policy. 
APPENDIX A

APPENDIX TO CHAPTER TWO

In chapter two, I combined data on traffic fatalities and the motor vehicle fleet from numerous sources to examine the relationship between traffic fatality risk and economic development. In this appendix, I provide a brief description of the construction of the dataset used in that chapter. Section A.1 describes the digitization of the International Road Federation (IRF) World Road Statistics, and other data sources are discussed in Section A.2. The regression results from chapter two (Tables $2.5-2.7$ ) are reported again, including all country dummy coefficients in Section A.3. Section A.4 presents the regression results when the same observations are used across all three spline equations. Section A.5 shows the estimates of Fatalities/Population when time dummies are used in place of a common time trend. Sensitivity of the estimated turning point in the Fatalities/Population models is summarized in Section A.6 and Section A.7. Finally, the issue of pooling HD1 and HD2 observations in the spline specification is addressed in Section A.8.

\section{A.1 Digitization of IRF World Road Statistics}

The IRF World Road Statistics (WRS) first appeared in 1958 and are based on data compiled from official sources within national statistics offices and national road administrations in up to 196 countries. The WRS contain data on over 100 variables, including data on road networks, vehicle fleets, road traffic accidents, fuel consumption, and road expenditures. 
Prior to 1990, the WRS yearbooks were published annually, each edition containing data from the previous five years. Since each variable appears in multiple editions, all data tables from every other edition were electronically scanned and then each series was compared across yearbooks to check for accuracy and to ensure that all revisions were recorded properly. Hence, the digitized version contains the more recently published figures for each year. For example, the 1971 and 1972 data come from the 1976 WRS yearbook, the 1973 and 1974 data from the 1978 yearbook, and so on.

After combining the electronic version of the 1963-1989 WRS data with the 1990-99 data (which was obtained in digitized form directly from the IRF), the traffic fatality statistics (from Table VII) and vehicle fleet figures (from Table IV) were inspected for reporting inconsistencies and anomalies using the following strategy. First, I selected only those countries for which there were at least 10 years of observations on the number of traffic deaths. All country land area and name changes were rectified. Then observations with traffic fatality values lying outside one standard deviation from the mean value of the series for the respective country were flagged as potential data outliers. The flagged observations were inspected individually and dropped from the sample if judged to be an input error. Finally, the data for each country were scrutinized for significant changes in reporting procedures through optical scan and also by flagging all observations that increased or declined by more than $10 \%$ from the previous year. These flagged observations were inspected and compared to the data in the unscanned yearbooks as well as any other available data sources (described in the Section A.2). If the inconsistencies were not 
resolved and the series could not be supplemented by data from other sources, the problematic observations were omitted from the sample.

The vehicle fleet data were processed using the same method. In addition, checks were performed to make sure the number of vehicles in each category sum to the reported total. I accounted for changes in the vehicle type categories (in 1983 and again in 1988). Reporting inconsistencies in the number of motorized two-wheelers were also common.

\section{A.2 Supplementary Data Sources}

The selected IRF data on traffic deaths and vehicles were also compared to and supplemented by numerous regional and country-specific road safety studies. Supplementary data was added from several sources where appropriate, including studies published by the following:

- Inter-American Development Bank (1998)

- Danish Road Directorate (1998)

- Transportation Research Laboratory (Jacobs et al. 2000)

- United Nations Economic and Social Commission for Asia and the Pacific (1997)

- Statistical Bureau of the People's Republic of China

- Ministry of Transport of Israel (2000)

- European Conference of Ministers of Transport (ECMT)

- Global Road Safety Partnership

- OECD International Road Traffic Accident Database (IRTAD)

- Cross-National Time Series Database (CNTS)

- Statistical Economic and Social Research and Training Centre for Islamic Countries (SESRTCIC) 
- Bangladesh Bureau of Statistics

- American Automobile Manufacturers Association

The complete list of countries included in the dataset in chapter two is provided in Table A.1. The countries are classified according to HDI group (HD1 or HD2) and World Bank geographic region. The number of observations for each country used to estimate the Fatalities/Population model is given in parentheses after the country name. The remaining countries are those for which fatalities are projected in Section 2.5.3.

\author{
A.3 Complete Regression Results, Including Country Dummy Coefficients \\ The country dummy coefficients from the F/P, V/P, and F/V models from \\ chapter two (Tables 2.5-2.7) are reported in Table A.3-A.5. Heteroskedasticity- \\ corrected standard errors, clustered on country to allow for within panel \\ autocorrelation, are provided in parentheses below each coefficient.
}

\title{
A.4 Regression Results Using Same Observations Across All Equations
}

Table A.2. displays the results from the spline models of Fatalities/Population, Vehicles/Population, and Fatalities/Vehicle when the income intervals are held constant across the three equations. The spline segments correspond to those used to estimate the Fatalities/Population models in Table 2.5. Therefore, there are an equal number of observations in each income range for the F/P models in Table A.2 but will vary somewhat for the $\mathrm{V} / \mathrm{P}$ and $\mathrm{F} / \mathrm{V}$ models. The results are displayed for the two region-specific specifications of the time trend. Heteroskedasticity-corrected 
standard errors, clustered on country to allow for within panel autocorrelation, are given in parentheses.

\section{A.5 Fatalities/Population Estimates with Year Dummies Instead of Common Time Trend}

Table A.6 displays the regression results from the Fatalities/Population model using the spline specification of per capita income. Results from both a common linear time trend specification as well as individual year dummies are shown in the table. Once again, heteroskedasticity-corrected standard errors, clustered on country to allow for within panel autocorrelation, are given in parentheses.

\section{A.6 Sensitivity Analysis of Turning Point in Fatalities/Population Model to Subsets of Sample}

Sensitivity of the turning point to various subsets of the Fatalities/Population sample is summarized in Table A.7. In the quadratic specification of income with logged, region-specific time trends, the turning point estimate is generally robust to variations in the sample, ranging from $\$ 5400-\$ 6500$ when the sample is limited to: 1 ) country-year observations where per capita GDP exceeds \$1,000 (1985 international dollars), 2) observations with income less than $\$ 15,000,3)$ observations from HD1 countries only, and 4) observations for years 1963-1991. The turning point does increase to approximately $\$ 10,000$, however, if the sample is reduced to 1) only the observations from 1970-1999, or 2) only the HD2 countries.

Using the spline specification of income with logged, region-specific time trends, the estimated turning points are as follows. If the sample is limited to 
observations from 1970-1999, the income elasticity becomes negative once income exceeds $\$ 9,500$ (but is only statistically significant for incomes over $\$ 11,480$ ). If only using observations from 1963-1991, the income elasticity becomes negative once income exceeds $\$ 7,900$ (but is only statistically significant for per capita GDP greater than $\$ 10,300)$. The income elasticity becomes negative for incomes exceeding $\$ 7,275$ when the sample is limited to per capita GDP over $\$ 1,000$ (1985 international dollars), and for incomes exceeding $\$ 7,696$ when the sample is limited to per capita GDP under $\$ 15,000$. Finally, if the sample is limited to only HD1 countries, the income elasticity becomes negative and statistically significant for incomes over $\$ 9,700$.

\section{A.7. Sensitivity Analysis of Turning Point in Fatalities/Population Model to Spline Segmentation}

As shown in Table A.8, the income range of the estimated turning point is fairly robust to using a different number of spline segments. When using $8,9,11$, or 12 spline intervals, the income elasticity becomes negative for incomes greater than $\$ 6,800-7,700$, but generally is not statistically significant until income exceeds $\$ 9,200$. There is no real difference in the turning point between common linear trend and logged region-specific time trend cases; except in the case of 9 intervals, the elasticity is significant for incomes exceeding $\$ 7,700$ with the common time trend but is only statistically significant for incomes over $\$ 10,400$ with the logged regionspecific trends. 
A.8. Pooling of HD1 and HD2 Countries in Spline Specification of Fatalities/Population Equation

Another issue in model specification is whether or not the same functional form of income applies to HD1 and HD2 countries. Since few HD1 observations fall into the lowest income segments and few HD2 observations occur in the higher income ranges, it is difficult to test this statistically using the spline specification. However, for the 3 rd to the 7 th spline segments, one can not reject the null hypothesis that the income elasticities are the same across the two groups of countries. In the specification with log-linear regional time trends, the F statistics testing the equality of the $3^{\text {rd }}-7^{\text {th }}$ spline income coefficients between HD1 and HD2 groups are as follows: $3^{\text {rd }}$ segment: $F(1,2087)=0.12,4^{\text {th }}: F(1,2087)=0.03,5^{\text {th }}: F(1$, $2087)=0.05,6^{\text {th }}: F(1,2087)=0.08,7^{\text {th }}: F(1,2087)=0.00$. 


\section{Table A.1. Classification of Countries for Which Fatalities Are Projected}

The number of observations for each country used to estimate the model is given in parentheses after the country name.

\begin{tabular}{|c|c|c|c|c|}
\hline \multirow{2}{*}{\multicolumn{2}{|c|}{$\begin{array}{l}\text { Region Country } \\
\text { South Asia (SA) } \\
\end{array}$}} & \multicolumn{2}{|c|}{ Region Country } & \\
\hline & & \multicolumn{3}{|c|}{ Latin America \&Caribbean (LAC) } \\
\hline \multicolumn{2}{|c|}{ HD2:Bangladesh } & \multicolumn{2}{|c|}{ (18) $\quad H D 1:$ Argentina } & \\
\hline & Bhutan & \multicolumn{2}{|r|}{ Chile } & $(34)$ \\
\hline & India & $(27)$ & Costa Rica & $(14)$ \\
\hline & Maldives & \multicolumn{2}{|r|}{ Uruguay } & \\
\hline & Nepal & (14) & HD2: Antigua \& Barbuda & \\
\hline & Pakistan & (33) & Belize & \\
\hline \multirow{2}{*}{\multicolumn{2}{|c|}{ Sri Lanka }} & (34) & Bolivia & \\
\hline & & & Brazil & (16) \\
\hline East Asia & \& Pacific (EAP) & & Colombia & $(27)$ \\
\hline & :Korea, Rep. & (29) & Dominica & \\
\hline & China & $(22)$ & Dom. Republic & \\
\hline & Fiji & (15) & Ecuador & (13) \\
\hline & Indonesia & (24) & El Salvador & \\
\hline & Kiribati & & Grenada & \\
\hline & Lao PDR & & Guatemala & \\
\hline & Malaysia & $(37)$ & Guyana & \\
\hline & Mongolia & (14) & Haiti & \\
\hline & Papua New Guinea & (12) & Honduras & \\
\hline & Philippines & (18) & Jamaica & \\
\hline & Samoa & (13) & Mexico & \\
\hline & Solomon Islands & & Nicaragua & \\
\hline & Thailand & $(28)$ & Panama & (16) \\
\hline & Tonga & (13) & Paraguay & \\
\hline \multirow{2}{*}{\multicolumn{2}{|c|}{ Vanuatu }} & & Peru & (11) \\
\hline & & & Puerto Rico & \\
\hline Middle Ea & \& N. Africa (MNA) & & St. Kitts \& Nevis & \\
\hline & :Bahrain & (12) & St. Lucia & \\
\hline & Algeria & & St. Vincent \& Grenadines & \\
\hline & Djibouti & & Suriname & \\
\hline & Egypt & (11) & Trinidad \& Tobago & \\
\hline & Iran & & Venezuela & \\
\hline & Iraq & (11) & & \\
\hline & Jordan & \multicolumn{2}{|c|}{ (32) Europe \& Central Asia (ECA) } & \\
\hline & Morocco & (34) $\quad I$ & HD1:Czech Republic & $(28)$ \\
\hline & Oman & & Hungary & (33) \\
\hline & Saudi Arabia & (20) & Poland & (19) \\
\hline & Syria & (22) & Slovak Republic & \\
\hline & Tunisia & (26) & HD2: Bulgaria & $(18)$ \\
\hline \multirow{5}{*}{\multicolumn{2}{|c|}{ Yemen }} & (12) & Georgia & \\
\hline & & & Latvia & $(11)$ \\
\hline & & & Romania & (13) \\
\hline & & & Turkey & (34) \\
\hline & & & Yugoslavia & $(20)$ \\
\hline
\end{tabular}


(Table A.1. continued)

Sub-Saharan Africa (SSA)

High-Income OECD

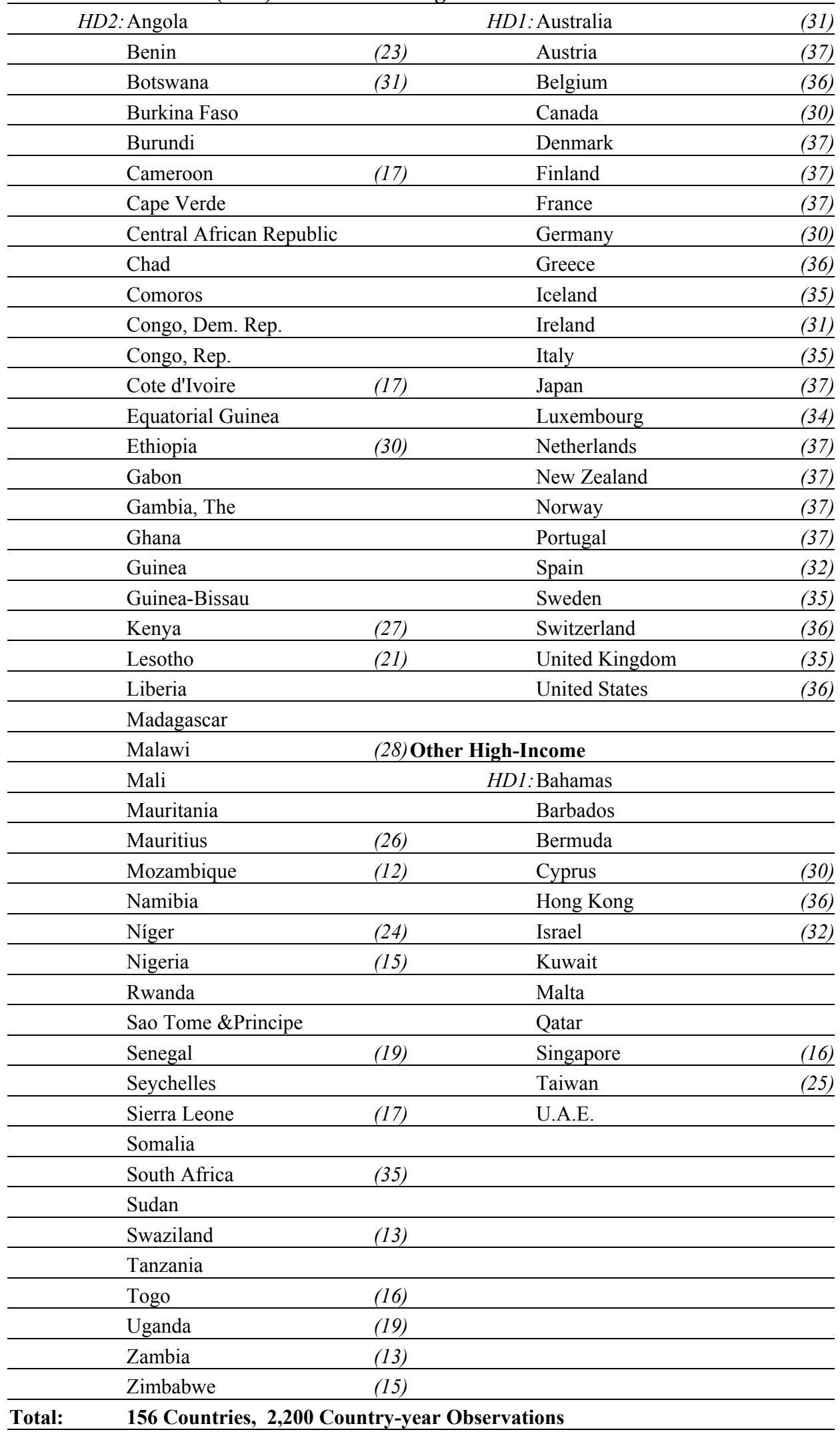




\section{Notes for Table A.2:}

Heteroskedasticity-corrected standard errors, clustered on country to allow for within panel autocorrelation, are given in parentheses.

The constant term reflects the intercept term for India. Country fixed effects were included in all regressions but are not displayed here.

$* * *$ indicates $1 \%$ level of significance. $* *$ indicates $5 \%$ level of significance.

$* 10 \%$ level of significance.

Model Specifications:

1. Regional linear time trends

2. Regional, log-linear time trends 
Table A.2. F/P, V/P, and F/V Regression Results Using Same Spline Segments Across All Equations

\begin{tabular}{|c|c|c|c|c|c|c|}
\hline & \multicolumn{2}{|c|}{ Fatalities/Population } & \multicolumn{2}{|c|}{ Vehicles/Population } & \multicolumn{2}{|c|}{ Fatalities/Vehicles } \\
\hline & 1 & 2 & 1 & 2 & 1 & 2 \\
\hline $\begin{array}{l}\text { lnY for: } \\
\$ 1-\$ 938\end{array}$ & $\begin{array}{c}1.444 * * * \\
(0.346)\end{array}$ & $\begin{array}{c}1.253 * * * \\
(0.328)\end{array}$ & $\begin{array}{c}0.478 \\
(0.401)\end{array}$ & $\begin{array}{c}0.248 \\
(0.495)\end{array}$ & $\begin{array}{c}1.518 * * * \\
(0.471)\end{array}$ & $\begin{array}{l}1.138 * \\
(0.658)\end{array}$ \\
\hline$\$ 938-\$ 1,395$ & $\begin{array}{c}1.119 * * * \\
(0.307)\end{array}$ & $\begin{array}{c}1.060 * * * \\
(0.282)\end{array}$ & $\begin{array}{c}0.756 \\
(0.576)\end{array}$ & $\begin{array}{l}1.537 * * \\
(0.769)\end{array}$ & $\begin{array}{c}0.017 \\
(0.697)\end{array}$ & $\begin{array}{l}-0.673 \\
(0.971)\end{array}$ \\
\hline$\$ 1,395-\$ 2,043$ & $\begin{array}{l}0.512^{*} \\
(0.268)\end{array}$ & $\begin{array}{c}0.326 \\
(0.283)\end{array}$ & $\begin{array}{c}0.946 * * * \\
(0.266)\end{array}$ & $\begin{array}{c}1.407 * * * \\
(0.320)\end{array}$ & $\begin{array}{l}-0.145 \\
(0.334)\end{array}$ & $\begin{array}{c}-0.988^{* *} \\
(0.411)\end{array}$ \\
\hline$\$ 2,043-\$ 3,045$ & $\begin{array}{c}0.976 * * \\
(0.386)\end{array}$ & $\begin{array}{l}0.765^{*} \\
(0.413)\end{array}$ & $\begin{array}{c}0.597 * * \\
(0.259) \\
\end{array}$ & $\begin{array}{c}0.783 * * \\
(0.348) \\
\end{array}$ & $\begin{array}{c}0.612 \\
(0.402)\end{array}$ & $\begin{array}{l}-0.006 \\
(0.553)\end{array}$ \\
\hline$\$ 3,045-\$ 4,065$ & $\begin{array}{c}0.960 * * * \\
(0.327)\end{array}$ & $\begin{array}{c}0.701 * * \\
(0.347)\end{array}$ & $\begin{array}{c}1.349 * * * \\
(0.357)\end{array}$ & $\begin{array}{c}1.699 * * * \\
(0.381)\end{array}$ & $\begin{array}{l}-0.403 \\
(0.427)\end{array}$ & $\begin{array}{c}-1.169 * * \\
(0.496)\end{array}$ \\
\hline$\$ 4,065-\$ 6,095$ & $\begin{array}{c}0.602 * * \\
(0.277)\end{array}$ & $\begin{array}{c}0.390 \\
(0.248)\end{array}$ & $\begin{array}{c}0.828 * * * \\
(0.292)\end{array}$ & $\begin{array}{c}1.214 * * * \\
(0.302)\end{array}$ & $\begin{array}{l}-0.190 \\
(0.281)\end{array}$ & $\begin{array}{c}-0.864 * * * \\
(0.307)\end{array}$ \\
\hline$\$ 6,095-\$ 8,592$ & $\begin{array}{c}0.258 \\
(0.284)\end{array}$ & $\begin{array}{c}0.075 \\
(0.274)\end{array}$ & $\begin{array}{c}0.840 * * * \\
(0.274)\end{array}$ & $\begin{array}{c}1.034 * * * \\
(0.327)\end{array}$ & $\begin{array}{l}-0.500 \\
(0.361)\end{array}$ & $\begin{array}{c}-0.953^{* *} \\
(0.408)\end{array}$ \\
\hline$\$ 8,592-\$ 10,894$ & $\begin{array}{l}-0.207 \\
(0.265)\end{array}$ & $\begin{array}{c}-0.542 * * \\
(0.267)\end{array}$ & $\begin{array}{l}-0.060 \\
(0.211)\end{array}$ & $\begin{array}{c}0.288 \\
(0.285)\end{array}$ & $\begin{array}{l}-0.085 \\
(0.259)\end{array}$ & $\begin{array}{c}-0.917 * * \\
(0.399)\end{array}$ \\
\hline$\$ 10,894-\$ 13,234$ & $\begin{array}{l}-0.668 * \\
(0.384)\end{array}$ & $\begin{array}{c}-1.338 * * * \\
(0.332)\end{array}$ & $\begin{array}{l}-0.605^{*} \\
(0.326)\end{array}$ & $\begin{array}{l}0.364 * \\
(0.222)\end{array}$ & $\begin{array}{c}0.110 \\
(0.354)\end{array}$ & $\begin{array}{c}-1.689 * * * \\
(0.403)\end{array}$ \\
\hline$>\$ 13,234$ & $\begin{array}{l}-0.522 * \\
(0.274)\end{array}$ & $\begin{array}{c}-0.996^{* * * *} \\
(0.242)\end{array}$ & $\begin{array}{c}-0.492 * * * \\
(0.246)\end{array}$ & $\begin{array}{c}0.228 \\
(0.166)\end{array}$ & $\begin{array}{l}-0.013 \\
(0.335)\end{array}$ & $\begin{array}{c}-1.306^{* * * *} \\
(0.275)\end{array}$ \\
\hline $\begin{array}{l}\text { Turning Point } \\
\text { (1985\$int'l) }\end{array}$ & $\$ 8,592$ & $\$ 8,592$ & $\$ 8,592$ & - & $\$ 1,395$ & $\$ 938$ \\
\hline$\frac{\text { Regional t: }}{\text { EAP }}$ & $\begin{array}{c}0.006 \\
(0.007)\end{array}$ & $\begin{array}{c}0.257 * * * \\
(0.096)\end{array}$ & $\begin{array}{c}0.058 * * * \\
(0.014)\end{array}$ & $\begin{array}{c}0.593 * * * \\
(0.221)\end{array}$ & $\begin{array}{c}-0.057 * * * \\
(0.016)\end{array}$ & $\begin{array}{l}-0.302 \\
(0.251)\end{array}$ \\
\hline ECA & $\begin{array}{c}-0.013 * * \\
(0.006)\end{array}$ & $\begin{array}{l}-0.031 \\
(0.087) \\
\end{array}$ & $\begin{array}{c}0.056^{* * *} \\
(0.005)\end{array}$ & $\begin{array}{c}0.509 * * * \\
(0.081)\end{array}$ & $\begin{array}{c}-0.070 * * * \\
(0.010)\end{array}$ & $\begin{array}{c}-0.478 * * * \\
(0.161)\end{array}$ \\
\hline India & $\begin{array}{c}0.022 * * * \\
(0.005)\end{array}$ & $\begin{array}{c}0.319 * * * \\
(0.046)\end{array}$ & $\begin{array}{c}0.076^{* * *} \\
(0.008)\end{array}$ & $\begin{array}{c}0.741 * * * \\
(0.091)\end{array}$ & $\begin{array}{l}-0.052 * * * \\
(0.009)\end{array}$ & $\begin{array}{c}-0.413^{* * *} \\
(0.118)\end{array}$ \\
\hline LAC & $\begin{array}{c}0.012 \\
(0.007)\end{array}$ & $\begin{array}{c}0.264 \\
(0.168)\end{array}$ & $\begin{array}{c}0.022 * * * \\
(0.007)\end{array}$ & $\begin{array}{c}0.185^{* *} \\
(0.075)\end{array}$ & $\begin{array}{c}-0.013 * * * \\
(0.006)\end{array}$ & $\begin{array}{l}-0.030 \\
(0.106)\end{array}$ \\
\hline MNA & $\begin{array}{l}-0.007 \\
(0.010)\end{array}$ & $\begin{array}{c}0.011 \\
(0.127)\end{array}$ & $\begin{array}{c}0.019 * * * \\
(0.006)\end{array}$ & $\begin{array}{c}0.030 \\
(0.070)\end{array}$ & $\begin{array}{c}-0.025 * * * \\
(0.008)\end{array}$ & $\begin{array}{r}0.034 \\
(0.109)\end{array}$ \\
\hline SA & $\begin{array}{c}0.004 \\
(0.004)\end{array}$ & $\begin{array}{c}0.096^{* *} \\
(0.041)\end{array}$ & $\begin{array}{c}0.041 * * * \\
(0.008)\end{array}$ & $\begin{array}{c}0.254^{* *} \\
(0.103)\end{array}$ & $\begin{array}{c}-0.038^{* * * *} \\
(0.008)\end{array}$ & $\begin{array}{l}-0.140 \\
(0.120)\end{array}$ \\
\hline SSA & $\begin{array}{l}0.011 * * \\
(0.005)\end{array}$ & $\begin{array}{l}0.161 * * \\
(0.068)\end{array}$ & $\begin{array}{c}0.030 * * * \\
(0.009)\end{array}$ & $\begin{array}{c}0.349 * * * \\
(0.118)\end{array}$ & $\begin{array}{c}-0.032 * * * \\
(0.007)\end{array}$ & $\begin{array}{c}-0.288 * * * \\
(0.096)\end{array}$ \\
\hline High Income & $\begin{array}{c}-0.015 * * * \\
(0.005)\end{array}$ & $\begin{array}{l}-0.057 \\
(0.043)\end{array}$ & $\begin{array}{c}0.029 * * * \\
(0.005)\end{array}$ & $\begin{array}{c}0.198 * * * \\
(0.058)\end{array}$ & $\begin{array}{c}-0.047 * * * \\
(0.005)\end{array}$ & $\begin{array}{c}-0.251^{* * * *} \\
(0.067)\end{array}$ \\
\hline $\begin{array}{l}\text { F statistic on regional } \\
\text { ts: }\end{array}$ & $\begin{array}{c}\mathrm{F}(7,87)= \\
8.67 * * *\end{array}$ & $\begin{aligned} & \mathrm{F}(7,87) \\
= & 9.28 * * *\end{aligned}$ & $\begin{array}{l}\mathrm{F}(7,74)= \\
19.22 * * *\end{array}$ & $\begin{array}{l}\mathrm{F}(7,4)= \\
23.44 * * *\end{array}$ & $\begin{array}{c}\mathrm{F}(7,69)= \\
10.42 * * *\end{array}$ & $\begin{array}{c}\mathrm{F}(7,69)= \\
6.83 * * *\end{array}$ \\
\hline constant & $\begin{array}{c}-11.360 * * * \\
(2.290)\end{array}$ & $\begin{array}{c}-10.463 * * * \\
(2.141)\end{array}$ & $\begin{array}{l}-0.437 \\
(2.661)\end{array}$ & $\begin{array}{c}0.445 \\
(3.265)\end{array}$ & $\begin{array}{c}-12.357 * * * \\
(3.132)\end{array}$ & $\begin{array}{c}-9.575^{* *} \\
(4.338)\end{array}$ \\
\hline DW statistic: & 0.841 & 0.816 & 0.192 & 0.196 & 0.605 & 0.472 \\
\hline Adjusted R2: & 0.8695 & 0.8656 & 0.9850 & 0.9799 & 0.9589 & 0.9391 \\
\hline Countries; Obs & $88 ;$ & & & & 70 & 695 \\
\hline
\end{tabular}




\section{Notes for Table A.3 - A.5:}

Heteroskedasticity-corrected standard errors, clustered on country to allow for within panel autocorrelation, are given in parentheses.

The constant term reflects the intercept term for India.

$* * *$ indicates $1 \%$ level of significance $* *$ indicates $5 \%$ level of significance.

$* 10 \%$ level of significance.

\section{Model Specifications:}

9. Quadratic, common linear time trend

10. Quadratic, common log-linear time trend

11. Quadratic, regional linear time trends

12. Quadratic, regional, log-linear time trends

13. Spline, common linear time trend

14. Spline, common log-linear time trend

15. Spline, regional linear time trends

16. Spline, regional, log-linear time trends 
Table A.3. Country Dummy Coefficients from F/P Models

\begin{tabular}{|c|c|c|c|c|c|c|c|c|}
\hline \multirow{2}{*}{$\begin{array}{l}\text { Country } \\
\text { Dummies }\end{array}$} & \multicolumn{4}{|c|}{ Quadratic } & \multicolumn{4}{|c|}{ Spline } \\
\hline & 1 & 2 & 3 & 4 & 5 & 6 & 7 & 8 \\
\hline & $0.733 * *$ & $0.971 * * *$ & $0.869 * * *$ & $1.792 * * *$ & $0.770 * * *$ & $0.965 * * *$ & $0.968 * * *$ & $1.828 * * *$ \\
\hline Australia & $(0.324)$ & $(0.291)$ & $(0.310)$ & $(0.319)$ & $(0.283)$ & $(0.257)$ & $(0.281)$ & $(0.285)$ \\
\hline Austria & $\begin{array}{c}0.646^{* *} \\
(0.296)\end{array}$ & $\begin{array}{c}0.855^{* * *} * \\
(0.269)\end{array}$ & $\begin{array}{c}0.941 * * * \\
(0.296)\end{array}$ & $\begin{array}{c}1.742 * * * \\
(0.317)\end{array}$ & $\begin{array}{c}0.637 * * \\
(0.259)\end{array}$ & $\begin{array}{c}0.808^{* * *} \\
(0.239)\end{array}$ & $\begin{array}{c}0.985^{* * *} \\
(0.269)\end{array}$ & $\begin{array}{c}1.742 * * * \\
(0.285)\end{array}$ \\
\hline Bahrain & $\begin{array}{c}-0.088 \\
(0.260)\end{array}$ & $\begin{array}{c}0.080 \\
(0.246)\end{array}$ & $\begin{array}{c}0.452 \\
(0.294)\end{array}$ & $\begin{array}{c}1.067 * * * \\
(0.325)\end{array}$ & $\begin{array}{l}-0.197 \\
(0.227)\end{array}$ & $\begin{array}{l}-0.059 \\
(0.222)\end{array}$ & $\begin{array}{c}0.403 \\
(0.270)\end{array}$ & $\begin{array}{c}0.981 * * * \\
(0.294)\end{array}$ \\
\hline Bangladesh & $\begin{array}{c}-1.413 * * * \\
(0.035)\end{array}$ & $\begin{array}{c}-1.418^{* * *} \\
(0.035)\end{array}$ & $\begin{array}{c}-0.935^{* * * *} \\
(0.059)\end{array}$ & $\begin{array}{c}-0.700^{* * *} \\
(0.050)\end{array}$ & $\begin{array}{c}-1.369^{* * *} \\
(0.046)\end{array}$ & $\begin{array}{c}-1.375^{* * * *} \\
(0.045)\end{array}$ & $\begin{array}{c}-0.978 * * * \\
(0.106) \\
\end{array}$ & $\begin{array}{c}-0.737 * * * \\
(0.123) \\
\end{array}$ \\
\hline Belgium & $\begin{array}{c}0.639^{* *} \\
(0.302)\end{array}$ & $\begin{array}{c}0.855^{* * *} \\
(0.274)\end{array}$ & $\begin{array}{c}0.902 * * * \\
(0.299)\end{array}$ & $\begin{array}{c}1.728^{* * *} \\
(0.317)\end{array}$ & $\begin{array}{c}0.636^{* *} \\
(0.264)\end{array}$ & $\begin{array}{c}0.812 * * * \\
(0.243)\end{array}$ & $\begin{array}{c}0.955^{* * *} \\
(0.271)\end{array}$ & $\begin{array}{c}1.731 * * * \\
(0.285)\end{array}$ \\
\hline Benin & $\begin{array}{c}-0.016^{* *} \\
(0.006)\end{array}$ & $\begin{array}{c}-0.014 * * * \\
(0.003)\end{array}$ & $\begin{array}{l}0.206^{*} \\
(0.105)\end{array}$ & $\begin{array}{c}0.363^{* *} \\
(0.170)\end{array}$ & $\begin{array}{c}-0.028 \\
(0.031)\end{array}$ & $\begin{array}{c}-0.026 \\
(0.029)\end{array}$ & $\begin{array}{l}0.246^{*} \\
(0.130)\end{array}$ & $\begin{array}{c}0.433 * * \\
(0.207)\end{array}$ \\
\hline Botswana & $\begin{array}{c}0.605 * * * \\
(0.067)\end{array}$ & $\begin{array}{c}0.637 * * * \\
(0.061)\end{array}$ & $\begin{array}{c}0.819 * * * \\
(0.145)\end{array}$ & $\begin{array}{c}1.043 * * * \\
(0.196)\end{array}$ & $\begin{array}{c}0.727 * * * \\
(0.071)\end{array}$ & $\begin{array}{c}0.754 * * * \\
(0.065)\end{array}$ & $\begin{array}{c}0.984 * * * \\
(0.157)\end{array}$ & $\begin{array}{c}1.227 * * * \\
(0.233)\end{array}$ \\
\hline Brazil & $\begin{array}{c}0.188 \\
(0.179)\end{array}$ & $\begin{array}{c}0.276 \\
(0.170)\end{array}$ & $\begin{array}{c}0.118 \\
(0.326)\end{array}$ & $\begin{array}{c}0.118 \\
(0.664)\end{array}$ & $\begin{array}{c}0.235 \\
(0.185)\end{array}$ & $\begin{array}{l}0.319^{*} \\
(0.184)\end{array}$ & $\begin{array}{c}0.306 \\
(0.299)\end{array}$ & $\begin{array}{c}0.438 \\
(0.585)\end{array}$ \\
\hline Bulgaria & $\begin{array}{c}0.004 \\
(0.206) \\
\end{array}$ & $\begin{array}{c}0.116 \\
(0.193) \\
\end{array}$ & $\begin{array}{c}0.518^{* *} \\
(0.244)\end{array}$ & $\begin{array}{c}0.899 * * \\
(0.374)\end{array}$ & $\begin{array}{c}0.002 \\
(0.198) \\
\end{array}$ & $\begin{array}{c}0.099 \\
(0.192) \\
\end{array}$ & $\begin{array}{c}0.673^{* * *} \\
(0.215)\end{array}$ & $\begin{array}{c}1.159^{* * *} \\
(0.309)\end{array}$ \\
\hline Cameroon & $\begin{array}{c}0.225 * * * \\
(0.012)\end{array}$ & $\begin{array}{c}0.230 * * * \\
(0.007)\end{array}$ & $\begin{array}{c}0.443 * * * \\
(0.107)\end{array}$ & $\begin{array}{c}0.606^{* * * *} \\
(0.172)\end{array}$ & $\begin{array}{c}0.233^{* * *} * \\
(0.018)\end{array}$ & $\begin{array}{c}0.233 * * * \\
(0.015)\end{array}$ & $\begin{array}{c}0.499 * * * \\
(0.137)\end{array}$ & $\begin{array}{c}0.677^{* * *} \\
(0.217)\end{array}$ \\
\hline Canada & $\begin{array}{c}0.653 * * \\
(0.327)\end{array}$ & $\begin{array}{c}0.898 * * * \\
(0.297)\end{array}$ & $\begin{array}{c}0.759 * * \\
(0.313)\end{array}$ & $\begin{array}{c}1.692 * * * \\
(0.318)\end{array}$ & $\begin{array}{c}0.722 * * \\
(0.284)\end{array}$ & $\begin{array}{c}0.921 * * * \\
(0.257)\end{array}$ & $\begin{array}{c}0.891 * * * \\
(0.284)\end{array}$ & $\begin{array}{c}1.771 * * * \\
(0.284)\end{array}$ \\
\hline Chile & $\begin{array}{c}0.005 \\
(0.193) \\
\end{array}$ & $\begin{array}{c}0.114 \\
(0.179) \\
\end{array}$ & $\begin{array}{c}0.724 * * * \\
(0.259)\end{array}$ & $\begin{array}{c}1.181 * * * \\
(0.300)\end{array}$ & $\begin{array}{c}0.081 \\
(0.200) \\
\end{array}$ & $\begin{array}{c}0.178 \\
(0.193) \\
\end{array}$ & $\begin{array}{c}0.789 * * * \\
(0.250)\end{array}$ & $\begin{array}{c}1.301 * * * \\
(0.288)\end{array}$ \\
\hline China & $\begin{array}{c}-0.425^{* * *} \\
(0.027)\end{array}$ & $\begin{array}{c}-0.424 * * * \\
(0.027)\end{array}$ & $\begin{array}{c}-0.145 \\
(0.175)\end{array}$ & $\begin{array}{c}-0.349 \\
(0.319)\end{array}$ & $\begin{array}{c}-0.382 * * * \\
(0.027)\end{array}$ & $\begin{array}{c}-0.382 * * * \\
(0.026)\end{array}$ & $\begin{array}{c}-0.061 \\
(0.178)\end{array}$ & $\begin{array}{c}-0.252 \\
(0.283)\end{array}$ \\
\hline Colombia & $\begin{array}{c}-0.086 \\
(0.152)\end{array}$ & $\begin{array}{c}-0.012 \\
(0.141)\end{array}$ & $\begin{array}{l}-0.001 \\
(0.277)\end{array}$ & $\begin{array}{l}-0.067 \\
(0.600)\end{array}$ & $\begin{array}{c}0.069 \\
(0.167)\end{array}$ & $\begin{array}{c}0.137 \\
(0.163)\end{array}$ & $\begin{array}{c}0.264 \\
(0.257)\end{array}$ & $\begin{array}{c}0.337 \\
(0.531)\end{array}$ \\
\hline Costa Rica & $\begin{array}{c}-0.450 * * * \\
(0.158)\end{array}$ & $\begin{array}{c}-0.381 * * \\
(0.154)\end{array}$ & $\begin{array}{l}0.492^{*} \\
(0.278)\end{array}$ & $\begin{array}{c}0.764 * * \\
(0.309)\end{array}$ & $\begin{array}{c}-0.370 * * \\
(0.183)\end{array}$ & $\begin{array}{c}-0.297 \\
(0.185)\end{array}$ & $\begin{array}{c}0.538^{* * *} \\
(0.270)\end{array}$ & $\begin{array}{c}0.903 * * * \\
(0.298)\end{array}$ \\
\hline Cote d'Ivoire & $\begin{array}{c}-0.178^{*} \\
(0.097)\end{array}$ & $\begin{array}{c}-0.113 \\
(0.086)\end{array}$ & $\begin{array}{c}0.182 \\
(0.145)\end{array}$ & $\begin{array}{c}0.399 * * \\
(0.179)\end{array}$ & $\begin{array}{l}-0.039 \\
(0.102)\end{array}$ & $\begin{array}{c}0.011 \\
(0.087)\end{array}$ & $\begin{array}{c}0.333^{* * *} \\
(0.168)\end{array}$ & $\begin{array}{c}0.578 * * * \\
(0.221)\end{array}$ \\
\hline Cyprus & $\begin{array}{c}0.259 \\
(0.224)\end{array}$ & $\begin{array}{c}0.401^{* *} \\
(0.203)\end{array}$ & $\begin{array}{c}0.825 * * * \\
(0.259)\end{array}$ & $\begin{array}{c}1.404 * * * \\
(0.297)\end{array}$ & $\begin{array}{c}0.306 \\
(0.211)\end{array}$ & $\begin{array}{c}0.426^{* *} \\
(0.198)\end{array}$ & $\begin{array}{c}0.883 * * * \\
(0.245)\end{array}$ & $\begin{array}{c}1.484 * * * \\
(0.280)\end{array}$ \\
\hline $\begin{array}{l}\text { Czech } \\
\text { Republic }\end{array}$ & $\begin{array}{c}0.330^{* *} \\
(0.167)\end{array}$ & $\begin{array}{c}0.421 * * * \\
(0.154)\end{array}$ & $\begin{array}{c}1.083 * * * \\
(0.244)\end{array}$ & $\begin{array}{c}1.492 * * * \\
(0.285)\end{array}$ & $\begin{array}{c}0.469 * * * \\
(0.173)\end{array}$ & $\begin{array}{c}0.552^{* * *} \\
(0.167)\end{array}$ & $\begin{array}{c}1.201 * * * \\
(0.232)\end{array}$ & $\begin{array}{c}1.676^{* * *}(0.271) \\
(0.27)\end{array}$ \\
\hline Denmark & $\begin{array}{c}0.369 \\
(0.314) \\
\end{array}$ & $\begin{array}{c}0.597 * * \\
(0.284) \\
\end{array}$ & $\begin{array}{l}0.566^{*} \\
(0.305) \\
\end{array}$ & $\begin{array}{c}1.439 * * * \\
(0.319)\end{array}$ & $\begin{array}{c}0.393 \\
(0.273) \\
\end{array}$ & $\begin{array}{c}0.580^{* *} \\
(0.250) \\
\end{array}$ & $\begin{array}{c}0.650^{* *} \\
(0.276) \\
\end{array}$ & $\begin{array}{c}1.468^{* * *} \\
(0.285) \\
\end{array}$ \\
\hline Ecuador & $\begin{array}{c}-0.055 \\
(0.131) \\
\end{array}$ & $\begin{array}{c}-0.007 \\
(0.129) \\
\end{array}$ & $\begin{array}{c}-0.075 \\
(0.319) \\
\end{array}$ & $\begin{array}{c}-0.168 \\
(0.670) \\
\end{array}$ & $\begin{array}{c}0.099 \\
(0.178) \\
\end{array}$ & $\begin{array}{c}0.152 \\
(0.179) \\
\end{array}$ & $\begin{array}{c}0.227 \\
(0.294) \\
\end{array}$ & $\begin{array}{c}0.274 \\
(0.592) \\
\end{array}$ \\
\hline Egypt & $\begin{array}{c}0.249 * * * \\
(0.076)\end{array}$ & $\begin{array}{c}0.272 * * * \\
(0.070)\end{array}$ & $\begin{array}{c}0.917 * * * \\
(0.253)\end{array}$ & $\begin{array}{c}1.223 * * * \\
(0.400)\end{array}$ & $\begin{array}{c}0.401 * * * \\
(0.078)\end{array}$ & $\begin{array}{c}0.414 * * * \\
(0.070)\end{array}$ & $\begin{array}{c}1.052 * * * \\
(0.256)\end{array}$ & $\begin{array}{c}1.345^{* * *} \\
(0.392)\end{array}$ \\
\hline Ethiopia & $\begin{array}{c}1.941 * * * \\
(0.236)\end{array}$ & $\begin{array}{c}1.875^{* * *} * \\
(0.234)\end{array}$ & $\begin{array}{c}1.714 * * * \\
(0.227)\end{array}$ & $\begin{array}{c}1.878^{* * * *} \\
(0.264)\end{array}$ & $\begin{array}{c}1.475^{* * *} * \\
(0.398)\end{array}$ & $\begin{array}{c}1.389 * * * \\
(0.378)\end{array}$ & $\begin{array}{c}1.493 * * * \\
(0.320)\end{array}$ & $\begin{array}{c}1.456^{* * *} \\
(0.357)\end{array}$ \\
\hline Fiji & $\begin{array}{c}-0.126 \\
(0.171) \\
\end{array}$ & $\begin{array}{c}-0.043 \\
(0.160)\end{array}$ & $\begin{array}{c}0.099 \\
(0.209) \\
\end{array}$ & $\begin{array}{c}0.066 \\
(0.335) \\
\end{array}$ & $\begin{array}{c}-0.038 \\
(0.189) \\
\end{array}$ & $\begin{array}{c}0.040 \\
(0.187)\end{array}$ & $\begin{array}{c}0.229 \\
(0.193) \\
\end{array}$ & $\begin{array}{c}0.210 \\
(0.256)\end{array}$ \\
\hline Finland & $\begin{array}{c}0.250 \\
(0.299) \\
\end{array}$ & $\begin{array}{c}0.463^{*} \\
(0.272) \\
\end{array}$ & $\begin{array}{c}0.526^{*} \\
(0.297) \\
\end{array}$ & $\begin{array}{c}1.341 * * * \\
(0.317)\end{array}$ & $\begin{array}{c}0.251 \\
(0.262) \\
\end{array}$ & $\begin{array}{l}0.426^{*} \\
(0.241) \\
\end{array}$ & $\begin{array}{c}0.580^{* *} \\
(0.270) \\
\end{array}$ & $\begin{array}{c}1.350^{* * *} \\
(0.285)\end{array}$ \\
\hline France & $\begin{array}{c}0.688^{* *} \\
(0.309)\end{array}$ & $\begin{array}{c}0.911 * * * \\
(0.281)\end{array}$ & $\begin{array}{c}0.911 * * * \\
(0.303)\end{array}$ & $\begin{array}{c}1.766^{* * * *} \\
(0.318)\end{array}$ & $\begin{array}{c}0.711^{* * *} \\
(0.270)\end{array}$ & $\begin{array}{c}0.894 * * * \\
(0.248)\end{array}$ & $\begin{array}{c}0.988 * * * \\
(0.274)\end{array}$ & $\begin{array}{c}1.792 * * * \\
(0.285)\end{array}$ \\
\hline Germany & $\begin{array}{c}0.427 \\
(0.315)\end{array}$ & $\begin{array}{c}0.656^{* *} \\
(0.283)\end{array}$ & $\begin{array}{c}0.614^{* *} \\
(0.304)\end{array}$ & $\begin{array}{c}1.500^{* * * *} \\
(0.318)\end{array}$ & $\begin{array}{c}0.433 \\
(0.274)\end{array}$ & $\begin{array}{c}0.618^{* * *} \\
(0.250)\end{array}$ & $\begin{array}{c}0.684 * * \\
(0.276)\end{array}$ & $\begin{array}{c}1.508^{* * *} \\
(0.284)\end{array}$ \\
\hline Greece & $\begin{array}{c}0.079 \\
(0.229) \\
\end{array}$ & $\begin{array}{c}0.223 \\
(0.211)\end{array}$ & $\begin{array}{c}0.669 * * \\
(0.269)\end{array}$ & $\begin{array}{c}1.236^{* * *} \\
(0.306)\end{array}$ & $\begin{array}{c}0.088 \\
(0.217) \\
\end{array}$ & $\begin{array}{c}0.208 \\
(0.204) \\
\end{array}$ & $\begin{array}{c}0.688 * * * \\
(0.257)\end{array}$ & $\begin{array}{c}1.278 * * * \\
(0.290)\end{array}$ \\
\hline Hong Kong & $\begin{array}{c}-0.474^{*} \\
(0.279)\end{array}$ & $\begin{array}{c}-0.279 \\
(0.252)\end{array}$ & $\begin{array}{l}-0.142 \\
(0.283)\end{array}$ & $\begin{array}{c}0.622 * * \\
(0.307)\end{array}$ & $\begin{array}{c}-0.421^{*} \\
(0.248)\end{array}$ & $\begin{array}{c}-0.262 \\
(0.227)\end{array}$ & $\begin{array}{c}-0.052 \\
(0.260)\end{array}$ & $\begin{array}{c}0.697 * * \\
(0.282)\end{array}$ \\
\hline
\end{tabular}


(Table A.3. continued)

\begin{tabular}{|c|c|c|c|c|c|c|c|c|}
\hline Hungary & $\begin{array}{c}0.117 \\
(0.207) \\
\end{array}$ & $\begin{array}{c}0.243 \\
(0.191) \\
\end{array}$ & $\begin{array}{c}0.767 * * * \\
(0.258)\end{array}$ & $\begin{array}{c}1.277 * * * \\
(0.298)\end{array}$ & $\begin{array}{c}0.188 \\
(0.202) \\
\end{array}$ & $\begin{array}{c}0.297 \\
(0.192) \\
\end{array}$ & $\begin{array}{c}0.830^{* * * *} \\
(0.247)\end{array}$ & $\begin{array}{c}1.385^{* * *} \\
(0.284)\end{array}$ \\
\hline & -0.195 & 0.015 & 0.084 & $0.901 * * *$ & -0.178 & -0.007 & 0.147 & $0.924 * * *$ \\
\hline \multirow[t]{2}{*}{ Iceland } & $(0.299)$ & $(0.270)$ & $(0.297)$ & $(0.318)$ & $(0.263)$ & $(0.240)$ & $(0.271)$ & $(0.285)$ \\
\hline & $-0.144 * * *$ & $-0.126^{* * *}$ & 0.160 & 0.013 & -0.062 & -0.052 & $0.275^{*}$ & 0.132 \\
\hline \multirow[t]{2}{*}{ Indonesia } & $(0.033)$ & $(0.026)$ & $(0.134)$ & $(0.280)$ & $(0.048)$ & $(0.040)$ & $(0.144)$ & $(0.252)$ \\
\hline & 0.069 & 0.213 & $0.510 * *$ & $1.102 * * *$ & 0.152 & 0.279 & $0.603 * *$ & $1.180 * * *$ \\
\hline \multirow[t]{2}{*}{ Iraq } & $(0.223)$ & $(0.201)$ & $(0.252)$ & $(0.342)$ & $(0.216)$ & $(0.203)$ & $(0.249)$ & $(0.341)$ \\
\hline & 0.133 & 0.301 & $0.615 * *$ & $1.278 * * *$ & 0.111 & 0.247 & $0.624 * *$ & $1.279 * * *$ \\
\hline \multirow[t]{2}{*}{ Ireland } & $(0.257)$ & $(0.234)$ & $(0.280)$ & $(0.313)$ & $(0.231)$ & $(0.214)$ & $(0.261)$ & $(0.290)$ \\
\hline & 0.043 & 0.225 & $0.476^{*}$ & $1.170 * * *$ & 0.002 & 0.152 & $0.481^{*}$ & $1.150 * * *$ \\
\hline \multirow[t]{2}{*}{ Israel } & $(0.268)$ & $(0.246)$ & $(0.283)$ & $(0.313)$ & $(0.236)$ & $(0.222)$ & $(0.262)$ & $(0.287)$ \\
\hline & 0.228 & 0.434 & $0.537^{*}$ & $1.330 * * *$ & 0.209 & 0.377 & $0.572 * *$ & $1.321 * * *$ \\
\hline \multirow[t]{2}{*}{ Italy } & $(0.293)$ & $(0.266)$ & $(0.294)$ & $(0.316)$ & $(0.257)$ & $(0.237)$ & $(0.268)$ & $(0.285)$ \\
\hline & -0.116 & 0.093 & 0.172 & $0.974 * * *$ & -0.094 & 0.077 & 0.241 & $1.009 * * *$ \\
\hline \multirow[t]{2}{*}{ Japan } & $(0.294)$ & $(0.267)$ & $(0.293)$ & $(0.314)$ & $(0.257)$ & $(0.237)$ & $(0.267)$ & $(0.283)$ \\
\hline & $0.325^{* *}$ & $0.404 * * *$ & $0.905 * * *$ & $1.330 * * *$ & $0.478 * * *$ & $0.549 * * *$ & $1.056^{* * *}$ & $1.474 * * *$ \\
\hline \multirow[t]{2}{*}{ Jordan } & $(0.141)$ & $(0.130)$ & $(0.233)$ & $(0.353)$ & $(0.142)$ & $(0.134)$ & $(0.240)$ & $(0.361)$ \\
\hline & $1.147 * * *$ & $1.138 * * *$ & $1.340 * * *$ & $1.469 * * *$ & $1.102 * * *$ & $1.091 * * *$ & $1.360 * * *$ & $1.501 * * *$ \\
\hline \multirow[t]{2}{*}{ Kenya } & $(0.037)$ & $(0.039)$ & $(0.076)$ & $(0.156)$ & $(0.052)$ & $(0.052)$ & $(0.087)$ & $(0.181)$ \\
\hline & $0.380^{*}$ & $0.492 * * *$ & $1.071 * * *$ & $1.548 * * *$ & $0.429 * *$ & $0.522 * * *$ & $1.124 * * *$ & $1.631 * * *$ \\
\hline \multirow[t]{2}{*}{ Korea, Rep. } & $(0.195)$ & $(0.180)$ & $(0.257)$ & $(0.297)$ & $(0.182)$ & $(0.173)$ & $(0.238)$ & $(0.275)$ \\
\hline & $0.787 * * *$ & $0.846^{* * *}$ & $1.460 * * *$ & $1.668 * * *$ & $0.904 * * *$ & $0.964 * * *$ & $1.729 * * *$ & $2.068 * * *$ \\
\hline \multirow[t]{2}{*}{ Latvia } & $(0.143)$ & $(0.140)$ & $(0.219)$ & $(0.365)$ & $(0.146)$ & $(0.146)$ & $(0.193)$ & $(0.306)$ \\
\hline & $1.272 * * *$ & $1.252 * * *$ & $1.423 * * *$ & $1.573 * * *$ & $1.241 * * *$ & $1.225 * * *$ & $1.457 * * *$ & $1.631 * * *$ \\
\hline \multirow[t]{2}{*}{ Lesotho } & $(0.018)$ & $(0.018)$ & $(0.122)$ & $(0.191)$ & $(0.035)$ & $(0.031)$ & $(0.146)$ & $(0.228)$ \\
\hline & $0.875 * * *$ & $1.110 * * *$ & $1.014 * * *$ & $1.932 * * *$ & $0.919 * * *$ & $1.107 * * *$ & $1.125 * * *$ & $1.985 * * *$ \\
\hline \multirow[t]{2}{*}{ Luxembourg } & $(0.322)$ & $(0.289)$ & $(0.310)$ & $(0.318)$ & $(0.279)$ & $(0.251)$ & $(0.280)$ & $(0.284)$ \\
\hline & $1.778 * * *$ & $1.741 * * *$ & $1.780 * * *$ & $1.930 * * *$ & $1.600 * * *$ & $1.555 * * *$ & $1.728 * * *$ & $1.790 * * *$ \\
\hline \multirow[t]{2}{*}{ Malawi } & $(0.140)$ & $(0.138)$ & $(0.125)$ & $(0.179)$ & $(0.234)$ & $(0.222)$ & $(0.182)$ & $(0.239)$ \\
\hline & $0.365^{* *}$ & $0.469 * * *$ & $0.598 * * *$ & $0.662 * *$ & $0.453 * * *$ & $0.542 * * *$ & $0.727 * * *$ & $0.792 * * *$ \\
\hline \multirow[t]{2}{*}{ Malaysia } & $(0.177)$ & $(0.164)$ & $(0.189)$ & $(0.289)$ & $(0.165)$ & $(0.156)$ & $(0.174)$ & $(0.229)$ \\
\hline & -0.072 & 0.049 & -0.037 & 0.437 & -0.053 & 0.050 & 0.053 & $0.518^{*}$ \\
\hline \multirow[t]{2}{*}{ Mauritius } & $(0.208)$ & $(0.193)$ & $(0.250)$ & $(0.276)$ & $(0.202)$ & $(0.194)$ & $(0.257)$ & $(0.312)$ \\
\hline & $0.503 * * *$ & $0.503 * * *$ & $0.784 * * *$ & 0.555 & $0.602 * * *$ & $0.602 * * *$ & $0.912 * * *$ & $0.700 * *$ \\
\hline Mongolia & $(0.057)$ & $(0.057)$ & $(0.219)$ & $(0.351)$ & $(0.065)$ & $(0.064)$ & $(0.231)$ & $(0.323)$ \\
\hline & $0.350 * * *$ & $0.394 * * *$ & $0.976^{* * *}$ & $1.312 * * *$ & $0.504 * * *$ & $0.539 * * *$ & $1.119^{* * *}$ & $1.449 * * *$ \\
\hline Morocco & $(0.085)$ & $(0.080)$ & $(0.220)$ & $(0.348)$ & $(0.082)$ & $(0.074)$ & $(0.224)$ & $(0.344)$ \\
\hline & $0.273 * * *$ & $0.267 * * *$ & $0.441 * * *$ & $0.610 * * *$ & $0.285 * * *$ & $0.278 * * *$ & $0.509 * * *$ & $0.691 * * *$ \\
\hline Mozambique & $(0.006)$ & $(0.006)$ & $(0.113)$ & $(0.179)$ & $(0.014)$ & $(0.014)$ & $(0.135)$ & $(0.218)$ \\
\hline & $-0.460 * * *$ & $-0.485 * * *$ & -0.023 & $0.183 * * *$ & $-0.501 * * *$ & $-0.520 * * *$ & -0.123 & 0.091 \\
\hline Nepal & $(0.023)$ & $(0.023)$ & $(0.046)$ & $(0.034)$ & $(0.048)$ & $(0.043)$ & $(0.105)$ & $(0.122)$ \\
\hline & 0.210 & 0.430 & 0.452 & $1.293 * * *$ & 0.212 & 0.393 & $0.514^{*}$ & $1.300 * * *$ \\
\hline Netherlands & $(0.306)$ & $(0.278)$ & $(0.301)$ & $(0.318)$ & $(0.267)$ & $(0.246)$ & $(0.273)$ & $(0.285)$ \\
\hline & $0.567^{*}$ & $0.785^{* * *}$ & $0.827^{* * *}$ & $1.657^{* * *}$ & $0.537 * *$ & $0.716^{* * *}$ & $0.865 * * *$ & $1.631 * * *$ \\
\hline New Zealand & $(0.305)$ & $(0.277)$ & $(0.301)$ & $(0.319)$ & $(0.264)$ & $(0.246)$ & $(0.272)$ & $(0.286)$ \\
\hline & $0.256 * * *$ & $0.240 * * *$ & $0.409 * * *$ & $0.529 * * *$ & $0.192 *$ & 0.169 & $0.420 * * *$ & $0.518 * * *$ \\
\hline Niger & $(0.072)$ & $(0.075)$ & $(0.069)$ & $(0.153)$ & $(0.113)$ & $(0.108)$ & $(0.090)$ & $(0.184)$ \\
\hline & $0.697 * * *$ & $0.692 * * *$ & $0.895 * * *$ & $1.049^{* * *}$ & $0.696^{* * *}$ & $0.689 * * *$ & $0.946^{* * *}$ & $1.125^{* * *}$ \\
\hline Nigeria & $(0.014)$ & $(0.014)$ & $(0.121)$ & $(0.188)$ & $(0.028)$ & $(0.026)$ & $(0.150)$ & $(0.231)$ \\
\hline & -0.036 & 0.193 & 0.154 & $1.030 * * *$ & 0.006 & 0.190 & 0.252 & $1.083 * * *$ \\
\hline Norway & $(0.313)$ & $(0.283)$ & $(0.304)$ & $(0.317)$ & $(0.273)$ & $(0.247)$ & $(0.276)$ & $(0.284)$ \\
\hline & $-0.194 * * *$ & $-0.184 * * *$ & $0.253 * * *$ & $0.504 * * *$ & $-0.189 * * *$ & $-0.181 * * *$ & $0.212^{* *}$ & $0.460 * * *$ \\
\hline Pakistan & $(0.018)$ & $(0.015)$ & $(0.048)$ & $(0.041)$ & $(0.024)$ & $(0.022)$ & $(0.091)$ & $(0.111)$ \\
\hline & 0.135 & 0.215 & 0.219 & 0.167 & 0.277 & $0.352 *$ & $0.474^{*}$ & 0.560 \\
\hline Panama & $(0.160)$ & $(0.149)$ & $(0.280)$ & $(0.599)$ & $(0.192)$ & $(0.189)$ & $(0.263)$ & $(0.529)$ \\
\hline Papua New & $0.166^{* * *}$ & $0.178 * * *$ & $0.487 * * *$ & 0.276 & $0.278 * * *$ & $0.282 * * *$ & $0.620 * * *$ & 0.423 \\
\hline Guinea & $(0.062)$ & $(0.059)$ & $(0.181)$ & $(0.328)$ & $(0.072)$ & $(0.066)$ & $(0.202)$ & $(0.307)$ \\
\hline
\end{tabular}


(Table A.3. continued)

\begin{tabular}{|c|c|c|c|c|c|c|c|c|}
\hline Peru & $\begin{array}{c}0.148 \\
(0.144) \\
\end{array}$ & $\begin{array}{l}0.224^{*} \\
(0.136) \\
\end{array}$ & $\begin{array}{c}0.297 \\
(0.258) \\
\end{array}$ & $\begin{array}{c}0.255 \\
(0.547) \\
\end{array}$ & $\begin{array}{c}0.347 * * \\
(0.162) \\
\end{array}$ & $\begin{array}{c}0.418^{* * *} \\
(0.158)\end{array}$ & $\begin{array}{l}0.590^{* *} \\
(0.241)\end{array}$ & $\begin{array}{c}0.682 \\
(0.486) \\
\end{array}$ \\
\hline & $-1.567 * * *$ & $-1.552 * * *$ & $-1.256 * * *$ & $-1.458 * * *$ & $-1.414 * * *$ & $-1.404 * * *$ & $-1.082 * * *$ & $-1.266 * * *$ \\
\hline \multirow[t]{2}{*}{ Philippines } & $(0.071)$ & $(0.069)$ & $(0.193)$ & $(0.333)$ & $(0.073)$ & $(0.068)$ & $(0.206)$ & $(0.307)$ \\
\hline & 0.160 & 0.252 & $0.994 * * *$ & $1.364 * * *$ & 0.210 & 0.297 & $1.019 * * *$ & $1.462 * * *$ \\
\hline \multirow[t]{2}{*}{ Poland } & $(0.181)$ & $(0.173)$ & $(0.273)$ & $(0.310)$ & $(0.187)$ & $(0.185)$ & $(0.264)$ & $(0.298)$ \\
\hline & $0.397 *$ & $0.533 * * *$ & $1.010 * * *$ & $1.550 * * *$ & $0.431 * *$ & $0.545 * * *$ & $1.053 * * *$ & $1.618 * * *$ \\
\hline \multirow[t]{2}{*}{ Portugal } & $(0.218)$ & $(0.201)$ & $(0.262)$ & $(0.300)$ & $(0.201)$ & $(0.191)$ & $(0.246)$ & $(0.280)$ \\
\hline & $0.677 * * *$ & $0.680 * * *$ & $1.380 * * *$ & $1.464 * * *$ & $0.767 * * *$ & $0.771 * * *$ & $1.601 * * *$ & $1.816^{* * *}$ \\
\hline \multirow[t]{2}{*}{ Romania } & $(0.043)$ & $(0.043)$ & $(0.159)$ & $(0.317)$ & $(0.042)$ & $(0.042)$ & $(0.173)$ & $(0.298)$ \\
\hline & 0.020 & 0.045 & $0.345^{*}$ & 0.159 & $0.203 * *$ & $0.219 * * *$ & $0.546 * * *$ & 0.379 \\
\hline \multirow[t]{2}{*}{ Samoa } & $(0.083)$ & $(0.078)$ & $(0.181)$ & $(0.325)$ & $(0.082)$ & $(0.074)$ & $(0.193)$ & $(0.298)$ \\
\hline & 0.405 & $0.574 * *$ & $0.668^{*}$ & $1.410 * * *$ & 0.343 & $0.477 * *$ & $0.677^{* *}$ & $1.309 * * *$ \\
\hline \multirow[t]{2}{*}{ Saudi Arabia } & $(0.262)$ & $(0.240)$ & $(0.353)$ & $(0.450)$ & $(0.232)$ & $(0.218)$ & $(0.343)$ & $(0.443)$ \\
\hline & $0.164 * * *$ & $0.170 * * *$ & $0.404 * * *$ & $0.555 * * *$ & $0.172 * * *$ & $0.174 * * *$ & $0.456 * * *$ & $0.634 * * *$ \\
\hline \multirow[t]{2}{*}{ Senegal } & $(0.019)$ & $(0.013)$ & $(0.111)$ & $(0.176)$ & $(0.030)$ & $(0.027)$ & $(0.139)$ & $(0.218)$ \\
\hline & $0.222 * * *$ & $0.203 * * *$ & $0.368 * * *$ & $0.513 * * *$ & $0.186^{* * *}$ & $0.166^{* * *}$ & $0.399 * * *$ & $0.550 * *$ \\
\hline \multirow[t]{2}{*}{ Sierra Leone } & $(0.029)$ & $(0.030)$ & $(0.104)$ & $(0.179)$ & $(0.033)$ & $(0.033)$ & $(0.124)$ & $(0.214)$ \\
\hline & -0.231 & -0.043 & 0.164 & $0.897 * * *$ & -0.263 & -0.113 & 0.184 & $0.879 * * *$ \\
\hline \multirow[t]{2}{*}{ Singapore } & $(0.281)$ & $(0.257)$ & $(0.294)$ & $(0.321)$ & $(0.245)$ & $(0.228)$ & $(0.267)$ & $(0.289)$ \\
\hline & $0.809 * * *$ & $0.903 * * *$ & $1.019 * * *$ & $1.370 * * *$ & $0.954 * * *$ & $1.043 * * *$ & $1.210 * * *$ & $1.586 * * *$ \\
\hline \multirow[t]{2}{*}{ South Africa } & $(0.169)$ & $(0.157)$ & $(0.217)$ & $(0.247)$ & $(0.198)$ & $(0.194)$ & $(0.231)$ & $(0.293)$ \\
\hline & 0.067 & 0.242 & $0.529 *$ & $1.214 * * *$ & 0.004 & 0.141 & $0.513^{*}$ & $1.170 * * *$ \\
\hline \multirow[t]{2}{*}{ Spain } & $(0.266)$ & $(0.242)$ & $(0.286)$ & $(0.318)$ & $(0.235)$ & $(0.219)$ & $(0.265)$ & $(0.291)$ \\
\hline & -0.107 & -0.066 & $0.368^{* * *}$ & $0.671^{* * *}$ & 0.024 & 0.056 & $0.437 * * *$ & $0.738 * * *$ \\
\hline \multirow[t]{2}{*}{ Sri Lanka } & $(0.079)$ & $(0.073)$ & $(0.097)$ & $(0.091)$ & $(0.075)$ & $(0.067)$ & $(0.109)$ & $(0.120)$ \\
\hline & $0.986^{* * *}$ & $1.028^{* * *}$ & $1.116^{* * *}$ & $1.422 * * *$ & $1.169^{* * *}$ & $1.214^{* * *}$ & $1.351 * * *$ & $1.682 * * *$ \\
\hline \multirow[t]{2}{*}{ Swaziland } & $(0.120)$ & $(0.118)$ & $(0.211)$ & $(0.252)$ & $(0.141)$ & $(0.141)$ & $(0.223)$ & $(0.297)$ \\
\hline & 0.062 & 0.296 & 0.222 & $1.123 * * *$ & 0.107 & 0.301 & 0.324 & $1.169 * * *$ \\
\hline \multirow[t]{2}{*}{ Sweden } & $(0.321)$ & $(0.290)$ & $(0.309)$ & $(0.319)$ & $(0.280)$ & $(0.256)$ & $(0.280)$ & $(0.285)$ \\
\hline & $0.595^{*}$ & $0.844 * * *$ & $0.673 * *$ & $1.630 * * *$ & $0.704 * *$ & $0.909 * * *$ & $0.831 * * *$ & $1.741 * * *$ \\
\hline \multirow[t]{2}{*}{ Switzerland } & $(0.333)$ & $(0.301)$ & $(0.318)$ & $(0.320)$ & $(0.293)$ & $(0.263)$ & $(0.289)$ & $(0.285)$ \\
\hline & $-0.473 * * *$ & $-0.377 * *$ & 0.078 & 0.555 & $-0.363 * *$ & $-0.277^{*}$ & 0.188 & $0.652 *$ \\
\hline \multirow[t]{2}{*}{ Syria } & $(0.172)$ & $(0.160)$ & $(0.271)$ & $(0.386)$ & $(0.161)$ & $(0.154)$ & $(0.262)$ & $(0.375)$ \\
\hline & 0.325 & $0.468 * *$ & $0.929 * * *$ & $1.494 * * *$ & 0.316 & $0.435 * *$ & $0.939 * * *$ & $1.513 * * *$ \\
\hline Taiwan & $(0.233)$ & $(0.215)$ & $(0.276)$ & $(0.313)$ & $(0.214)$ & $(0.204)$ & $(0.258)$ & $(0.290)$ \\
\hline & -0.184 & -0.124 & 0.145 & 0.062 & -0.034 & 0.014 & $0.317^{*}$ & 0.251 \\
\hline Thailand & $(0.120)$ & $(0.108)$ & $(0.165)$ & $(0.291)$ & $(0.112)$ & $(0.101)$ & $(0.166)$ & $(0.251)$ \\
\hline & $1.312 * * *$ & $1.278 * * *$ & $1.416^{* * *}$ & $1.522 * * *$ & $1.240 * * *$ & $1.201 * * *$ & $1.426^{* * *}$ & $1.503 * * *$ \\
\hline Togo & $(0.082)$ & $(0.086)$ & $(0.089)$ & $(0.176)$ & $(0.123)$ & $(0.120)$ & $(0.110)$ & $(0.209)$ \\
\hline & 0.106 & 0.132 & $0.423 * *$ & 0.241 & $0.308 * * *$ & $0.326 * * *$ & $0.646^{* * *}$ & 0.483 \\
\hline Tonga & $(0.088)$ & $(0.084)$ & $(0.188)$ & $(0.330)$ & $(0.086)$ & $(0.079)$ & $(0.197)$ & $(0.301)$ \\
\hline & $0.202^{*}$ & $0.269^{* * *}$ & $0.776^{* * *}$ & $1.172 * * *$ & $0.364 * * *$ & $0.418^{* * *}$ & $0.933 * * *$ & $1.322 * * *$ \\
\hline Tunisia & $(0.112)$ & $(0.100)$ & $(0.193)$ & $(0.320)$ & $(0.108)$ & $(0.095)$ & $(0.200)$ & $(0.326)$ \\
\hline & -0.058 & 0.030 & $0.532 * * *$ & $0.842 * * *$ & 0.104 & 0.183 & $0.787 * * *$ & $1.226^{* * *}$ \\
\hline Turkey & $(0.157)$ & $(0.145)$ & $(0.199)$ & $(0.308)$ & $(0.162)$ & $(0.155)$ & $(0.181)$ & $(0.263)$ \\
\hline & $1.242 * * *$ & $1.207^{* * *}$ & $1.304^{* * *}$ & $1.454 * * *$ & $1.155^{* * *}$ & $1.123 * * *$ & $1.308 * * *$ & $1.426^{* * *}$ \\
\hline Uganda & $(0.093)$ & $(0.089)$ & $(0.105)$ & $(0.172)$ & $(0.135)$ & $(0.128)$ & $(0.127)$ & $(0.206)$ \\
\hline United & -0.087 & 0.130 & 0.169 & $1.002 * * *$ & -0.102 & 0.074 & 0.216 & $0.993 * * *$ \\
\hline Kingdom & $(0.304)$ & $(0.275)$ & $(0.299)$ & $(0.318)$ & $(0.264)$ & $(0.243)$ & $(0.272)$ & $(0.285)$ \\
\hline & $0.904 * * *$ & $1.166^{* * *}$ & $0.906 * * *$ & $1.917 * * *$ & $1.036 * * *$ & $1.247 * * *$ & $1.096^{* * *}$ & $2.056^{* * *}$ \\
\hline United States & $(0.344)$ & $(0.310)$ & $(0.326)$ & $(0.320)$ & $(0.302)$ & $(0.267)$ & $(0.297)$ & $(0.285)$ \\
\hline & 0.101* & $0.114 * *$ & $0.750 * * *$ & $1.046^{* * *}$ & $0.182 * * *$ & $0.185 * * *$ & $0.822 * * *$ & $1.099 * * *$ \\
\hline Yemen & $(0.055)$ & $(0.049)$ & $(0.234)$ & $(0.392)$ & $(0.067)$ & $(0.060)$ & $(0.255)$ & $(0.402)$ \\
\hline & $1.008 * * *$ & $1.139 * * *$ & $1.480 * * *$ & $1.922 * * *$ & $1.097 * * *$ & $1.210 * * *$ & $1.660 * * *$ & $2.209 * * *$ \\
\hline Yugoslavia & $(0.207)$ & $(0.190)$ & $(0.225)$ & $(0.312)$ & $(0.197)$ & $(0.184)$ & $(0.204)$ & $(0.264)$ \\
\hline & $1.334 * * *$ & $1.346^{* * *}$ & $1.581 * * *$ & $1.737 * * *$ & $1.326^{* * *}$ & $1.334 * * *$ & $1.622 * * *$ & $1.796 * * *$ \\
\hline Zambia & $(0.019)$ & $(0.015)$ & $(0.080)$ & $(0.147)$ & $(0.021)$ & $(0.018)$ & $(0.099)$ & $(0.180)$ \\
\hline
\end{tabular}


(Table A.3. continued)

\begin{tabular}{lcccccccc}
\hline & $0.811^{* * *}$ & $0.831^{* * *}$ & $1.060^{* * *}$ & $1.257^{* * *}$ & $0.809^{* * *}$ & $0.831^{* * *}$ & $1.104^{* * *}$ & $1.334 * * *$ \\
Zimbabwe & $(0.017)$ & $(0.021)$ & $(0.102)$ & $(0.152)$ & $(0.029)$ & $(0.031)$ & $(0.127)$ & $(0.190)$ \\
\hline & $-32.948^{* * *}$ & $-33.046^{* * *}$ & $-23.796^{* * *}$ & $-27.427^{* * *}$ & $-12.550^{* * *}$ & $-12.149^{* * *}$ & $-11.360^{* * *}$ & $-10.463 * * *$ \\
constant (India) & $(2.659)$ & $(2.647)$ & $(3.702)$ & $(3.263)$ & $(2.650)$ & $(2.494)$ & $(2.290)$ & $(2.141)$ \\
\hline Adjusted R2: & 0.8455 & 0.8460 & 0.8634 & 0.8557 & 0.8554 & 0.8567 & 0.8695 & 0.8656 \\
\hline Hausman chi ${ }^{2}$ & $36.20^{* * *}$ & $40.63 * * *$ & $80.90^{* * *}$ & $353.13 * * *$ & $40.75 * * *$ & $53.42^{* * *}$ & $90.27^{* * *}$ & $70.17 * * *$ \\
\hline DW statistic & 0.734 & 0.732 & 0.807 & 0.768 & 0.774 & 0.776 & 0.841 & 0.815 \\
\hline
\end{tabular}

No. of Countries: 88 , No. of observations: 2200 
Table A.4. Country Dummy Coefficients from V/P Models

\begin{tabular}{|c|c|c|c|c|c|c|c|c|}
\hline \multirow{2}{*}{$\begin{array}{l}\text { Country } \\
\text { Dummies }\end{array}$} & \multicolumn{4}{|c|}{ Quadratic } & \multicolumn{4}{|c|}{ Spline } \\
\hline & 1 & 2 & 3 & 4 & 5 & 6 & 7 & 8 \\
\hline Australia & $\begin{array}{c}2.056 * * * \\
(0.530)\end{array}$ & $\begin{array}{c}1.387 * * * \\
(0.528)\end{array}$ & $\begin{array}{c}3.100 * * * \\
(0.517)\end{array}$ & $\begin{array}{c}2.880 * * * \\
(0.607)\end{array}$ & $\begin{array}{c}2.121 * * * \\
(0.480)\end{array}$ & $\begin{array}{c}1.357 * * * \\
(0.499)\end{array}$ & $\begin{array}{c}3.304 * * * \\
(0.411)\end{array}$ & $\begin{array}{c}2.913 * * * \\
(0.545)\end{array}$ \\
\hline Austria & $\begin{array}{c}1.817 * * * \\
(0.479)\end{array}$ & $\begin{array}{c}1.244 * * \\
(0.487)\end{array}$ & $\begin{array}{c}2.913 * * * \\
(0.491)\end{array}$ & $\begin{array}{c}2.780 * * * \\
(0.589)\end{array}$ & $\begin{array}{c}1.801 * * * \\
(0.433)\end{array}$ & $\begin{array}{c}1.153 * * \\
(0.459)\end{array}$ & $\begin{array}{c}3.012 * * * \\
(0.401)\end{array}$ & $\begin{array}{c}2.753^{* * *} * \\
(0.532)\end{array}$ \\
\hline Bahrain & $\begin{array}{c}1.179 * * * \\
(0.412)\end{array}$ & $\begin{array}{l}0.776^{*} \\
(0.439)\end{array}$ & $\begin{array}{c}2.368^{* * * *} \\
(0.477)\end{array}$ & $\begin{array}{c}2.382 * * * \\
(0.580)\end{array}$ & $\begin{array}{c}1.012 * * * \\
(0.370)\end{array}$ & $\begin{array}{c}0.611 \\
(0.418)\end{array}$ & $\begin{array}{c}2.264 * * * \\
(0.408)\end{array}$ & $\begin{array}{c}2.267 * * * \\
(0.528)\end{array}$ \\
\hline Bangladesh & $\begin{array}{c}-2.132 * * * \\
(0.063)\end{array}$ & $\begin{array}{c}-2.098 * * * \\
(0.067)\end{array}$ & $\begin{array}{c}-1.521 * * * \\
(0.104)\end{array}$ & $\begin{array}{c}-0.929 * * * \\
(0.138)\end{array}$ & $\begin{array}{c}-2.068 * * * \\
(0.106)\end{array}$ & $\begin{array}{c}-2.054 * * * \\
(0.126)\end{array}$ & $\begin{array}{c}-1.374 * * * \\
(0.128)\end{array}$ & $\begin{array}{c}-0.672 * * * \\
(0.204)\end{array}$ \\
\hline Belgium & $\begin{array}{c}1.766 * * * \\
(0.490)\end{array}$ & $\begin{array}{c}1.177 * * \\
(0.497)\end{array}$ & $\begin{array}{c}2.852 * * * \\
(0.497)\end{array}$ & $\begin{array}{c}2.703 * * * \\
(0.594)\end{array}$ & $\begin{array}{c}1.765 * * * \\
(0.443)\end{array}$ & $\begin{array}{l}1.097 * * \\
(0.469)\end{array}$ & $\begin{array}{c}2.971 * * * \\
(0.403)\end{array}$ & $\begin{array}{c}2.686 * * * \\
(0.535)\end{array}$ \\
\hline Benin & $\begin{array}{c}0.631 * * * \\
(0.031)\end{array}$ & $\begin{array}{c}0.643 * * * \\
(0.044)\end{array}$ & $\begin{array}{c}1.341 * * * \\
(0.163)\end{array}$ & $\begin{array}{c}1.626 * * * \\
(0.249)\end{array}$ & $\begin{array}{c}0.718^{* * *} \\
(0.044)\end{array}$ & $\begin{array}{c}0.733 * * * \\
(0.057)\end{array}$ & $\begin{array}{c}1.551 * * * \\
(0.170)\end{array}$ & $\begin{array}{c}1.834 * * * \\
(0.258)\end{array}$ \\
\hline Botswana & $\begin{array}{c}0.513 * * * \\
(0.118)\end{array}$ & $\begin{array}{c}0.392 * * * \\
(0.124)\end{array}$ & $\begin{array}{c}1.362 * * * \\
(0.227)\end{array}$ & $\begin{array}{c}1.448 * * * \\
(0.325)\end{array}$ & $\begin{array}{c}0.659 * * * \\
(0.147)\end{array}$ & $\begin{array}{c}0.470 * * * \\
(0.157)\end{array}$ & $\begin{array}{c}1.631^{* * * *} \\
(0.238)\end{array}$ & $\begin{array}{c}1.543 * * * \\
(0.367)\end{array}$ \\
\hline Brazil & $\begin{array}{c}0.745^{* * * *} \\
(0.281)\end{array}$ & $\begin{array}{c}0.457 \\
(0.299)\end{array}$ & $\begin{array}{c}1.807 * * * \\
(0.338)\end{array}$ & $\begin{array}{c}1.889 * * * \\
(0.365)\end{array}$ & $\begin{array}{c}0.873 * * * \\
(0.286)\end{array}$ & $\begin{array}{c}0.484 \\
(0.309)\end{array}$ & $\begin{array}{c}2.154 * * * \\
(0.343)\end{array}$ & $\begin{array}{c}2.110 * * * \\
(0.452)\end{array}$ \\
\hline Bulgaria & $\begin{array}{c}1.252 * * * \\
(0.315)\end{array}$ & $\begin{array}{c}0.972 * * * \\
(0.342)\end{array}$ & $\begin{array}{c}1.466^{* * * *} \\
(0.339)\end{array}$ & $\begin{array}{c}1.388 * * * \\
(0.393)\end{array}$ & $\begin{array}{c}1.204 * * * \\
(0.299)\end{array}$ & $\begin{array}{c}0.838 * * \\
(0.329)\end{array}$ & $\begin{array}{c}1.782 * * * \\
(0.338)\end{array}$ & $\begin{array}{c}1.568 * * * \\
(0.472)\end{array}$ \\
\hline Cameroon & $\begin{array}{c}0.592 * * * \\
(0.028)\end{array}$ & $\begin{array}{c}0.497 * * * \\
(0.010)\end{array}$ & $\begin{array}{c}1.264 * * * \\
(0.139)\end{array}$ & $\begin{array}{c}1.432 * * * \\
(0.269)\end{array}$ & $\begin{array}{c}0.619 * * * \\
(0.025)\end{array}$ & $\begin{array}{c}0.510 * * * \\
(0.011)\end{array}$ & $\begin{array}{c}1.417 * * * \\
(0.146)\end{array}$ & $\begin{array}{c}1.530 * * * \\
(0.277)\end{array}$ \\
\hline Canada & $\begin{array}{c}2.048 * * * \\
(0.544)\end{array}$ & $\begin{array}{c}1.360 * * \\
(0.540)\end{array}$ & $\begin{array}{c}3.070 * * * \\
(0.524)\end{array}$ & $\begin{array}{c}2.832 * * * \\
(0.610)\end{array}$ & $\begin{array}{c}2.174 * * * \\
(0.492)\end{array}$ & $\begin{array}{c}1.355 * * * \\
(0.505)\end{array}$ & $\begin{array}{c}3.349 * * * \\
(0.412)\end{array}$ & $\begin{array}{c}2.903 * * * \\
(0.547)\end{array}$ \\
\hline Chile & $\begin{array}{c}0.451 \\
(0.297)\end{array}$ & $\begin{array}{c}0.163 \\
(0.318)\end{array}$ & $\begin{array}{c}1.626^{* * *} \\
(0.399)\end{array}$ & $\begin{array}{c}1.778 * * * \\
(0.505)\end{array}$ & $\begin{array}{l}0.522^{*} \\
(0.293)\end{array}$ & $\begin{array}{c}0.147 \\
(0.321)\end{array}$ & $\begin{array}{c}1.768 * * * \\
(0.367)\end{array}$ & $\begin{array}{c}1.842 * * * \\
(0.495)\end{array}$ \\
\hline China & $\begin{array}{c}-0.756^{* * *} \\
(0.065)\end{array}$ & $\begin{array}{c}-0.719 * * * \\
(0.074)\end{array}$ & $\begin{array}{c}-0.613 * * * \\
(0.231)\end{array}$ & $\begin{array}{c}-0.503 \\
(0.450)\end{array}$ & $\begin{array}{c}-0.696^{* * *} \\
(0.095)\end{array}$ & $\begin{array}{c}-0.691 * * * \\
(0.114)\end{array}$ & $\begin{array}{c}-0.474 \\
(0.357)\end{array}$ & $\begin{array}{c}-0.450 \\
(0.610)\end{array}$ \\
\hline Colombia & $\begin{array}{c}0.212 \\
(0.227) \\
\end{array}$ & $\begin{array}{c}0.104 \\
(0.260) \\
\end{array}$ & $\begin{array}{c}1.320 * * * \\
(0.336)\end{array}$ & $\begin{array}{c}1.561 * * * \\
(0.335) \\
\end{array}$ & $\begin{array}{c}0.312 \\
(0.239) \\
\end{array}$ & $\begin{array}{c}0.141 \\
(0.277) \\
\end{array}$ & $\begin{array}{c}1.728 * * * \\
(0.365)\end{array}$ & $\begin{array}{c}1.838 * * * \\
(0.458)\end{array}$ \\
\hline Costa Rica & $\begin{array}{c}0.836 * * * \\
(0.237)\end{array}$ & $\begin{array}{c}0.710^{* * * *} \\
(0.269)\end{array}$ & $\begin{array}{c}2.069 * * * \\
(0.396)\end{array}$ & $\begin{array}{c}2.366 * * * \\
(0.496)\end{array}$ & $\begin{array}{c}0.912 * * * \\
(0.250)\end{array}$ & $\begin{array}{c}0.728 * * \\
(0.290)\end{array}$ & $\begin{array}{c}2.183 * * * \\
(0.381)\end{array}$ & $\begin{array}{c}2.462 * * * \\
(0.501)\end{array}$ \\
\hline Cote d'Ivoire & $\begin{array}{c}0.447 * * * \\
(0.151)\end{array}$ & $\begin{array}{l}0.291^{*} \\
(0.161)\end{array}$ & $\begin{array}{c}1.316^{* * * *} \\
(0.213)\end{array}$ & $\begin{array}{c}1.414 * * * \\
(0.287)\end{array}$ & $\begin{array}{c}0.607 * * * \\
(0.211)\end{array}$ & $\begin{array}{c}0.368 \\
(0.233)\end{array}$ & $\begin{array}{c}1.603 * * * \\
(0.267)\end{array}$ & $\begin{array}{c}1.523 * * * \\
(0.382)\end{array}$ \\
\hline Cyprus & $\begin{array}{c}1.667 * * * \\
(0.350)\end{array}$ & $\begin{array}{c}1.278 * * * \\
(0.365)\end{array}$ & $\begin{array}{c}2.805^{* * * *} \\
(0.414)\end{array}$ & $\begin{array}{c}2.860 * * * \\
(0.521)\end{array}$ & $\begin{array}{c}1.709^{* * *} \\
(0.331)\end{array}$ & $\begin{array}{c}1.220^{* * *} \\
(0.352)\end{array}$ & $\begin{array}{c}2.929 * * * \\
(0.367)\end{array}$ & $\begin{array}{c}2.872 * * * \\
(0.495)\end{array}$ \\
\hline $\begin{array}{l}\text { Czech } \\
\text { Republic }\end{array}$ & $\begin{array}{c}2.264 * * * \\
(0.257)\end{array}$ & $\begin{array}{c}2.024 * * * \\
(0.276)\end{array}$ & $\begin{array}{c}3.412 * * * \\
(0.369)\end{array}$ & $\begin{array}{c}3.620 * * * \\
(0.473)\end{array}$ & $\begin{array}{c}2.417 * * * \\
(0.266)\end{array}$ & $\begin{array}{c}2.084^{* * *} \\
(0.290)\end{array}$ & $\begin{array}{c}3.608 * * * \\
(0.359)\end{array}$ & $\begin{array}{c}3.731 * * * \\
(0.485)\end{array}$ \\
\hline Denmark & $\begin{array}{c}1.678 * * * \\
(0.514)\end{array}$ & $\begin{array}{c}1.050^{* *} \\
(0.517)\end{array}$ & $\begin{array}{c}2.739 * * * \\
(0.509)\end{array}$ & $\begin{array}{c}2.554 * * * \\
(0.602)\end{array}$ & $\begin{array}{c}1.712 * * * \\
(0.464)\end{array}$ & $\begin{array}{c}0.999 * * \\
(0.488)\end{array}$ & $\begin{array}{c}2.904 * * * \\
(0.408)\end{array}$ & $\begin{array}{c}2.567 * * * \\
(0.541)\end{array}$ \\
\hline Ecuador & $\begin{array}{c}0.002 \\
(0.197)\end{array}$ & $\begin{array}{l}-0.059 \\
(0.227)\end{array}$ & $\begin{array}{c}1.092 * * * \\
(0.316)\end{array}$ & $\begin{array}{c}1.385 * * * \\
(0.310)\end{array}$ & $\begin{array}{c}0.172 \\
(0.216)\end{array}$ & $\begin{array}{c}0.038 \\
(0.248)\end{array}$ & $\begin{array}{c}1.529 * * * \\
(0.366)\end{array}$ & $\begin{array}{c}1.680 * * * \\
(0.461)\end{array}$ \\
\hline Egypt & $\begin{array}{c}0.124 \\
(0.122) \\
\end{array}$ & $\begin{array}{c}0.073 \\
(0.137) \\
\end{array}$ & $\begin{array}{c}1.340 * * * \\
(0.173)\end{array}$ & $\begin{array}{c}1.983 * * * \\
(0.208)\end{array}$ & $\begin{array}{c}0.277 \\
(0.182) \\
\end{array}$ & $\begin{array}{c}0.151 \\
(0.208) \\
\end{array}$ & $\begin{array}{c}1.560 * * * \\
(0.246)\end{array}$ & $\begin{array}{c}2.207 * * * \\
(0.322)\end{array}$ \\
\hline Ethiopia & $\begin{array}{c}0.498 \\
(0.324)\end{array}$ & $\begin{array}{l}0.624^{*} \\
(0.369)\end{array}$ & $\begin{array}{c}0.463 \\
(0.408)\end{array}$ & $\begin{array}{l}0.984^{*} \\
(0.559)\end{array}$ & $\begin{array}{l}-0.610 \\
(0.487)\end{array}$ & $\begin{array}{c}-0.453 \\
(0.537)\end{array}$ & $\begin{array}{c}-0.303 \\
(0.368)\end{array}$ & $\begin{array}{c}-0.248 \\
(0.581)\end{array}$ \\
\hline Finland & $\begin{array}{c}1.741 * * * \\
(0.489)\end{array}$ & $\begin{array}{l}1.143 * * \\
(0.493)\end{array}$ & $\begin{array}{c}2.825 * * * \\
(0.493)\end{array}$ & $\begin{array}{c}2.670 * * * \\
(0.591)\end{array}$ & $\begin{array}{c}1.725 * * * \\
(0.442)\end{array}$ & $\begin{array}{l}1.047 * * \\
(0.464)\end{array}$ & $\begin{array}{c}2.931 * * * \\
(0.402)\end{array}$ & $\begin{array}{c}2.640 * * * \\
(0.533)\end{array}$ \\
\hline France & $\begin{array}{c}2.095 * * * \\
(0.511)\end{array}$ & $\begin{array}{c}1.449 * * * \\
(0.510)\end{array}$ & $\begin{array}{c}3.159 * * * \\
(0.504)\end{array}$ & $\begin{array}{c}2.962 * * * \\
(0.599)\end{array}$ & $\begin{array}{c}2.093 * * * \\
(0.461)\end{array}$ & $\begin{array}{c}1.371 * * * \\
(0.482)\end{array}$ & $\begin{array}{c}3.288^{* * * *} \\
(0.407)\end{array}$ & $\begin{array}{c}2.946^{* * *} \\
(0.539)\end{array}$ \\
\hline Germany & $\begin{array}{c}1.613 * * * \\
(0.515)\end{array}$ & $\begin{array}{l}0.961^{*} \\
(0.513)\end{array}$ & $\begin{array}{c}2.673 * * * \\
(0.507)\end{array}$ & $\begin{array}{c}2.470 * * * \\
(0.600)\end{array}$ & $\begin{array}{c}1.624 * * * \\
(0.465)\end{array}$ & $\begin{array}{l}0.890^{*} \\
(0.485)\end{array}$ & $\begin{array}{c}2.816^{* * * *} \\
(0.408)\end{array}$ & $\begin{array}{c}2.462 * * * \\
(0.540)\end{array}$ \\
\hline Greece & $\begin{array}{c}0.891 * * \\
(0.360)\end{array}$ & $\begin{array}{c}0.502 \\
(0.377)\end{array}$ & $\begin{array}{c}2.045^{* * *} * \\
(0.425)\end{array}$ & $\begin{array}{c}2.095 * * * \\
(0.533)\end{array}$ & $\begin{array}{c}0.898 * * * \\
(0.337)\end{array}$ & $\begin{array}{c}0.400 \\
(0.358)\end{array}$ & $\begin{array}{c}2.137 * * * \\
(0.373)\end{array}$ & $\begin{array}{c}2.071 * * * \\
(0.500)\end{array}$ \\
\hline Hong Kong & $\begin{array}{l}-0.075 \\
(0.451)\end{array}$ & $\begin{array}{l}-0.619 \\
(0.457)\end{array}$ & $\begin{array}{l}1.011 * * \\
(0.469)\end{array}$ & $\begin{array}{c}0.913 \\
(0.565)\end{array}$ & $\begin{array}{c}0.001 \\
(0.412)\end{array}$ & $\begin{array}{l}-0.659 \\
(0.430)\end{array}$ & $\begin{array}{c}1.211^{* * * *} \\
(0.386)\end{array}$ & $\begin{array}{l}0.954 * \\
(0.517)\end{array}$ \\
\hline
\end{tabular}


(Table A.4. continued)

\begin{tabular}{|c|c|c|c|c|c|c|c|c|}
\hline Hungary & $\begin{array}{c}1.351 * * * \\
(0.323)\end{array}$ & $\begin{array}{c}1.022 * * * \\
(0.343)\end{array}$ & $\begin{array}{c}2.549 * * * \\
(0.421)\end{array}$ & $\begin{array}{c}2.657 * * * \\
(0.529)\end{array}$ & $\begin{array}{c}1.340 * * * \\
(0.310)\end{array}$ & $\begin{array}{c}0.915 * * * \\
(0.336)\end{array}$ & $\begin{array}{c}2.612 * * * \\
(0.376)\end{array}$ & $\begin{array}{c}2.630 * * * \\
(0.498)\end{array}$ \\
\hline Iceland & $\begin{array}{c}1.812 * * * \\
(0.483)\end{array}$ & $\begin{array}{l}1.232 * * \\
(0.490)\end{array}$ & $\begin{array}{c}2.900 * * * \\
(0.492)\end{array}$ & $\begin{array}{c}2.761 * * * \\
(0.589)\end{array}$ & $\begin{array}{c}1.827 * * * \\
(0.439)\end{array}$ & $\begin{array}{l}1.155^{* *} \\
(0.462)\end{array}$ & $\begin{array}{c}3.035^{* * * *} \\
(0.400)\end{array}$ & $\begin{array}{c}2.750 * * * \\
(0.532)\end{array}$ \\
\hline Indonesia & $\begin{array}{c}0.704 * * * \\
(0.067)\end{array}$ & $\begin{array}{c}0.664 * * * \\
(0.075)\end{array}$ & $\begin{array}{c}0.965^{* * *} \\
(0.184)\end{array}$ & $\begin{array}{c}0.962 * * \\
(0.401)\end{array}$ & $\begin{array}{c}0.756^{* * *} * \\
(0.106)\end{array}$ & $\begin{array}{c}0.666^{* * *} \\
(0.116)\end{array}$ & $\begin{array}{c}1.095 * * * \\
(0.298)\end{array}$ & $\begin{array}{l}0.972 * \\
(0.557)\end{array}$ \\
\hline Ireland & $\begin{array}{c}1.424 * * * \\
(0.404)\end{array}$ & $\begin{array}{c}0.970^{* *} \\
(0.418) \\
\end{array}$ & $\begin{array}{c}2.568 * * * \\
(0.450)\end{array}$ & $\begin{array}{c}2.551^{* * *} \\
(0.556)\end{array}$ & $\begin{array}{c}1.382 * * * \\
(0.370)\end{array}$ & $\begin{array}{c}0.840^{* *} \\
(0.394) \\
\end{array}$ & $\begin{array}{c}2.624 * * * \\
(0.384)\end{array}$ & $\begin{array}{c}2.498 * * * \\
(0.511)\end{array}$ \\
\hline Israel & $\begin{array}{c}0.958^{* *} \\
(0.427)\end{array}$ & $\begin{array}{c}0.480 \\
(0.443)\end{array}$ & $\begin{array}{c}2.094 * * * \\
(0.464)\end{array}$ & $\begin{array}{c}2.049 * * * \\
(0.568)\end{array}$ & $\begin{array}{c}0.891 * * \\
(0.387)\end{array}$ & $\begin{array}{c}0.347 \\
(0.417)\end{array}$ & $\begin{array}{c}2.127 * * * \\
(0.391)\end{array}$ & $\begin{array}{c}1.986^{* * *} \\
(0.518)\end{array}$ \\
\hline Italy & $\begin{array}{c}1.926^{* * * *} \\
(0.474)\end{array}$ & $\begin{array}{c}1.352 * * * \\
(0.480)\end{array}$ & $\begin{array}{c}3.024 * * * \\
(0.486)\end{array}$ & $\begin{array}{c}2.892^{* * * *} \\
(0.585)\end{array}$ & $\begin{array}{c}1.889^{* * *} * \\
(0.428)\end{array}$ & $\begin{array}{c}1.242 * * * \\
(0.452)\end{array}$ & $\begin{array}{c}3.103^{* * *} \\
(0.400)\end{array}$ & $\begin{array}{c}2.848^{* * *} \\
(0.529)\end{array}$ \\
\hline Japan & $\begin{array}{c}1.880^{* * *} \\
(0.476)\end{array}$ & $\begin{array}{c}1.305^{* * *} * \\
(0.482)\end{array}$ & $\begin{array}{c}2.966^{* * *} \\
(0.486)\end{array}$ & $\begin{array}{c}2.833 * * * \\
(0.583)\end{array}$ & $\begin{array}{c}1.905^{* * *} \\
(0.433)\end{array}$ & $\begin{array}{c}1.235^{* * *} \\
(0.455)\end{array}$ & $\begin{array}{c}3.112 * * * \\
(0.397)\end{array}$ & $\begin{array}{c}2.833^{* * * *} \\
(0.528) \\
\end{array}$ \\
\hline Kenya & $\begin{array}{c}0.827 * * * \\
(0.047)\end{array}$ & $\begin{array}{c}0.857 * * * \\
(0.053) \\
\end{array}$ & $\begin{array}{c}1.403 * * * \\
(0.175)\end{array}$ & $\begin{array}{c}1.709 * * * \\
(0.294)\end{array}$ & $\begin{array}{c}0.760 * * * \\
(0.070)\end{array}$ & $\begin{array}{c}0.809 * * * \\
(0.083)\end{array}$ & $\begin{array}{c}1.469 * * * \\
(0.160)\end{array}$ & $\begin{array}{c}1.744 * * * \\
(0.280)\end{array}$ \\
\hline Korea, Rep. & $\begin{array}{c}0.219 \\
(0.327)\end{array}$ & $\begin{array}{c}-0.094 \\
(0.350)\end{array}$ & $\begin{array}{c}1.415^{* * * *} \\
(0.425)\end{array}$ & $\begin{array}{c}1.533 * * * \\
(0.530)\end{array}$ & $\begin{array}{c}0.193 \\
(0.305)\end{array}$ & $\begin{array}{c}-0.181 \\
(0.337)\end{array}$ & $\begin{array}{c}1.444 * * * \\
(0.378)\end{array}$ & $\begin{array}{c}1.510 * * * \\
(0.500)\end{array}$ \\
\hline Luxembourg & $\begin{array}{c}1.851 * * * \\
(0.534) \\
\end{array}$ & $\begin{array}{c}1.182 * * \\
(0.531) \\
\end{array}$ & $\begin{array}{c}2.877 * * * \\
(0.523) \\
\end{array}$ & $\begin{array}{c}2.660 * * * \\
(0.606)\end{array}$ & $\begin{array}{c}2.015 * * * \\
(0.479)\end{array}$ & $\begin{array}{c}1.204 * * \\
(0.491) \\
\end{array}$ & $\begin{array}{c}3.197 * * * \\
(0.409) \\
\end{array}$ & $\begin{array}{c}2.769 * * * \\
(0.543) \\
\end{array}$ \\
\hline Malawi & $\begin{array}{c}1.067 * * * \\
(0.175)\end{array}$ & $\begin{array}{c}1.063 * * * \\
(0.200)\end{array}$ & $\begin{array}{c}1.334 * * * \\
(0.188)\end{array}$ & $\begin{array}{c}1.711^{* * *} \\
(0.323)\end{array}$ & $\begin{array}{c}0.505^{*} \\
(0.299) \\
\end{array}$ & $\begin{array}{c}0.498 \\
(0.316) \\
\end{array}$ & $\begin{array}{c}0.967 * * * \\
(0.196)\end{array}$ & $\begin{array}{c}1.077 * * * \\
(0.353)\end{array}$ \\
\hline Malaysia & $\begin{array}{c}1.509 * * * \\
(0.271)\end{array}$ & $\begin{array}{c}1.251 * * * \\
(0.292)\end{array}$ & $\begin{array}{c}2.035^{* * * *} \\
(0.273)\end{array}$ & $\begin{array}{c}1.766^{* * * *} \\
(0.383)\end{array}$ & $\begin{array}{c}1.597 * * * \\
(0.273)\end{array}$ & $\begin{array}{c}1.244 * * * \\
(0.297)\end{array}$ & $\begin{array}{c}2.238^{* * * *} \\
(0.321)\end{array}$ & $\begin{array}{c}1.802 * * * \\
(0.537)\end{array}$ \\
\hline Mauritius & $\begin{array}{c}0.518 \\
(0.323) \\
\end{array}$ & $\begin{array}{c}0.208 \\
(0.346) \\
\end{array}$ & $\begin{array}{c}1.541^{* * *} \\
(0.380)\end{array}$ & $\begin{array}{c}1.386^{* * * *} \\
(0.468)\end{array}$ & $\begin{array}{c}0.524^{*} \\
(0.306)\end{array}$ & $\begin{array}{c}0.126 \\
(0.335) \\
\end{array}$ & $\begin{array}{c}1.753 * * * \\
(0.300)\end{array}$ & $\begin{array}{c}1.370^{* * *} \\
(0.443)\end{array}$ \\
\hline Mongolia & $\begin{array}{c}0.550 * * * \\
(0.087)\end{array}$ & $\begin{array}{c}0.687 * * * \\
(0.090)\end{array}$ & $\begin{array}{l}0.571^{*} \\
(0.294) \\
\end{array}$ & $\begin{array}{l}0.829^{*} \\
(0.502) \\
\end{array}$ & $\begin{array}{c}0.590 * * * \\
(0.153)\end{array}$ & $\begin{array}{c}0.706^{* * *} * \\
(0.190)\end{array}$ & $\begin{array}{c}0.721 \\
(0.465) \\
\end{array}$ & $\begin{array}{c}0.879 \\
(0.695) \\
\end{array}$ \\
\hline Morocco & $\begin{array}{c}0.612 * * * \\
(0.131)\end{array}$ & $\begin{array}{c}0.525^{* * *} * \\
(0.148)\end{array}$ & $\begin{array}{c}1.731 * * * \\
(0.175)\end{array}$ & $\begin{array}{c}2.312^{* * * *} \\
(0.209)\end{array}$ & $\begin{array}{c}0.793 * * * \\
(0.173)\end{array}$ & $\begin{array}{c}0.628 * * * \\
(0.193)\end{array}$ & $\begin{array}{c}1.971 * * * \\
(0.231)\end{array}$ & $\begin{array}{c}2.552^{* * * *} \\
(0.304)\end{array}$ \\
\hline Netherlands & $\begin{array}{c}1.816^{* * *} \\
(0.499)\end{array}$ & $\begin{array}{c}1.211^{* *} \\
(0.504)\end{array}$ & $\begin{array}{c}2.894 * * * \\
(0.501)\end{array}$ & $\begin{array}{c}2.732 * * * \\
(0.597)\end{array}$ & $\begin{array}{c}1.822 * * * \\
(0.450)\end{array}$ & $\begin{array}{c}1.143^{* *} \\
(0.476)\end{array}$ & $\begin{array}{c}3.023 * * * \\
(0.405)\end{array}$ & $\begin{array}{c}2.725^{* * *} \\
(0.538)\end{array}$ \\
\hline New Zealand & $\begin{array}{c}2.064 * * * \\
(0.498) \\
\end{array}$ & $\begin{array}{c}1.455^{* * *} \\
(0.502) \\
\end{array}$ & $\begin{array}{c}3.148^{* * *} * \\
(0.501) \\
\end{array}$ & $\begin{array}{c}2.982 * * * \\
(0.598)\end{array}$ & $\begin{array}{c}2.025 * * * \\
(0.447) \\
\end{array}$ & $\begin{array}{c}1.372 * * * \\
(0.477) \\
\end{array}$ & $\begin{array}{c}3.228^{* * *} \\
(0.407) \\
\end{array}$ & $\begin{array}{c}2.955^{* * *} * \\
(0.539) \\
\end{array}$ \\
\hline Niger & $\begin{array}{c}0.167 * * \\
(0.079) \\
\end{array}$ & $\begin{array}{c}0.125 \\
(0.090) \\
\end{array}$ & $\begin{array}{c}0.651 * * * \\
(0.111)\end{array}$ & $\begin{array}{c}0.938 * * * \\
(0.252)\end{array}$ & $\begin{array}{c}-0.031 \\
(0.134) \\
\end{array}$ & $\begin{array}{c}-0.074 \\
(0.140) \\
\end{array}$ & $\begin{array}{c}0.586^{* * *} \\
(0.101)\end{array}$ & $\begin{array}{c}0.766^{* * *} \\
(0.253) \\
\end{array}$ \\
\hline Nigeria & $\begin{array}{c}-0.113 * * * \\
(0.031)\end{array}$ & $\begin{array}{c}-0.175^{* * *} \\
(0.027)\end{array}$ & $\begin{array}{c}0.593 * * * \\
(0.169)\end{array}$ & $\begin{array}{c}0.778^{* * *} \\
(0.286)\end{array}$ & $\begin{array}{c}-0.087^{*} \\
(0.050)\end{array}$ & $\begin{array}{c}-0.167 * * * \\
(0.053)\end{array}$ & $\begin{array}{c}0.765^{* * *} \\
(0.179)\end{array}$ & $\begin{array}{c}0.860 * * * \\
(0.308)\end{array}$ \\
\hline Norway & $\begin{array}{c}1.768^{* * *} \\
(0.512)\end{array}$ & $\begin{array}{c}1.135^{* *} \\
(0.514) \\
\end{array}$ & $\begin{array}{c}2.822 * * * \\
(0.507)\end{array}$ & $\begin{array}{c}2.636^{* * *} \\
(0.598)\end{array}$ & $\begin{array}{c}1.837 * * * \\
(0.463)\end{array}$ & $\begin{array}{c}1.089^{* *} \\
(0.480)\end{array}$ & $\begin{array}{c}3.030 * * * \\
(0.405)\end{array}$ & $\begin{array}{c}2.664 * * * \\
(0.538) \\
\end{array}$ \\
\hline Pakistan & $\begin{array}{c}-0.275^{* * *} * \\
(0.036) \\
\end{array}$ & $\begin{array}{c}-0.266^{* * *} \\
(0.043) \\
\end{array}$ & $\begin{array}{c}0.323 * * * \\
(0.083)\end{array}$ & $\begin{array}{c}0.863 * * * \\
(0.115)\end{array}$ & $\begin{array}{c}-0.220 * * * \\
(0.059) \\
\end{array}$ & $\begin{array}{c}-0.221 * * * \\
(0.071) \\
\end{array}$ & $\begin{array}{c}0.460 * * * \\
(0.104)\end{array}$ & $\begin{array}{c}1.125^{* * *} * \\
(0.171)\end{array}$ \\
\hline Panama & $\begin{array}{c}0.733 * * * \\
(0.232) \\
\end{array}$ & $\begin{array}{c}0.570 * * \\
(0.258) \\
\end{array}$ & $\begin{array}{c}1.823 * * * \\
(0.327) \\
\end{array}$ & $\begin{array}{c}2.018 * * * \\
(0.334) \\
\end{array}$ & $\begin{array}{c}0.878 * * * \\
(0.247) \\
\end{array}$ & $\begin{array}{c}0.639 * * \\
(0.278) \\
\end{array}$ & $\begin{array}{c}2.239 * * * \\
(0.356) \\
\end{array}$ & $\begin{array}{c}2.309 * * * \\
(0.457)\end{array}$ \\
\hline Philippines & $\begin{array}{c}0.193^{*} \\
(0.110) \\
\end{array}$ & $\begin{array}{c}0.194 \\
(0.126) \\
\end{array}$ & $\begin{array}{c}0.402 * \\
(0.246) \\
\end{array}$ & $\begin{array}{c}0.438 \\
(0.458) \\
\end{array}$ & $\begin{array}{c}0.312^{*} \\
(0.178) \\
\end{array}$ & $\begin{array}{c}0.252 \\
(0.211) \\
\end{array}$ & $\begin{array}{c}0.606 \\
(0.405) \\
\end{array}$ & $\begin{array}{c}0.494 \\
(0.657) \\
\end{array}$ \\
\hline Poland & $\begin{array}{c}1.277 * * * \\
(0.296) \\
\end{array}$ & $\begin{array}{c}0.997 * * * \\
(0.318)\end{array}$ & $\begin{array}{c}2.476^{* * * *} \\
(0.407)\end{array}$ & $\begin{array}{c}2.633 * * * \\
(0.514)\end{array}$ & $\begin{array}{c}1.311 * * * \\
(0.291)\end{array}$ & $\begin{array}{c}0.943 * * * \\
(0.320) \\
\end{array}$ & $\begin{array}{c}2.575 * * * \\
(0.372) \\
\end{array}$ & $\begin{array}{c}2.657 * * * \\
(0.496)\end{array}$ \\
\hline Portugal & $\begin{array}{c}1.221 * * * \\
(0.337)\end{array}$ & $\begin{array}{c}0.868^{* *} \\
(0.356)\end{array}$ & $\begin{array}{c}2.369 * * * \\
(0.410)\end{array}$ & $\begin{array}{c}2.456^{* * * *} \\
(0.517)\end{array}$ & $\begin{array}{c}1.257 * * * \\
(0.320)\end{array}$ & $\begin{array}{c}0.807 * * \\
(0.344)\end{array}$ & $\begin{array}{c}2.473 * * * \\
(0.367)\end{array}$ & $\begin{array}{c}2.455^{* * * *} \\
(0.492)\end{array}$ \\
\hline Romania & $\begin{array}{c}1.446^{* * *} \\
(0.112) \\
\end{array}$ & $\begin{array}{c}1.498 * * * \\
(0.129)\end{array}$ & $\begin{array}{c}1.410 * * * \\
(0.187)\end{array}$ & $\begin{array}{c}1.773 * * * \\
(0.232)\end{array}$ & $\begin{array}{c}1.568 * * * \\
(0.173)\end{array}$ & $\begin{array}{c}1.563 * * * \\
(0.207)\end{array}$ & $\begin{array}{c}1.850 * * * \\
(0.340)\end{array}$ & $\begin{array}{c}2.084 * * * \\
(0.478)\end{array}$ \\
\hline Senegal & $\begin{array}{c}0.502 * * * \\
(0.041)\end{array}$ & $\begin{array}{c}0.473 * * * \\
(0.047)\end{array}$ & $\begin{array}{c}1.231 * * * \\
(0.168)\end{array}$ & $\begin{array}{c}1.461 * * * \\
(0.265)\end{array}$ & $\begin{array}{c}0.595 * * * \\
(0.052)\end{array}$ & $\begin{array}{c}0.558 * * * \\
(0.061)\end{array}$ & $\begin{array}{c}1.450 * * * \\
(0.177)\end{array}$ & $\begin{array}{c}1.651 * * * \\
(0.279)\end{array}$ \\
\hline Sierra Leone & $\begin{array}{c}0.132 * * * \\
(0.010)\end{array}$ & $\begin{array}{c}0.120 * * * \\
(0.015)\end{array}$ & $\begin{array}{c}0.804 * * * \\
(0.187)\end{array}$ & $\begin{array}{c}1.034 * * * \\
(0.307)\end{array}$ & $\begin{array}{c}0.150 * * * \\
(0.020)\end{array}$ & $\begin{array}{c}0.141 * * * \\
(0.022)\end{array}$ & $\begin{array}{c}0.962 * * * \\
(0.183)\end{array}$ & $\begin{array}{c}1.142 * * * \\
(0.305)\end{array}$ \\
\hline
\end{tabular}




\begin{tabular}{|c|c|c|c|c|c|c|c|c|}
\hline Singapore & $\begin{array}{c}0.697 \\
(0.468)\end{array}$ & $\begin{array}{c}0.167 \\
(0.480)\end{array}$ & $\begin{array}{c}1.810 * * * \\
(0.494)\end{array}$ & $\begin{array}{c}1.713 * * * \\
(0.589)\end{array}$ & $\begin{array}{l}0.720^{*} \\
(0.421)\end{array}$ & $\begin{array}{c}0.104 \\
(0.450)\end{array}$ & $\begin{array}{c}1.938^{* * *} \\
(0.402)\end{array}$ & $\begin{array}{c}1.717 * * * \\
(0.532)\end{array}$ \\
\hline South Africa & $\begin{array}{c}1.289 * * * \\
(0.256)\end{array}$ & $\begin{array}{c}1.068^{* * *} \\
(0.280)\end{array}$ & $\begin{array}{c}2.302 * * * \\
(0.329)\end{array}$ & $\begin{array}{c}2.255^{* * *} * \\
(0.414)\end{array}$ & $\begin{array}{c}1.451^{* * *} * \\
(0.268)\end{array}$ & $\begin{array}{c}1.144 * * * \\
(0.296)\end{array}$ & $\begin{array}{c}2.634 * * * \\
(0.295)\end{array}$ & $\begin{array}{c}2.382 * * * \\
(0.426)\end{array}$ \\
\hline Spain & $\begin{array}{c}1.516^{* * *} \\
(0.424)\end{array}$ & $\begin{array}{c}1.016^{* *} \\
(0.434)\end{array}$ & $\begin{array}{c}2.666^{* * *} * \\
(0.467)\end{array}$ & $\begin{array}{c}2.607 * * * \\
(0.571)\end{array}$ & $\begin{array}{c}1.420 * * * \\
(0.384)\end{array}$ & $\begin{array}{c}0.847 * * \\
(0.405)\end{array}$ & $\begin{array}{c}2.662 * * * \\
(0.396)\end{array}$ & $\begin{array}{c}2.508 * * * \\
(0.520)\end{array}$ \\
\hline Sri Lanka & $\begin{array}{c}0.355^{* * *} * \\
(0.123)\end{array}$ & $\begin{array}{l}0.264^{*} \\
(0.136) \\
\end{array}$ & $\begin{array}{c}1.094 * * * \\
(0.155)\end{array}$ & $\begin{array}{c}1.493 * * * \\
(0.180)\end{array}$ & $\begin{array}{c}0.519 * * * \\
(0.156)\end{array}$ & $\begin{array}{c}0.361 * * \\
(0.175)\end{array}$ & $\begin{array}{c}1.318^{* * *} \\
(0.167)\end{array}$ & $\begin{array}{c}1.741^{* * *} \\
(0.216)\end{array}$ \\
\hline Swaziland & $\begin{array}{c}0.508 * * * \\
(0.190)\end{array}$ & $\begin{array}{c}0.423^{* *} \\
(0.216) \\
\end{array}$ & $\begin{array}{c}1.487 * * * \\
(0.326)\end{array}$ & $\begin{array}{c}1.549^{* * * *} \\
(0.410)\end{array}$ & $\begin{array}{c}0.715^{* * *} * \\
(0.213)\end{array}$ & $\begin{array}{c}0.542 * * \\
(0.238) \\
\end{array}$ & $\begin{array}{c}1.824 * * * \\
(0.303)\end{array}$ & $\begin{array}{c}1.648^{* * *} \\
(0.435)\end{array}$ \\
\hline Sweden & $\begin{array}{c}1.758 * * * \\
(0.526)\end{array}$ & $\begin{array}{l}1.103 * * \\
(0.525)\end{array}$ & $\begin{array}{c}2.808^{* * *} * \\
(0.515)\end{array}$ & $\begin{array}{c}2.600 * * * \\
(0.606)\end{array}$ & $\begin{array}{c}1.820 * * * \\
(0.476)\end{array}$ & $\begin{array}{c}1.073 * * \\
(0.498)\end{array}$ & $\begin{array}{c}3.005 * * * \\
(0.410)\end{array}$ & $\begin{array}{c}2.630 * * * \\
(0.545)\end{array}$ \\
\hline Switzerland & $\begin{array}{c}1.925 * * * \\
(0.552)\end{array}$ & $\begin{array}{c}1.226^{* * *} \\
(0.548)\end{array}$ & $\begin{array}{c}2.941 * * * \\
(0.530)\end{array}$ & $\begin{array}{c}2.693 * * * \\
(0.615)\end{array}$ & $\begin{array}{c}2.081 * * * \\
(0.502)\end{array}$ & $\begin{array}{l}1.247 * * \\
(0.515)\end{array}$ & $\begin{array}{c}3.250 * * * \\
(0.414)\end{array}$ & $\begin{array}{c}2.783 * * * \\
(0.550)\end{array}$ \\
\hline Syria & $\begin{array}{c}-0.497 * * \\
(0.237)\end{array}$ & $\begin{array}{c}-0.725^{* * *} \\
(0.257)\end{array}$ & & $\begin{array}{c}0.905^{* * * *} \\
(0.308)\end{array}$ & & $\begin{array}{c}-0.573 * * \\
(0.286)\end{array}$ & $\begin{array}{c}0.856^{* * *} \\
(0.301)\end{array}$ & $\begin{array}{c}1.129 * * * \\
(0.378)\end{array}$ \\
\hline Taiwan & $\begin{array}{c}1.891 * * * \\
(0.350)\end{array}$ & $\begin{array}{c}1.508^{* * *} \\
(0.365)\end{array}$ & $\begin{array}{c}3.076^{* * * *} \\
(0.433)\end{array}$ & $\begin{array}{c}3.134 * * * \\
(0.539)\end{array}$ & $\begin{array}{c}1.847 * * * \\
(0.326)\end{array}$ & $\begin{array}{c}1.385^{* * *} * \\
(0.350)\end{array}$ & $\begin{array}{c}3.107 * * * \\
(0.380)\end{array}$ & $\begin{array}{c}3.085 * * * \\
(0.503)\end{array}$ \\
\hline Thailand & $\begin{array}{c}0.820 * * * \\
(0.191)\end{array}$ & $\begin{array}{c}0.641 * * * \\
(0.204)\end{array}$ & $\begin{array}{c}1.275^{* * * *} \\
(0.229)\end{array}$ & $\begin{array}{c}1.061 * * * \\
(0.390)\end{array}$ & $\begin{array}{c}0.970 * * * \\
(0.218)\end{array}$ & $\begin{array}{c}0.701 * * * \\
(0.236)\end{array}$ & $\begin{array}{c}1.512 * * * \\
(0.321)\end{array}$ & $\begin{array}{c}1.139 * * \\
(0.565)\end{array}$ \\
\hline Togo & $\begin{array}{c}1.796^{* * *} \\
(0.133)\end{array}$ & $\begin{array}{c}1.857 * * * \\
(0.153)\end{array}$ & $\begin{array}{c}2.194 * * * \\
(0.217)\end{array}$ & $\begin{array}{c}2.564 * * * \\
(0.351)\end{array}$ & $\begin{array}{c}1.433 * * * \\
(0.192)\end{array}$ & $\begin{array}{c}1.508 * * * \\
(0.216)\end{array}$ & $\begin{array}{c}2.007 * * * \\
(0.182)\end{array}$ & $\begin{array}{c}2.194 * * * \\
(0.348)\end{array}$ \\
\hline Tonga & $\begin{array}{c}0.587 * * * \\
(0.134) \\
\end{array}$ & $\begin{array}{c}0.521 * * * \\
(0.150)\end{array}$ & $\begin{array}{c}0.884 * * * \\
(0.234)\end{array}$ & & $\begin{array}{c}0.769 * * * \\
(0.188)\end{array}$ & $\begin{array}{c}0.618 * * * \\
(0.211)\end{array}$ & $\begin{array}{c}1.121 * * * \\
(0.374)\end{array}$ & $\begin{array}{c}0.882 \\
(0.635)\end{array}$ \\
\hline Tunisia & $\begin{array}{c}0.704^{* * *} \\
(0.175)\end{array}$ & $\begin{array}{c}0.524 * * * \\
(0.186)\end{array}$ & $\begin{array}{c}1.800 * * * \\
(0.210)\end{array}$ & $\begin{array}{c}2.292 * * * \\
(0.239)\end{array}$ & $\begin{array}{c}0.913^{* * *} * \\
(0.202)\end{array}$ & $\begin{array}{c}0.639 * * * \\
(0.214)\end{array}$ & $\begin{array}{c}2.071 * * * \\
(0.244)\end{array}$ & $\begin{array}{c}2.540 * * * \\
(0.315)\end{array}$ \\
\hline Turkey & $\begin{array}{c}-0.097 \\
(0.240)\end{array}$ & $\begin{array}{c}-0.311 \\
(0.261)\end{array}$ & $\begin{array}{c}0.368 \\
(0.287)\end{array}$ & $\begin{array}{c}0.288 \\
(0.334)\end{array}$ & $\begin{array}{c}0.092 \\
(0.255)\end{array}$ & & & $\begin{array}{c}0.594 \\
(0.456)\end{array}$ \\
\hline Uganda & $\begin{array}{c}0.426 * * * \\
(0.100)\end{array}$ & $\begin{array}{c}0.371 * * * \\
(0.117)\end{array}$ & $\begin{array}{c}0.863 * * * \\
(0.123)\end{array}$ & $\begin{array}{c}1.141 * * * \\
(0.277)\end{array}$ & $\begin{array}{c}0.151 \\
(0.172)\end{array}$ & $\begin{array}{c}0.090 \\
(0.182)\end{array}$ & $\begin{array}{c}0.731^{* * *} \\
(0.116)\end{array}$ & $\begin{array}{c}0.859 * * * \\
(0.282)\end{array}$ \\
\hline $\begin{array}{l}\text { United } \\
\text { Kingdom }\end{array}$ & $\begin{array}{c}1.640 * * * \\
(0.493)\end{array}$ & $\begin{array}{c}1.044^{* *} \\
(0.499)\end{array}$ & $\begin{array}{c}2.726^{* * *} \\
(0.498)\end{array}$ & $\begin{array}{c}2.571^{* * * *} \\
(0.595)\end{array}$ & $\begin{array}{c}1.623 * * * \\
(0.445)\end{array}$ & $\begin{array}{c}0.956^{* *} \\
(0.471)\end{array}$ & $\begin{array}{c}2.827 * * * \\
(0.406)\end{array}$ & $\begin{array}{c}2.544 * * * \\
(0.537)\end{array}$ \\
\hline United States & $\begin{array}{c}2.322 * * * \\
(0.575)\end{array}$ & $\begin{array}{c}1.576^{* * *} \\
(0.565)\end{array}$ & $\begin{array}{c}3.304 * * * \\
(0.542)\end{array}$ & $\begin{array}{c}3.015 * * * \\
(0.621)\end{array}$ & $\begin{array}{c}2.532 * * * \\
(0.522)\end{array}$ & $\begin{array}{c}1.620 * * * \\
(0.526)\end{array}$ & $\begin{array}{c}3.690 * * * \\
(0.419)\end{array}$ & $\begin{array}{c}3.144 * * * \\
(0.554)\end{array}$ \\
\hline Yemen & $\begin{array}{c}0.628 * * * \\
(0.087)\end{array}$ & $\begin{array}{c}0.560 * * * \\
(0.093)\end{array}$ & $\begin{array}{c}1.743 * * * \\
(0.143)\end{array}$ & $\begin{array}{c}2.400 * * * \\
(0.176)\end{array}$ & $\begin{array}{c}0.720 * * * \\
(0.150)\end{array}$ & $\begin{array}{c}0.602 * * * \\
(0.174)\end{array}$ & $\begin{array}{c}1.934 * * * \\
(0.223)\end{array}$ & $\begin{array}{c}2.633 * * * \\
(0.300)\end{array}$ \\
\hline Yugoslavia & $\begin{array}{c}1.596 * * * \\
(0.324) \\
\end{array}$ & $\begin{array}{c}1.255^{* * *} \\
(0.342) \\
\end{array}$ & $\begin{array}{c}2.161 * * * \\
(0.348)\end{array}$ & $\begin{array}{c}1.922 * * * \\
(0.399)\end{array}$ & $\begin{array}{c}1.685^{* * *} * \\
(0.314)\end{array}$ & $\begin{array}{c}1.231 * * * \\
(0.333)\end{array}$ & $\begin{array}{c}2.486 * * * \\
(0.338)\end{array}$ & $\begin{array}{c}2.126 * * * \\
(0.462)\end{array}$ \\
\hline $\begin{array}{l}\text { Constant } \\
\text { (India) }\end{array}$ & $\begin{array}{c}-20.688 * * * \\
(3.804)\end{array}$ & $\begin{array}{c}-19.675^{* * *} \\
(4.171)\end{array}$ & $\begin{array}{c}-11.378^{* * *} \\
(5.083)\end{array}$ & $\begin{array}{c}-12.806^{* *} \\
(5.650)\end{array}$ & $\begin{array}{l}-2.287 \\
(3.291)\end{array}$ & $\begin{array}{l}-3.104 \\
(3.536)\end{array}$ & $\begin{array}{l}-0.069 \\
(2.553)\end{array}$ & $\begin{array}{c}0.842 \\
(3.134)\end{array}$ \\
\hline Adjusted R2: & 0.9783 & 0.9742 & 0.9818 & 0.9775 & 0.9820 & 0.9767 & 0.9849 & 0.9799 \\
\hline & $133.87 * * *$ & $21.96 * * *$ & $127.23 * * *$ & $164.60 * * *$ & $87.94 * * *$ & $21.47 * * *$ & $185.42 * * *$ & $118.67 * * *$ \\
\hline DW statistic & 0.181 & 0.188 & 0.175 & 0.187 & 0.188 & 0.190 & 0.190 & 0.196 \\
\hline
\end{tabular}


Table A.5. Country Dummy Coefficients from F/V Models

\begin{tabular}{|c|c|c|c|c|c|c|c|c|}
\hline \multirow{2}{*}{$\begin{array}{l}\text { Country } \\
\text { Dummies }\end{array}$} & \multicolumn{4}{|c|}{ Quadratic } & \multicolumn{4}{|c|}{ Spline } \\
\hline & 1 & 2 & 3 & 4 & 5 & 6 & 7 & 8 \\
\hline Australia & $\begin{array}{c}-1.833 * * * \\
(0.444)\end{array}$ & $\begin{array}{c}-0.465 \\
(0.472) \\
\end{array}$ & $\begin{array}{c}-2.520 * * * \\
(0.430)\end{array}$ & $\begin{array}{c}-0.824 \\
(0.625) \\
\end{array}$ & $\begin{array}{c}-1.860 * * * \\
(0.454)\end{array}$ & $\begin{array}{c}-0.405 \\
(0.486)\end{array}$ & $\begin{array}{c}-2.520 * * * \\
(0.430)\end{array}$ & $\begin{array}{c}-0.953 \\
(0.648) \\
\end{array}$ \\
\hline Austria & $\begin{array}{c}-1.595^{* * * *} \\
(0.400)\end{array}$ & $\begin{array}{c}-0.418 \\
(0.437)\end{array}$ & $\begin{array}{c}-2.181 * * * \\
(0.410)\end{array}$ & $\begin{array}{c}-0.777 \\
(0.615)\end{array}$ & $\begin{array}{c}-1.598 * * * \\
(0.414)\end{array}$ & $\begin{array}{c}-0.351 \\
(0.449)\end{array}$ & $\begin{array}{c}-2.181 * * * \\
(0.410)\end{array}$ & $\begin{array}{c}-0.889 \\
(0.633)\end{array}$ \\
\hline Bahrain & $\begin{array}{c}-1.590^{* * *} \\
(0.346) \\
\end{array}$ & $\begin{array}{c}-0.701^{*} \\
(0.398) \\
\end{array}$ & $\begin{array}{c}-1.988^{* * *} \\
(0.403) \\
\end{array}$ & $\begin{array}{c}-1.063^{*} \\
(0.611) \\
\end{array}$ & $\begin{array}{c}-1.534 * * * \\
(0.367) \\
\end{array}$ & $\begin{array}{c}-0.663 \\
(0.416) \\
\end{array}$ & $\begin{array}{c}-1.988^{* * *} \\
(0.403) \\
\end{array}$ & $\begin{array}{r}-1.185^{*} \\
(0.627) \\
\end{array}$ \\
\hline Bangladesh & $\begin{array}{c}0.795^{* * * *} \\
(0.048)\end{array}$ & $\begin{array}{c}0.783^{* * * *} \\
(0.054)\end{array}$ & $\begin{array}{c}0.370^{* *} \\
(0.144)\end{array}$ & $\begin{array}{c}0.314^{* * * *} \\
(0.108)\end{array}$ & $\begin{array}{c}0.751^{* * *} \\
(0.066)\end{array}$ & $\begin{array}{c}0.750 * * * \\
(0.079)\end{array}$ & $\begin{array}{c}0.370^{* *} \\
(0.144)\end{array}$ & $\begin{array}{c}-0.183 \\
(0.329)\end{array}$ \\
\hline Belgium & $\begin{array}{c}-1.569^{* * * *} \\
(0.409)\end{array}$ & $\begin{array}{c}-0.353 \\
(0.446) \\
\end{array}$ & $\begin{array}{c}-2.173^{* * *} * \\
(0.414)\end{array}$ & $\begin{array}{c}-0.712 \\
(0.618) \\
\end{array}$ & $\begin{array}{c}-1.575^{* * * *} \\
(0.423)\end{array}$ & $\begin{array}{c}-0.286 \\
(0.458) \\
\end{array}$ & $\begin{array}{c}-2.173 * * * \\
(0.414)\end{array}$ & $\begin{array}{c}-0.826 \\
(0.636) \\
\end{array}$ \\
\hline Benin & $\begin{array}{c}-0.631 * * * \\
(0.014) \\
\end{array}$ & $\begin{array}{c}-0.588 * * * \\
(0.016) \\
\end{array}$ & $\begin{array}{c}-1.212 * * * \\
(0.186)\end{array}$ & $\begin{array}{c}-0.872 * * * \\
(0.261)\end{array}$ & $\begin{array}{c}-0.680 * * * \\
(0.042)\end{array}$ & $\begin{array}{c}-0.649 * * * \\
(0.053)\end{array}$ & $\begin{array}{c}-1.212^{* * *} \\
(0.186)\end{array}$ & $\begin{array}{c}-1.269^{* * *} \\
(0.290) \\
\end{array}$ \\
\hline Botswana & $\begin{array}{c}-0.094 \\
(0.098) \\
\end{array}$ & $\begin{array}{c}0.157 \\
(0.112) \\
\end{array}$ & $\begin{array}{c}-0.666^{* * *} \\
(0.258) \\
\end{array}$ & $\begin{array}{c}-0.126 \\
(0.341) \\
\end{array}$ & $\begin{array}{c}-0.142 \\
(0.132) \\
\end{array}$ & $\begin{array}{c}0.182 \\
(0.139) \\
\end{array}$ & $\begin{array}{c}-0.666^{* * *} \\
(0.258) \\
\end{array}$ & $\begin{array}{c}-0.300 \\
(0.402) \\
\end{array}$ \\
\hline Brazil & $\begin{array}{c}-2.373 * * * \\
(0.244) \\
\end{array}$ & $\begin{array}{c}-1.711^{* * *} \\
(0.278) \\
\end{array}$ & $\begin{array}{c}-3.413^{* * *} \\
(0.361) \\
\end{array}$ & $\begin{array}{c}-2.655^{* * *} * \\
(0.419) \\
\end{array}$ & $\begin{array}{c}-2.415^{* * *} \\
(0.284) \\
\end{array}$ & $\begin{array}{c}-1.626^{* * *} \\
(0.321) \\
\end{array}$ & $\begin{array}{c}-3.413 * * * \\
(0.361) \\
\end{array}$ & $\begin{array}{c}-2.774 * * * \\
(0.554) \\
\end{array}$ \\
\hline Bulgaria & $\begin{array}{c}-1.469 * * * \\
(0.266) \\
\end{array}$ & $\begin{array}{c}-0.844 * * * \\
(0.314) \\
\end{array}$ & $\begin{array}{c}-1.251 * * * \\
(0.409) \\
\end{array}$ & $\begin{array}{c}-0.512 \\
(0.644) \\
\end{array}$ & $\begin{array}{c}-1.469 * * * \\
(0.297) \\
\end{array}$ & $\begin{array}{c}-0.740 * * \\
(0.337) \\
\end{array}$ & $\begin{array}{c}-1.251^{* * * *} \\
(0.409) \\
\end{array}$ & $\begin{array}{c}-0.549 \\
(0.723) \\
\end{array}$ \\
\hline Canada & $\begin{array}{c}-1.865^{* * *} \\
(0.451) \\
\end{array}$ & $\begin{array}{c}-0.496 \\
(0.480) \\
\end{array}$ & $\begin{array}{c}-2.605^{* * *} \\
(0.431) \\
\end{array}$ & $\begin{array}{l}-0.856 \\
(0.622) \\
\end{array}$ & $\begin{array}{c}-1.932 * * * \\
(0.457) \\
\end{array}$ & $\begin{array}{c}-0.437 \\
(0.486) \\
\end{array}$ & $\begin{array}{c}-2.605^{* * *} \\
(0.431) \\
\end{array}$ & $\begin{array}{c}-0.987 \\
(0.648) \\
\end{array}$ \\
\hline Chile & $\begin{array}{c}-0.659 * * * \\
(0.249)\end{array}$ & $\begin{array}{c}-0.033 \\
(0.292) \\
\end{array}$ & $\begin{array}{c}-1.075^{* * *} * \\
(0.365)\end{array}$ & $\begin{array}{c}-0.391 \\
(0.551) \\
\end{array}$ & $\begin{array}{c}-0.703^{* *} \\
(0.289) \\
\end{array}$ & $\begin{array}{c}0.043 \\
(0.328) \\
\end{array}$ & $\begin{array}{c}-1.075^{* * *} \\
(0.365) \\
\end{array}$ & $\begin{array}{c}-0.450 \\
(0.608) \\
\end{array}$ \\
\hline China & $\begin{array}{c}0.433 * * * \\
(0.046)\end{array}$ & $\begin{array}{c}0.437 * * * \\
(0.056)\end{array}$ & $\begin{array}{c}0.533^{*} \\
(0.300) \\
\end{array}$ & $\begin{array}{c}0.202 \\
(0.590) \\
\end{array}$ & $\begin{array}{c}0.408^{* * *} \\
(0.065)\end{array}$ & $\begin{array}{c}0.443 * * * \\
(0.074)\end{array}$ & $\begin{array}{l}0.533^{*} \\
(0.300) \\
\end{array}$ & $\begin{array}{c}0.071 \\
(0.547) \\
\end{array}$ \\
\hline Costa Rica & $\begin{array}{c}-1.414 * * * \\
(0.201) \\
\end{array}$ & $\begin{array}{c}-1.076^{* * *} \\
(0.250) \\
\end{array}$ & $\begin{array}{c}-1.722 * * * \\
(0.375) \\
\end{array}$ & $\begin{array}{c}-1.435^{* * *} * \\
(0.544)\end{array}$ & $\begin{array}{c}-1.453^{* * *} \\
(0.252) \\
\end{array}$ & $\begin{array}{c}-1.008^{* * *} \\
(0.303) \\
\end{array}$ & $\begin{array}{c}-1.722 * * * \\
(0.375) \\
\end{array}$ & $\begin{array}{c}-1.486^{* *} \\
(0.615) \\
\end{array}$ \\
\hline Cote d'Ivoire & $\begin{array}{c}-0.725 * * * \\
(0.123) \\
\end{array}$ & $\begin{array}{c}-0.366^{* * *} \\
(0.141) \\
\end{array}$ & $\begin{array}{c}-1.207 * * * \\
(0.281) \\
\end{array}$ & $\begin{array}{c}-0.665^{*} * \\
(0.320) \\
\end{array}$ & $\begin{array}{c}-0.772 * * * \\
(0.166) \\
\end{array}$ & $\begin{array}{c}-0.328^{*} \\
(0.182) \\
\end{array}$ & $\begin{array}{c}-1.207 * * * \\
(0.281) \\
\end{array}$ & $\begin{array}{c}-0.826 * * \\
(0.419) \\
\end{array}$ \\
\hline Cyprus & $\begin{array}{c}-1.699 * * * \\
(0.292)\end{array}$ & $\begin{array}{c}-0.884 * * * \\
(0.332)\end{array}$ & $\begin{array}{c}-2.173 * * * \\
(0.368)\end{array}$ & $\begin{array}{c}-1.241^{* *} \\
(0.564)\end{array}$ & $\begin{array}{c}-1.734 * * * \\
(0.323)\end{array}$ & $\begin{array}{c}-0.806^{* *} \\
(0.354)\end{array}$ & $\begin{array}{c}-2.173 * * * \\
(0.368)\end{array}$ & $\begin{array}{c}-1.311^{* *} \\
(0.604)\end{array}$ \\
\hline $\begin{array}{l}\text { Czech } \\
\text { Republic }\end{array}$ & $\begin{array}{c}-2.103^{* * *} \\
(0.214)\end{array}$ & $\begin{array}{c}-1.579 * * * \\
(0.252) \\
\end{array}$ & $\begin{array}{c}-2.484 * * * \\
(0.359) \\
\end{array}$ & $\begin{array}{c}-1.934^{* * *} \\
(0.518) \\
\end{array}$ & $\begin{array}{c}-2.173^{* * *} \\
(0.258) \\
\end{array}$ & $\begin{array}{c}-1.524 * * * \\
(0.291) \\
\end{array}$ & $\begin{array}{c}-2.484 * * * \\
(0.359) \\
\end{array}$ & $\begin{array}{c}-1.990 * * * \\
(0.591) \\
\end{array}$ \\
\hline Denmark & $\begin{array}{c}-1.766^{* * *} \\
(0.428)\end{array}$ & $\begin{array}{c}-0.481 \\
(0.462) \\
\end{array}$ & $\begin{array}{c}-2.418^{* * *} \\
(0.423)\end{array}$ & $\begin{array}{c}-0.841 \\
(0.621) \\
\end{array}$ & $\begin{array}{c}-1.788^{* * *} \\
(0.439)\end{array}$ & $\begin{array}{c}-0.421 \\
(0.474) \\
\end{array}$ & $\begin{array}{c}-2.418^{* * *} \\
(0.423)\end{array}$ & $\begin{array}{c}-0.966 \\
(0.643) \\
\end{array}$ \\
\hline Ecuador & $\begin{array}{c}-0.121 \\
(0.166) \\
\end{array}$ & $\begin{array}{c}0.083 \\
(0.209) \\
\end{array}$ & $\begin{array}{c}-1.432 * * * \\
(0.376) \\
\end{array}$ & $\begin{array}{c}-0.980^{* * *} \\
(0.361) \\
\end{array}$ & $\begin{array}{c}-0.237 \\
(0.236) \\
\end{array}$ & $\begin{array}{c}0.073 \\
(0.268) \\
\end{array}$ & $\begin{array}{c}-1.432 * * * \\
(0.376) \\
\end{array}$ & $\begin{array}{c}-1.133^{*} \\
(0.601) \\
\end{array}$ \\
\hline Egypt & $\begin{array}{c}0.133 \\
(0.097) \\
\end{array}$ & $\begin{array}{c}0.309^{* * * *} \\
(0.115)\end{array}$ & $\begin{array}{c}-0.551^{*} \\
(0.288) \\
\end{array}$ & $\begin{array}{c}-0.596^{*} \\
(0.352) \\
\end{array}$ & $\begin{array}{c}0.112 \\
(0.155) \\
\end{array}$ & $\begin{array}{c}0.366^{* *} \\
(0.173) \\
\end{array}$ & $\begin{array}{c}-0.551^{*} \\
(0.288) \\
\end{array}$ & $\begin{array}{c}-1.109^{* * *} \\
(0.423) \\
\end{array}$ \\
\hline Ethiopia & $\begin{array}{c}1.672 * * * \\
(0.290)\end{array}$ & $\begin{array}{c}.418^{* * * *} \\
(0.367)\end{array}$ & $\begin{array}{c}1.952 * * * \\
(0.303)\end{array}$ & $\begin{array}{c}1.157^{* *} \\
(0.515) \\
\end{array}$ & $\begin{array}{c}1.970^{* * *} \\
(0.395)\end{array}$ & $\begin{array}{c}1.643 * * * \\
(0.521)\end{array}$ & $\begin{array}{c}1.952^{* * *} \\
(0.303) \\
\end{array}$ & $\begin{array}{c}1.444 * * * \\
(0.489)\end{array}$ \\
\hline Finland & $\begin{array}{c}-1.906^{* * *} \\
(0.407)\end{array}$ & $\begin{array}{c}-0.686 \\
(0.443)\end{array}$ & $\begin{array}{c}-2.507 * * * \\
(0.413)\end{array}$ & $\begin{array}{c}-1.045^{*} \\
(0.617)\end{array}$ & $\begin{array}{c}-1.910^{* * *} \\
(0.421)\end{array}$ & $\begin{array}{c}-0.620 \\
(0.454)\end{array}$ & $\begin{array}{c}-2.507 * * * \\
(0.413)\end{array}$ & $\begin{array}{c}-1.160^{*} \\
(0.634) \\
\end{array}$ \\
\hline France & $\begin{array}{c}-1.830 * * * \\
(0.425) \\
\end{array}$ & $\begin{array}{c}-0.528 \\
(0.457) \\
\end{array}$ & $\begin{array}{c}-2.463^{* * *} * \\
(0.420)\end{array}$ & $\begin{array}{l}0.887 \\
(0.622) \\
\end{array}$ & $\begin{array}{c}-1.838 * * * \\
(0.437) \\
\end{array}$ & $\begin{array}{l}-0.470 \\
(0.469) \\
\end{array}$ & $\begin{array}{c}-2.463^{* * *} \\
(0.420) \\
\end{array}$ & $\begin{array}{l}-1.013 \\
(0.640) \\
\end{array}$ \\
\hline Germany & $\begin{array}{c}-1.656^{* * *} \\
(0.429)\end{array}$ & $\begin{array}{c}-0.342 \\
(0.459) \\
\end{array}$ & $\begin{array}{c}-2.298^{* * *} \\
(0.423) \\
\end{array}$ & $\begin{array}{c}-0.701 \\
(0.622) \\
\end{array}$ & $\begin{array}{c}-1.667 * * * \\
(0.441)\end{array}$ & $\begin{array}{c}-0.282 \\
(0.472) \\
\end{array}$ & $\begin{array}{c}-2.298 * * * \\
(0.423) \\
\end{array}$ & $\begin{array}{c}-0.825 \\
(0.641) \\
\end{array}$ \\
\hline Greece & $\begin{array}{c}-1.144 * * * \\
(0.300)\end{array}$ & $\begin{array}{c}-0.321 \\
(0.344) \\
\end{array}$ & $\begin{array}{c}-1.618^{* * *} \\
(0.370)\end{array}$ & $\begin{array}{c}-0.678 \\
(0.576) \\
\end{array}$ & $\begin{array}{c}-1.169^{* * *} \\
(0.330)\end{array}$ & $\begin{array}{c}-0.230 \\
(0.360) \\
\end{array}$ & $\begin{array}{c}-1.618^{* * * *} \\
(0.370)\end{array}$ & $\begin{array}{c}-0.742 \\
(0.607) \\
\end{array}$ \\
\hline Hong Kong & $\begin{array}{c}-0.792 * * \\
(0.376) \\
\end{array}$ & $\begin{array}{c}0.321 \\
(0.410) \\
\end{array}$ & $\begin{array}{c}-1.411 * * * \\
(0.395) \\
\end{array}$ & $\begin{array}{c}-0.038 \\
(0.592) \\
\end{array}$ & $\begin{array}{c}-0.843 * * \\
(0.392) \\
\end{array}$ & $\begin{array}{c}0.392 \\
(0.422) \\
\end{array}$ & $\begin{array}{c}-1.411 * * * \\
(0.395) \\
\end{array}$ & $\begin{array}{c}-0.140 \\
(0.624) \\
\end{array}$ \\
\hline Hungary & $\begin{array}{c}-1.418 * * * \\
(0.273) \\
\end{array}$ & $\begin{array}{c}-0.711^{* *} \\
(0.316) \\
\end{array}$ & $\begin{array}{c}-1.852 * * * \\
(0.372) \\
\end{array}$ & $\begin{array}{c}-1.069^{*} \\
(0.574) \\
\end{array}$ & $\begin{array}{c}-1.433^{* * *} \\
(0.305)\end{array}$ & $\begin{array}{c}-0.607^{*} \\
(0.341)\end{array}$ & $\begin{array}{c}-1.852 * * * \\
(0.372)\end{array}$ & $\begin{array}{c}-1.122^{*} \\
(0.613)\end{array}$ \\
\hline Iceland & $\begin{array}{c}-2.445^{* * *} \\
(0.404)\end{array}$ & $\begin{array}{c}-1.239^{* * *} \\
(0.438) \\
\end{array}$ & $\begin{array}{c}-3.053^{* * *} \\
(0.411)\end{array}$ & $\begin{array}{c}-1.599^{* * *} \\
(0.614)\end{array}$ & $\begin{array}{c}-2.459^{* * *} \\
(0.419)\end{array}$ & $\begin{array}{c}-1.164 * * * \\
(0.451)\end{array}$ & $\begin{array}{c}-3.053^{* * *} \\
(0.411) \\
\end{array}$ & $\begin{array}{c}-1.702 * * * \\
(0.633) \\
\end{array}$ \\
\hline
\end{tabular}


(Table A.5. continued)

\begin{tabular}{|c|c|c|c|c|c|c|c|c|}
\hline Indonesia & $\begin{array}{c}-0.852 * * * \\
(0.043)\end{array}$ & $\begin{array}{c}-0.713 * * * \\
(0.046)\end{array}$ & $\begin{array}{c}-0.783 * * * \\
(0.223)\end{array}$ & $\begin{array}{c}-0.959 * \\
(0.514) \\
\end{array}$ & $\begin{array}{c}-0.836^{* * *} \\
(0.087)\end{array}$ & $\begin{array}{c}-0.648 * * * \\
(0.086) \\
\end{array}$ & $\begin{array}{c}-0.783 * * * \\
(0.223) \\
\end{array}$ & $\begin{array}{c}-0.996^{* *} \\
(0.478) \\
\end{array}$ \\
\hline Ireland & $\begin{array}{c}-1.637 * * * \\
(0.338)\end{array}$ & $\begin{array}{c}-0.673^{*} \\
(0.377)\end{array}$ & $\begin{array}{c}-2.123 * * * \\
(0.385)\end{array}$ & $\begin{array}{l}-1.032^{*} \\
(0.596)\end{array}$ & $\begin{array}{c}-1.630 * * * \\
(0.360)\end{array}$ & $\begin{array}{c}-0.585 \\
(0.390)\end{array}$ & $\begin{array}{c}-2.123 * * * \\
(0.385)\end{array}$ & $\begin{array}{c}-1.108^{*} \\
(0.616)\end{array}$ \\
\hline Israel & $\begin{array}{c}-1.282^{* * *} \\
(0.356) \\
\end{array}$ & $\begin{array}{c}-0.277 \\
(0.400) \\
\end{array}$ & $\begin{array}{c}-1.786^{* * *} \\
(0.391) \\
\end{array}$ & $\begin{array}{c}-0.635 \\
(0.603) \\
\end{array}$ & $\begin{array}{c}-1.272 * * * \\
(0.375) \\
\end{array}$ & $\begin{array}{c}-0.204 \\
(0.412) \\
\end{array}$ & $\begin{array}{c}-1.786^{* * *} \\
(0.391) \\
\end{array}$ & $\begin{array}{c}-0.732 \\
(0.621) \\
\end{array}$ \\
\hline Italy & $\begin{array}{c}-2.117 * * * \\
(0.395)\end{array}$ & $\begin{array}{c}-0.943 * * \\
(0.432)\end{array}$ & $\begin{array}{c}-2.689 * * * \\
(0.407)\end{array}$ & $\begin{array}{c}-1.302^{* *} \\
(0.614)\end{array}$ & $\begin{array}{c}-2.114 * * * \\
(0.410)\end{array}$ & $\begin{array}{c}-0.877^{* *} \\
(0.442) \\
\end{array}$ & $\begin{array}{c}-2.689 * * * \\
(0.407)\end{array}$ & $\begin{array}{c}-1.413 * * \\
(0.630) \\
\end{array}$ \\
\hline Japan & $\begin{array}{c}-2.418^{* * *} \\
(0.397)\end{array}$ & $\begin{array}{c}-1.239 * * * \\
(0.433)\end{array}$ & $\begin{array}{c}-3.029 * * * \\
(0.407)\end{array}$ & $\begin{array}{c}-1.598^{* * * *} \\
(0.608)\end{array}$ & $\begin{array}{c}-2.440 * * * \\
(0.412)\end{array}$ & $\begin{array}{c}-1.165^{* * *} \\
(0.444)\end{array}$ & $\begin{array}{c}-3.029 * * * \\
(0.407)\end{array}$ & $\begin{array}{c}-1.703 \\
(0.631)\end{array}$ \\
\hline Kenya & $\begin{array}{c}0.338 * * * \\
(0.050)\end{array}$ & $\begin{array}{c}0.349 * * * \\
(0.064)\end{array}$ & $\begin{array}{c}0.012 \\
(0.124)\end{array}$ & $\begin{array}{c}0.069 \\
(0.245)\end{array}$ & $\begin{array}{c}0.407 * * * \\
(0.071)\end{array}$ & $\begin{array}{c}0.411^{* * * *} \\
(0.093)\end{array}$ & $\begin{array}{c}0.012 \\
(0.124)\end{array}$ & $\begin{array}{c}-0.111 \\
(0.224)\end{array}$ \\
\hline Korea, Rep. & $\begin{array}{c}0.014 \\
(0.275) \\
\end{array}$ & $\begin{array}{c}0.699 * * \\
(0.321) \\
\end{array}$ & $\begin{array}{c}-0.373 \\
(0.370) \\
\end{array}$ & $\begin{array}{c}0.339 \\
(0.571) \\
\end{array}$ & $\begin{array}{c}0.005 \\
(0.306) \\
\end{array}$ & $\begin{array}{c}0.762 * * \\
(0.344) \\
\end{array}$ & $\begin{array}{c}-0.373 \\
(0.370) \\
\end{array}$ & $\begin{array}{c}0.264 \\
(0.607) \\
\end{array}$ \\
\hline Luxembourg & $\begin{array}{c}-1.426^{* * *} \\
(0.444) \\
\end{array}$ & $\begin{array}{c}-0.076 \\
(0.469) \\
\end{array}$ & $\begin{array}{c}-2.180^{* * * *} \\
(0.425) \\
\end{array}$ & $\begin{array}{c}-0.437 \\
(0.613) \\
\end{array}$ & $\begin{array}{c}-1.521^{* * *} \\
(0.446)\end{array}$ & $\begin{array}{c}-0.037 \\
(0.474) \\
\end{array}$ & $\begin{array}{c}-2.180^{* * *} \\
(0.425) \\
\end{array}$ & $\begin{array}{c}-0.582 \\
(0.644) \\
\end{array}$ \\
\hline Malawi & $\begin{array}{c}0.569^{* * * *} \\
(0.174)\end{array}$ & $\begin{array}{c}0.556^{* * * *} \\
(0.213)\end{array}$ & $\begin{array}{c}0.702^{* * *} \\
(0.151) \\
\end{array}$ & $\begin{array}{c}0.274 \\
(0.284) \\
\end{array}$ & $\begin{array}{c}0.793 * * * \\
(0.258) \\
\end{array}$ & $\begin{array}{c}0.764 * * \\
(0.322) \\
\end{array}$ & $\begin{array}{c}0.702^{* * * *} \\
(0.151)\end{array}$ & $\begin{array}{c}0.427 \\
(0.264) \\
\end{array}$ \\
\hline Malaysia & $\begin{array}{c}-1.352 * * * \\
(0.227) \\
\end{array}$ & $\begin{array}{c}-0.777 * * * \\
(0.266) \\
\end{array}$ & $\begin{array}{c}-1.551 * * * \\
(0.290) \\
\end{array}$ & $\begin{array}{c}-1.034^{* *} \\
(0.495) \\
\end{array}$ & $\begin{array}{c}-1.391 * * * \\
(0.259) \\
\end{array}$ & $\begin{array}{c}-0.705^{* *} \\
(0.287) \\
\end{array}$ & $\begin{array}{c}-1.551 * * * \\
(0.290) \\
\end{array}$ & $\begin{array}{c}-1.081 * * \\
(0.487) \\
\end{array}$ \\
\hline Mauritius & $\begin{array}{c}-0.830^{* * *} \\
(0.271) \\
\end{array}$ & $\begin{array}{c}-0.151 \\
(0.317) \\
\end{array}$ & $\begin{array}{c}-1.659 * * * \\
(0.348) \\
\end{array}$ & $\begin{array}{c}-0.440 \\
(0.510) \\
\end{array}$ & $\begin{array}{c}-0.844 * * * \\
(0.304) \\
\end{array}$ & $\begin{array}{c}-0.062 \\
(0.343) \\
\end{array}$ & $\begin{array}{c}-1.659 * * * \\
(0.348) \\
\end{array}$ & $\begin{array}{c}-0.592 \\
(0.553) \\
\end{array}$ \\
\hline Mongolia & $\begin{array}{c}0.161^{* *} \\
(0.071)\end{array}$ & $\begin{array}{c}0.015 \\
(0.076)\end{array}$ & $\begin{array}{c}0.379 \\
(0.382) \\
\end{array}$ & $\begin{array}{c}-0.208 \\
(0.659) \\
\end{array}$ & $\begin{array}{c}0.145 \\
(0.101) \\
\end{array}$ & $\begin{array}{c}0.029 \\
(0.120) \\
\end{array}$ & $\begin{array}{c}0.379 \\
(0.382) \\
\end{array}$ & $\begin{array}{c}-0.323 \\
(0.607) \\
\end{array}$ \\
\hline Morocco & $\begin{array}{c}-0.301 * * * \\
(0.107)\end{array}$ & $\begin{array}{c}-0.064 \\
(0.130) \\
\end{array}$ & $\begin{array}{c}-0.982 * * * \\
(0.252)\end{array}$ & $\begin{array}{c}-0.876^{* * *} \\
(0.328)\end{array}$ & $\begin{array}{c}-0.365^{* * *} \\
(0.139)\end{array}$ & $\begin{array}{c}-0.055 \\
(0.158) \\
\end{array}$ & $\begin{array}{c}-0.982 * * * \\
(0.252)\end{array}$ & $\begin{array}{c}-1.408 * * * \\
(0.393) \\
\end{array}$ \\
\hline Netherlands & $\begin{array}{c}-2.048 * * * \\
(0.416) \\
\end{array}$ & $\begin{array}{c}-0.810 * \\
(0.451) \\
\end{array}$ & $\begin{array}{c}-2.665 * * * \\
(0.416) \\
\end{array}$ & $\begin{array}{c}-1.170^{*} \\
(0.619) \\
\end{array}$ & $\begin{array}{c}-2.059 * * * \\
(0.428) \\
\end{array}$ & $\begin{array}{c}-0.750 \\
(0.464) \\
\end{array}$ & $\begin{array}{c}-2.665 * * * \\
(0.416) \\
\end{array}$ & $\begin{array}{c}-1.292 * * \\
(0.638)\end{array}$ \\
\hline New Zealand & $\begin{array}{c}-1.929 * * * \\
(0.415) \\
\end{array}$ & $\begin{array}{c}-0.687 \\
(0.450) \\
\end{array}$ & $\begin{array}{c}-2.521 * * * \\
(0.418) \\
\end{array}$ & $\begin{array}{c}-1.047^{*} \\
(0.622) \\
\end{array}$ & $\begin{array}{c}-1.923 * * * \\
(0.426) \\
\end{array}$ & $\begin{array}{c}-0.648 \\
(0.465) \\
\end{array}$ & $\begin{array}{c}-2.521 * * * \\
(0.418)\end{array}$ & $\begin{array}{c}-1.189 * \\
(0.640) \\
\end{array}$ \\
\hline Niger & $\begin{array}{c}0.220 * * * \\
(0.081)\end{array}$ & $\begin{array}{c}0.309 * * * \\
(0.105)\end{array}$ & $\begin{array}{c}0.049 \\
(0.090)\end{array}$ & $\begin{array}{c}0.029 \\
(0.247)\end{array}$ & $\begin{array}{c}0.339 * * * \\
(0.123)\end{array}$ & $\begin{array}{c}0.425^{* * *} \\
(0.159)\end{array}$ & $\begin{array}{c}0.049 \\
(0.090)\end{array}$ & $\begin{array}{c}-0.044 \\
(0.213)\end{array}$ \\
\hline Nigeria & $\begin{array}{c}0.768 * * * \\
(0.035) \\
\end{array}$ & $\begin{array}{c}0.879 * * * \\
(0.037)\end{array}$ & $\begin{array}{c}0.180 \\
(0.215) \\
\end{array}$ & $\begin{array}{c}0.599 * * \\
(0.299) \\
\end{array}$ & $\begin{array}{c}0.724 * * * \\
(0.046) \\
\end{array}$ & $\begin{array}{c}0.845^{* * *} * \\
(0.054)\end{array}$ & $\begin{array}{c}0.180 \\
(0.215) \\
\end{array}$ & $\begin{array}{c}0.264 \\
(0.335) \\
\end{array}$ \\
\hline Norway & $\begin{array}{c}-2.263 * * * \\
(0.427) \\
\end{array}$ & $\begin{array}{c}-0.975^{* *} \\
(0.459) \\
\end{array}$ & $\begin{array}{c}-2.940 * * * \\
(0.419)\end{array}$ & $\begin{array}{c}-1.334^{* *} \\
(0.617) \\
\end{array}$ & $\begin{array}{c}-2.308^{* * *} \\
(0.437) \\
\end{array}$ & $\begin{array}{c}-0.907^{*} \\
(0.466) \\
\end{array}$ & $\begin{array}{c}-2.940 * * * \\
(0.419)\end{array}$ & $\begin{array}{c}-1.450 * * \\
(0.639) \\
\end{array}$ \\
\hline Pakistan & $\begin{array}{c}0.135 * * * \\
(0.024)\end{array}$ & $\begin{array}{c}0.198 * * * \\
(0.028)\end{array}$ & $\begin{array}{c}-0.242^{* *} \\
(0.110)\end{array}$ & $\begin{array}{c}-0.244 * * * \\
(0.090)\end{array}$ & $\begin{array}{c}0.107 * * * \\
(0.029)\end{array}$ & $\begin{array}{c}0.176^{* * *} * \\
(0.038)\end{array}$ & $\begin{array}{c}-0.242 * * \\
(0.110)\end{array}$ & $\begin{array}{c}-0.700 * * * \\
(0.265)\end{array}$ \\
\hline Panama & $\begin{array}{c}-0.716 * * * \\
(0.200) \\
\end{array}$ & $\begin{array}{c}-0.298 \\
(0.242) \\
\end{array}$ & $\begin{array}{c}-1.889 * * * \\
(0.363) \\
\end{array}$ & $\begin{array}{c}-1.294 * * * \\
(0.389) \\
\end{array}$ & $\begin{array}{c}-0.801 * * * \\
(0.254) \\
\end{array}$ & $\begin{array}{c}-0.265 \\
(0.290) \\
\end{array}$ & $\begin{array}{c}-1.889 * * * \\
(0.363) \\
\end{array}$ & $\begin{array}{c}-1.432 * * \\
(0.572) \\
\end{array}$ \\
\hline Philippines & $\begin{array}{c}-1.780 * * * \\
(0.090) \\
\end{array}$ & $\begin{array}{c}-1.707 * * * \\
(0.111) \\
\end{array}$ & $\begin{array}{c}-1.622 * * * \\
(0.327) \\
\end{array}$ & $\begin{array}{c}-1.939 * * * \\
(0.602)\end{array}$ & $\begin{array}{c}-1.784 * * * \\
(0.159) \\
\end{array}$ & $\begin{array}{c}-1.635 * * * \\
(0.183) \\
\end{array}$ & $\begin{array}{c}-1.622 * * * \\
(0.327)\end{array}$ & $\begin{array}{c}-1.929 * * * \\
(0.568) \\
\end{array}$ \\
\hline Poland & $\begin{array}{c}-1.379 * * * \\
(0.232) \\
\end{array}$ & $\begin{array}{c}-0.891 * * * \\
(0.282) \\
\end{array}$ & $\begin{array}{c}-1.738 * * * \\
(0.372) \\
\end{array}$ & $\begin{array}{c}-1.251 * * \\
(0.559) \\
\end{array}$ & $\begin{array}{c}-1.401 * * * \\
(0.273) \\
\end{array}$ & $\begin{array}{c}-0.802 * * \\
(0.321) \\
\end{array}$ & $\begin{array}{c}-1.738 * * * \\
(0.372) \\
\end{array}$ & $\begin{array}{c}-1.301 * * \\
(0.614) \\
\end{array}$ \\
\hline Portugal & $\begin{array}{c}-1.104 * * * \\
(0.282)\end{array}$ & $\begin{array}{l}-0.346 \\
(0.325)\end{array}$ & $\begin{array}{c}-1.550 * * * \\
(0.365)\end{array}$ & $\begin{array}{c}-0.703 \\
(0.560) \\
\end{array}$ & $\begin{array}{c}-1.135^{* * * *} \\
(0.312)\end{array}$ & $\begin{array}{c}-0.269 \\
(0.344) \\
\end{array}$ & $\begin{array}{c}-1.550 * * * \\
(0.365)\end{array}$ & $\begin{array}{c}-0.768 \\
(0.600) \\
\end{array}$ \\
\hline Romania & $\begin{array}{c}-1.027 * * * \\
(0.084)\end{array}$ & $\begin{array}{c}-1.127 * * * \\
(0.100)\end{array}$ & $\begin{array}{c}-0.320 \\
(0.449) \\
\end{array}$ & $\begin{array}{c}-0.742 \\
(0.547) \\
\end{array}$ & $\begin{array}{c}-1.023 * * * \\
(0.144) \\
\end{array}$ & $\begin{array}{c}-1.063^{* * *} \\
(0.171)\end{array}$ & $\begin{array}{c}-0.320 \\
(0.449) \\
\end{array}$ & $\begin{array}{c}-0.735 \\
(0.703) \\
\end{array}$ \\
\hline Sierra Leone & $\begin{array}{c}0.116^{* * *} \\
(0.006) \\
\end{array}$ & $\begin{array}{c}0.148 * * * \\
(0.016) \\
\end{array}$ & $\begin{array}{c}-0.426^{* *} \\
(0.181) \\
\end{array}$ & $\begin{array}{c}-0.129 \\
(0.280) \\
\end{array}$ & $\begin{array}{c}0.096^{* * *} * \\
(0.028)\end{array}$ & $\begin{array}{c}0.114 * * * \\
(0.032) \\
\end{array}$ & $\begin{array}{c}-0.426^{* *} \\
(0.181) \\
\end{array}$ & $\begin{array}{c}-0.479 * \\
(0.285) \\
\end{array}$ \\
\hline Singapore & $\begin{array}{c}-1.369 * * * \\
(0.382) \\
\end{array}$ & $\begin{array}{c}-0.277 \\
(0.420) \\
\end{array}$ & $\begin{array}{c}-1.903 * * * \\
(0.404)\end{array}$ & $\begin{array}{c}-0.639 \\
(0.610) \\
\end{array}$ & $\begin{array}{c}-1.365^{* * *} \\
(0.397) \\
\end{array}$ & $\begin{array}{c}-0.217 \\
(0.433) \\
\end{array}$ & $\begin{array}{c}-1.903 * * * \\
(0.404)\end{array}$ & $\begin{array}{c}-0.747 \\
(0.628) \\
\end{array}$ \\
\hline South Africa & $\begin{array}{c}-0.674 * * * \\
(0.217)\end{array}$ & $\begin{array}{c}-0.154 \\
(0.258) \\
\end{array}$ & $\begin{array}{c}-1.422 * * * \\
(0.328)\end{array}$ & $\begin{array}{c}-0.446 \\
(0.457) \\
\end{array}$ & $\begin{array}{c}-0.763 * * * \\
(0.267)\end{array}$ & $\begin{array}{c}-0.115 \\
(0.302) \\
\end{array}$ & $\begin{array}{c}-1.422 * * * \\
(0.328)\end{array}$ & $\begin{array}{c}-0.601 \\
(0.532) \\
\end{array}$ \\
\hline Spain & $\begin{array}{c}-1.814 * * * \\
(0.354) \\
\end{array}$ & $\begin{array}{c}-0.794 * * \\
(0.393) \\
\end{array}$ & $\begin{array}{c}-2.292 * * * \\
(0.392) \\
\end{array}$ & $\begin{array}{c}-1.154^{*} \\
(0.606) \\
\end{array}$ & $\begin{array}{c}-1.793 * * * \\
(0.375) \\
\end{array}$ & $\begin{array}{c}-0.718^{*} \\
(0.403) \\
\end{array}$ & $\begin{array}{c}-2.292 * * * \\
(0.392) \\
\end{array}$ & $\begin{array}{c}-1.241 * * \\
(0.619) \\
\end{array}$ \\
\hline Sri Lanka & $\begin{array}{c}-0.509 * * * \\
(0.100)\end{array}$ & $\begin{array}{c}-0.275^{* *} \\
(0.120) \\
\end{array}$ & $\begin{array}{c}-0.965 * * * \\
(0.173)\end{array}$ & $\begin{array}{c}-0.720 * * * \\
(0.185)\end{array}$ & $\begin{array}{c}-0.588 * * * \\
(0.123)\end{array}$ & $\begin{array}{c}-0.294 * * \\
(0.142) \\
\end{array}$ & $\begin{array}{c}-0.965 * * * \\
(0.173) \\
\end{array}$ & $\begin{array}{c}-1.118 * * * \\
(0.333) \\
\end{array}$ \\
\hline
\end{tabular}




\begin{tabular}{|c|c|c|c|c|c|c|c|c|}
\hline \multicolumn{9}{|c|}{ (Table A.5. continued) } \\
\hline Swaziland & $\begin{array}{c}0.421 * * * \\
(0.153) \\
\end{array}$ & $\begin{array}{c}0.617 * * * \\
(0.192)\end{array}$ & $\begin{array}{c}-0.370 \\
(0.330) \\
\end{array}$ & $\begin{array}{c}0.338 \\
(0.435) \\
\end{array}$ & $\begin{array}{c}0.296 \\
(0.227) \\
\end{array}$ & $\begin{array}{c}0.595 * * \\
(0.253) \\
\end{array}$ & $\begin{array}{l}-0.370 \\
(0.330) \\
\end{array}$ & $\begin{array}{c}0.162 \\
(0.516) \\
\end{array}$ \\
\hline Sweden & $\begin{array}{c}-2.173 * * * \\
(0.438) \\
\end{array}$ & $\begin{array}{c}-0.842 * \\
(0.469)\end{array}$ & $\begin{array}{c}-2.851 * * * \\
(0.428)\end{array}$ & $\begin{array}{c}-1.201 * \\
(0.624)\end{array}$ & $\begin{array}{c}-2.200 * * * \\
(0.449)\end{array}$ & $\begin{array}{l}-0.778 \\
(0.484)\end{array}$ & $\begin{array}{c}-2.851 * * * \\
(0.428)\end{array}$ & $\begin{array}{c}-1.326^{* *} \\
(0.647)\end{array}$ \\
\hline Switzerland & $\begin{array}{c}-1.829 * * * \\
(0.460)\end{array}$ & $\begin{array}{l}-0.418 \\
(0.487)\end{array}$ & $\begin{array}{c}-2.594 * * * \\
(0.436)\end{array}$ & $\begin{array}{l}-0.777 \\
(0.625)\end{array}$ & $\begin{array}{c}-1.898^{* * * *} \\
(0.468)\end{array}$ & $\begin{array}{l}-0.342 \\
(0.498)\end{array}$ & $\begin{array}{c}-2.594 * * * \\
(0.436)\end{array}$ & $\begin{array}{l}-0.896 \\
(0.653)\end{array}$ \\
\hline Taiwan & $\begin{array}{c}-1.798 * * * \\
(0.294) \\
\end{array}$ & $\begin{array}{c}-1.005 * * * \\
(0.334)\end{array}$ & $\begin{array}{c}-2.223 * * * \\
(0.374) \\
\end{array}$ & $\begin{array}{c}-1.365^{* *} \\
(0.581) \\
\end{array}$ & $\begin{array}{c}-1.797 * * * \\
(0.322)\end{array}$ & $\begin{array}{c}-0.919 * * * \\
(0.355) \\
\end{array}$ & $\begin{array}{c}-2.223 * * * \\
(0.374)\end{array}$ & $\begin{array}{c}-1.430 * * \\
(0.612)\end{array}$ \\
\hline Thailand & $\begin{array}{c}-1.071 * * * \\
(0.153)\end{array}$ & $\begin{array}{c}-0.681 * * * \\
(0.178)\end{array}$ & $\begin{array}{c}-1.197 * * * \\
(0.263)\end{array}$ & $\begin{array}{l}-0.931^{*} \\
(0.504) \\
\end{array}$ & $\begin{array}{c}-1.134 * * * \\
(0.189)\end{array}$ & $\begin{array}{c}-0.646^{* * * *} \\
(0.205)\end{array}$ & $\begin{array}{c}-1.197 * * * \\
(0.263)\end{array}$ & $\begin{array}{c}-0.998 * * \\
(0.489) \\
\end{array}$ \\
\hline Togo & $\begin{array}{c}-0.173^{*} \\
(0.094) \\
\end{array}$ & $\begin{array}{c}-0.181 \\
(0.128) \\
\end{array}$ & $\begin{array}{c}-0.348^{* * *} \\
(0.122) \\
\end{array}$ & $\begin{array}{c}-0.453 \\
(0.285) \\
\end{array}$ & $\begin{array}{c}-0.032 \\
(0.137) \\
\end{array}$ & $\begin{array}{c}-0.051 \\
(0.188) \\
\end{array}$ & $\begin{array}{c}-0.348 * * * \\
(0.122) \\
\end{array}$ & $\begin{array}{c}-0.503^{* *} \\
(0.245)\end{array}$ \\
\hline Tonga & $\begin{array}{c}-0.551 * * * \\
(0.112)\end{array}$ & $\begin{array}{c}-0.371 * * * \\
(0.135)\end{array}$ & $\begin{array}{l}-0.461 \\
(0.314)\end{array}$ & $\begin{array}{l}-0.607 \\
(0.581)\end{array}$ & $\begin{array}{c}-0.577 * * * \\
(0.175)\end{array}$ & $\begin{array}{l}-0.304 \\
(0.193)\end{array}$ & $\begin{array}{c}-0.461 \\
(0.314)\end{array}$ & $\begin{array}{l}-0.587 \\
(0.557)\end{array}$ \\
\hline Tunisia & $\begin{array}{c}-0.620 * * * \\
(0.144)\end{array}$ & $\begin{array}{l}-0.219 \\
(0.165) \\
\end{array}$ & $\begin{array}{c}-1.292 * * * \\
(0.253)\end{array}$ & $\begin{array}{c}-0.990 * * * \\
(0.342)\end{array}$ & $\begin{array}{c}-0.725^{* * *} \\
(0.177)\end{array}$ & $\begin{array}{l}-0.233 \\
(0.192) \\
\end{array}$ & $\begin{array}{c}-1.292 * * * \\
(0.253)\end{array}$ & $\begin{array}{c}-1.507 * * * \\
(0.403)\end{array}$ \\
\hline Turkey & $\begin{array}{l}-0.129 \\
(0.200)\end{array}$ & $\begin{array}{c}0.360 \\
(0.238)\end{array}$ & $\begin{array}{c}-0.103 \\
(0.366)\end{array}$ & $\begin{array}{c}0.547 \\
(0.528)\end{array}$ & $\begin{array}{l}-0.208 \\
(0.245)\end{array}$ & $\begin{array}{c}0.406 \\
(0.272)\end{array}$ & $\begin{array}{l}-0.103 \\
(0.366)\end{array}$ & $\begin{array}{c}0.505 \\
(0.631)\end{array}$ \\
\hline $\begin{array}{l}\text { United } \\
\text { Kingdom }\end{array}$ & $\begin{array}{c}-2.178 * * * \\
(0.411)\end{array}$ & $\begin{array}{c}-0.951 * * \\
(0.447)\end{array}$ & $\begin{array}{c}-2.773 * * * \\
(0.417)\end{array}$ & $\begin{array}{c}-1.310^{* *} \\
(0.619) \\
\end{array}$ & $\begin{array}{c}-2.177 * * * \\
(0.425)\end{array}$ & $\begin{array}{l}-0.888^{*} \\
(0.460) \\
\end{array}$ & $\begin{array}{c}-2.773 * * * \\
(0.417)\end{array}$ & $\begin{array}{c}-1.427 * * \\
(0.637) \\
\end{array}$ \\
\hline United States & $\begin{array}{c}-1.944 * * * \\
(0.479)\end{array}$ & $\begin{array}{l}-0.449 \\
(0.501)\end{array}$ & $\begin{array}{c}-2.781 * * * \\
(0.444)\end{array}$ & $\begin{array}{l}-0.809 \\
(0.626)\end{array}$ & $\begin{array}{c}-2.051 * * * \\
(0.482)\end{array}$ & $\begin{array}{c}-0.385 \\
(0.505)\end{array}$ & $\begin{array}{c}-2.781 * * * \\
(0.444)\end{array}$ & $\begin{array}{c}-0.941 \\
(0.657)\end{array}$ \\
\hline Yemen & $\begin{array}{c}-0.519^{* * *} \\
(0.069)\end{array}$ & $\begin{array}{c}-0.367 * * * \\
(0.079) \\
\end{array}$ & $\begin{array}{c}-1.233^{* * *} \\
(0.249) \\
\end{array}$ & $\begin{array}{c}-1.264 * * * \\
(0.330)\end{array}$ & $\begin{array}{c}-0.562 * * * \\
(0.098)\end{array}$ & $\begin{array}{c}-0.371^{* * *} \\
(0.114) \\
\end{array}$ & $\begin{array}{c}-1.233^{* * *} \\
(0.249) \\
\end{array}$ & $\begin{array}{c}-1.910 * * * \\
(0.389)\end{array}$ \\
\hline Yugoslavia & $\begin{array}{c}-0.793 * * * \\
(0.271)\end{array}$ & $\begin{array}{c}-0.059 \\
(0.313) \\
\end{array}$ & $\begin{array}{c}-0.934 * * \\
(0.366)\end{array}$ & $\begin{array}{c}0.085 \\
(0.563)\end{array}$ & $\begin{array}{c}-0.853 * * * \\
(0.305)\end{array}$ & $\begin{array}{c}0.013 \\
(0.333)\end{array}$ & $\begin{array}{c}-0.934 * * \\
(0.366)\end{array}$ & $\begin{array}{c}0.026 \\
(0.637) \\
\end{array}$ \\
\hline $\begin{array}{l}\text { Constant } \\
\text { (India) }\end{array}$ & $\begin{array}{c}-11.105 * * * \\
(3.477)\end{array}$ & $\begin{array}{c}-12.166 * * * \\
(4.067)\end{array}$ & $\begin{array}{c}-11.092 * * \\
(4.665)\end{array}$ & $\begin{array}{c}-12.055^{*} \\
(6.299)\end{array}$ & $\begin{array}{c}-6.583 * * * \\
(2.440)\end{array}$ & $\begin{array}{l}-4.518 \\
(3.121)\end{array}$ & $\begin{array}{c}-9.243 * * * \\
(2.214)\end{array}$ & $\begin{array}{l}-6.327^{*} \\
(3.266)\end{array}$ \\
\hline Adjusted $\mathrm{R}^{2}$ : & 0.9532 & 0.9363 & 0.9569 & 0.9377 & 0.9540 & 0.9368 & 0.9588 & 0.9394 \\
\hline Hausman chi ${ }^{2}$ & $257.15 * * *$ & $21.75 * * *$ & $175.57 * * *$ & $32.86 * * *$ & $167.26^{* * *}$ & $29.58 * * *$ & $190.31 * * *$ & $101.17 * * *$ \\
\hline DW statistic & 0.534 & 0.443 & 0.576 & 0.457 & 0.548 & 0.451 & 0.606 & 0.476 \\
\hline
\end{tabular}


Table A.6. Regression Results from Fatalities/Population Models, Common time trend vs. year dummies

\begin{tabular}{|c|c|c|}
\hline Variable & Common time trend (Model 5) & Year Dummies \\
\hline \multicolumn{3}{|l|}{ ln Y for: } \\
\hline$\$ 1-\$ 938$ & $1.684 * * *(0.393)$ & $1.528 * * *(0.387)$ \\
\hline$\$ 938-\$ 1,395$ & $1.180 * * *(0.325)$ & $1.168 * * *(0.326)$ \\
\hline$\$ 1,395-\$ 2,043$ & $0.506 * *(0.242)$ & $0.468^{*}(0.244)$ \\
\hline$\$ 2,043-\$ 3,045$ & $0.920 *(0.481)$ & $0.877 *(0.495)$ \\
\hline$\$ 3,045-\$ 4,065$ & $0.699 *(0.392)$ & $0.618(0.401)$ \\
\hline$\$ 4,065-\$ 6,095$ & $0.323(0.258)$ & $0.340(0.250)$ \\
\hline$\$ 6,095-\$ 8,592$ & $-0.048(0.251)$ & $-0.147(0.247)$ \\
\hline$\$ 8,592-\$ 10,894$ & $-0.791 * * *(0.247)$ & $-0.951 * * *(0.234)$ \\
\hline$\$ 10,894-13,234$ & $-1.572 * * *(0.363)$ & $-1.468 * * *(0.336)$ \\
\hline$>\$ 13,234$ & $-1.151 * * *(0.277)$ & $-1.112 * * *(0.267)$ \\
\hline $\mathrm{t}$ & $0.001(0.003)$ & \\
\hline Year Dummies: 1964 & & $0.077 * * *(0.028)$ \\
\hline 1965 & & $-0.011(0.058)$ \\
\hline 1966 & & $0.005(0.060)$ \\
\hline 1967 & & $0.048(0.053)$ \\
\hline 1968 & & $0.073(0.062)$ \\
\hline 1969 & & $0.144 * *(0.059)$ \\
\hline 1970 & & $0.194 * * *(0.056)$ \\
\hline 1971 & & $0.195 * * *(0.057)$ \\
\hline 1972 & & $0.219 * * *(0.060)$ \\
\hline 1973 & & $0.275 * * *(0.067)$ \\
\hline 1974 & & $0.213 * * *(0.074)$ \\
\hline 1975 & & $0.200 * * *(0.068)$ \\
\hline 1976 & & $0.161 * *(0.079)$ \\
\hline 1977 & & $0.181 * *(0.079)$ \\
\hline 1978 & & $0.227 * * *(0.085)$ \\
\hline 1979 & & $0.238 * * *(0.087)$ \\
\hline 1980 & & $0.199 * *(0.087)$ \\
\hline 1981 & & $0.149 *(0.089)$ \\
\hline 1982 & & $0.116(0.095)$ \\
\hline 1983 & & $0.176^{* *}(0.088)$ \\
\hline 1984 & & $0.165 *(0.099)$ \\
\hline 1985 & & $0.126(0.093)$ \\
\hline 1986 & & $0.126(0.098)$ \\
\hline 1987 & & $0.121(0.099)$ \\
\hline 1988 & & $0.174 *(0.102)$ \\
\hline 1989 & & $0.150(0.119)$ \\
\hline 1990 & & $0.208 * *(0.102)$ \\
\hline 1991 & & $0.197 *(0.109)$ \\
\hline 1992 & & $0.188 *(0.112)$ \\
\hline 1993 & & $0.161(0.111)$ \\
\hline 1994 & & $0.195 *(0.116)$ \\
\hline 1995 & & $0.207 *(0.113)$ \\
\hline 1996 & & $0.118(0.118)$ \\
\hline 1997 & & $0.155(0.112)$ \\
\hline 1998 & & $0.145(0.116)$ \\
\hline 1999 & & $0.149(0.123)$ \\
\hline Constant & & $-11.605 * * *(2.611)$ \\
\hline $\begin{array}{l}\text { F statistic on year } \\
\text { effects: }\end{array}$ & & $\mathrm{F}(36,87)=4.87 * * *$ \\
\hline Adjusted R2: & 0.8554 & 0.8594 \\
\hline Hausman chi ${ }^{2}$ & $40.75 * * *$ & \\
\hline DW statistic & 0.774 & \\
\hline Countries: 88 , Observa & 2200 & \\
\hline
\end{tabular}


Table A.7. Sensitivity Analysis of Turning Point in Fatalities/Population Model to Subsets of Sample

(1985 International Dollars)

\begin{tabular}{lcccc}
\hline & $\begin{array}{c}\text { Number of } \\
\text { Observations }\end{array}$ & $\begin{array}{c}\text { Number } \\
\text { of } \\
\text { Countries }\end{array}$ & $\begin{array}{c}\text { Quadratic, } \\
\text { Logged regional } \\
\text { time trends }\end{array}$ & $\begin{array}{c}\text { Spline, Logged } \\
\text { regional time } \\
\text { trends }\end{array}$ \\
\hline Full Sample & 2200 & 88 & $\begin{array}{c}\$ 5,738 \\
{[\$ 4,360, \$ 7,551]}\end{array}$ & $\$ 8,600$ \\
\hline $\begin{array}{l}\text { Real Per Capita GDP } \\
>\$ 1,000(1985 \text { int'1 } \$)\end{array}$ & 1944 & 82 & $\$ 6,074$ & $\$ 7,275$ \\
\hline $\begin{array}{l}\text { Real Per Capita GDP } \\
<\$ 15,000 \text { (1985 int'1\$) }\end{array}$ & 2101 & 88 & $\$ 5,950$ & $\$ 7,696$ \\
\hline HD1 Countries Only & 1113 & 35 & $\$ 6,563$ & $\$ 9,700$ \\
\hline HD2 Countries Only & 1087 & 53 & $\$ 9,081$ & - \\
\hline Years 1963-1991 & 1719 & 88 & $\$ 5,372$ & $\$ 7,900$ \\
\hline Years 1970-1999 & 1855 & 88 & $\$ 9,476$ & $\$ 9,500$ \\
\hline
\end{tabular}


Table A.8. Sensitivity Analysis of Turning Point in Fatalities/Population Model to Spline Segmentation

(1985 International Dollars)

\begin{tabular}{lcccc}
\hline \multirow{2}{*}{$\begin{array}{l}\text { Number of Spline } \\
\text { Segments }\end{array}$} & $\begin{array}{c}\text { Common } \\
\text { linear }\end{array}$ & $\begin{array}{c}\text { Common, } \\
\text { log-linear }\end{array}$ & $\begin{array}{c}\text { Regional, } \\
\text { linear }\end{array}$ & $\begin{array}{c}\text { Regional, } \\
\text { log-linear }\end{array}$ \\
\hline 10 (Base Model) & $\$ 6,095$ & $\$ 6,095$ & $\$ 8,592$ & $\$ 8,592$ \\
\hline 8 & 6,768 & 6,768 & 9,771 & 6,768 \\
\hline 9 & 7,673 & 7,673 & 7,673 & 7,673 \\
\hline 11 & 7,053 & 7,053 & 9,238 & 7,053 \\
\hline 12 & 7,673 & 5,629 & 9,771 & 7,673 \\
\hline
\end{tabular}

Observations: 2200, Countries: 88 
APPENDIX B

\section{APPENDIX TO CHAPTER THREE}

In chapter three, I combined data from numerous sources to estimate reduced form models of traffic fatality rates by road user group. This appendix provides a brief description of the construction of the dataset used in that chapter. Section B.1 describes the data sources for each variable and Section B.2 explains the methods used to extend the statistics on total vehicle-kilometers traveled (VKT) for several countries. A comparison of the regression results using the official VKT statistics versus those using the extended VKT series is presented in Section B.3. Section B.4 displays the growth rates used to extend the per capita income series to 2002. Finally, Section B.5 shows the results from the income-only regressions of Section 3.5.1 using the income series from chapter two (measured in 1985 international prices).

\section{B.1 Data Sources}

Traffic Fatalities, by road user group. In chapter three, traffic fatalities are broken into road user groups. For the models in Table 3.7 and 3.9, "pedestrians" include both pedestrian and bicyclist deaths and "occupants" include all other road users (passengers and drivers of any motorized vehicle). In the models including the seatbelt usage variables (Tables 3.8 and 3.10), fatalities are divided "non-occupants" and "occupants" where two-wheeler deaths are now included in the former. The primary data source used to construct these variables is the OECD International Road Traffic Accident Database (IRTAD). Supplementary data was also added from other sources for the following countries: 
- Canada: Statistics Canada (for 1963-1969); Transport Canada (for 2001-2002)

- Chile: Carabineros de Chile (for 1992-2002) (bicyclists could not be separated from occupants)

- Israel: Central Bureau of Statistics (for 1988-2002)

- New Zealand: Land Transport Safety Authority (for 1963-1969)

- Poland: Poland Police Headquarters (for 1985-2002) (pedestrians include moped deaths)

- Slovak Republic: Note Prepared for 27th IRTAD Operational Commitee Meeting (for 1998-2002)

Total Vehicle-Kilometers Traveled. Annual estimates of the total vehicle-

kilometers (VKT) traveled by all motorized vehicles were taken primarily from IRTAD and from the digitized version of the International Road Federation (IRF) World Road Statistics yearbooks. (All IRF data mentioned throughout Appendix B were digitized according to the same process described in detail in Section A.1 of Appendix A.) The IRTAD and IRF data were supplemented by data from other sources for the following countries:

- Czech Republic: Hungary Ministry of Environment (for 1991-1993)

- Hungary: Hungary Ministry of Environment (for 1970, 1975, 1980, 1985-1997)

- Israel: Central Bureau of Statistics (for 1988-2002)

- Portugal: Hungary Ministry of Environment (for 1970)

- Sweden: Swedish National Road Administration (for 2000-2002)

- Spain: Spain Ministry of Public Works and Infrastructure (for 1995-2002)

The compiled VKT statistics were then extended for several countries as described in Section B.2 below. 
Per Capita Income. The real per capita GDP data used in chapter three (1996 international prices) was taken from the Penn World Tables 6.1. This series was extended to 2002 using GDP growth rates, as described in Section B.4 below.

Vehicle Stock and Road Length. Data on the motor vehicle fleet and the length of the road network (kms) came from IRTAD, the IRF World Road Statistics, and numerous national sources. Motor vehicle counts include all cars, buses, trucks, and motorized two-wheelers. The IRTAD and IRF data were supplemented by data from other sources for the following countries:

\section{Road length data:}

- Canada: Statistics Canada (for 1964-1975)

- Greece: European Commission Directorate-General Energy and Transport (for 2000)

- Hungary: Hungary Ministry of Economy and Transport (for 2000)

- Iceland: European Commission Directorate-General Energy and Transport (for 2000); Statistics Iceland (for 2001-2002)

- Israel: Canning (1998) (for 1988-1994), Israel Central Bureau of Statistics (for 1995-2002)

- Japan: Hokkaido Police Headquarters (for 2002)

- Korea, Rep.: Korea National Statistics Office (for 1964-2002)

- Luxembourg: European Commission Directorate-General Energy and Transport (for 2000)

- New Zealand: Transfund New Zealand (for 2001-2002)

- Portugal: European Commission Directorate-General Energy and Transport (for 2000)

- Slovak Republic: Slovak Statistics (for 1991-2002)

- Spain: Spain Ministry of Public Works and Infrastructure (Ministerio de Fomento) (for 1990-2002) 
- Switzerland: Swiss Federal Statistics Office (for 2000-2001); Swiss Federal Tourism Office (for 2002)

- United Kingdom: UK(GB) and N.IRL transport statistics (for 1999-2000, 2002)

- United States: U.S. Department of Transportation (for 1997-1998)

\section{Vehicles Data:}

- Canada: Statistics Canada (for 1963-1970), Transport Canada (for 2001-2002)

- Hungary: Hungary Ministry of Economy and Transport (for 2001-2002)

- Iceland: Statistics Iceland (for 1963-2002)

- Israel: Israel Central Bureau of Statistics (for 1963-2002)

- Korea, Rep.: Korea National Statistics Office (for 1966-2002)

- Norway: Statistics Norway (for 1963-2002)

- New Zealand: Land Transport Safety Authority (for 1963-2002)

- Spain: Spain Statistics (for 1986-2002)

- Sweden: Swedish National Road Administration (for 1990-2002)

- Switzerland: Swiss Federal Statistics Office (for 2001-2002)

- United Kingdom: Northern Ireland Department for Regional Development (for 1998-2002)

Population, by age cohort. The population estimates needed to compute the percentage of driving age population (ages 15 and up) between 15-24 (YOUTH) and the percentage over age 65 (ELDERLY) came primarily from the U.S. Census International Data Base and IRTAD. Additional data was added for a few countries from the following sources:

- Australia: United Nations (for 1965, 1970, 1975, 1980)

- Canada: Statistics Canada (for 1964-2002)

- Denmark: Statistics Denmark (for 1964-2002)

- Finland: United Nations (for 1970) 
- Iceland: United Nations (for 1965, 1970, 1975, 1980)

- Korea, Rep.: Korea National Statistics Office (for 1970-2002)

- New Zealand: United Nations (for 1965, 1970, 1975, 1980)

- Norway: Statistics Norway (for 1970-1980), United Nations (for 1965)

- Portugal: United Nations (for 1965, 1970, 1975, 1980, 1985, 1990)

Finally, data on the percentage of population living in urban areas (URBAN) came from the World Bank's World Development Indicators Database.

Alcohol- related variables. Alcohol consumption data was taken from World Drink Trends 2000 and supplemented by figures from OECD Health Data 2003. Death rates due to cirrhosis of the liver came from the World Health Organization and was checked against and supplemented by data from the OECD Health Data 2003 where appropriate.

Medical indicators. Data on the number of licensed physicians per capita was taken from the OECD Health Data 2003 database. The data used to calculate an indicator of heart attack survival also came from OECD Health Data 2003. This includes: the number of hospital discharges after admission for acute myocardial infarction (myocardial discharges), the total number of hospital discharges (total discharges), and the number of deaths due to myocardial infarctions (deaths). Then heart attack survival rate variable (HEART) was computed as:

$$
\begin{aligned}
\text { HEART } & =\text { myocardial discharges } / \text { total heart attacks } \\
& =\text { myocardial discharges } /(\text { total discharges }+ \text { deaths }) .
\end{aligned}
$$

Seatbelt wearing rates. Seatbelt usage data come primarily from IRTAD. Wearing rates are available for three road classes (urban, rural, and motorways) and are 
defined as the average wearing rate for drivers of passenger cars. In the IRTAD classification, rural roads include motorways. Efforts were made to supplement the IRTAD data for OECD countries with missing observations. The following additions were made:

\section{Urban roads:}

- Belgium: Belgium Road Safety Institute (BIVV) (for 1993, 1998, 1999)

- Denmark: Danish Transport Research Institute (for 2000-2001)

- Korea, Rep.: Korea Transportation Safety Authority (KOTSA) (for 19982002)

- Spain: Dirección General de Tráfico (for 1995-6, 1998, 2002)

- United Kingdom: U.K. Department of Transport (1982-2002) ${ }^{96}$

- United States: U.S. Department of Transportation (for 1999-2002) ${ }^{97}$

\section{Rural roads:}

- Denmark: Danish Transport Research Institute (for 2000-2001)

\section{Motorways:}

- Denmark: Danish Transport Research Institute (for 2000-2001)

\section{B.2 Extension of VKT Series Using Fuel Consumption Data}

Reliable annual estimates of Total Vehicle-Kilometers traveled (VKT) on the road network are limited, even for some OECD countries. In an effort to increase the sample size of the dataset used in chapter three, I extrapolated the existing VKT statistics for

\footnotetext{
${ }^{96}$ The U.K. survey includes seatbelt rates for Great Britain only.

97 The 1982 - 1999 data is also from U.S. DOT. They are the National Highway Safety Administration's national estimates that I received through email correspondence from Professor Liran Einav at Stanford University (February 24, 2004).
} 
several countries using fuel consumption data. To do this, I estimated the following reduced-form equation of VKT for each country:

$$
\text { (B1) } \text { VKT }_{t}=a+b \text { PETROL }_{t}+c \text { DIESEL }_{t}+d t+\varepsilon_{t}
$$

where PETROL $_{t}=$ total petrol consumed in road vehicles in year $t$, DIESEL $_{t}=$ total diesel fuel consumed in road vehicles in year $\mathrm{t}$, and $\mathrm{t}$ is a linear time trend.

PETROL and DIESEL (measured in thousands of metric tons) come primarily from the IRF World Road Statistics yearbooks. These series were cross-checked and supplemented by data from OECD Energy Statistics (various editions) and national sources where appropriate, including:

\section{Petrol:}

- Canada: Statistics Canada (for 1998-2002)

\section{Diesel:}

- United Kingdom: U.K. Department of Transport (for 1991-2001)

For years when VKT data are missing, VKT were predicted directly from equation (B1). In total, the predicted values were used to extend the base VKT data for the following 17 countries: Australia, Canada, Chile, Greece, Hungary, Iceland, Ireland, Italy, Korea, Rep., Luxembourg, Netherlands, New Zealand, Poland, Portugal, Slovak Republic, United Kingdom, and United States. The total sample size increased by 126 observations (from 704 to 830). The summary statistics for the base VKT and extended VKT series for countries used in the income-only regressions of chapter three (equations $(3.11)-(3.13))$ are provided in Table B.1. 


\section{B.3 Income Only Regression Results Using Base VKT Data}

Table B.2 displays the results from fixed-effects models of Pedestrian

Fatalities/VKT and Occupant Fatalities/VKT on per capita income and a linear time trend using the base and extended VKT series. (In all specifications, the standard errors given in parentheses below each coefficient are corrected for heteroskedasticity and within panel correlation in errors.) The magnitude and significance of both the income and time trend coefficients are relatively stable across the two VKT series for both road user groups. However, when a common time trend is assumed the income elasticity of the occupant fatality rate does lose significance at the $10 \%$ level with the VKT extension.

B.4 Extension of Per Capita Income Data (1996 International Dollars) to 2002 In chapter three, real per capita GDP is measured in 1996 international dollars. Like the income measure used in chapter two, this series comes from the Penn World Tables RGDPCH variable (real per capita GDP, chain method) and accounts for differences in purchasing power across countries and allows for comparisons over time. In Version 6.1 of the Penn World Tables, RGDPCH is measured in 1996 international prices and covers years 1963-2000 in my sample. To extend this income measure to 2002, I used the real per capita GDP growth rates implied by the national accounts data from OECD (real per capita GDP measured at the price levels and PPPs of 1995 (U.S. dollars)). Table B.3 displays the annual growth rates for 2000-2002 for each of the countries included in the chapter three base sample. 


\section{B.5 Income Only Regression Results Using Per Capita Income in 1985 International Dollars}

To provide some comparison with the income coefficients from chapter two, Table B.4 displays the regression results from equations (3.11) - (3.13) using the income series from chapter two (measured in 1985 international dollars). (Again, all standard errors are corrected for heteroskedasticity and within panel correlation in errors.) It is not surprising that the income elasticity estimates from using the 1985 international dollars data are larger than when using the 1996 international dollars. Since income measured in 1996 dollars always exceeds income in 1985 dollars, at each level of income a one percent increase in 1996 income is equivalent to a greater than one percent increase in income measured in 1985 dollars. Therefore, the income coefficient from the former estimates the effect of a smaller increase in income than from the latter.

\section{B.6 Sensitivity Analysis of VEHGROWTH Variable in Estimates of Occupant Fatalities/VKT}

I also tried two other specifications of VEHGROWTH: 1) VEHGROWTH2, a two-year average of the annual vehicle growth rate and 2) VEHGROWTH3, a three-year average of the annual vehicle growth rate. Results from these specifications are displayed in Models 4 and 5 of Table B.5. In general, the coefficient increases in magnitude as more years are included in the average growth rate. All other coefficient estimates remain stable across specifications.

The rate of motorization is significantly larger in South Korea than other countries included in the dataset for much of the sample period. (The mean VEHGROWTH is $0.171(0.093)$ in South Korea over the sample period but only $0.033(0.028)$ over the 
other countries included in the sample.) To test the significance of this outlier, Model 1 was reestimated without South Korea. As shown in Model 6 of Table B.5, omitting these observations causes the VEHGROWTH coefficient to increase in magnitude (to 0.837 (0.298)), although the other coefficients remain stable in magnitude and significance. 
Table B.1. Descriptive Statistics for Base and Extended VKT Data ${ }^{a}$

\begin{tabular}{|c|c|c|c|c|c|c|}
\hline Country & Variable & $\mathbf{N}$ & Mean & Std. Dev. & Minimum & Maximum \\
\hline \multirow[t]{2}{*}{ Australia } & Base VKT & 9 & 169332.2 & 19491.9 & 135267.0 & 192209.0 \\
\hline & Extended VKT & 21 & 156231.6 & 20412.7 & 124586.4 & 192209.0 \\
\hline \multirow[t]{2}{*}{ Canada } & Base VKT & 23 & 170727.8 & 66785.2 & 82110.0 & 315815.0 \\
\hline & Extended VKT & 40 & 198491.4 & 65260.5 & 82110.0 & 315815.0 \\
\hline \multirow[t]{2}{*}{ Chile } & Base VKT & 1 & 23829.0 & - & 23829.0 & 23829.0 \\
\hline & Extended VKT & 4 & 23008.5 & 1121.1 & 21434.0 & 23829.0 \\
\hline \multirow[t]{2}{*}{ Greece } & Base VKT & 15 & 38582.1 & 28435.2 & 11924.0 & 81635.0 \\
\hline & Extended VKT & 31 & 42453.5 & 24443.3 & 6091.3 & 83334.2 \\
\hline \multirow[t]{2}{*}{ Hungary } & Base VKT & 16 & 22000.0 & 5278.9 & 8000.0 & 28000.0 \\
\hline & Extended VKT & 32 & 20178.5 & 6485.2 & 8000.0 & 30622.8 \\
\hline \multirow[t]{2}{*}{ Iceland } & Base VKT & 21 & 1674.9 & 299.5 & 1185.0 & 2045.0 \\
\hline & Extended VKT & 22 & 1692.5 & 303.8 & 1185.0 & 2063.3 \\
\hline \multirow[t]{2}{*}{ Ireland } & Base VKT & 16 & 24540.3 & 6580.2 & 14309.0 & 37840.0 \\
\hline & Extended VKT & 27 & 21605.8 & 7940.3 & 6099.3 & 37840.0 \\
\hline \multirow[t]{2}{*}{ Italy } & Base VKT & 21 & 261199.5 & 70515.3 & 88184.0 & 387361.0 \\
\hline & Extended VKT & 30 & 300495.5 & 101785.2 & 88184.0 & 464939.3 \\
\hline \multirow[t]{2}{*}{ Korea, Rep. } & Base VKT & 10 & 43134.8 & 13993.2 & 25556.0 & 67266.0 \\
\hline & Extended VKT & 13 & 48108.0 & 15381.2 & 25556.0 & 67266.0 \\
\hline \multirow[t]{2}{*}{ Luxembourg } & Base VKT & 15 & 3285.8 & 695.9 & 1774.0 & 4120.0 \\
\hline & Extended VKT & 30 & 2837.2 & 949.2 & 1143.1 & 4164.7 \\
\hline \multirow{2}{*}{ Netherlands } & Base VKT & 32 & 84080.6 & 23713.8 & 24197.5 & 126660.0 \\
\hline & Extended VKT & 33 & 85093.9 & 24035.4 & 24197.5 & 124796.2 \\
\hline \multirow[t]{2}{*}{ New Zealand } & Base VKT & 31 & 24558.3 & 9667.6 & 9492.0 & 40878.0 \\
\hline & Extended VKT & 33 & 24784.1 & 9726.7 & 9492.0 & 40322.7 \\
\hline \multirow[t]{2}{*}{ Poland } & Base VKT & 16 & 95271.8 & 41624.3 & 47507.0 & 178400.0 \\
\hline & Extended VKT & 18 & 107780.1 & 53541.2 & 47507.0 & 218203.6 \\
\hline \multirow[t]{2}{*}{ Portugal } & Base VKT & 11 & 54777.2 & 32370.9 & 5098.0 & 94260.0 \\
\hline & Extended VKT & 22 & 55376.1 & 33562.1 & 5098.0 & 102353.1 \\
\hline \multirow{2}{*}{$\begin{array}{l}\text { Slovak } \\
\text { Republic }\end{array}$} & Base VKT & 2 & 10265.5 & 294.9 & 10057.0 & 10474.0 \\
\hline & Extended VKT & 4 & 10586.5 & 432.9 & 10057.0 & 11085.1 \\
\hline \multirow{2}{*}{$\begin{array}{l}\text { United } \\
\text { Kingdom }\end{array}$} & Base VKT & 29 & 323380.2 & 85835.8 & 206600.0 & 474680.0 \\
\hline & Extended VKT & 33 & 343428.4 & 97263.8 & 206600.0 & 501897.8 \\
\hline \multirow[t]{2}{*}{ United States } & Base VKT & 32 & 2977385.0 & 874377.9 & 1420224.0 & 4478154.0 \\
\hline & Extended VKT & 33 & 2990024.0 & 863664.3 & 1420224.0 & 4478154.0 \\
\hline
\end{tabular}

${ }^{\mathrm{a}}$ VKT is measured in millions of vehicle kilometers traveled annually. 
Table B.2. Income-Only Regression Results Using Base and Extended VKT Data

\begin{tabular}{|c|c|c|c|c|c|c|c|c|}
\hline \multirow{2}{*}{ - } & \multicolumn{4}{|c|}{ Vehicle Occupant Fatalities/VKT } & \multicolumn{4}{|c|}{ Pedestrian Fatalities/VKT } \\
\hline & \multicolumn{2}{|c|}{ Base VKT } & \multicolumn{2}{|c|}{ Extended VKT } & \multicolumn{2}{|c|}{ Base VKT } & \multicolumn{2}{|c|}{ Extended VKT } \\
\hline $\begin{array}{l}\text { GDP (1996 } \\
\text { Int'1\$) }\end{array}$ & $\begin{array}{c}-0.299 * \\
(0.171) \\
\end{array}$ & $\begin{array}{l}-0.044 \\
(0.296)\end{array}$ & $\begin{array}{c}-0.237 \\
(0.188) \\
\end{array}$ & $\begin{array}{c}-0.077 \\
(0.268) \\
\end{array}$ & $\begin{array}{c}-0.553 * * * \\
(0.146) \\
\end{array}$ & $\begin{array}{l}-0.404^{*} \\
(0.220)\end{array}$ & $\begin{array}{c}-0.643 * * * \\
(0.146) \\
\end{array}$ & $\begin{array}{c}-0.376^{* *} \\
(0.187)\end{array}$ \\
\hline $\mathrm{T}$ & $\begin{array}{c}-0.043 * * * \\
(0.004) \\
\end{array}$ & & $\begin{array}{c}-0.044^{* * *} \\
(0.004)\end{array}$ & & $\begin{array}{c}-0.062 * * * \\
(0.003) \\
\end{array}$ & & $\begin{array}{c}-0.060^{* * *} \\
(0.004)\end{array}$ & \\
\hline Constant & $\begin{array}{c}0.030 \\
(1.578) \\
\end{array}$ & $\begin{array}{c}-2.250 \\
(2.716) \\
\end{array}$ & $\begin{array}{l}-0.531 \\
(1.726) \\
\end{array}$ & $\begin{array}{l}-1.927 \\
(2.459) \\
\end{array}$ & $\begin{array}{c}2.032 \\
(1.364)\end{array}$ & $\begin{array}{c}0.742 \\
(2.019)\end{array}$ & $\begin{array}{c}2.877 * * \\
(1.349)\end{array}$ & $\begin{array}{c}0.518 \\
(1.709)\end{array}$ \\
\hline Adjusted R2: & 0.9474 & 0.9590 & 0.9468 & 0.9587 & 0.9541 & 0.9674 & 0.9543 & 0.9677 \\
\hline Observations & 704 & 704 & 830 & 830 & 704 & 704 & 830 & 830 \\
\hline Countries: & 32 & 32 & 32 & 32 & 32 & 32 & 32 & 32 \\
\hline \multicolumn{9}{|c|}{ Country-specific T: } \\
\hline Australia & & $\begin{array}{c}-0.044 * * * \\
(0.006)\end{array}$ & & $\begin{array}{c}-0.048^{* * *} \\
(0.006)\end{array}$ & & $\begin{array}{c}-0.050 * * * \\
(0.005)\end{array}$ & & $\begin{array}{c}-0.052 * * * \\
(0.004)\end{array}$ \\
\hline Austria & & $\begin{array}{c}-0.062 * * * \\
(0.007)\end{array}$ & & $\begin{array}{c}-0.061 * * * \\
(0.006)\end{array}$ & & $\begin{array}{c}-0.079 * * * \\
(0.005)\end{array}$ & & $\begin{array}{c}-0.079 * * * \\
(0.004) \\
\end{array}$ \\
\hline Belgium & & $\begin{array}{c}-0.049 * * * \\
(0.006) \\
\end{array}$ & & $\begin{array}{c}-0.048 * * * \\
(0.005) \\
\end{array}$ & & $\begin{array}{c}-0.078 * * * \\
(0.004) \\
\end{array}$ & & $\begin{array}{c}-0.079 * * * \\
(0.004) \\
\end{array}$ \\
\hline Canada & & $\begin{array}{c}-0.041^{* * *} * \\
(0.007) \\
\end{array}$ & & $\begin{array}{c}-0.042 * * * \\
(0.005) \\
\end{array}$ & & $\begin{array}{c}-0.057 * * * \\
(0.005) \\
\end{array}$ & & $\begin{array}{c}-0.057 * * * \\
(0.004) \\
\end{array}$ \\
\hline Chile & & & & $\begin{array}{c}-0.089 * * * \\
(0.006)\end{array}$ & & & & $\begin{array}{c}-0.070 * * * \\
(0.004)\end{array}$ \\
\hline $\begin{array}{l}\text { Czech } \\
\text { Republic }\end{array}$ & & $\begin{array}{c}-0.042^{* * *} * \\
(0.003)\end{array}$ & & $\begin{array}{c}-0.042 * * * \\
(0.003)\end{array}$ & & $\begin{array}{c}-0.056^{* * *} \\
(0.003) \\
\end{array}$ & & $\begin{array}{c}-0.056^{* * *} \\
(0.002) \\
\end{array}$ \\
\hline Denmark & & $\begin{array}{c}-0.044 * * * \\
(0.005)\end{array}$ & & $\begin{array}{c}-0.043^{* * * *} \\
(0.004)\end{array}$ & & $\begin{array}{c}-0.051 * * * \\
(0.004)\end{array}$ & & $\begin{array}{c}-0.051 * * * \\
(0.003)\end{array}$ \\
\hline Finland & & $\begin{array}{c}-0.055^{* * *} \\
(0.006)\end{array}$ & & $\begin{array}{c}-0.054 * * * \\
(0.006)\end{array}$ & & $\begin{array}{c}-0.072 * * * \\
(0.005)\end{array}$ & & $\begin{array}{c}-0.072 * * * \\
(0.004)\end{array}$ \\
\hline France & & $\begin{array}{c}-0.053^{* * *} \\
(0.006)\end{array}$ & & $\begin{array}{c}-0.052^{* * *} * \\
(0.005)\end{array}$ & & $\begin{array}{c}-0.070^{* * *} \\
(0.004) \\
\end{array}$ & & $\begin{array}{c}-0.070^{* * *} \\
(0.004) \\
\end{array}$ \\
\hline Germany & & $\begin{array}{c}-0.058^{* * *} \\
(0.006)\end{array}$ & & $\begin{array}{c}-0.057^{* * *} * \\
(0.005)\end{array}$ & & $\begin{array}{c}-0.082^{* * *} \\
(0.004) \\
\end{array}$ & & $\begin{array}{c}-0.083^{* * *} \\
(0.004) \\
\end{array}$ \\
\hline Greece & & $\begin{array}{c}-0.036 * * * \\
(0.003) \\
\end{array}$ & & $\begin{array}{c}-0.040 * * * \\
(0.003) \\
\end{array}$ & & $\begin{array}{c}-0.064 * * * \\
(0.002) \\
\end{array}$ & & $\begin{array}{c}-0.069 * * * \\
(0.002) \\
\end{array}$ \\
\hline Hungary & & $\begin{array}{c}-0.037 * * * \\
(0.004) \\
\end{array}$ & & $\begin{array}{c}-0.039 * * * \\
(0.004) \\
\end{array}$ & & $\begin{array}{c}-0.039 * * * \\
(0.003) \\
\end{array}$ & & $\begin{array}{c}-0.043 * * * \\
(0.003)\end{array}$ \\
\hline Iceland & & $\begin{array}{c}-0.029 * * * \\
(0.004)\end{array}$ & & $\begin{array}{c}-0.024 * * * \\
(0.003)\end{array}$ & & $\begin{array}{c}-0.090^{* * *} \\
(0.003)\end{array}$ & & $\begin{array}{c}-0.098 * * * \\
(0.002) \\
\end{array}$ \\
\hline Ireland & & $\begin{array}{c}-0.039 * * * \\
(0.012) \\
\end{array}$ & & $\begin{array}{c}-0.039 * * * \\
(0.010) \\
\end{array}$ & & $\begin{array}{c}-0.055 * * * \\
(0.009) \\
\end{array}$ & & $\begin{array}{c}-0.058 * * * \\
(0.007) \\
\end{array}$ \\
\hline Israel & & $\begin{array}{c}-0.060^{* * *} * \\
(0.007)\end{array}$ & & $\begin{array}{c}-0.059 * * * \\
(0.006)\end{array}$ & & $\begin{array}{c}-0.059^{* * *} \\
(0.005) \\
\end{array}$ & & $\begin{array}{c}-0.060 * * * \\
(0.004) \\
\end{array}$ \\
\hline Italy & & $\begin{array}{c}-0.049 * * * \\
(0.009)\end{array}$ & & $\begin{array}{c}-0.044 * * * \\
(0.006)\end{array}$ & & $\begin{array}{c}-0.076 * * * \\
(0.006)\end{array}$ & & $\begin{array}{c}-0.070 * * * \\
(0.004)\end{array}$ \\
\hline Japan & & $\begin{array}{c}-0.055^{* * *} \\
(0.009) \\
\end{array}$ & & $\begin{array}{c}-0.054 * * * \\
(0.008)\end{array}$ & & $\begin{array}{c}-0.055^{* * *} \\
(0.006) \\
\end{array}$ & & $\begin{array}{c}-0.056^{* * *} \\
(0.005) \\
\end{array}$ \\
\hline Korea, Rep. & & $\begin{array}{c}-0.081 * * * \\
(0.018)\end{array}$ & & $\begin{array}{c}-0.084 * * * \\
(0.013)\end{array}$ & & $\begin{array}{c}-0.135 * * * \\
(0.013)\end{array}$ & & $\begin{array}{c}-0.125 * * * \\
(0.009)\end{array}$ \\
\hline Luxembourg & & $\begin{array}{c}-0.054 * * * \\
(0.015)\end{array}$ & & $\begin{array}{c}-0.043 * * * \\
(0.010)\end{array}$ & & $\begin{array}{c}-0.053 * * * \\
(0.011)\end{array}$ & & $\begin{array}{c}-0.077 * * * \\
(0.007) \\
\end{array}$ \\
\hline Netherlands & & $\begin{array}{c}-0.062^{* * *} \\
(0.006)\end{array}$ & & $\begin{array}{c}-0.061^{* * *} \\
(0.005)\end{array}$ & & $\begin{array}{c}-0.067 * * * \\
(0.004) \\
\end{array}$ & & $\begin{array}{c}-0.067 * * * \\
(0.004) \\
\end{array}$ \\
\hline
\end{tabular}


(Table B.2. continued)

\begin{tabular}{lcccc}
\hline & $-0.037^{* * *}$ & $-0.037^{* * *}$ & $-0.058^{* * *}$ & $-0.058^{* * *}$ \\
New Zealand & $(0.003)$ & $(0.002)$ & $(0.002)$ & $(0.002)$ \\
\hline & $-0.043^{* * *}$ & $-0.042^{* * *}$ & $-0.072^{* * *}$ & $-0.073^{* * *}$ \\
Norway & $(0.008)$ & $(0.007)$ & $(0.006)$ & $(0.005)$ \\
\hline & $-0.049^{* * *}$ & $-0.059^{* * *}$ & $-0.066^{* * *}$ & $-0.075^{* * *}$ \\
Poland & $(0.004)$ & $(0.004)$ & $(0.003)$ & $(0.003)$ \\
\hline & $-0.053^{* * *}$ & $-0.057^{* * *}$ & $-0.080^{* * *}$ & $-0.085^{* * *}$ \\
Portugal & $(0.010)$ & $(0.008)$ & $(0.007)$ & $(0.006)$ \\
\hline Slovak & $-0.276^{* * *}$ & $-0.112^{* * *}$ & $-0.266^{* * *}$ & $-0.163^{* * *}$ \\
Republic & $(0.006)$ & $(0.006)$ & $(0.005)$ & $(0.004)$ \\
\hline & $-0.105^{* * *}$ & $-0.103^{* * *}$ & $-0.058^{* * *}$ & $-0.059^{* * *}$ \\
Slovenia & $(0.013)$ & $(0.012)$ & $(0.010)$ & $(0.008)$ \\
\hline & $-0.044^{* * *}$ & $-0.044 * * *$ & $-0.067^{* * *}$ & $-0.067^{* * *}$ \\
Spain & $(0.006)$ & $(0.005)$ & $(0.004)$ & $(0.004)$ \\
\hline & $-0.042^{* * *}$ & $-0.042^{* * *}$ & $-0.057^{* * *}$ & $-0.057^{* * *}$ \\
Sweden & $(0.004)$ & $(0.004)$ & $(0.003)$ & $(0.003)$ \\
\hline & $-0.050^{* * *}$ & $-0.065^{* * *}$ & $-0.065^{* * *}$ \\
Switzerland & $(0.003)$ & $(0.002)$ & $(0.002)$ & $(0.002)$ \\
\hline & $-0.111^{* * *}$ & $-0.110^{* * *}$ & $(0.003)$ & $-0.160^{* * *}$ \\
Turkey & $(0.004)$ & $(0.004)$ & $-0.060^{* * *}$ & $(0.003)$ \\
\hline United & $-0.052^{* * *}$ & $-0.048^{* * *}$ & $(0.004)$ & $-0.062^{* * *}$ \\
Kingdom & $(0.006)$ & $(0.005)$ & $-0.039^{* * *}$ & $(0.004)$ \\
\hline & $-0.034^{* * *}$ & $-0.034^{* * *}$ & $-0.039^{* * *}$ \\
United States & $(0.006)$ & $(0.006)$ & $(0.005)$ & $(0.004)$ \\
\hline
\end{tabular}

*** Indicates $1 \%$ level of significance ** Indicates $5 \%$ level of significance

$*$ Indicates $10 \%$ level of significance 
Table B.3. Annual Growth Rates of Real per capita GDP (PPP adjusted, 1995 U.S. dollars) in OECD Member Countries (\%), 2000-2002

\begin{tabular}{lrr}
\hline Country & $\mathbf{2 0 0 0 - 2 0 0 1}$ & $\mathbf{2 0 0 1 - 2 0 0 2}$ \\
\hline Australia & 2.645111 & 1.451588 \\
\hline Austria & 0.498676 & 1.088333 \\
\hline Belgium & 0.29211 & 0.22192 \\
\hline Canada & 0.852108 & 2.242088 \\
\hline Czech Republic & 3.557968 & 2.078533 \\
\hline Denmark & 1.062202 & 1.688957 \\
\hline Finland & 0.95768 & 0.019248 \\
\hline France & 1.541996 & 0.00679 \\
\hline Germany & 0.659657 & $3.72 \mathrm{E}-05$ \\
\hline Greece & 3.786373 & 0.03579 \\
\hline Hungary & 4.006004 & 0.036889 \\
\hline Iceland & 1.417351 & -0.01497 \\
\hline Ireland & 4.615688 & 0.052461 \\
\hline Italy & 1.505089 & 0.001968 \\
\hline Japan & 0.123882 & 0.000316 \\
\hline Korea, Republic & 2.345467 & 0.055272 \\
\hline Luxembourg & 0.539112 & 0.00215 \\
\hline Netherlands & 0.450993 & -0.0041 \\
\hline New Zealand & 2.420616 & 0.026394 \\
\hline Norway & 1.421165 & 0.003713 \\
\hline Poland & 0.995636 & 0.024877 \\
\hline Portugal & 0.959396 & -0.00289 \\
\hline Slovak Republic & 3.667736 & 0.047584 \\
\hline Spain & 1.960182 & 0.013272 \\
\hline Sweden & 0.649738 & 0.015754 \\
\hline Switzerland & 0.167179 & -0.00569 \\
\hline Turkey & -9.4801 & 0.059691 \\
\hline United Kingdom & 3.661346 & 0.010848 \\
\hline United States & -0.69714 & 0.014852 \\
\hline & &
\end{tabular}

Growth rates were computed from National Accounts for OECD Member Countries. Available from OECD Statistical Database:

http://www.oecd.org/document/28/0,2340,en_2825_495684_2750044_1_1_1_1,00.html. 
Table B.4. Income-Only Regression Results Using Per Capita Income Series in 1985 and 1996 International Dollars

\begin{tabular}{|c|c|c|c|c|c|c|c|c|}
\hline \multirow{3}{*}{$\begin{array}{l} \\
\text { Real per } \\
\text { capita GDP } \\
\text { (1996 Int'1\$) } \\
\end{array}$} & \multicolumn{4}{|c|}{ Vehicle Occupant Fatalities/VKT } & \multicolumn{4}{|c|}{ Pedestrian Fatalities/VKT } \\
\hline & \multicolumn{2}{|c|}{$\begin{array}{c}\text { Income Measured in } \\
1985 \text { Int'1 Dollars }\end{array}$} & \multicolumn{2}{|c|}{$\begin{array}{l}\text { Income Measured in } \\
1996 \text { Int'1 Dollars }\end{array}$} & \multicolumn{2}{|c|}{$\begin{array}{c}\text { Income Measured in } \\
1985 \text { Int'1 Dollars } \\
\end{array}$} & \multicolumn{2}{|c|}{$\begin{array}{c}\text { Income Measured in } \\
1996 \text { Int'l Dollars }\end{array}$} \\
\hline & $\begin{array}{c}-0.394 * * \\
(0.196) \\
\end{array}$ & $\begin{array}{l}-0.181 \\
(0.279)\end{array}$ & $\begin{array}{c}-0.237 \\
(0.188)\end{array}$ & $\begin{array}{l}-0.077 \\
(0.268)\end{array}$ & $\begin{array}{c}-0.859 * * * \\
(0.165) \\
\end{array}$ & $\begin{array}{c}-0.464 * * * \\
(0.167) \\
\end{array}$ & $\begin{array}{c}-0.643 * * * \\
(0.146)\end{array}$ & $\begin{array}{c}-0.376^{* *} \\
(0.187)\end{array}$ \\
\hline $\mathrm{T}$ & $\begin{array}{c}-0.040 * * * \\
(0.004)\end{array}$ & & $\begin{array}{c}-0.044 * * * \\
(0.004) \\
\end{array}$ & & $\begin{array}{c}-0.056^{* * *} \\
(0.004) \\
\end{array}$ & & $\begin{array}{c}-0.060 * * * \\
(0.004)\end{array}$ & \\
\hline Constant & $\begin{array}{c}0.730 \\
(1.717)\end{array}$ & $\begin{array}{c}-1.088 \\
(2.447)\end{array}$ & $\begin{array}{l}-0.531 \\
(1.726)\end{array}$ & $\begin{array}{l}-1.927 \\
(2.459)\end{array}$ & $\begin{array}{c}4.510 * * * \\
(1.451)\end{array}$ & $\begin{array}{c}1.126 \\
(1.467)\end{array}$ & $\begin{array}{c}2.877 * * \\
(1.349)\end{array}$ & $\begin{array}{c}0.518 \\
(1.709)\end{array}$ \\
\hline Adjusted R2: & 0.9445 & 0.9573 & 0.9468 & 0.9587 & 0.9553 & 0.9676 & 0.9543 & 0.9677 \\
\hline Observations & 798 & 798 & 830 & 830 & 798 & 798 & 830 & 830 \\
\hline Countries: & 31 & 31 & 32 & 32 & 31 & 31 & 32 & 32 \\
\hline \multicolumn{9}{|c|}{ Country-specific T: } \\
\hline Australia & & $\begin{array}{c}-0.048^{* * *} \\
(0.005)\end{array}$ & & $\begin{array}{c}-0.048^{* * *} \\
(0.006)\end{array}$ & & $\begin{array}{c}-0.051 * * * \\
(0.003)\end{array}$ & & $\begin{array}{c}-0.052 * * * \\
(0.004)\end{array}$ \\
\hline Austria & & $\begin{array}{c}-0.058 * * * \\
(0.006) \\
\end{array}$ & & $\begin{array}{c}-0.061 * * * \\
(0.006) \\
\end{array}$ & & $\begin{array}{c}-0.079 * * * \\
(0.004) \\
\end{array}$ & & $\begin{array}{c}-0.079 * * * \\
(0.004) \\
\end{array}$ \\
\hline Belgium & & $\begin{array}{c}-0.047 * * * \\
(0.005) \\
\end{array}$ & & $\begin{array}{c}-0.048 * * * \\
(0.005) \\
\end{array}$ & & $\begin{array}{c}-0.078 * * * \\
(0.003) \\
\end{array}$ & & $\begin{array}{c}-0.079 * * * \\
(0.004) \\
\end{array}$ \\
\hline Canada & & $\begin{array}{c}-0.039 * * * \\
(0.006)\end{array}$ & & $\begin{array}{c}-0.042 * * * \\
(0.005)\end{array}$ & & $\begin{array}{c}-0.055^{* * * *} \\
(0.004)\end{array}$ & & $\begin{array}{c}-0.057 * * * \\
(0.004)\end{array}$ \\
\hline Chile & & $\begin{array}{c}-0.086 * * * \\
(0.007)\end{array}$ & & $\begin{array}{c}-0.089 * * * \\
(0.006)\end{array}$ & & $\begin{array}{c}-0.067 * * * \\
(0.004)\end{array}$ & & $\begin{array}{c}-0.070 * * * \\
(0.004)\end{array}$ \\
\hline $\begin{array}{l}\text { Czech } \\
\text { Republic }\end{array}$ & & $\begin{array}{c}0.001 \\
(0.001) \\
\end{array}$ & & $\begin{array}{c}-0.042 * * * \\
(0.003) \\
\end{array}$ & & $\begin{array}{c}-0.033 * * * \\
(0.001) \\
\end{array}$ & & $\begin{array}{c}-0.056^{* * *} \\
(0.002) \\
\end{array}$ \\
\hline Denmark & & $\begin{array}{c}-0.041^{* * *} \\
(0.005)\end{array}$ & & $\begin{array}{c}-0.043 * * * \\
(0.004)\end{array}$ & & $\begin{array}{c}-0.047 * * * \\
(0.003)\end{array}$ & & $\begin{array}{c}-0.051^{* * *} \\
(0.003) \\
\end{array}$ \\
\hline Finland & & $\begin{array}{c}-0.055^{* * *} \\
(0.006)\end{array}$ & & $\begin{array}{c}-0.054 * * * \\
(0.006)\end{array}$ & & $\begin{array}{c}-0.072 * * * \\
(0.003)\end{array}$ & & $\begin{array}{c}-0.072 * * * \\
(0.004) \\
\end{array}$ \\
\hline France & & $\begin{array}{c}-0.051^{* * *} \\
(0.005)\end{array}$ & & $\begin{array}{c}-0.052 * * * \\
(0.005)\end{array}$ & & $\begin{array}{c}-0.070^{* * *} \\
(0.003) \\
\end{array}$ & & $\begin{array}{c}-0.070^{* * *} \\
(0.004) \\
\end{array}$ \\
\hline Germany & & $\begin{array}{c}-0.056^{* * *} \\
(0.005)\end{array}$ & & $\begin{array}{c}-0.057 * * * \\
(0.005) \\
\end{array}$ & & $\begin{array}{c}-0.083^{* * *} \\
(0.003) \\
\end{array}$ & & $\begin{array}{c}-0.083^{* * *} * \\
(0.004) \\
\end{array}$ \\
\hline Greece & & $\begin{array}{c}-0.038 * * * \\
(0.005) \\
\end{array}$ & & $\begin{array}{c}-0.040 * * * \\
(0.003) \\
\end{array}$ & & $\begin{array}{c}-0.065 * * * \\
(0.003) \\
\end{array}$ & & $\begin{array}{c}-0.069 * * * \\
(0.002) \\
\end{array}$ \\
\hline Hungary & & $\begin{array}{c}-0.038 * * * \\
(0.003) \\
\end{array}$ & & $\begin{array}{c}-0.039 * * * \\
(0.004) \\
\end{array}$ & & $\begin{array}{c}-0.044 * * * \\
(0.002) \\
\end{array}$ & & $\begin{array}{c}-0.043 * * * \\
(0.003) \\
\end{array}$ \\
\hline Iceland & & $\begin{array}{c}-0.028 * * * \\
(0.003)\end{array}$ & & $\begin{array}{c}-0.024 * * * \\
(0.003) \\
\end{array}$ & & $\begin{array}{c}-0.089 * * * \\
(0.002)\end{array}$ & & $\begin{array}{c}-0.098 * * * \\
(0.002)\end{array}$ \\
\hline Ireland & & $\begin{array}{c}-0.037 * * * \\
(0.010) \\
\end{array}$ & & $\begin{array}{c}-0.039 * * * \\
(0.010) \\
\end{array}$ & & $\begin{array}{c}-0.056^{* * *} \\
(0.006) \\
\end{array}$ & & $\begin{array}{c}-0.058 * * * \\
(0.007) \\
\end{array}$ \\
\hline Israel & & $\begin{array}{c}-0.054 * * * \\
(0.007) \\
\end{array}$ & & $\begin{array}{c}-0.059 * * * \\
(0.006) \\
\end{array}$ & & $\begin{array}{c}-0.058 * * * \\
(0.004) \\
\end{array}$ & & $\begin{array}{c}-0.060 * * * \\
(0.004)\end{array}$ \\
\hline Italy & & $\begin{array}{c}-0.042 * * * \\
(0.006)\end{array}$ & & $\begin{array}{c}-0.044 * * * \\
(0.006)\end{array}$ & & $\begin{array}{c}-0.068 * * * \\
(0.004)\end{array}$ & & $\begin{array}{c}-0.070 * * * \\
(0.004)\end{array}$ \\
\hline Japan & & $\begin{array}{c}-0.051 * * * \\
(0.009)\end{array}$ & & $\begin{array}{c}-0.054 * * * \\
(0.008) \\
\end{array}$ & & $\begin{array}{c}-0.054 * * * \\
(0.005)\end{array}$ & & $\begin{array}{c}-0.056^{* * *} * \\
(0.005)\end{array}$ \\
\hline Korea, Rep. & & $\begin{array}{c}-0.072 * * * \\
(0.016)\end{array}$ & & $\begin{array}{c}-0.084 * * * \\
(0.013)\end{array}$ & & $\begin{array}{c}-0.122 * * * \\
(0.009)\end{array}$ & & $\begin{array}{c}-0.125 * * * \\
(0.009)\end{array}$ \\
\hline Luxembourg & & $\begin{array}{c}-0.042 * * * \\
(0.008)\end{array}$ & & $\begin{array}{c}-0.043^{* * *} \\
(0.010)\end{array}$ & & $\begin{array}{c}-0.082 * * * \\
(0.005)\end{array}$ & & $\begin{array}{c}-0.077 * * * \\
(0.007)\end{array}$ \\
\hline
\end{tabular}


(Table B.4. continued)

\begin{tabular}{lcccc}
\hline & $-0.060^{* * *}$ & $-0.061^{* * *}$ & $-0.067^{* * *}$ & $-0.067^{* * *}$ \\
Netherlands & $(0.005)$ & $(0.005)$ & $(0.003)$ & $(0.004)$ \\
\hline & $-0.035^{* * *}$ & $-0.037^{* * *}$ & $-0.056^{* * *}$ & $-0.058^{* * *}$ \\
New Zealand & $(0.003)$ & $(0.002)$ & $(0.002)$ & $(0.002)$ \\
\hline & $-0.039^{* * *}$ & $-0.042^{* * *}$ & $-0.071^{* * *}$ & $-0.073^{* * *}$ \\
Norway & $(0.008)$ & $(0.007)$ & $(0.005)$ & $(0.005)$ \\
\hline & $-0.057^{* * *}$ & $-0.059^{* * *}$ & $-0.074^{* * *}$ & $-0.075^{* * *}$ \\
Poland & $(0.004)$ & $(0.004)$ & $(0.003)$ & $(0.003)$ \\
\hline & $-0.049^{* * *}$ & $-0.057^{* * *}$ & $-0.078^{* * *}$ & $-0.085^{* * *}$ \\
Portugal & $(0.010)$ & $(0.008)$ & $(0.006)$ & $(0.006)$ \\
\hline Slovak & $-0.273^{* * *}$ & $-0.112^{* * *}$ & $-0.078^{* * *}$ & $-0.163^{* * *}$ \\
Republic & $(0.005)$ & $(0.006)$ & $(0.006)$ & $(0.004)$ \\
\hline & & $-0.103^{* * *}$ & $-0.059^{* * *}$ \\
Slovenia & & $(0.012)$ & $(0.008)$ \\
\hline & & $-0.044^{* * *}$ & $-0.067^{* * *}$ \\
Spain & $-0.040^{* * *}$ & $(0.005)$ & $\left(0.064^{* * *}\right.$ & $(0.004)$ \\
\hline & $(0.006)$ & $-0.042^{* * *}$ & $-0.004)$ & $(0.003 * *$ \\
Sweden & $-0.041^{* * *}$ & $(0.004)$ & $(0.002)$ & $-0.065^{* * *}$ \\
\hline & $(0.004)$ & $-0.050^{* * *}$ & $(0.002)$ \\
Switzerland & $-0.048^{* * *}$ & $(0.002)$ & $(0.002)$ & $-0.160^{* * *}$ \\
\hline & $(0.003)$ & $-0.110^{* * *}$ & $-0.155^{* * *}$ & $(0.003)$ \\
\hline Turkey & $-0.107^{* * *}$ & $(0.004)$ & $(0.004)$ & $-0.062^{* * *}$ \\
United & $(0.007)$ & $-0.048^{* * *}$ & $(0.004)$ \\
\hline Kingdom & $-0.047^{* * *}$ & $(0.005)$ & $(0.003)$ & $-0.039^{* * *}$ \\
United States & $(0.005)$ & $-0.034^{* * *}$ & $\left(0.040^{* * *}\right.$ & $(0.004)$ \\
\hline
\end{tabular}

$* * *$ Indicates $1 \%$ level of significance $* *$ Indicates $5 \%$ level of significance

* Indicates $10 \%$ level of significance 
Table B.5. Sensitivity Analysis of Income and VEHGROWTH Variable Specification, Occupant Fatalities/VKT Equation

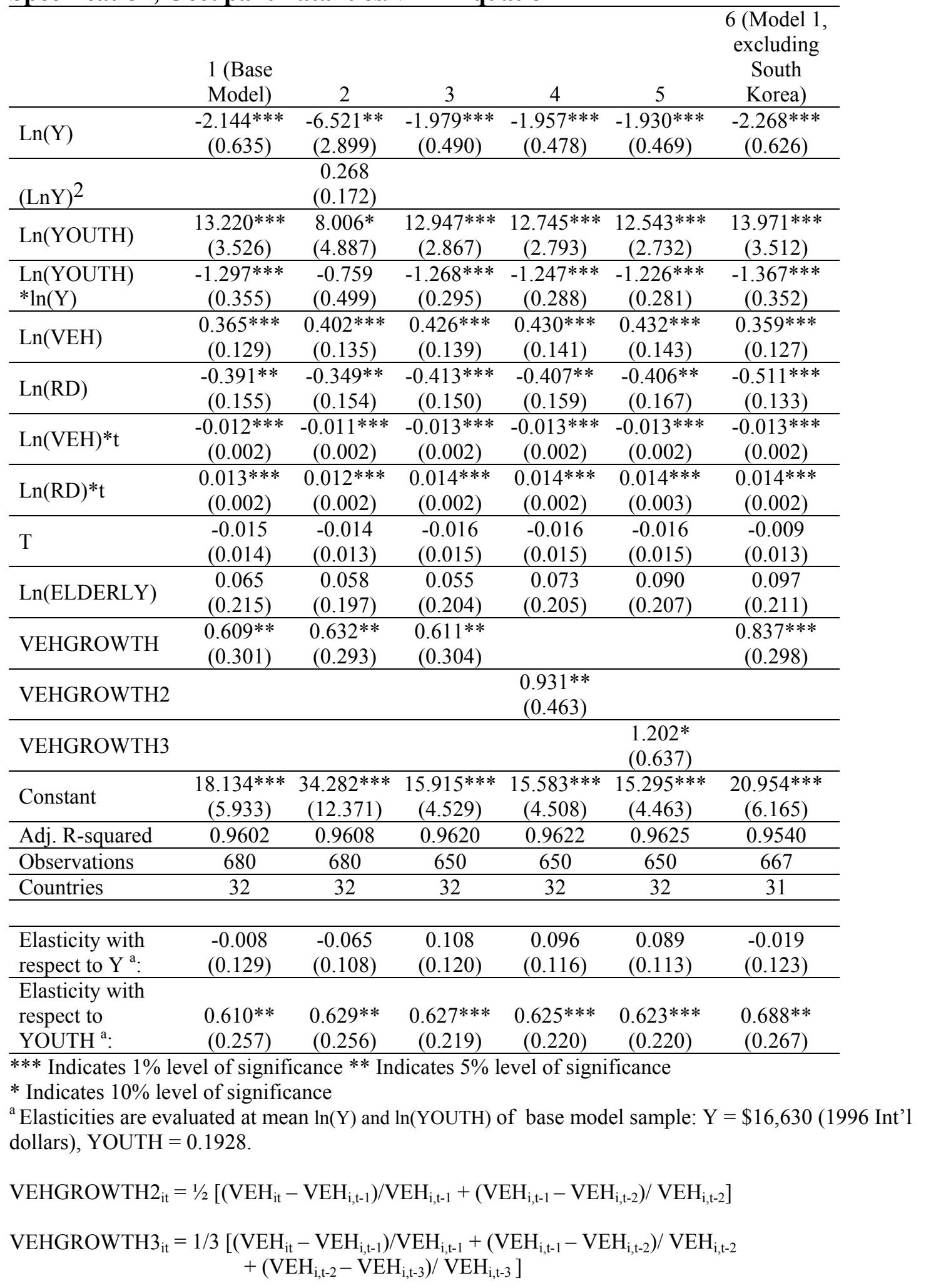


Table B.6. Number of Observations Included in Table 3.7 and Table 3.9 Samples, by Country

\begin{tabular}{|c|c|c|c|c|c|c|c|}
\hline Country & $\begin{array}{l}\text { Base Sample } \\
\text { (Models 1-3) }\end{array}$ & Model 4 & $\begin{array}{c}\text { Models } \\
5,9\end{array}$ & Model 6 & Model 7 & Model 8 & $\begin{array}{c}\text { Models } \\
10,11\end{array}$ \\
\hline Australia & 12 & 11 & 12 & 11 & 4 & 12 & 11 \\
\hline Austria & 23 & 20 & 21 & 22 & 12 & 23 & 21 \\
\hline Belgium & 29 & 27 & 24 & 28 & 4 & 15 & 24 \\
\hline Canada & 25 & 12 & 12 & 25 & 11 & 25 & 12 \\
\hline Chile & 4 & 4 & 1 & & & & \\
\hline \multicolumn{8}{|l|}{ Czech } \\
\hline Republic & 6 & 6 & 2 & 6 & 5 & 6 & 2 \\
\hline Denmark & 32 & 23 & 17 & 31 & 5 & 25 & 16 \\
\hline Finland & 31 & 28 & 24 & 30 & 14 & 31 & 24 \\
\hline France & 33 & 30 & 30 & 18 & 5 & 33 & 16 \\
\hline Germany & 26 & 23 & 17 & 8 & 4 & 9 & \\
\hline Greece & 16 & 15 & 15 & 16 & 15 & 6 & 15 \\
\hline Hungary & 25 & 24 & 23 & 24 & 1 & 25 & 23 \\
\hline Iceland & 21 & 18 & 14 & 21 & & 20 & 14 \\
\hline Ireland & 19 & 17 & 17 & 7 & 2 & 19 & 5 \\
\hline Israel & 13 & 11 & 10 & 4 & & 13 & \\
\hline Italy & 27 & 27 & 27 & 24 & 1 & 27 & 4 \\
\hline Japan & 33 & 31 & 26 & 13 & & 33 & 21 \\
\hline $\begin{array}{l}\text { Korea, } \\
\text { Republic }\end{array}$ & 13 & 10 & 5 & 27 & & 13 & 5 \\
\hline Luxembourg & 27 & 26 & 24 & 25 & 3 & 20 & 24 \\
\hline Netherlands & 31 & 31 & 27 & 21 & 12 & 31 & 23 \\
\hline \multicolumn{8}{|l|}{ New } \\
\hline Zealand & 25 & 19 & 19 & 29 & 11 & 21 & 19 \\
\hline Norway & 32 & 20 & 16 & 14 & 10 & 32 & 13 \\
\hline Poland & 14 & 12 & 11 & 9 & 8 & 14 & 11 \\
\hline Portugal & 9 & 5 & 6 & 3 & 4 & 9 & 6 \\
\hline \multicolumn{8}{|l|}{ Slovak } \\
\hline Republic & 4 & & & & 3 & 4 & \\
\hline Slovenia & 6 & & & & & 6 & \\
\hline Spain & 20 & 17 & 2 & 5 & 17 & 18 & 3 \\
\hline Sweden & 26 & 23 & 16 & 23 & 13 & 26 & 19 \\
\hline Switzerland & 34 & 31 & 20 & 33 & & 34 & 26 \\
\hline Turkey & 8 & 8 & 26 & 8 & & 8 & \\
\hline \multicolumn{8}{|l|}{ United } \\
\hline Kingdom & 27 & 25 & 25 & 25 & & 26 & 25 \\
\hline \multicolumn{8}{|l|}{ United } \\
\hline States & 29 & 27 & 26 & 27 & 17 & 29 & 26 \\
\hline Countries: & 32 & 30 & 30 & 29 & 23 & 31 & 26 \\
\hline $\begin{array}{l}\text { Total } \\
\text { Observations: }\end{array}$ & 680 & 581 & 515 & 537 & 181 & 613 & 408 \\
\hline
\end{tabular}


Table B.7. Number of Observations Included in Table 3.8 and Table 3.10 Samples, by Country

\begin{tabular}{|c|c|c|c|c|c|c|c|c|}
\hline Country & $\begin{array}{c}\text { Base } \\
\text { Sample } \\
\text { (Model } \\
\text { 1-3) }\end{array}$ & $\begin{array}{c}\text { Model } \\
12\end{array}$ & $\begin{array}{c}\text { Models } \\
13,14 \\
\end{array}$ & $\begin{array}{c}\text { Model } \\
15\end{array}$ & $\begin{array}{c}\text { Models } \\
16,17\end{array}$ & $\begin{array}{l}\text { Occupants: } \\
\text { Model } 18\end{array}$ & $\begin{array}{l}\text { Occupants: } \\
\text { Model } 19\end{array}$ & $\begin{array}{l}\text { Occupants: } \\
\text { Models } \\
\text { 20, 21 } \\
\text { Pedestrians: } \\
\text { Model 18 }\end{array}$ \\
\hline Australia & 12 & 9 & & & & & & \\
\hline Austria & 23 & 23 & 22 & 20 & 22 & 20 & 21 & 22 \\
\hline Belgium & 29 & 29 & 5 & 1 & 5 & 1 & 4 & 5 \\
\hline Canada & 25 & 25 & 13 & 11 & & & & \\
\hline Chile & 4 & & & & & & & \\
\hline Czech & & & & & & & & \\
\hline Republic & 6 & 6 & & & & & & \\
\hline Denmark & 32 & 32 & 2 & & 2 & & 2 & 21 \\
\hline Finland & 31 & 31 & 14 & 7 & 10 & 3 & 9 & 1 \\
\hline France & 33 & 33 & 23 & 20 & 31 & 28 & 18 & 31 \\
\hline Germany & 26 & 26 & 9 & & 17 & 14 & 3 & 9 \\
\hline Greece & 16 & 16 & & & & & & 1 \\
\hline Hungary & 25 & 17 & 5 & 3 & 5 & 3 & 4 & 4 \\
\hline Iceland & 21 & 21 & & & & & & \\
\hline Ireland & 19 & 19 & 1 & & 1 & & 1 & \\
\hline Israel & 13 & 13 & & & & & & \\
\hline Italy & 27 & 27 & & & & & & \\
\hline Japan & 33 & 33 & 26 & 19 & & & & 26 \\
\hline $\begin{array}{l}\text { Korea, } \\
\text { Republic }\end{array}$ & 13 & 8 & 3 & & & & & \\
\hline Luxembourg & 27 & 18 & & & & & & \\
\hline Netherlands & 31 & 31 & 17 & 15 & 17 & 15 & 14 & 17 \\
\hline New Zealand & 25 & 25 & 7 & 5 & 7 & 5 & 6 & \\
\hline Norway & 32 & 32 & 24 & 13 & 24 & 13 & 22 & 5 \\
\hline Poland & 14 & 14 & & & & & & \\
\hline Portugal & 9 & 9 & & & & & & \\
\hline $\begin{array}{l}\text { Slovak } \\
\text { Republic }\end{array}$ & 4 & & & & & & & \\
\hline Slovenia & 6 & 6 & 6 & 2 & 6 & 2 & & 6 \\
\hline Spain & 20 & 20 & 4 & 3 & 3 & 2 & 1 & 1 \\
\hline Sweden & 26 & 26 & 9 & 3 & 9 & 3 & 7 & 9 \\
\hline Switzerland & 34 & 34 & 33 & 25 & 34 & 26 & 33 & 33 \\
\hline Turkey & 8 & 8 & & & & & & \\
\hline $\begin{array}{l}\text { United } \\
\text { Kingdom }\end{array}$ & 27 & 24 & 20 & 18 & & & & \\
\hline United States & 29 & 21 & 18 & 15 & 5 & 3 & 3 & \\
\hline Countries: & 32 & 30 & 20 & 16 & 16 & 14 & 15 & 15 \\
\hline $\begin{array}{l}\text { Total } \\
\text { Observations: }\end{array}$ & 680 & 636 & 261 & 180 & 198 & 138 & 148 & 191 \\
\hline
\end{tabular}


Table B.8. Country-Specific Time Trend Coefficients from Income-Only

Pedestrian and Occupant Fatalities/VKT Models (Table 3.2) ${ }^{\mathbf{a}}$

\begin{tabular}{|c|c|c|c|c|c|c|}
\hline & \multicolumn{3}{|c|}{ In(Pedestrian Fatalities/VKT) } & \multicolumn{3}{|c|}{$\begin{array}{c}\text { In(Vehicle Occupant } \\
\text { Fatalities/VKT) }\end{array}$} \\
\hline & 1 & 3 & 5 & 1 & 3 & 5 \\
\hline $\ln Y$ & $\begin{array}{c}-0.376 * * \\
(0.187) \\
\end{array}$ & & $\begin{array}{l}-4.613 \\
(4.121) \\
\end{array}$ & $\begin{array}{l}-0.077 \\
(0.268) \\
\end{array}$ & & $\begin{array}{l}-7.727^{*} \\
(4.676) \\
\end{array}$ \\
\hline$(\ln Y)^{2}$ & & & $\begin{array}{c}0.223 \\
(0.212)\end{array}$ & & & $\begin{array}{l}0.403^{*} \\
(0.242)\end{array}$ \\
\hline lnY for: & & & & & & \\
\hline $\begin{array}{l}\$ 4,552- \\
13,165\end{array}$ & & $\begin{array}{l}-0.475^{*} \\
(0.286)\end{array}$ & & & $\begin{array}{l}-0.349 \\
(0.350)\end{array}$ & \\
\hline $\begin{array}{l}\$ 13,165- \\
16,565\end{array}$ & & $\begin{array}{c}-0.751 * * \\
(0.302)\end{array}$ & & & $\begin{array}{l}-0.284 \\
(0.406)\end{array}$ & \\
\hline $\begin{array}{l}\$ 16,565- \\
20,700\end{array}$ & & $\begin{array}{l}-0.347 \\
(0.362)\end{array}$ & & & $\begin{array}{c}0.503 \\
(0.353) \\
\end{array}$ & \\
\hline $\begin{array}{l}\$ 20,700- \\
44,227\end{array}$ & & $\begin{array}{c}0.201 \\
(0.177) \\
\end{array}$ & & & $\begin{array}{l}0.570 * * \\
(0.266)\end{array}$ & \\
\hline $\begin{array}{l}\text { Constant } \\
\text { (Austria) }\end{array}$ & $\begin{array}{c}0.907 \\
(1.712) \\
\end{array}$ & $\begin{array}{c}1.861 \\
(2.698) \\
\end{array}$ & $\begin{array}{c}21.040 \\
(19.991) \\
\end{array}$ & $\begin{array}{l}-1.421 \\
(2.463)\end{array}$ & $\begin{array}{c}1.220 \\
(3.290) \\
\end{array}$ & $\begin{array}{c}34.927 \\
(22.632)\end{array}$ \\
\hline $\begin{array}{l}\text { Turning Point } \\
\text { (1996 Int'1\$): }\end{array}$ & & & $\$ 30,800$ & & & $\$ 14,572$ \\
\hline Adjusted $\mathrm{R}^{2}$ : & 0.9677 & 0.9686 & 0.9679 & 0.9587 & 0.9617 & 0.9604 \\
\hline Countries & 32 & 32 & 32 & 32 & 32 & 32 \\
\hline Observations & 830 & 830 & 830 & 830 & 830 & 830 \\
\hline \multicolumn{7}{|c|}{ Country-Specific t: } \\
\hline Australia & $\begin{array}{c}-0.052^{* * *} \\
(0.004)\end{array}$ & $\begin{array}{c}-0.059 * * * \\
(0.005)\end{array}$ & $\begin{array}{c}-0.081 * * * \\
(0.004)\end{array}$ & $\begin{array}{c}-0.048 * * * \\
(0.006)\end{array}$ & $\begin{array}{c}-0.061 * * * \\
(0.006)\end{array}$ & $\begin{array}{c}-0.056^{* * *} \\
(0.005) \\
\end{array}$ \\
\hline Austria & $\begin{array}{c}-0.079 * * * \\
(0.004)\end{array}$ & $\begin{array}{c}-0.078^{* * *} * \\
(0.004)\end{array}$ & $\begin{array}{c}-0.056^{* * * *} \\
(0.004)\end{array}$ & $\begin{array}{c}-0.061 * * * \\
(0.006)\end{array}$ & $\begin{array}{c}-0.065^{* * *} * \\
(0.006)\end{array}$ & $\begin{array}{c}-0.065^{* * *} \\
(0.004)\end{array}$ \\
\hline Belgium & $\begin{array}{c}-0.079 * * * \\
(0.004)\end{array}$ & $\begin{array}{c}-0.079 * * * \\
(0.004)\end{array}$ & $\begin{array}{c}-0.081 * * * \\
(0.003)\end{array}$ & $\begin{array}{c}-0.048 * * * \\
(0.005)\end{array}$ & $\begin{array}{c}-0.056^{* * *} \\
(0.005)\end{array}$ & $\begin{array}{c}-0.053 * * * \\
(0.004)\end{array}$ \\
\hline Canada & $\begin{array}{c}-0.057 * * * \\
(0.004) \\
\end{array}$ & $\begin{array}{c}-0.059 * * * \\
(0.004) \\
\end{array}$ & $\begin{array}{c}-0.060 * * * \\
(0.003)\end{array}$ & $\begin{array}{c}-0.042 * * * \\
(0.005) \\
\end{array}$ & $\begin{array}{c}-0.048 * * * \\
(0.005) \\
\end{array}$ & $\begin{array}{c}-0.047 * * * \\
(0.004)\end{array}$ \\
\hline Chile & $\begin{array}{c}-0.070^{* * *} \\
(0.004)\end{array}$ & $\begin{array}{c}-0.067 * * * \\
(0.006)\end{array}$ & $\begin{array}{c}-0.066^{* * *} * \\
(0.006)\end{array}$ & $\begin{array}{c}-0.089 * * * \\
(0.006) \\
\end{array}$ & $\begin{array}{c}-0.083^{* * *} * \\
(0.008)\end{array}$ & $\begin{array}{c}-0.083 * * * \\
(0.007) \\
\end{array}$ \\
\hline Czech Republic & $\begin{array}{c}-0.056^{* * *} \\
(0.002)\end{array}$ & $\begin{array}{c}-0.054^{* * *} * \\
(0.002)\end{array}$ & $\begin{array}{c}-0.056^{* * *} \\
(0.002)\end{array}$ & $\begin{array}{c}-0.042 * * * \\
(0.003)\end{array}$ & $\begin{array}{c}-0.039^{* * *} \\
(0.003)\end{array}$ & $\begin{array}{c}-0.041 * * * \\
(0.002) \\
\end{array}$ \\
\hline Denmark & $\begin{array}{c}-0.051^{* * *} \\
(0.003)\end{array}$ & $\begin{array}{c}-0.055^{* * *} \\
(0.004) \\
\end{array}$ & $\begin{array}{c}-0.054 * * * \\
(0.003)\end{array}$ & $\begin{array}{c}-0.043^{* * *} \\
(0.004)\end{array}$ & $\begin{array}{c}-0.052^{* * *} \\
(0.004) \\
\end{array}$ & $\begin{array}{c}-0.048^{* * *} \\
(0.004) \\
\end{array}$ \\
\hline Finland & $\begin{array}{c}-0.072 * * * \\
(0.004)\end{array}$ & $\begin{array}{c}-0.071 * * * \\
(0.004)\end{array}$ & $\begin{array}{c}-0.074 * * * \\
(0.003)\end{array}$ & $\begin{array}{c}-0.054 * * * \\
(0.006)\end{array}$ & $\begin{array}{c}-0.058^{* * *} \\
(0.005)\end{array}$ & $\begin{array}{c}-0.058^{* * * *} \\
(0.004) \\
\end{array}$ \\
\hline France & $\begin{array}{c}-0.070^{* * *} \\
(0.004)\end{array}$ & $\begin{array}{c}-0.069^{* * *} \\
(0.004)\end{array}$ & $\begin{array}{c}-0.072 * * * \\
(0.003)\end{array}$ & $\begin{array}{c}-0.052^{* * *} \\
(0.005)\end{array}$ & $\begin{array}{c}-0.056^{* * *} \\
(0.005)\end{array}$ & $\begin{array}{c}-0.055^{* * *} \\
(0.004) \\
\end{array}$ \\
\hline Germany & $\begin{array}{c}-0.083^{* * *} * \\
(0.004)\end{array}$ & $\begin{array}{c}-0.082^{* * *} * \\
(0.004)\end{array}$ & $\begin{array}{c}-0.085^{* * *} * \\
(0.003)\end{array}$ & $\begin{array}{c}-0.057 * * * \\
(0.005)\end{array}$ & $\begin{array}{c}-0.063^{* * *} \\
(0.006)\end{array}$ & $\begin{array}{c}-0.062^{* * *} \\
(0.004) \\
\end{array}$ \\
\hline Greece & $\begin{array}{c}-0.069^{* * *} \\
(0.002) \\
\end{array}$ & $\begin{array}{c}-0.067 * * * \\
(0.003) \\
\end{array}$ & $\begin{array}{c}-0.068^{* * *} * \\
(0.002) \\
\end{array}$ & $\begin{array}{c}-0.040 * * * \\
(0.003) \\
\end{array}$ & $\begin{array}{c}-0.037 * * * \\
(0.004) \\
\end{array}$ & $\begin{array}{c}-0.039 * * * \\
(0.003)\end{array}$ \\
\hline Hungary & $\begin{array}{c}-0.043^{* * *} * \\
(0.003)\end{array}$ & $\begin{array}{c}-0.041 * * * \\
(0.004)\end{array}$ & $\begin{array}{c}-0.039^{* * *} * \\
(0.005)\end{array}$ & $\begin{array}{c}-0.039 * * * \\
(0.004)\end{array}$ & $\begin{array}{c}-0.034 * * * \\
(0.005)\end{array}$ & $\begin{array}{c}-0.032 * * * \\
(0.006)\end{array}$ \\
\hline Iceland & $\begin{array}{c}-0.098 * * * \\
(0.002)\end{array}$ & $\begin{array}{c}-0.102 * * * \\
(0.003)\end{array}$ & $\begin{array}{c}-0.100 * * * \\
(0.002)\end{array}$ & $\begin{array}{c}-0.024 * * * \\
(0.003)\end{array}$ & $\begin{array}{c}-0.032 * * * \\
(0.003)\end{array}$ & $\begin{array}{c}-0.029 * * * \\
(0.003)\end{array}$ \\
\hline
\end{tabular}


(Table B.8. continued)

\begin{tabular}{|c|c|c|c|c|c|c|}
\hline Ireland & $\begin{array}{c}-0.058 * * * \\
(0.007) \\
\end{array}$ & $\begin{array}{c}-0.056^{* * *} * \\
(0.006)\end{array}$ & $\begin{array}{c}-0.057 * * * \\
(0.007) \\
\end{array}$ & $\begin{array}{c}-0.039 * * * \\
(0.010) \\
\end{array}$ & $\begin{array}{c}-0.036^{* * *} * \\
(0.009)\end{array}$ & $\begin{array}{c}-0.037 * * * \\
(0.008)\end{array}$ \\
\hline Israel & $\begin{array}{c}-0.060 * * * \\
(0.004)\end{array}$ & $\begin{array}{c}-0.051^{* * *} \\
(0.007)\end{array}$ & $\begin{array}{c}-0.061 * * * \\
(0.004)\end{array}$ & $\begin{array}{c}-0.059 * * * \\
(0.006)\end{array}$ & $\begin{array}{c}-0.055^{* * *} * \\
(0.009)\end{array}$ & $\begin{array}{c}-0.061 * * * \\
(0.004)\end{array}$ \\
\hline Italy & $\begin{array}{c}-0.070 * * * \\
(0.004) \\
\end{array}$ & $\begin{array}{c}-0.066^{* * *} \\
(0.004) \\
\end{array}$ & $\begin{array}{c}-0.071 * * * \\
(0.004) \\
\end{array}$ & $\begin{array}{c}-0.044 * * * \\
(0.006) \\
\end{array}$ & $\begin{array}{c}-0.046^{* * *} * \\
(0.006) \\
\end{array}$ & $\begin{array}{c}-0.047 * * * \\
(0.004) \\
\end{array}$ \\
\hline Japan & $\begin{array}{c}-0.056^{* * *} * \\
(0.005) \\
\end{array}$ & $\begin{array}{c}-0.056^{* * *} \\
(0.005) \\
\end{array}$ & $\begin{array}{c}-0.058 * * * \\
(0.004) \\
\end{array}$ & $\begin{array}{c}-0.054 * * * \\
(0.008) \\
\end{array}$ & $\begin{array}{c}-0.060 * * * \\
(0.007)\end{array}$ & $\begin{array}{c}-0.058 * * * \\
(0.005) \\
\end{array}$ \\
\hline Korea, Rep. & $\begin{array}{c}-0.125 * * * \\
(0.009)\end{array}$ & $\begin{array}{c}-0.116^{* * *} \\
(0.010)\end{array}$ & $\begin{array}{c}-0.123 * * * \\
(0.009)\end{array}$ & $\begin{array}{c}-0.084 * * * \\
(0.013)\end{array}$ & $\begin{array}{c}-0.072 * * * \\
(0.013)\end{array}$ & $\begin{array}{c}-0.080 * * * \\
(0.011)\end{array}$ \\
\hline Luxembourg & $\begin{array}{c}-0.077 * * * \\
(0.007) \\
\end{array}$ & $\begin{array}{c}-0.091 * * * \\
(0.006)\end{array}$ & $\begin{array}{c}-0.087 * * * \\
(0.008)\end{array}$ & $\begin{array}{c}-0.043 * * * \\
(0.010) \\
\end{array}$ & $\begin{array}{c}-0.064 * * * \\
(0.009) \\
\end{array}$ & $\begin{array}{c}-0.061 * * * \\
(0.010) \\
\end{array}$ \\
\hline Netherlands & $\begin{array}{c}-0.067 * * * \\
(0.004)\end{array}$ & $\begin{array}{c}-0.067 * * * \\
(0.004)\end{array}$ & $\begin{array}{c}-0.069 * * * \\
(0.003)\end{array}$ & $\begin{array}{c}-0.061 * * * \\
(0.005)\end{array}$ & $\begin{array}{c}-0.067 * * * \\
(0.005)\end{array}$ & $\begin{array}{c}-0.065 * * * \\
(0.004)\end{array}$ \\
\hline New Zealand & $\begin{array}{c}-0.058 * * * \\
(0.002)\end{array}$ & $\begin{array}{c}-0.056^{* * * *} \\
(0.002)\end{array}$ & $\begin{array}{c}-0.059 * * * \\
(0.001)\end{array}$ & $\begin{array}{c}-0.037 * * * \\
(0.002)\end{array}$ & $\begin{array}{c}-0.037 * * * \\
(0.003)\end{array}$ & $\begin{array}{c}-0.038 * * * \\
(0.002)\end{array}$ \\
\hline Norway & $\begin{array}{c}-0.073 * * * \\
(0.005)\end{array}$ & $\begin{array}{c}-0.075^{* * *} \\
(0.005)\end{array}$ & $\begin{array}{c}-0.077 * * * \\
(0.004)\end{array}$ & $\begin{array}{c}-0.042 * * * \\
(0.007)\end{array}$ & $\begin{array}{c}-0.051^{* * *} \\
(0.007)\end{array}$ & $\begin{array}{c}-0.049 * * * \\
(0.006)\end{array}$ \\
\hline Poland & $\begin{array}{c}-0.075^{* * *} * \\
(0.003)\end{array}$ & $\begin{array}{c}-0.073 * * * \\
(0.005)\end{array}$ & $\begin{array}{c}-0.071 * * * \\
(0.006)\end{array}$ & $\begin{array}{c}-0.059 * * * \\
(0.004)\end{array}$ & $\begin{array}{c}-0.054 * * * \\
(0.006)\end{array}$ & $\begin{array}{c}-0.052 * * * \\
(0.007)\end{array}$ \\
\hline Portugal & $\begin{array}{c}-0.085^{* * *} * \\
(0.006)\end{array}$ & $\begin{array}{c}-0.081^{* * *} \\
(0.008)\end{array}$ & $\begin{array}{c}-0.080^{* * *} \\
(0.009)\end{array}$ & $\begin{array}{c}-0.057 * * * \\
(0.008)\end{array}$ & $\begin{array}{c}-0.048 * * * \\
(0.010)\end{array}$ & $\begin{array}{c}-0.048^{* * *} \\
(0.010)\end{array}$ \\
\hline $\begin{array}{l}\text { Slovak } \\
\text { Republic }\end{array}$ & $\begin{array}{c}-0.163 * * * \\
(0.004)\end{array}$ & $\begin{array}{c}-0.161 * * * \\
(0.006)\end{array}$ & $\begin{array}{c}-0.161 * * * \\
(0.005)\end{array}$ & $\begin{array}{c}-0.112 * * * \\
(0.006)\end{array}$ & $\begin{array}{c}-0.106^{* * *} \\
(0.008)\end{array}$ & $\begin{array}{c}-0.110 * * * \\
(0.005)\end{array}$ \\
\hline Slovenia & $\begin{array}{c}-0.059 * * * \\
(0.008)\end{array}$ & $\begin{array}{c}-0.045^{* * *} * \\
(0.012)\end{array}$ & $\begin{array}{c}-0.061 * * * \\
(0.007)\end{array}$ & $\begin{array}{c}-0.103 * * * \\
(0.012)\end{array}$ & $\begin{array}{c}-0.094 * * * \\
(0.016)\end{array}$ & $\begin{array}{c}-0.105^{* * *} * \\
(0.008)\end{array}$ \\
\hline Spain & $\begin{array}{c}-0.079^{* * *} \\
(0.004)\end{array}$ & $\begin{array}{c}-0.063^{* * *} * \\
(0.004)\end{array}$ & $\begin{array}{c}-0.067 * * * \\
(0.003)\end{array}$ & $\begin{array}{c}-0.048^{* * *} \\
(0.006)\end{array}$ & $\begin{array}{c}-0.040 * * * \\
(0.005)\end{array}$ & $\begin{array}{c}-0.044 * * * \\
(0.004)\end{array}$ \\
\hline Sweden & $\begin{array}{c}-0.052 * * * \\
(0.004)\end{array}$ & $\begin{array}{c}-0.058^{* * *} \\
(0.004)\end{array}$ & $\begin{array}{c}-0.059 * * * \\
(0.002)\end{array}$ & $\begin{array}{c}-0.061 * * * \\
(0.006)\end{array}$ & $\begin{array}{c}-0.048 * * * \\
(0.004)\end{array}$ & $\begin{array}{c}-0.045^{* * *} * \\
(0.003)\end{array}$ \\
\hline Switzerland & $\begin{array}{c}-0.079 * * * \\
(0.004)\end{array}$ & $\begin{array}{c}-0.069^{* * *} \\
(0.002)\end{array}$ & $\begin{array}{c}-0.067 * * * \\
(0.002)\end{array}$ & $\begin{array}{c}-0.048^{* * *} \\
(0.005)\end{array}$ & $\begin{array}{c}-0.055^{* * *} \\
(0.002)\end{array}$ & $\begin{array}{c}-0.054 * * * \\
(0.002)\end{array}$ \\
\hline Turkey & $\begin{array}{c}-0.057 * * * \\
(0.004)\end{array}$ & $\begin{array}{c}-0.159 * * * \\
(0.004)\end{array}$ & $\begin{array}{c}-0.155^{* * * *} \\
(0.007)\end{array}$ & $\begin{array}{c}-0.042 * * * \\
(0.005)\end{array}$ & $\begin{array}{c}-0.106^{* * *} * \\
(0.005)\end{array}$ & $\begin{array}{c}-0.101 * * * \\
(0.007)\end{array}$ \\
\hline $\begin{array}{l}\text { United } \\
\text { Kingdom }\end{array}$ & $\begin{array}{c}-0.070 * * * \\
(0.004)\end{array}$ & $\begin{array}{c}-0.060 * * * \\
(0.004)\end{array}$ & $\begin{array}{c}-0.064 * * * \\
(0.003)\end{array}$ & $\begin{array}{c}-0.089 * * * \\
(0.006)\end{array}$ & $\begin{array}{c}-0.052 * * * \\
(0.006)\end{array}$ & $\begin{array}{c}-0.052 * * * \\
(0.004)\end{array}$ \\
\hline United States & $\begin{array}{c}-0.056^{* * * *} \\
(0.002)\end{array}$ & $\begin{array}{c}-0.048^{* * *} \\
(0.004)\end{array}$ & $\begin{array}{c}-0.045^{* * * *} \\
(0.005)\end{array}$ & $\begin{array}{c}-0.042 * * * \\
(0.003)\end{array}$ & $\begin{array}{c}-0.047 * * * \\
(0.006)\end{array}$ & $\begin{array}{c}-0.043 * * * \\
(0.006)\end{array}$ \\
\hline Observations & 798 & 798 & 830 & 798 & 830 & 830 \\
\hline Countries: & 31 & 31 & 32 & 31 & 32 & 32 \\
\hline \multicolumn{7}{|c|}{$\begin{array}{l}* * * \text { Indicates } 1 \% \text { level of significance } * * \text { Indicates } 5 \% \text { level of significance } \\
* \text { Indicates } 10 \% \text { level of significance }\end{array}$} \\
\hline
\end{tabular}




\section{REFERENCES}

Abdelwahab, H.T., and M.A. Abdel-Aty. 2001. Development of artificial neural network models to predict driver injury severity in traffic accidents at signalized intersections. Transportation Research Record 1746: 6-13.

American Automobile Manufacturers Association, 1993. World Motor Vehicle Data 1993. AAMA, Washington, D.C.

Arrow, K., B. Bolin, R. Costanza, P. Dasgupta, C. Folke, C.S. Holling, et al. 1995. Economic Growth, Carrying Capacity, and the Environment. Science 268: 520521.

Asch, Peter, and David T. Levy. 1987. Does the Minimum Drinking Age Affect Traffic Fatalities? Journal of Policy Analysis and Management 6(2): 80-92.

Asch, Peter, and David T. Levy. 1990. Young Driver Fatalities: The Roles of Drinking Age and Drinking Experience. Southern Economic Journal 57: 512-20.

Baltagi, B.H. 1995. Econometric Analysis of Panel Data. John Wiley and Sons.

Bangladesh Bureau of Statistics. National Data Bank. http://www.bbsgov.org/ .

Bartlett, Bruce. 1994. "The High Cost of Turning Green.” Wall Street Journal, September 14, Section A, p.18.

Beckerman, W. 1992. Economic Growth and the Environment: Whose Growth? Whose Environment? World Development 20: 481-96.

Belgium Road Safety Institute (BIVV). Seatbelt Wearing Rates Statistics. Received through correspondence with Tobias Verbeke. May 3, 2004.

Bhattacharyya, M.N., and Allan Layton. 1979. Effectiveness of Seat Belt Legislation on the Queensland Road Toll - An Australian Case Study in Intervention Analysis. Journal of the American Statistical Association 74(367): 596-603.

Bishai, David, Asma Quresh, Prashant James and Abdul Ghaffar. 2000. What Lies Behind the Pandemic of Motor Vehicle Fatalities? Mimeo. Johns Hopkins University.

Branas, C.C., and M.M. Knudson. 2001. Helmet Laws and Motorcycle Rider Death Rates. Accident Analysis and Prevention 33(5): 641-8.

Button, K., N. Ngoe, and J. Hine. 1993. Modeling vehicle ownership and use in lowincome countries. Journal of Transport Economics and Policy 27(1), 51-67. 
Canning, David. 1998. A Database of World Infrastructure Stocks, 1950-95. World Bank Paper 1929. http://www.worldbank.org/html/dec/Publications/Workpapers/WPS1900series/wp s1929/wps1929.pdf.

Carabineros de Chile. Víctimas de Accidentes de Tránsito, por Edad y Calidad, 19922002. Received from Tatiana Consuegra, Librarian, Chile National Comission of Road Safety (CONASET).

Chaloupka, F.J., H. Saffer, and M. Grossman. 1993. Alcohol Control Policies and Motor Vehicle Fatalities. Journal of Legal Studies 22: 161-86.

Chang, L-Y, and F. Mannering. 1999. Analysis of injury severity and vehicle occupancy in truck- non-truck-involved accidents. Accident Analysis and Prevention 31: 579-592.

Charbotel, B., J.L. Martin, B. Gadegbeku, et al. 2003. Severity factors for truck drivers' injuries. American Journal of Epidemiology 158(8): 753-9.

China Statistical Yearbook, (various years). State Statistical Bureau, People's Republic of China.

Cohen, Alma, and Liran Einav. 2003. The Effects of Mandatory Seat Belt Laws on Driving Behavior and Traffic Fatalities. The Review of Economics and Statistics 85(4): 828-843.

Cooper, R.S., B. Osotimehim, J. Kaufman, and T. Forrester. 1998. Disease burden in Sub-Saharan Africa: what should we conclude in the absence of data? The Lancet $351,208-210$.

Crandall, Robert, and John Graham. 1984. Automobile Safety Regulation and Offsetting Behavior: Some New Empirical Estimates. American Economic Review, Papers and Proceedings 74(2): 328-31.

Crandall, Robert, and John Graham. 1989. The Effect of Fuel Economy Standards on Automobile Safety. Journal of Law and Economics 32(1): 97-118.

Cross National Time Series Database (CNTS). Access through Rutgers University Libraries. http://www.scc.rutgers.edu/cnts/about.cfm .

Danish Transport Research Institute. 2001. Seat belt usage in Danish cars and small vans. Report 1-2001. http://www.dtf.dk/sw10767.asp.

Dargay, J., and D. Gately. 1999. Income's effect on car and vehicle ownership, worldwide: 1960-2015. Transportation Research A 33, 101-138.

Das, Sanghamitra, Charles F. Manski, and Mark Manuszak. 2002. Walk or Wait? An Empirical Analysis of Street Crossing Decisions. Working Paper. 
Dee, Thomas S. 1999. State Alcohol Policies, Teen Drinking, and Traffic Fatalities. Journal of Public Economics 72(2):289-315.

Dee, Thomas S., and William N. Evans. 2001. Behavioral Policies and Teen Traffic Safety. AEA Papers and Proceedings 91-96.

Delucchi, Mark, et al. 1997. The Annualized Cost of Motor-Vehicle Use in the U.S., 1990-1991: Summary of Theory, Data, Methods, and Results. Report \#1 in the series: The Annualized Social Cost of Motor-Vehicle Use in the United States, based on 1990-1991 Data. Report UCD-ITS-RR-96-3(1). Institute of Transportation Studies, University of California, Davis.

Denmark Ministry of Transport. 1998. Road Safety in Latin America and the Caribbean: Analysis of the Road Safety Situation in Nine Countries. Ministry of Transport Road Directorate, Copenhagen, Denmark.

Dickerson, Andrew, John Peirson, and Roger Vickerman. 2000. Road Accidents and Traffic Flows: An Econometric Investigation. Economica 67: 101-21.

Dirección General de Tráfico (DGT), Spain. Seatbelt Usage Statistics. Provided through correspondence with Pilar Zori, Head of Statistics Service, DGT. April, 29, 2004.

Edlin, Aaron S. 1999. Per Mile Premiums for Auto Insurance. Working Paper 6934, National Bureau of Economic Research.

Edwards, J.B. 1998. The relationship between road accident severity and recorded weather. Journal of Safety Research 29(4): 249-62.

Elvik, R., B.A. Mysen, and T. Vaa. 1997. Trafikksikkerhetshåndbok (Traffic safety handbook). Oslo, Institute of Transport Economics. Complete Norwegian version accessible at www.toi.no.

European Commission Directorate-General Energy and Transport. Energy \& Transport in Figures. http://www.europa.eu.int/comm/dgs/energy transport/figures/pocketbook/2003 e $\underline{\text { n.htm. }}$.

European Conference of Ministers of Transport (ECMT). 1998. Statistical Report on Road Accidents 1993-1994. OECD Publications Service, Paris.

European Conference of Ministers of Transport (ECMT). 2000. Statistical Report on Road Accidents 1995-1996. OECD Publications Service, Paris.

European Conference of Ministers of Transport (ECMT). 2001. Statistical Report on Road Accidents 1997-1998. OECD Publications Service, Paris. 
Evans, Leonard. 1986. The Effectiveness of Safety Belts in Preventing Fatalities. Accident Analysis and Prevention 18(3): 229-41.

Evans, W.N., and J.D. Graham. 1991. Risk Reduction or Risk Compensation? The Case of Mandatory Safety-Belt Use Laws. Journal of Risk and Uncertainty 4(1): 61-73.

Evans, W.N., N. Neville, and J.D. Graham. 1991. General Deterrence of Drunk Driving: Evaluation of Recent American Policies. Risk Analysis 11: 279-89.

Farmer, Charles M., Adrian K. Lund, Rebecca E. Trempel, and Elisa R. Braver. 1997. Fatal crashes of passenger vehicles before and after adding antilock braking systems. Accident Analysis and Prevention 29: 745-57.

Fowles, R., and P.D. Loeb. 1989. Speeding, Coordination, and the 55 MPH Speed Limit: Comment. American Economic Review 79: 916-21.

Fridstrom, Lasse, and Siv Ingebrigsten. 1991. An Aggregate Model Based on Pooled, Regional Time-Series Data. Accident Analysis and Prevention 23: 363-378.

Garbacz, C. 1985. A Note on Peltzman's Offsetting Consumer Behavior. Economic Letters 19: 183-7.

Garbacz, C. 1989. Traffic Fatalities in Taiwan. Journal of Transport Economics and Policy 23(3): 317-27.

Garbacz, C. 1990. Estimating Seat Belt Effectiveness with Seat Belt Data from the Centers for Disease Control. Economic Letters 34: 83-88.

Garbacz, C. 1991. Impact of the New Zealand Seat Belt Law. Economic Inquiry 29: 310-16.

Garbacz, C. 1992. More Evidence on the Effectiveness of Seat Belt Laws. Applied Economics 24: 313-315.

Garber, S., and J.D. Graham. 1989. The Effects of the New 65 Mile-Per-Hour Speed Limit on Rural Highways Fatalities: A State-by-State Analysis. Final Grant Report HS 807 452, July. Washington, D.C.: Department of Transportation.

Gayer, Ted. 2004. The Fatality Risks of Sport-Utility Vehicles, Vans, and Pickups Relative to Cars. Journal of Risk and Uncertainty. 28(2): 103-133.

Global Road Safety Partnership. http://www.grsproadsafety.org/.

Godwin, S.R. 1992. Effect of the 65 MPH Speed Limit on Highway Safety in the USA (with comments by C. Lave and reply to comments). Transport Reviews 12 : 1-14. 
Golob, Thomas, and Amelia Regan. 2004. Truck-Involved Crashes and Traffic Levels on Urban Freeways. Prepared for 2004 Transportation Research Board Annual Meeting. Washington, D.C.

Golob, T.F., and W.W. Recker. 2003. Relationships among urban freeway accidents, traffic flow, weather, and lighting conditions. Journal of Transportation Engineering - ASCE 129(4): 342-53.

Golob, T.F., W.W. Recker, and V.M. Alvarez. (in press). Freeway safety as a function of traffic flow. Accident Analysis and Prevention.

Graham, Daniel, and Stephen Glaister. 2003. Spatial Variation in Road Pedestrian Casualties: The Role of Urban Scale, Density and Land-use Mix. Urban Studies 40(8): 1591-1607.

Grossman, Gene, and Alan Krueger. 1995. Economic Growth and the Environment. Quarterly Journal of Economics 3: 53-77.

Harless, D.W., and G.E. Hoffer. 2003. Testing for offsetting behavior and adverse recruitment among drivers of airbag-equipped vehicles. Journal of Risk Insurance 70(4): 629-650.

Harvey, Andrew, and James Durbin. 1986. The Effect of Seat Belt Legislation on British Road Casualties: A Case Study in Structural Time Series Modeling. Journal of the Royal Statistical Society Series A-Statistics in Society 149(3): $187-210$.

Hausman, J., B.H. Hall, and Z. Griliches. 1984. Econometric Models for Count Data with an Application to the Patents R\&D Relationship. Econometrica 52: 909-38.

Heston, Alan, Robert Summers, and Bettina Aten. 2002. Penn World Table Version 6.1, Center for International Comparisons at the University of Pennsylvania (CICUP), October.

Hilton, F.G., and Arik Levinson. 1998. Factoring the Environmental Kuznets Curve: Evidence from Automotive Lead Emissions. Journal of Environmental Economics and Management 35(2): 126-41.

Hokkaido Police Headquarters, Japan. www.city.sapporo.jp/kensetsu/stn/eng/info/ib/ib02.

Houston, David, Lilliard Richardson, Jr., and Grant Neeley. 1995. Legislation Traffic Safety: A Pooled Time Series Analysis. Social Science Quarterly 76(2): 328-45.

Hungary Ministry of Economy and Transport (Gazdasági és Közlekedési Minisztérium). National Road Length Statistics. Received through email correspondence with Peter Vasi, March 16, 2004. 
Hungary Ministry of Environment. www.kvvm.hu/korny/allapot/.

Ingram, G.K., and Z. Liu. 1998. Vehicles, Roads, and Road Use: Alternative Specifications. Working Paper 2036. World Bank.

Inter-American Development Bank (IADB), 1998. Review of Traffic Safety Latin America and Caribbean Region. Transport Research Laboratory and Ross Silcock.

International Road Federation. (Various years). I.R.F. World Road Statistics. International Road Federation, Geneva, Switzerland.

International Road Traffic Accident Database (IRTAD). Federal Highway Research Institute (BASt)/OECD Road Transport Research Programme, Paris, France.

Israel Central Bureau of Statistics. Annual Kilometers Travelled by Type of Vehicle Grand Total, 1984-2002. http://www.cbs.gov.il//mse.cgi.

Israel Central Bureau of Statistics. Casualties in Road Accidents, by Type of Casualty and Severity, 1988-2002. http://www.cbs.gov.il/lmse.cgi.

Israel Central Bureau of Statistics. Motor Vehicles by Type. http://www.cbs.gov.il $/$ lmse.cgi? $\mathrm{i}=36 \& \mathrm{ti}=17 \& \mathrm{r}=0 \& \mathrm{f}=3 \& \mathrm{o}=0$.

Israel Central Bureau of Statistics. Statistical Abstract of Israel, 1999 - 2003 Editions.

Israel National Road Safety Authority. 2000. The National Road Safety Authority Structure, Activities, \& Responsibilities. State of Israel Ministry of Transport.

Jacobs, G., A. Aeron-Thomas, and A. Astrop. 2000. Estimating Global Road Fatalities. TRL Report 445. Transportation Research Laboratory, London, England.

Jacobs, G. D., and C.A. Cutting. 1986. Further Research on Accident Rates in Developing Countries. Accident Analysis and Prevention 18: 119-27.

Jones-Lee, M. 1990. The Value of Transport Safety. Oxford Review of Economic Policy 6: 39-60.

Keeler, Theodore E. 1994. Highway Safety, Economic Behavior and Driving Environment. American Economic Review 84(3): 684-693.

Kenkel, D.S. 1993. Drinking, Driving, and Deterrence: The Effectiveness and Social Costs of Alternative Policies. Journal of Law and Economics 36: 877-913.

Koepsell, Thomas, et al. 2002. Crosswalk Markings and the Risk of Pedestrian-Motor Vehicle Collisions in Older Pedestrians. Journal of the American Medical Association 288(17): 2136-43. 
Korea National Statistics Office. www.nso.go.kr/.

Korea National Statistics Office. Population Projections. http://www.nso.go.kr/cgibin/sws 888.cgi?ID=DT 1B01001\&IDTYPE=3\&A LANG=2\&FPUB=4\&SELI $\underline{\mathrm{TEM}}=$.

Korea Transportation Safety Authority (KOTSA). Annual Reports 1998-2002. www.kotsa.or.kr. (English translation of relevant sections received from Byung Jung Park, The Korea Transport Institute- Department of Highway Research.)

Kuznets, Simon. 1955. Economic Growth and Income Inequality. American Economic Review 1: 1-28.

Lave, C. 1985. Speeding, Coordination, and the 55 MPH Speed Limit. American Economic Review 75: 1159-64.

Lee, J., and F. Mannering. 2002. Impact of roadside features on the frequency and severity of run-off roadway accidents: an empirical analysis. Accident Analysis and Prevention 34(2): 149-161.

Levitt, Steven, and Jack Porter. 2001. Sample Selection in the Estimation of Air Bag and Seat Belt Effectiveness. Review of Economics and Statistics 83(4): 603-15.

Levy, D.T., and P. Asch. 1989. Speeding, Coordination, and the 55 MPH Speed Limit: Comment. American Economic Review 79: 913-15.

Liang, Kung-Yee, and Scott Zeger. 1986. Longitudinal Data Analysis Using Generalized Linear Models. Biometrika 73(1):13-22.

Lindgren, Bjorn, and Charles Stuart. 1980. The Effects of Traffic Safety Regulation in Sweden. The Journal of Political Economy 88(2): 412-27.

Liren, D. 1996. Viewing China Road Traffic Safety and the Countermeasures in Accordance with International Comparison. Beijing Research in Traffic Engineering, Second Conference in Asian Road Safety, October 28-31.

Loeb, Peter D. 1985. The Efficacy and Cost-effectiveness of Motor Vehicle Safety Inspection Using Cross-sectional Data-An Econometric Analysis. Southern Economic Journal 500-509.

Loeb, Peter. 1987. The Determinants of Automobile Fatalities. Journal of Transport Economics and Policy 21:279-87.

Loeb, Peter. 1990. Automobile Safety Inspection: Further Econometric Evidence. Applied Economics December: 1697-704.

Loeb, P., and B. Gilad. 1984. The Efficacy and Cost-effectiveness of Motor Vehicle Inspection. Journal of Transport Economics and Policy 18:145-64. 
Mahalel, David, and Zvi Szternfeld. 1986. Safety Improvements and Driver Perception. Accident Analysis and Prevention 18(1): 37-42.

Mann, R.E., S. MacDonald, G. Stoduto, et al. 2001. The Effects of Introducing or Lowering Legal Per Se Blood Alcohol Limits for Driving: An International Review. Accident Analysis and Prevention 33(5): 569-583.

Mayeres, Inge, Sara Ochelen, and Stef Proost. 1996. The Marginal External Costs of Urban Transport. Transportation Research D 1: 111-130.

McCarthy, Patrick. 1994a. An Empirical Analysis of the Direct and Indirect Effects of Relaxed Interstate Speed Limits on Highway Safety. Journal of Urban Economics 36: 353-364.

McCarthy, Patrick. 1994b. Relaxed Speed Limits and Highway Safety: New Evidence from California. Economic Letters 46: 173-179.

McCarthy, Patrick. 2001. Effect of Speed Limits on Speed Distributions and Highway Safety: A Survey of Recent Literature. Transport Reviews 21(1): 31-50.

McCornac, Dennis C. 1993. The Efficacy of Government Safety Policies on Trafficrelated Fatalities: Empirical Estimates from Japan. Applied Economics 25: 409412.

Merrell, D., M. Poitras, and D. Sutter. 1999. The Effectiveness of Vehicle Safety Inspections: An Analysis Using Panel Data. Southern Economic Journal 65(3): 571-83.

Michener, Ron, and Carla Tighe. 1992. A Poisson Model of Highway Fatalities. American Economic Review 82(2): 452-56.

Milton, John, and Fred Mannering. 1998. The Relationship Among Highway Geometrics, Traffic-Related Elements and Motor Vehicle Accident Frequencies. Transportation 25: 395-413.

Murray, C., and A. Lopez, Eds., 1996. The Global Burden of Disease. Harvard Press, Cambridge, MA.

Newbery, David M. 1988. Road User Charges in Britain. Economic Journal 98 (conference 1988): 161-176.

New Zealand Land Transport Safety Authority. Casualty Rates- Historical. http://www.ltsa.govt.nz/research/annual-statistics-2002/docs/historical-table1.pdf.

New Zealand Land Transport Safety Authority. Reported Accidents- Historical. http://www.ltsa.govt.nz/research/annual-statistics-2001/docs/historical-table3.pdf. 
Noland, Robert. 2003a. Medical treatment and traffic fatality reductions in industrialized countries. Accident Analysis and Prevention 35: 877-83.

Noland, Robert. 2003b. Traffic fatalities and injuries: the effect of changes in infrastructure and other trends. Accident Analysis and Prevention 35(4): 599-611.

Noland, Robert, and Mohammed Quddus. 2002. Improvements in Medical Care and Technology and Reductions in Traffic-related Fatalities in Great Britain. Presented at the 2002 Annual Meeting of the European Regional Science Association, Dortmund, Germany.

Northern Ireland Department for Regional Development. Transportation Statistics 2002-2003. Central Statistics and Research Branch. http://csrb.drdni.gov.uk/statistics/details.asp?publication_id=92.

Nunziata, L. 2002. xtdw.ado: a Stata command for Durbin Watson statistic in fixed effects panel data models. Available to download from: http://www.nuff.ox.ac.uk/users/nunziata/publications.htm.

Organization for Economic Cooperation and Development (OECD). Annual National Accounts for OECD Member Countries. Comparative tables available from OECD Statistical Database: http://www.oecd.org/document/28/0,2340,en_2825_495684_2750044_1_1_1_1,0 $\underline{0 . h t m l}$.

Organization for Economic Cooperation and Development (OECD). Health Data 2003. http://www.oecd.org/document/30/0,2340,en_2649_34631_12968734_1_1_1_1, $\underline{0 . h t m l}$

Organization for Economic Cooperation and Development (OECD). (Various years). OECD Energy Statistics.

Page, Yves. 2001. A Statistical Model to Compare Road Mortality in OECD Countries. Accident Analysis and Prevention 33: 371-85.

Peden, M., et al., Eds. 2004. World Report on Road Traffic Injury Prevention. Geneva, Switzerland: World Health Organization.

Peltzman, Sam. 1975. The Effects of Automobile Safety Regulation. Journal of Political Economy 83(4): 677-726.

Persson, U., and K. Odegaard. 1995. External Cost Estimates of Road Traffic Accidents: An International Comparison. Journal of Transport Economics and Policy 29: 291-304. 
Peterson, S., G. Hoffer, and E. Millner. 1995. Are Drivers of Air-Bag-Equipped Cars More Aggressive - A Test of the Offsetting Behavior Hypothesis. Journal of Law and Economics 38(2): 251-64.

Poland Police Headquarters. Accident Statistics, 1985-2002. Received through email correspondence with Slawomir Nowicki (Linköping University, Sweden).

Porter, Bryan, and Kelli England. 2000. Predicting Red-light Running Behavior: A Traffic Study in Three Urban Settings. Journal of Safety Research 31(1): 1-8.

Risa, Alf Erling. 1994. Adverse Incentives from Improved Technology: Traffic Safety Regulation in Norway. Southern Economic Journal 60(4): 844-57.

Ruhm, Christopher J. 1996. Alcohol Policies and Highway Vehicle Fatalities. Journal of Health Economics 15:435-454.

Sass, T.R., and P.R. Zimmerman. 2000. Motorcycle Helmet Laws and Motorcyclist Fatalities. Journal of Regulatory Economics 18(3): 195-215.

Schafer, A. 1998. The Global Demand for Motorized Mobility. Transportation Research A 32(6): 455-477.

Schmalensee, R., Stoker, T., and R. Judson. 2000. World Carbon Dioxide Emissions: 1950-2050. Review of Economics and Statistics 80(1), 15-27.

Scuffman, P.A. 2003. Economic Factors and Traffic Crashes in New Zealand. Applied Economics 35(2): 179-188.

Scuffman, P.A., and J.D. Langley. 2002. A Model of Traffic Crashes in New Zealand. Accident Analysis and Prevention 34(5): 673-87.

Seldon, T., and D. Song. 1994. Environmental Quality and Development: Is There an Environmental Kuznets Curve for Air Pollution Emissions? Journal of Environmental Economics and Management 27: 147-62.

Sen, Anindya. 2001. An Empirical Test of the Offset Hypothesis. Journal of Law and Economics 44: 481-510.

Shafik, N., and S. Bandyopadhyay. 1992. Economic Growth and Environmental Quality: Time-Series and Cross-Country Evidence. Background Paper for World Development Report 1992. World Bank, Washington, D.C.

Shefer, Daniel, and Piet Rietveld. 1997. Congestion and Safety on Highways: Towards an Analytical Model. Urban Studies 34(4): 679-92.

Sloan, F.A., B.A. Reilly, and C.M. Schenzler. 1994. Tort liability versus other approaches for deterring careless driving. International Review of Law and Economics 14: 53-71. 
Slovak Republic Road Accidents Data. Note Prepared for 27th IRTAD Operational Commitee Meeting. Received through email from Slovak IRTAD member.

Smeed, R.J., 1949. Some Statistical Aspects of Road Safety Research. Journal of the Royal Statistical Society Series A 112: 1-23.

Snyder, D. 1989. Speeding, Coordination, and the 55 MPH Speed Limit: Comment. American Economic Review 79: 922-925.

Spain Ministry of Public Works and Infrastructure (Ministerio de Fomento). Anuario Estadístico 2002. http://www.mfom.es/ (Spanish only).

Spain Statistics. www.ine.es/inebase/.

Statistical Economic and Social Research and Training Centre for Islamic Countries (SESRTCIC). Basic Socio-Economic Indicators Database (BASEIND). http://www.sesrtcic.org/defaulteng.shtml.

Statistics Canada. CANSIM Database. Population Statistics Tables.

Statistics Canada. Historical Statistics of Canada. Motor vehicle traffic accidents, 1921 to 1975. Series T271-284. http://www.statcan.ca/english/freepub/11-516XIE/sectiont/sectiont.htm.

Statistics Canada. Historical Statistics of Canada. Road and street mileage, by type of surface, 1946 to 1975. Series T142-146. http://www.statcan.ca/english/freepub/11-516-XIE/sectiont/sectiont.htm.

Statistics Canada. Sales of fuel used for road motor vehicles, by provinces and territories. http://www.statcan.ca/english/Pgdb/trade37a.htm.

Statistics Denmark. StatBank Database. http://www.statbank.dk/statbank5a/SelectTable/Omrade0.asp?PLanguage=1.

Statistics Iceland. Statistical Yearbook of Iceland 2003. http://www.hagstofa.is/template44.asp?PageID=1164.

Statistics Norway. Historical Statistics 1994. http://wwwopen.ssb.no/english/subjects/00/histstat/.

Statistics Norway. http://www.ssb.no/english/subjects/.

Suri, V., and D. Chapman. 1998. Economic Growth, Trade, and Energy: Implications for the Environmental Kuznets Curve. Ecological Economics 25: 195-208.

Swedish National Road Administration. Estimates of Vehicle-Kilometers Traveled, 2000-2002. Received through email correspondence with Thomas Lekander, Section Transport- and Market Analysis, Swedish National Road Administration. 
Swedish National Road Administration. Statistics on vehicles in use at the end of the year 1990 - 2003. Provided by Thomas Lekander, Section Transport- and Market Analysis, Swedish National Road Administration.

Swiss Federal Statistics Office. Swiss Statistics. www.statistik.admin.ch/.

Swiss Federal Tourism Office. Swiss Tourism in Figures 2003. http://www.swisstourfed.ch/art/dokumente/vademekum/2003/en/S.28 30 engl.pd f.

Transfund New Zealand. Roading Statistics 2000/2001. http://www.transfund.govt.nz/pubs/roading_2001.pdf.

Transport Canada. 2002. Canadian Motor Vehicle Traffic Collision Statistics 2002. http://www.ccmta.ca/english/pdf/2002StatsE.pdf.

U.K. Department of Transport. Great Britain Car and Van Seatbelt Wearing Rates, 1982-2002. Received through email correspondence with Tim Norman, Road Safety Division. February 26, 2004. Also available from: www.trl.co.uk.

U.K. Department of Transport. Petroleum Consumption: by transport mode and fuel type: United Kingdom: 1991-2001. Available from: http://www.dft.gov.uk.

United Nations. World Population Prospects: The 2002 Revision Population Database. http://esa.un.org/unpp/.

United Nations Economic and Social Commission for Asia and the Pacific. 1997. Asia-Pacific Road Accident Statistics and Road Safety Inventory. United Nations, New York.

U.S. Census Bureau. International Data Base (IDB). http://www.census.gov/ipc/www/idbsprd.html.

U.S. Department of Transportation (U.S. DOT). http://wwwfars.nhtsa.dot.gov/report.cfm?stateid $=0 \&$ year $=2000 \&$ title $=$ Trends.

U.S. Department of Transportation (U.S. DOT). National Occupant Protection Use Survey. http://ntl.bts.gov.

U.S. Department of Transportation, Bureau of Transportation Statistics. National Transportation Statistics 2003. http://www.bts.gov/publications/national transportation_statistics/2003/.

Van Beeck, Eduard, Gerard Borsboom, and Johan Mackenbach. 2000. Economic development and traffic accident mortality in the industrialized world, 19621990.

International Journal of Epidemiology 29: 503-509. 
Vitaliano, D.F., and J. Held. 1991. Road accident external effects: an empirical investigation. Applied Economics 23: 373-8.

Wagenaar, Alexander, Richard Maybee, and Kathleen Sullivan. 1988. Mandatory Seat Belt Laws in Eight States: A Time-Series Evaluation. Journal of Safety Research 19: 51-70.

Whetten-Goldstein, Kathryn, Frank Sloan, Emily Stout, and Lan Liang. 2000. Civil liability, criminal law, and other policies and alcohol-related motor vehicle fatalities in the United States: 1984-1995. Accident Analysis and Prevention 32: 723-33.

Wilkinson, J.T. 1987. Reducing Drunken Driving: Which Policies Are Most Effective? Southern Economic Journal 54: 322-334.

Wooldridge, Jeffrey. 2003. Cluster-Sample Methods in Applied Econometrics. Working Paper. Michigan State University.

World Bank. Global Development Network Growth Database Macro Time Series. http://www.worldbank.org/research/growth/GDNdata.htm.

World Bank. Global Economic Prospects and the Developing Countries 2002. http://www.worldbank.org/prospects/gep2002/toc.htm.

World Bank. World Development Indicators 2004. http://www.worldbank.org/data/wdi2004/index.htm.

World Drink Trends. 2000. World Drink Trends 2000: International Beverage Consumption and Production Trends. Henley-on-Thames, Oxfordshire, U.K.: NTC Publications Ltd.

Zlatoper, T.J. 1984. Regression-Analysis of Time-Series Data on Motor Vehicle Deaths in the United States. Journal of Transport Economics and Policy 18(3): 263-274. 